\title{
Water vapor, precipitation and evapotranspiration isotopic composition in the tropical atmospheric boundary layer
}

\author{
Dissertation \\ to attain the Doctor of Philosophy (Ph.D.) \\ of the Faculty of Forest Sciences and Forest Ecology \\ Georg-August-Universität Göttingen \\ Submitted by \\ Mattia Bonazza \\ born on the $13^{\text {th }}$ October 1979 in Trieste, Italy
}

Göttingen, 12/2020 
1. Referee: Prof. Dr. Alexander Knohl

2. Referee: Prof. Dr. Dirk Hölscher

3. Referee: Dr. Jens Dyckmans

Date of oral examination: 11.03.2021 


\section{Declaration of Authorship}

I, Mattia BONAZZA, declare that this thesis titled, "Water vapor, precipitation and evapotranspiration isotopic composition in the tropical atmospheric boundary layer" and the work presented in it is my own. I confirm that:

- This work was done wholly or mainly while in candidature for a research degree at this University.

-Where any part of this thesis has previously been submitted for a degree or any other qualification at this University or any other institution, this has been clearly stated.

- Where I have consulted the published work of others, this is always clearly attributed.

- Where I have quoted from the work of others, the source is always given. With the exception of such quotations, this thesis is entirely my own work.

- I have acknowledged all main sources of help.

-Where the thesis is based on work done by myself jointly with others, I have made clear exactly what was done by others and what I have contributed myself.

Signed: Mattia Bonazza

Date: 02.12 .2020 

"It is not the strongest of the species that survives, nor the most intelligent that survives. It is the one that is the most adaptable to change."

Charles Darwin 

University of Göttingen

\section{Abstract}

Faculty of Forest Science and Forest Ecology

Bioclimatology Group

Doctor of Philosophy

Water vapor, precipitation and evapotranspiration isotopic composition in the tropical atmospheric boundary layer

by Mattia BONAZZA

The tropical areas are home to important large-scale climatic phenomena, like the El-Niño Southern Oscillation (ENSO), the Madden-Julian Oscillation (MJO) and the monsoons, that influence the global climate to a large extent. One of the areas of the planet where these perturbations exert their effect with a particular intensity is Indonesia. In this region, where the climate is mostly warm and humid throughout the year, these atmospheric phenomena are responsible for the alternation between periods of drought and periods of very intense rainfall with consequences for the agriculture and the tropical forests. In hydrogeological studies, the isotopic composition of water plays a role of primary importance. By exploiting the property that different isotopes have of combining into molecules having the same chemical behavior but different masses, the isotopic composition of water molecules provides information about their origin and their distribution in space and time. Furthermore, due to the isotopic fractionation that occurs during phase transitions, the evolution of the isotopic composition of moisture and precipitation reflects the processes that characterize the origin and transport of air masses through the troposphere.

Due the importance that the Indonesian climate has for the agriculture and for the conservation of tropical forests and due to the scarcity of direct measurements of the isotopic composition of rainfall and water vapor in this area, in the framework of the Bariri-Flux and the EFFORTS CRC 990 projects we performed a study aiming at

1. measure the precipitation isotopic composition along a transect in Central Sulawesi and evaluate the sources of its variability concerning the effects of large-scale weather phenomena and cloud type,

2. measure the precipitation and moisture isotopic composition in a mature oil palm plantation and determine the effect of the Madden-Julian Oscillation on the surface layer moisture isotopic composition,

3. measure the isotopic composition of water extracted from the soil and leaves and partition the evapotranspiration flux into transpiration and evaporation in a mature oil palm plantation. 
Using the most common methods available nowadays in this research field, we

1. sampled, for about 1 year, rainfall in 3 stations along a north to south transect in Central Sulawesi. The $\delta D$ and $\delta^{18} O$ were measured using an Isotope Ratio Mass Spectrometer (IRMS) and a Cavity Ring-Down Spectrometer (CRDS) at the University of Göttingen and at the International Atomic Energy Agency (IAEA) Vienna,

2. measured continuously, for 2 weeks, the $\delta D$ and $\delta^{18} O$ of moisture along a profile and sampled precipitation in a mature oil palm plantation near Jambi, Sumatra using a CRDS on site,

3. sampled, during 3 days, oil palm leaves at 2 different heights and soil at 2 different depths in the same oil palm plantation. Precipitation, leaves and soil samples were transported to the University of Göttingen where, using a cryogenic vacuum line, the water content was extracted and the isotopic composition measured with a CRDS.

Our results revealed that the rainfall isotopic composition at the 3 measuring sites was not only characterized by a significant elevation effect but also that the $\delta D$ and $\delta^{18} O$ were modulated by the intensity of the convective activity in the area. Moreover, a comparison between our dataset and Mulu station (Borneo), suggests that the precipitation isotopic composition might principally depends on the stratiform clouds fraction associated to the convective activity. The principal moisture source for the Jambi area during our campaign was the South China Sea (77,5\% occurrences). Under these conditions, air parcels travel at low altitude (on average $1000 \mathrm{~m}$ a.s.l.) carrying large amounts of isotopically enriched moisture $(\overline{\delta D}-100 \% 0)$. During the active phase of the Madden-Julian Oscillation the development of a convective cloud cluster in the Indian Ocean was associated with higher air parcels altitudes (> $2000 \mathrm{~m}$ a.s.l.) that resulted in an injection of upper tropospheric depleted moisture into the surface atmospheric layer. The rapid depletion in heavy isotopes of the water vapor $(\approx-60 \%$ within 3 days $)$ associated with the convective activity was not only evident from the isotopic composition of moisture and precipitation, but also from the deuterium excess. However, the main source of surface water vapor isotopic composition variability was the proportion of moisture derived from the precipitation re-evaporation (up to $50 \%$ ). The transpiration might accounts for up to the $60 \%$ of the evapotranspiration flux during midday, in close agreement with the results published for the same site and estimated using micrometeorological methods.

Despite suffering from major technical and logistic issues, our study provides some improvements and new insights in the understanding of the interactions between the MJO, the large-scale convection and the local precipitation and moisture isotopic composition in South Sumatra and in Central Sulawesi. In the future a more systematic sampling strategy and the addition of other measuring techniques could also better disentangle the role of convective and stratiform clouds on the surface layer moisture and precipitation isotopic composition at both sites. 


\section{Zusammenfassung}

In den tropischen Gebieten finden wichtige großräumige Klimaphänomene wie die El-Niño-Südoszillation (ENSO), die Madden-Julian-Oszillation (MJO) und der Monsun statt, die das globale Klima in hohem Maße beeinflussen. Eines der Gebiete der Erde, in denen diese Störungen ihre Wirkung mit besonderer Intensität entfalten, ist Indonesien. In dieser Region, in der das Klima das ganze Jahr über meist warm und feucht ist, sind diese atmosphärischen Phänomene für den Wechsel zwischen Dürreperioden und Perioden sehr intensiver Niederschläge mit Folgen für die Landwirtschaft und die Tropenwälder verantwortlich. In hydrogeologischen Studien spielt die Isotopenzusammensetzung des Wassers eine vorrangige Rolle. Unter Ausnutzung der Eigenschaft verschiedener Isotope, sich zu Molekülen mit gleichem chemischen Verhalten, aber unterschiedlichen Massen zu verbinden, liefert die Isotopenzusammensetzung von Wassermolekülen Informationen über ihren Ursprung und ihre Verteilung in Raum und Zeit. Darüber hinaus spiegelt die Entwicklung der Isotopenzusammensetzung von Feuchtigkeit und Niederschlag aufgrund der Isotopenfraktionierung, die während der Phasenübergänge auftritt, die Prozesse wider, die den Ursprung und den Transport von Luftmassen durch die Troposphäre charakterisieren.

Aufgrund der großen Bedeutung, des indonesischen Klimas für die Landwirtschaft und die Erhaltung der Tropenwälder, sowie wenige direkte Messungen der Isotopenzusammensetzung von Niederschlag und Wasserdampf in diesem Gebiet haben wir im Rahmen der Projekte Bariri-Flux und EFFORTS CRC 990 diese Studie durchgeführt. Ziel dieser Studie war es

1. die Isotopenzusammensetzung des Niederschlags entlang eines NordSüd Gradienten in Zentralsulawesi zu messen und den Einfluss der Großwetterlage und des Wolkentyps auf die zeitliche Variabilität der Isotopenzusammensetzung zu untersuchen,

2. die Isotopenzusammensetzung von Niederschlag- und Wasserdampf in einer ausgewachsenen Ölpalmenplantage zu messen und den Einfluss der MJO auf die Isotopenzusammensetzung von Wasserdampf in Bodennähe zu untersuchen und

3. die Isotopenzusammensetzung des aus dem Boden und den Blättern extrahierten Wassers zu bestimmen und die Evapotranspiration über einer ausgewachsenen Ölpalmenplantage in seine Bestandteile zu zerlegen.

\section{Zum Erreichen der Ziele haben wir}

1. für die Dauer von etwa einem Jahr Niederschlag an 3 Stationen entlang eines Nord-Süd Gradienten in Zentralsulawesi gesammelt. Die $\delta$-Werte $\left(\delta D, \delta^{18} O\right)$ wurden mit einem Isotopic Ratio Mass Spectrometer (IRMS) an der International Atomic Energy Agency (IAEA) Wien und einem 
Cavity Ring-Down Spectrometer (CRDS) an der Universität Göttingen gemessen.

2. über zwei Wochen hinweg $\delta D$ und $\delta^{18} O$ in Wasserdampf entlang eines Vertikalprofils gemessen und Niederschlag in einer ausgewachsenen Ölpalmenplantage in der Nähe von Jambi, Sumatra, gesammelt. Ein CRDS wurde zur Analyse der $\delta$-Werte verwendet.

3. für eine Dauer von 3 Tagen Ölpalmenblätter in 2 verschiedenen Höhen und Bodenproben in 2 verschiedenen Tiefen in derselben Ölpalmenplantage gesammelt. Das Wasser aus den Blättern und den Bodenproben wurde mit Hilfe einer Tieftemperatur-Vakuumleitung extrahiert. Die Isotopenzusammensetzung des Niederschlags und des Wassers aus Blättern und Bodenproben wurde mit einem CRDS gemessen.

Unsere Ergebnisse zeigten, dass die Isotopenzusammensetzung des Niederschlags an den 3 Standorten signifikant durch die geographische Höhe der Standorte beeinflusst wurde und dass $\delta D$ und $\delta^{18} O$ durch die Intensität der konvektiven Bewölkung in dem Gebiet reguliert wurde. Darüber hinaus deutet ein Vergleich unseres Datensatzes mit der Station Mulu (Borneo) darauf hin, dass die Isotopenzusammensetzung des Niederschlags hauptsächlich vom Bedeckungsgrad der stratiformen Bewölkung abhängt, welchedurch die Intensität der konvektiven Bewölkung beeinflusst wird.

Das Jambi-Gebiet wurde während unserer Kampagne hauptsächlich mit Wasserdampf aus dem Südchinesischen Meer (77,5\% Vorkommen) versorgt. Unter diesen Bedingungen bewegen sich die Luftpakete in niedriger Höhe (1000 m ü.d.M.) mit großen Mengen isotopisch angereichertem Wasserdampf $(\overline{\delta D}-100 \%$ ). Während der aktiven Phase der Madden-Julian -Oszillation wurde die Entwicklung einer konvektiven Wolkenzelle im Indischen Ozean mit Luftpaketen in höheren Höhen (> 2000 m ü.d.M.) in Verbindung gebracht. Dies führte zum Transport von abgereichertem Wasserdampf aus der oberen Troposphäre in die atmosphärische Bodenschicht. Die rasche Abreicherung des Wasserdampfes ( $\approx-60 \%$ innerhalb von 3 Tagen), die mit der Intensität der konvektiven Bewölkung verbunden war, zeigte sich nicht nur an der Isotopenzusammensetzung vom Wasserdampf und Niederschlag, sondern auch am Deuteriumüberschuss. Die zeitliche Variabilität der Isotopenzusammensetzung des Wasserdampfs in der Bodenschicht wurde hauptsächlich durch den Anteil der Wiederverdampfung des Niederschlags dominiert (bis zu 50\%).

In der ausgewachsenen Ölpalmenplantage machte die Transpiration während der Mittagszeit einen Anteil von 50 bis 60\% der Evapotranspiration aus. Dieses Ergebnis ist in enger Übereinstimmung mit Ergebnissen, die für denselben Standort veröffentlicht und mit mikrometeorologischen Methoden abgeschätzt wurden.

Trotz großer technischer und logistischer Probleme liefert unsere Studie einige kleine Verbesserungen und neue Erkenntnisse zum Verständnis der 
Wechselwirkungen zwischen der MJO, der großräumigen Konvektion und der Isotopenzusammensetzung des Niederschlags und Wasserdampfs auf Süd-Sumatra und in Zentralsulawesi. In Zukunft könnten eine systematischere Probenahmestrategie und das Hinzufügen anderer Messtechniken helfen die Rolle konvektiver und stratiformer Wolken auf die Isotopenzusammensetzung von Niederschlag und Wasserdampf in der atmosphärischen Bodenschicht an beiden Standorten besser zu beschreiben. 



\section{Acknowledgements}

After 7 years it is really a challenge to remember all the people that interacted with me and in some way are involved in this project. So, hoping not to forget somebody (and, in such a case, I apologize beforehand), I would like to start remembering all the assistants, colleagues and professors that helped me to discover and carry out my research in Central Sulawesi, pak Dudin, Ibu Ilfi Anty, pak Alex, pak Ore and of course the professors of the Palu Tadulako University, Dr. Aiyen Tjoa, Dr. Henry Barus and Dr. Abdul Rauf. Without your support I couldn't even come to your beautiful country and carry out my research.

Living in Palu for almost a year was not only a research experience but also a lesson of life. For this reason I cannot avoid to mention and thank all the friends that I have met during my stay in this beautiful corner of Indonesia, that are the Palu Vespa Club 777 and in particular Sapto Patrowo and friends (not forgetting the family that had the wonderful kiosk serving Saraba near the Hospital), who welcomed and included me (and later my wife) as part of a family in their Vespa club as an Italian guest driving an authentic old timer Vespa along the streets of Palu and throughout Central Sulawesi. Unfortunately I spent only a couple of weeks in Jambi and I didn't have the time to know all the Indonesian colleagues and partners of the EFFORTS CRC 990 at the University of Jambi, however I thank all of them for the support and help during the measurements that I have carried out there.

My deep gratitude goes for all the technical and non-technical staff of the Bioclimatology Group at the University of Göttingen, and especially to Edgar Tunsch and to Dr. Heiner Kreilein for sharing with me the frustration of carrying out a research in a beautiful, but sometimes too demanding, place like Indonesia. This gratitude is as well extended to the members of the technical staff of the Bioclimatology group, Frank Tiedmann and Dietmar Fellert, because your contribute is everywhere tangible and help us researchers in collect our data and finalize our research.

In these years I had the privilege to work with a lot of smart and interesting scientists and students at the Bioclimatology Group. Not always our research goals crossed but, in any case, I thank all of you for sharing with me your working environment. In particular I would like to thank Dr. Julian Denventer, Dr. Ana Meijide, Dr. Fernando Mojano, Dr. Christian Markwitz for the support that was always beyond the pure scientific pragmatism. Dr. Florian Heimsch and I spent together almost a year in Indonesia. We shared all sorts of feelings that a PhD student could experience when doing research abroad, therefore I thank him for sharing with me a part of life that we will never forget.

There are many friends here in Göttingen and in my hometown Trieste that I have to thank for their support, but in these last rows I want to thank 
my family who always asked me only the essential and never pretended me to be the more that what I am. Despite the issues that we had during these 7 years I want to thank my supervisor Prof. Dr. Alexander Knohl due to the encouragement to finish my $\mathrm{PhD}$ and his understanding during my hardest moments.

During my doctorate I had the privilege of becoming a father. There are not enough ways to express gratitude to my wife and daughter to give me the strength and motivation to be a better person (and perhaps a better scientist) in everyday life. 


\section{Contents}

Declaration of Authorship iii

Abstract vii

Acknowledgements $\quad$ xiii

1 Introduction $\mathbf{1}$

1.1 The global water cycle and its role on climate . . . . . . . . . 1

1.2 The role of tropics in the global water cycle . . . . . . . . . 3

1.3 Water stable isotopes in the tropics . . . . . . . . . . 5

1.3.1 The BaririFlux and SFB990 projects . . . . . . . . . 6

1.4 Organization of the thesis ............. 7

2 Theory and concepts of stable isotopes 9

2.1 Introduction to stable isotope in hydrology . . . . . . . . . 9

2.2 Isotopic ratio and $\delta$-notation $\ldots \ldots \ldots . \ldots \ldots$

2.3 Isotopic fractionation in hydrology . . . . . . . . . . . . . 13

2.3.1 Equilibrium fractionation ................ 14

2.3.2 Batch and Rayleigh processes . . . . . . . . . . . 15

2.3.3 Kinetic fractionation . . . . . . . . . . . . 18

2.4 Global Meteoric Water Line . . . . . . . . . . . . . . . . . . . 19

2.4 .1 Deuterium Excess . . . . . . . . . . . . . . 21

2.4.2 The Craig-Gordon Model . . . . . . . . . . . . 21

2.4.3 Global closure assumption .............. 24

2.5 Factors controlling the isotopic composition . . . . . . . . . 27

2.5 .1 Altitude Effect . . . . . . . . . . . . . . 28

2.5 .2 Latitudinal Effect . . . . . . . . . . . . . 28

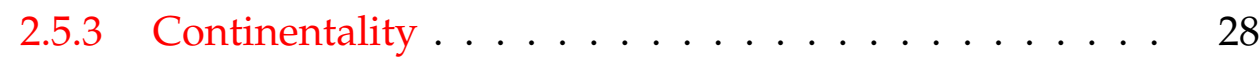

2.5 .4 Amount Effect. . . . . . . . . . . . . . . . . 29

2.6 Stable isotopes in the water vapor . . . . . . . . . 30

2.6.1 Distillation and mixing model for the water vapor iso-

topic composition . . . . . . . . . . . . . . 31

Condensation .................. 33

Rain reevaporation . . . . . . . . . . . . . . . . 34

Air mass mixing . . . . . . . . . . . . 35

2.7 Ecosystem water flux partitioning . . . . . . . . . . 36

2.7.1 Keeling plot approach for $\delta_{E T}$ determination . . . . . 37

2.7.2 Soil water isotopic composition . . . . . . . . . . . 38

2.7.3 Leaf water isotopic composition . . . . . . . . . 39 
xvi

3 Methods in water stable isotopes analysis 43

3.1 Introduction . . . . . . . . . . . . . . . . 43

3.2 Isotopic Ratio Mass Spectrometry . . . . . . . . . . . . . . . . 43

3.3 Wavelength Scanned Cavity Ring-Down Spectroscopy . . . . 45

3.4 Calibration ....................... 46

3.4.1 Discrete IRMS and WS-CRDS . . . . . . . . . . . . 47

3.4 .2 Continuous WS-CRDS . . . . . . . . . . . . . 47

3.5 Sample collection and preparation . . . . . . . . . . . . 49

3.5.1 Rainfall collection . . . . . . . . . . . . . . . . . 49

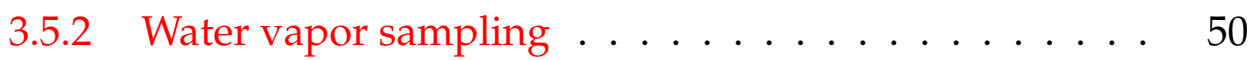

3.5.3 Extraction of water samples . . . . . . . . . . 52

4 Isotopic characterization of the precipitation regime in Central Sulawesi, Indonesia $\quad 55$

4.1 Introduction . . . . . . . . . . . . . . 55

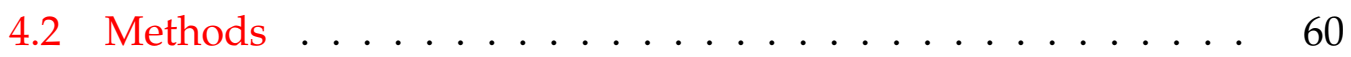

4.2 .1 Site description . . . . . . . . . . . . . . . 60

4.2 .2 Isotopic measurements . . . . . . . . . . . . . 61

4.2 .3 Meteorological data . . . . . . . . . . . . 62

4.3 Results and discussion . . . . . . . . . . . . . 62

4.3 .1 Local meteorology . . . . . . . . . . . . . . . . 62

4.3 .2 Precipitation regime ...................... 63

4.3.3 Rainfall isotopic composition $\delta^{18} O \ldots \ldots$. . . . . . . . 67

4.3.4 Rainfall deuterium excess $\left(d_{\text {exc }}\right) \ldots \ldots \ldots$. . . . . . 69

4.3.5 Amount effect and its drivers . . . . . . . . . . . 70

4.4 Conclusion . . . . . . . . . . . . . . . . 75

5 The influence of the MJO on the isotopic composition of the landsurface water vapor and precipitation in Sumatra, Indonesia. $\quad 79$

5.1 Introduction . . . . . . . . . . . . . . . . . 79

5.2 Materials and Methods . . . . . . . . . . . . . . . . 82

5.2 .1 Site description . . . . . . . . . . . . 82

5.2.2 Water vapor and precipitation measurements .... 82

5.2 .3 Synoptic data . . . . . . . . . . . . . . 84

5.2 .4 Isotopic distillation and mixing model . . . . . . . . . 85

5.3 Results ....................... 85

5.3 .1 MJO index ....................... 85

5.3.2 Precipitation trend and isotopic composition . . . . . . 87

5.3.3 Water Vapor Isotopic Composition . . . . . . . . . . . . 87

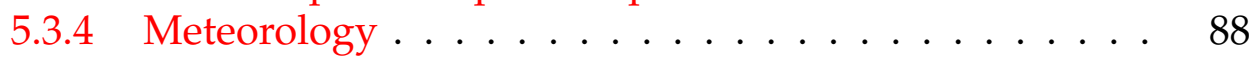

5.4 Discussion . . . . . . . . . . . . . . . . . . 90

5.4.1 Relationship Between $\delta D_{p}, \delta D_{v}$, dexc $c_{p}$ and Meteorological Variables . . . . . . . . . . . . . . 90 90

5.4.2 Analysis of the Air Parcels Backward Trajectories . . . 91

5.4.3 Large-scale convective patterns and their effect on the surface layer moisture and precipitation . . . . . . . . . 91

5.4.4 The influence of rain re-evaporation on the surface layer water vapor $\delta D_{v} \ldots \ldots \ldots . \ldots . \ldots 99$ 
5.4 .5 Summary and conclusion . . . . . . . . . . 100

6 Partitioning water fluxes in a mature oil palm plantation in Jambi province, Sumatra. $\quad 103$

6.1 Introduction . . . . . . . . . . . . . . . . . . . 103

6.2 Methods . . . . . . . . . . . . . . . . 105

6.2 .1 Site location . . . . . . . . . . . . . . 105

6.2.2 Water vapor and meteorological measurements . . . . 107

6.2.3 Evapotranspiration isotopic composition . . . . . . . . 108

6.2 .4 Leaves and soil sampling . . . . . . . . . . . . . . 109

6.2.5 Determination of $\delta_{T}$ and $\delta_{E} \ldots \ldots \ldots \ldots$

6.3 Results and discussion . . . . . . . . . . . . . . . 113

6.3 .1 Meteorology . . . . . . . . . . . . . . 113

6.3.2 Determination of $\delta_{E T}$ and isoforcing . . . . . . . 113

6.3.3 Isotopic composition of $\delta_{L, b}$ and $\delta_{s} \ldots \ldots \ldots \ldots$

6.3.4 Modeling the bulk leaf water isotopic composition . . 119

6.3.5 Transpiration isotopic composition and flux partitioning 121

6.4 Conclusion . . . . . . . . . . . . . . . . 123

7 Conclusion $\quad \mathbf{1 2 5}$

7.1 Conclusion . . . . . . . . . . . . . . . 125

$\begin{array}{ll}\text { Bibliography } & 131\end{array}$ 



\section{List of Figures}

1.1 The global water cycle ................ 2

2.1 Hydrogen isotopes . . . . . . . . . . . . . . . 10

2.2 IAEA WICO . . . . . . . . . . . . . . . . 12

2.3 Batch and Rayleigh condensation . . . . . . . . . . . . . . 17

2.4 Rayleigh condensation process . . . . . . . . . . . . 18

2.5 Global Meteoric Water Line . . . . . . . . . . . . . . . . . . . 20

2.6 Deuterium Excess in evaporating waters . . . . . . . . . . . 22

2.7 Craig-Gordon model for the evaporation flux . . . . . . . . . 23

2.8 Wind speed dependency of the kinetic enrichment factor . . . 25

2.9 Global closure assumption . . . . . . . . . . . . . . . 26

2.10 IAEA/WMO GNIP stations . . . . . . . . . . . . . . . 27

2.11 Isotopic thermometer . . . . . . . . . . . . . . . . . . 29

2.12 Water vapor isotopic composition modeling . . . . . . . . . . 30

2.13 Theoretical curves in the $\delta(q)$ space . . . . . . . . . . . . 32

2.14 Ecosystem Partitioning . . . . . . . . . . . . . . . . . 36

2.15 Keeling plot example . . . . . . . . . . . . . 38

3.1 A scheme of an IRMS . . . . . . . . . . . . . . . . . . . . 44

3.2 Principle of optical spectrometry . . . . . . . . . . . . . 46

3.3 Example of configuration for liquid analysis . . . . . . . . . 48

3.4 Diagram of a Picarro SDM . . . . . . . . . . . . . . 49

3.5 The event pluviometer . . . . . . . . . . . . . 50

3.6 Sampling tube, heating system and insulation . . . . . . . . 51

3.7 Water cryogenic vacuum extraction . . . . . . . . . . . 53

4.1 Mesoscale system schematic . . . . . . . . . . . . . . . . 57

4.2 Convective vs. Stratiform clouds . . . . . . . . . . . . . 59

4.3 Central Sulawesi elevation map . . . . . . . . . . . . . . 60

4.4 N-S Transect . . . . . . . . . . . . . . . . . 62

4.5 Central Sulawesi Meteorology . . . . . . . . . . . . . . . . . 63

4.6 GPM Precipitation map . . . . . . . . . . . . . . . 64

4.7 Nino34 and rainfall correlation . . . . . . . . . . . 65

4.8 GNIP monthly amount . . . . . . . . . . . . . . . . 66

4.9 Monthly cumulative precipitation . . . . . . . . . . 67

4.10 Precipitation ${ }^{18} \mathrm{O}$ boxplot . . . . . . . . . . . . . 68

4.11 Elevation effect . . . . . . . . . . . . . . . 69

4.12 Daily OLR and $\delta^{18} O_{p} \ldots \ldots \ldots \ldots$. . . . . . . . . . . . . . . . . . . 70

4.13 Precipitation $d_{e x c}$ boxplot . . . . . . . . . . . . . 71

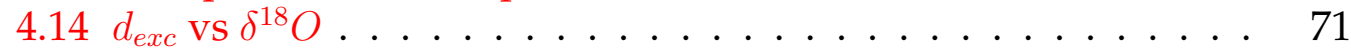


4.15 Local Meteoric Water Line . . . . . . . . . . . . . . . . . 72

4.16 Daily amount effect . . . . . . . . . . . . . . . . 73

4.17 Monthly weighted amount effect . . . . . . . . . . . . . . 74

4.18 Daily amount effect . . . . . . . . . . . . . 76

5.1 ROI experiment $2 \ldots \ldots \ldots$. . . . . . . . . . . . 83

5.2 MJO Phase Diagram . . . . . . . . . . . . . . . . . . 86

5.3 Precipitation comparison . . . . . . . . . . . . . 87

5.4 Picarro time-series . . . . . . . . . . . . . . . . 89

5.5 Trajectories frequency . . . . . . . . . . . . . . . . 92

5.6 Air parcels altitude . . . . . . . . . . . . . . 93

5.7 Hovmoller OLR . . . . . . . . . . . . . . . . . . . . . 94

5.8 Daily TRMM . . . . . . . . . . . . . . . . . . . . . 95

5.9 Cumulative precipitation . . . . . . . . . . . . . . 96

5.10 Amount effect . . . . . . . . . . . . . . . . . 97

5.11 Local Meteoric Water Line Jambi . . . . . . . . . . . . . . . 98

5.12 Isotopic Mixing Model . . . . . . . . . . . . . . . . . 102

6.1 Mature oil palm . . . . . . . . . . . . . . . 106

6.2 PTPN VI Map . . . . . . . . . . . . . . . . . . . 107

6.3 Vertical profile . . . . . . . . . . . . . . . . . . . 114

6.4 Leaves dataset . . . . . . . . . . . . . . . . . . . . . 115

6.5 Isoforcing . . . . . . . . . . . . . . . . . . . . . . . . . . . . . . . 116

$6.6 g_{s}$ and $L e a f_{t} \ldots \ldots \ldots \ldots \ldots \ldots$

6.7 Jambi LWML . . . . . . . . . . . . . . . . . . . . 118

6.8 Enrichment models . . . . . . . . . . . . . . . . . . 120

6.9 Transpiration . . . . . . . . . . . . . . 122 


\section{List of Tables}

1.1 Main physical properties of water . . . . . . . . . . . . 1

2.1 Relative abundance of isotopic water and principal physical

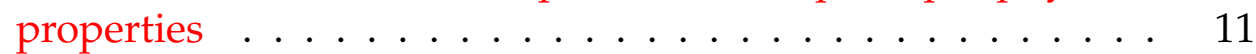

2.2 Range of isotopic composition values in different water reservoirs. After Mook and Rozanski (2000) . . . . . . . . . . . . . . 13

2.3 Ratio of molecular diffusivities of the main water isotopologues in air . . . . . . . . . . . . . . . . .

3.1 International standards for water isotopic measurements reference . . . . . . . . . . . . . . . . 47

4.1 Average $(2014-15)$ values with $\pm 1 \sigma \ldots \ldots . \ldots . \ldots 63$

4.2 Precipitation event isotopic composition $\delta^{18} O$ median and inter-

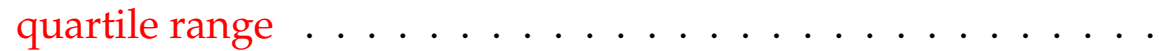

5.1 Mean and standard deviation (sd) of the working standard measured with an IRMS (Delta Plus, Thermo Fisher Scientific inc. $\mathbb{R}$, Bremen, Germany) and calibrated against V-SMOW; TS 2013 and ITASE were used for calibration of water vapor and STD A, B, C for precipitation samples and leaves extracted water respectively. . . . . . . . . . . . . . .

5.2 Date of the rainfall event, amount and isotopic composition $\left(\delta^{18} O_{p}, \delta D_{p}\right)$ and deuterium excess $\left(d_{p}\right)$ of the rain collected in $2016 \ldots \ldots \ldots \ldots \ldots \ldots \ldots$

6.13 hourly $\Delta_{L, b}-\Delta_{L, e}$ values in $\%$. . . . . . . . . . . . 119

6.2 Non steady state in $\%$. . . . . . . . . . . . . . . . 123

6.3 Bulk leaf water in $\%$. . . . . . . . . . . . . . 123 



\section{List of Abbreviations}

$\begin{array}{ll}\text { ENSO } & \text { El Niño Southern Oscillation } \\ \text { GMWL } & \text { Global Meteoric Water Line } \\ \text { GNIP } & \text { Global Network of Isotopes in Precipitation } \\ \text { GPM } & \text { Global Precipitation Measuring } \\ \text { IAEA } & \text { International Atomic Energy Agency } \\ \text { IPCC } & \text { Intergovernmental Panel on Climate Change } \\ \text { IRMS } & \text { Isotopic Ratio Mass Spectrometry } \\ \text { ITCZ } & \text { Inter Tropical Convergence Zone } \\ \text { LEL } & \text { Local Evaporation Line } \\ \text { LMWL } & \text { Local Meteoric Water Line } \\ \text { MJO } & \text { Madden Julian Oscillation } \\ \text { NIST } & \text { National Institute for Standards and Technology } \\ \text { NOAA } & \text { National Oceanic and Atmospheric Administration } \\ \text { OLR } & \text { Outgoing Longwave Radiation } \\ \text { PAR } & \text { Photosynthetically Active Radiation } \\ \text { QBO } & \text { Quasi Biennial Oscillation } \\ \text { SDM } & \text { Standard Delivery Module } \\ \text { SST } & \text { Sea Surface Temperature } \\ \text { TRMM } & \text { Tropical Rainfall Measurement Mission } \\ \text { WMO } & \text { World Meteorological Organization } \\ \text { WS-CRDS } & \text { Wavelenght Scanned - Cavity Ring Down Spectroscopy }\end{array}$





\section{List of Symbols}

\begin{tabular}{|c|c|c|}
\hline$d$ & deuterium excess & $\%$ \\
\hline$d_{E T}$ & evapotranspiration deuterium excess & $\%$ \\
\hline$d_{p}$ & precipitation deuterium excess & $\%$ \\
\hline$d_{v}$ & water vapor deuterium excess & $\%$ \\
\hline$E_{S}$ & soil evaporation & $\mathrm{mol} \mathrm{m}{ }^{-2} \mathrm{~s}$ \\
\hline$E_{T}$ & transpiration & $\mathrm{mol} \mathrm{m} \mathrm{m}^{-2} \mathrm{~s}$ \\
\hline$E T$ & evapotranspiration & $\mathrm{mol} \mathrm{m}^{-2} \mathrm{~s}$ \\
\hline$g_{s}$ & stomatal conductance & $\mathrm{mol} \mathrm{m}^{-2} \mathrm{~s}$ \\
\hline$g_{b l}$ & leaf boundary layer conductance & $\mathrm{mol} \mathrm{m}^{-2} \mathrm{~s}$ \\
\hline$g_{t}$ & total leaf conductance & $\mathrm{mol} \mathrm{m}^{-2} \mathrm{~s}$ \\
\hline$h$ & humidity relative to the saturation vapor pressure at leaf temperature & \\
\hline$I_{E T}$ & ET isoforcing & $\mathrm{mmol} / \mathrm{m}^{2} \mathrm{~s} \% 0$ \\
\hline$L_{e f f}$ & effective leaf diffusion length & $\mathrm{m}$ \\
\hline$R$ & isotopic Ratio & \\
\hline$P$ & power & $\mathrm{W}\left(\mathrm{J} \mathrm{s}^{-1}\right)$ \\
\hline$p$ & vapor pressure & $\mathrm{kPa}\left(\mathrm{N} \mathrm{m}^{-2}\right)$ \\
\hline$q_{E T}$ & evapotranspiration mixing ratio & $\mathrm{mmol} \mathrm{mol}-1$ \\
\hline$q_{v}$ & atmospheric water vapor mixing ratio & $\mathrm{mmol} \mathrm{mol}{ }^{-1}$ \\
\hline$r_{s}$ & stomatal resistance & $\mathrm{ms}^{-1}$ \\
\hline$r_{b}$ & leaf boundary layer resistance & $\mathrm{ms}^{-1}$ \\
\hline$R H$ & relative humidity & $\%$ \\
\hline$T_{\text {leaf }}$ & leaf temperature & ${ }^{\circ} \mathrm{C}$ \\
\hline$V P D_{l, a}$ & leaf-to-air vapor pressure deficit & $\mathrm{hPa}$ \\
\hline$\alpha_{e q}$ & equilibrium fractionation factor & \\
\hline$\alpha_{\text {kin }}$ & kinetic fractionation factor & \\
\hline$\delta$ & isotopic composition & $\%$ \\
\hline$\delta_{E}$ & isotopic composition of evaporation & $\%$ \\
\hline$\delta_{E T}$ & isotopic composition of evapotranspiration & $\%$ \\
\hline$\delta_{L, b}$ & isotopic composition of bulk leaf water & $\%$ \\
\hline$\delta_{L, e}$ & isotopic composition of leaf water at the site of evaporative site & $\%$ \\
\hline$\delta_{L, s s}$ & isotopic composition of leaf water in steady-state & $\%$ \\
\hline$\delta_{L, n s s}$ & isotopic composition of leaf water in non steady-state & $\%$ \\
\hline$\delta_{p}$ & isotopic composition of precipitation & $\% 0$ \\
\hline$\delta_{w, p}$ & weighted isotopic composition of precipitation & $\%$ \\
\hline$\delta_{s}$ & isotopic composition of soil water & $\%$ \\
\hline$\delta_{S W}$ & isotopic composition of sea water & $\%$ \\
\hline$\delta_{T}$ & isotopic composition of transpiration & $\%$ \\
\hline$\delta_{v}$ & isotopic composition of water vapor & $\%$ \\
\hline$\delta_{x}$ & isotopic composition of xylem water & $\% 0$ \\
\hline
\end{tabular}


xxvi

$\Delta \quad$ isotopic discrimination $\quad \%$

$\epsilon_{e q} \quad$ equilibrium enrichment factor $\quad \%$

$\epsilon_{k i n} \quad$ kinetic enrichment factor $\quad \%$

$\wp \quad$ Péclet number 
Dedicated to my daughter Agnese and my wife Erika 



\section{Chapter 1}

\section{Introduction}

\subsection{The global water cycle and its role on climate}

Water $\left(\mathrm{H}_{2} \mathrm{O}\right)$ is one of the most important molecules in nature in that it is essential for all living organisms, it participates as solvent in many chemical reactions and it contributes to the modulation of the climate of the Earth. Water bodies cover almost $71 \%$ of the earth's surface and $96,5 \%$ of it is found in seas and in oceans including the polar ice caps (The World Factbook 2018, CIA, Washington, DC, USA). The remaining water is distributed in lakes, in rivers, in the soil (as soil moisture) and in the atmosphere (as moisture, clouds and other hydrometeors). Due to its physical properties (see Table 1.1), water is the only substance that can co-exist in different physical states (solid, liquid and gas) in the terrestrial biosphere and is one of the most important climate regulators of the Earth (Trenberth, Fasullo, and Kiehl, 2009).

TABLE 1.1: Main physical properties of water

\begin{tabular}{lcc}
\hline Parameter & Value & Units \\
\hline Molar mass & 18.015 & $\mathrm{~g} \mathrm{~mol}^{-1}$ \\
Density $^{*}$ & 0.997 & $\mathrm{~g} \mathrm{~mL}^{-1}$ \\
Melting Point & 0 & ${ }^{\circ} \mathrm{C}$ \\
Boiling Point & 99.98 & ${ }^{\circ} \mathrm{C}$ \\
Vapor Pressure & 2.338 & $\mathrm{kPa}^{* *}$ \\
Std. Fus. Enthalpy & 6.01 & $\mathrm{~kJ} \mathrm{~mol}^{-1}$ \\
Std. Vap. Enthalpy & 44.0 & $\mathrm{~kJ} \mathrm{~mol}^{-1}$ \\
\hline${ }^{*}$ At normal conditions. & & \\
${ }^{* *}$ At $20^{\circ} \mathrm{C}$ & &
\end{tabular}

The natural cycle of water, that is the flow of water in multiple phases between various reservoirs, is called the global hydrological cycle (figure 1.1) and the field of study that investigates the interactions among this cycle is called hydrology.

The global water cycle starts and ends in the oceans surrounding the earth's surface, where most of the evaporation flux feeds the atmospheric clouds. These later produce rainfall or snowfall, depending on the latitude and on the mixing processes, which they undergo during their transport. 


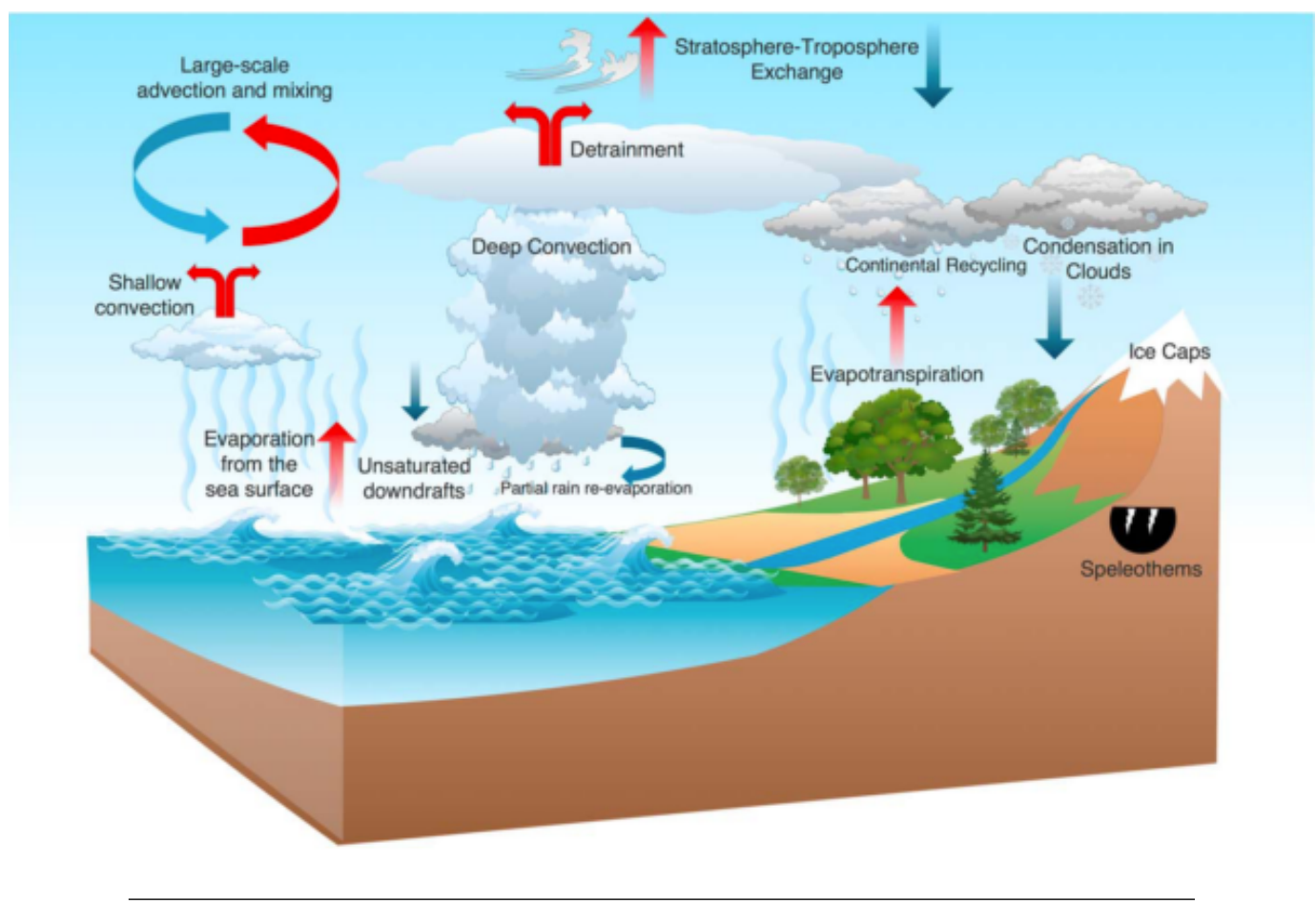

FIGURE 1.1: The global water cycle showing the reservoir and the associated input and output fluxes (Galewsky et al., 2016)

It is estimated that $86 \%$ of the global water vapor is being formed above the oceans, and $78 \%$ of this returns directly to the ocean as precipitation (Schmitt, 1995) without contributions to the land water budget. The remaining water vapor travels to the continents where it encounters condensation, sublimation, advection and vertical mixing, producing a large variety of precipitable hydrometeors (rain, drizzle, hail and so on). The "terrestrial" part of the cycle is mostly characterized by the interactions occurring between the oceanoriginated atmospheric moisture and the local evaporative fluxes, introducing moisture to the sub-cloud layers from the atmospheric boundary layer.

The surface moisture flux contribution is represented by the evapotranspiration from the canopy and upper soil layers (Good, Noone, and Bowen, 2015; Jasechko et al., 2013) and by the evaporative fluxes from the internal water bodies such as lakes, rivers (Trenberth et al., 2007) and peatlands. Other important fluxes of the water cycle occurring at high latitudes and altitudes are represented by the snow and ice deposition and sublimation on polar ice caps (Arctic and Antarctic) and on high mountain ranges and by the runoff of water above the terrain surface and by the river discharge. All these different components of the cycle act in a reciprocal equilibrium with the Sun's radiation as the main driving force.

Global warming is progressively disturbing this equilibrium increasing the fraction of water vapor reaching continents and producing rainfall (Huntington, 2006). This increase in the rate of oceanic water vapor reaching the continents amplifies the impacts of the local precipitation regime due to the 
intensification of the water cycle (Huntington, 2010; Milly et al., 2002; Trenberth, 2011). Evident on-going effects of the changes of the Earths mean temperatures and wind patterns, responsible for the transport of moisture, are affecting polar regions (Smith, 2005; Vihma et al., 2016; Rintoul et al., 2018) as well as perennial glaciers (Dyurgerov, 2003; Oerlemans, 2005), which represent the freshwater source for billions of people worldwide. Moreover, the intensification of rainfall events is followed by prolonged droughts globally (Chadwick et al., 2016; Tietjen et al., 2017; Marengo and Espinoza, 2016).

The mechanism for which the global water cycle controls the climate is related to the ocean thermal capacity (the ocean heat content was $\approx 15 * 10^{22}$ Joules in 2015, updated from Levitus et al., 2012) that represents the accumulated incoming solar radiation, stored as thermal energy, and to the absorption or release of this energy during water phase transitions. One important source of energy release from the oceanic surfaces to the atmosphere is represented by the seawater evaporation, which is characterized by a latitudinal gradient as it depends on the angle of incidence of the solar irradiance. Moisture and heat are then transported to higher altitudes and latitudes by buoyancy and atmospheric circulation from the Equator towards the poles following a seasonal cycle. In the higher troposphere moisture condenses on condensation nuclei (fine dusts, ice particles) forming clouds that, besides being the source for precipitation, act with a feedback mechanism reflecting a consistent fraction of the solar radiation back to space, thus cooling the atmosphere. Moreover, the latitudinal transport towards higher latitudes is important for the thermal equilibrium of the atmosphere because this mechanism transfers heat from the zones with an energy surplus(i.e.the equatorial zone), to the zones with an energy deficit (i.e. the Polar regions).

Global heat and moisture circulation patterns follow a latitudinal pattern, the so-called Hadley-Ferrel-Polar cell scheme, where the trade winds converging on the Inter-Tropical-Convergence-Zone (ITCZ) force the ascension of large amounts of moisture triggering important convective phenomena, thunderstorms and typhoons. Another important transport pattern for ENSO and MJO (see below), occurring due to a heat gradient between land and ocean along the Equator (longitudinally) is the Walker circulation.

\subsection{The role of tropics in the global water cycle}

The intertropical zone is the area of the planet where the larger amount of moisture and heat release occurs (Petersen and Rutledge, 2001; Jakob and Schumacher, 2008; Seidel et al., 2008). Due to this constant and massive supply of water vapor to the atmosphere (Hsu and Wallace, 1976; Rasmusson and Arkin, 1993), related to the higher and sustained sea surface temperatures in the area (Graham and Barnett, 1987; Deser et al., 2010), the rainfall intensity is larger than in any other place on earth, creating hydrometeorological conditions for the establishment and growth of rainforests and wetlands. Most of the tropical forests that cover the surface of the planet 
grow in a narrow equatorial belt, contributing largely to the release of water vapor into the lower atmosphere, adding to the water vapor coming from the surfaces of the oceans (Yakir and Wang, 1996; Jasechko et al., 2013).

Due to the accumulation of the energy surplus and to the thickness of the troposphere at this latitude, the principal two types of clouds systems, responsible for the abundant tropical rainfalls, are convective and stratiform clouds (Williams, Ecklund, and Gage, 1995; Zhang et al., 2007; Behrangi, Kubar, and Lambrigtsen, 2012). These clouds systems, associated with different meteorological phenomena (Tokay et al., 1999), propagate throughout the tropics under the influence of various climatic modes. The principal global climatic modes of this region are the El-Niño Southern Oscillation (ENSO) and the Madden-Julian Oscillation (MJO). These modes interact and exert considerable influence on other weather phenomena, occurring at smaller scale, such as monsoons (Qian, Robertson, and Moron, 2010; Cai, Tian, and Bowen, 2017), or tropical cyclones (Chu, 2004; Girishkumar and Ravichandran, 2012; Kang, Kim, and Elsner, 2019).

One of the most representative countries for the study of the interactions between mesoscale (i.e. MJO), regional (i.e. monsoon) and local meteorological phenomena, in the hydrogeological cycle context, is Indonesia. Known also as the Maritime Continent, Indonesia is one of the largest and most geographically diverse countries in the world. The Indonesian territory, including the inland and surrounding seas, covers an area comparable to that of the United States but is spread over more than 14000 islands, mainly distributed along the equator. Due to its position in the centre of the IndoPacific Warm Pool, an area characterized by high sea surface temperature located between the Indian and the Pacific oceans, most of the country is characterized as Tropical rainforest (Af), following the Köppen-Geiger (Peel, Finlayson, and McMahon, 2007) climate classification. Therefore the climate features a high average annual temperature, high relative humidity and the alternation of heavy rainfall and periods of drought due to the periodic effect of the seasonal monsoons. Similarly, the temperature of the seas surrounding the archipelago remains high throughout the year, releasing large quantities of moisture into the atmosphere. The combined effect of high temperatures and the release of large quantities of water vapor into the atmosphere produces important convective phenomena that on the one hand feed the intense episodic rainfalls and on the other hand provides a feedback mechanism cooling and maintaining the sea surface temperature within a certain interval (Wallace, 1992; Larson, Hartmann, and Klein, 1999; Hartmann and Larson, 2002).

The release, distribution and loss of moisture, in the form of abundant rainfall, follow dynamics dependent on the equilibrium between the absorption of solar radiation by the oceans and the loss of this stored energy through enhanced evaporation, convection, mesoscale and seasonal weather patterns. 
This balance is, on the one side, passively influenced by climatic teleconnections (for example ENSO) and, on the other side, influences the global climate due to the dissipation of surplus energy through the Hadley cell circulation. The importance of the tropics as the engine of the global water cycle requires an understanding of all those mechanisms, such as advection, air masses mixing and convection that affect the formation and transport of water vapor and precipitation within this area. Among the various tools used in climate research and in the traceability and quantification of hydrogeological cycles, stable water isotope measurements have seen increasing usage.

\subsection{Water stable isotopes in the tropics}

Until a decade ago research in this field was limited to the measurement of the isotopic content of liquid water, which is useful for the determination of the isotopic composition of precipitation. Due to recent instrumental developments and the adaptation of a monochromatic light source (laser) to determine the isotopic composition in the gaseous phase, it is now feasible to simultaneously measure the isotopic composition of precipitation and moisture, thus enabling the study of the fluxes and processes that influence air masses humidity along the water cycle (Berden, Peeters, and Meijer, 2000; LaFranchi, 2003; Gupta et al., 2009). A comprehensive discussion of the principles concerning stable water isotopes will be provided in the following chapters of this thesis (Chapter 2 and 3). Through the measurement of stable water isotopes, it is therefore possible to identify the areas of origin of moist air masses, and to reconstruct their trajectories. Continuous measurements of the atmospheric component of the water cycle yield information about their temporal evolution and variability.

These measurements, coupled with atmospheric general circulation models (Hoffmann, Jouzel, and Masson, 2000; Risi et al., 2010; Werner et al., 2011) can help to disentangle the effects of large scale meteorological phenomena like ENSO, MJO and monsoon occurring at different scales, from local circulation mechanisms, such as land-sea breeze, local amount effects triggered by topography or elevation. Water stable isotopes measurements have successfully been applied to constrain not only the evolution of precipitation patterns occurring in modern times (Berkelhammer et al., 2012; Sutanto et al., 2015; Sánchez-Murillo et al., 2016; Belgaman et al., 2017), but also, to reconstruct the climatic conditions of the past using water-related proxies (Cobb et al., 2007; Thompson et al., 2011; Permana et al., 2019) including but not limited to the maritime continent (Thompson et al., 2002; Ramirez et al., 2003; Herreros et al., 2009).

Given the importance of performing stable isotope measurements in the tropics and despite the extensive use of data acquisition through satellites, e.g. Liebmann and Smith, 1996; Worden et al., 2006; Huffman et al., 2010; Huffman et al., 2019, the available datasets are still affected by large spatial 
and temporal gaps (Vuille et al., 2005; Terzer et al., 2013). A possible explanation responsible for these gaps, might be related to the intrinsic difficulty in finding appropriate sampling locations in this area. In order to perform reliable and long-lasting measurements, certain conditions in terms of infrastructure and logistic are required and this characteristic cannot be always found. For example, continuous measurements of the isotopic composition of water vapor in a rainforest requires a shelter, a stable and a constant electricity supply, a clean and relatively dry-air source (or a reliable alternative method to obtain a dry-air source) and a robust system for data transmission. In remote areas, the access to the measuring site can be difficult and sporadic, because in some cases it foresees the use of bumpy and muddy roads or the wade of rivers. In this case, enough time for the planning of the campaign needs to be invested beforehand. Therefore research activity and data gathering in tropical zones can be underrepresented.

In the framework of the BaririFlux and SFB 990 project, from which results this thesis, we tried to overcome these technical and logistic issues in order to reduce geographical gaps by providing new stable isotope measurements in areas never monitored before. Indonesia is a broad country with a complex topography and, in the hydrological context, any water isotopic measurement gathered in such remote area, might be helpful to add a piece to understand the complexity of the global water cycle.

\subsubsection{The BaririFlux and SFB990 projects}

The BaririFlux and the SFB990 projects were both carried out in Indonesia. The first one in a mountain rainforest in Central Sulawesi and the second one in a mature oil palm plantation in Jambi province, Sumatra. In both cases the aim of the research was to perform measurements of the water vapor and precipitation isotopic composition using a Cavity Ring-Down Spectrometer.

- Baririflux: The initial goal of the BaririFlux project was to perform water vapor isotopic measurement along a vertical profile in a montane primary rainforest using a $70 \mathrm{~m}$ tall meteorological tower in the Lore Lindu National park in Central Sulawesi. The main objective of this project was to measure the isotopic composition of water and vapor in different compartments of the hydrologic cycle. In order to fulfill this objectives we wanted to combine the precipitation isotopic composition from samples collected along a North-South transect from Palu to Bariri, seawater samples from the Makassar Strait, water extracted from leafs, stems and soils samples collected from selected trees in the remote rain forest and, to complete the whole local hydrological cycle, continuous measurements of the isotopic composition of water vapor would have been sampled from three different heights of a Flux Tower. Besides the logistic challenges in establishing a measurement site in the tropics mentioned above, we further encountered a critical failure of the instrument for measuring the isotopic composition. The required repairs consumed 8 months of our campaign. In this time, I was able 
to perform fluid water sampling of the precipitation events along the north-south transect.

- SFB 990: EFForTS is a Collaborative Research Centre 990 founded by the DFG (German Research Foundation) investigating the ecological and socio-economical effects produced by a land use transformation occurring in Sumatra due to the extensive conversion from tropical rainforest to rubber jungle and palm oil plantation. In the framework of this project I deployed a Cavity Ring-Down Spectrometer in a mature palm oil plantation and measured the water vapor isotopic composition along a vertical profile aiming at disentangling the isotopic composition of the evapotranspiration fluxes (soil evaporation and leaf transpiration) separating the ecosystem's fluxes from the atmospheric background. To compute the isotopic mass balance equations, I collected the water extracted from the surface soil and from oil palm leaves in order to measure the source isotopic composition of the fluxes components. Moreover, using the atmospheric background isotopic signal I investigated the effects of a mesoscale weather event (Madden-Julian Oscillation) on the atmospheric surface layer water vapor isotopic composition.

\subsection{Organization of the thesis}

This thesis consists of 6 chapters that are organized in the following order:

- Chapter 2: "Theory and concepts of stable isotopes" gives an introduction to water stable isotopes, to isotopic fractionation and to equilibrium and kinetic processes. Furthermore this chapter explores the foundations of the use of water stable isotopes in climatological studies.

- Chapter 3: "Methods in water stable isotopes analysis" explains the conventional methods used for the analysis of water and water vapor measurements, the instrumental calibrations and samples manipulation.

- Chapter 4: "Isotopic characterization of the precipitation regime in Central Sulawesi, Indonesia" is the first study showing the results of the field campaign that I spent in Central Sulawesi were I collected precipitation samples at event resolution along a north south altitudinal transect.

- Chapter 5: "Influence of the MJO on the surface water vapor isotopic composition in Eastern Sumatra" is the second study focusing on my research in an oil palm plantation. Here I measured the water vapor isotopic composition continuously and found the effect of the MJO in the area. 
- Chapter 6: "Partitioning water fluxes in a mature oil palm plantation in Jambi province" is the third study, were I report the results of the water flux partitioning together with the isotopic composition of water extracted from oil palm leaves, soil and trunk organic matter in a mature oil palm plantation.

- Chapter 7: "Conclusion" reporting the thesis conclusions with some final remarks. 


\section{Chapter 2}

\section{Theory and concepts of stable isotopes}

\subsection{Introduction to stable isotope in hydrology}

The term isotope has been coined in 1913 by the Nobel-prize winner Frederick Soddy (1921). The exact definition according to the Encyclopaedia Britannica is "Isotope, one of two or more species of atoms of a chemical element with the same atomic number and position in the periodic table and nearly identical chemical behavior but with different atomic masses and physical properties. Every chemical element has one or more isotopes".

This characteristic implies that isotopes react chemically in the same manner (because they have the same electrical charge) but they react at slightly different rates due to their different masses. An important distinction among isotopes is their stability that depends on their "ability" in maintaining a constant number of neutrons. Isotopes whose number of neutrons remains constant are called stable, whilst others, losing their neutrons, are called unstable or more commonly radioactive because they emit radiation of various wavelengths during the decay process.

Hydrogen (also known with the name of protium, figure 2.1) for example, is the first element of the periodic table. It is constituted by a proton and an electron. The stable isotope of protium is the deuterium $\left({ }^{2} \mathrm{H}\right)$, which has a proton, an electron and one neutron. The second isotope of protium is the tritium $\left({ }^{3} H\right)$ that is radioactive as a consequence of the disequilibrium between the number of protons and neutrons. The half-life of tritium is approx. 13 years, that is the $50 \%$ of the initial concentration of tritium in a sample is converted to an atom of helium, an electron and an electron antineutrino every 13 years through of a beta-decay. This thesis focuses entirely on the geochemical cycle of stable isotopes therefore the characteristics of the radioactive decay will not be treated.

Isotopic geochemistry is the branch of geochemistry that incorporates and extends the research of biological and biophysical processes using the theory and the properties of isotopes. The year of 1946 is considered as the birth-year of light stable isotopic geochemistry $(\mathrm{H}, \mathrm{C}, \mathrm{O}, \mathrm{N}$ and $\mathrm{S})$ due to unprecedented advancements in measurement technology. 


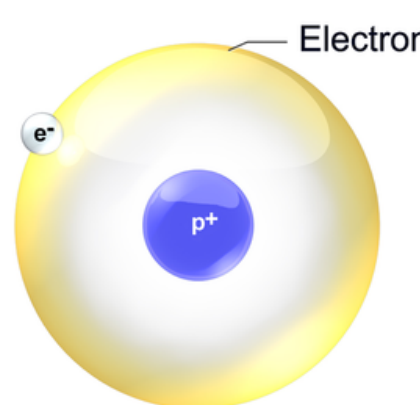

Hydrogen-1 mass number: 1

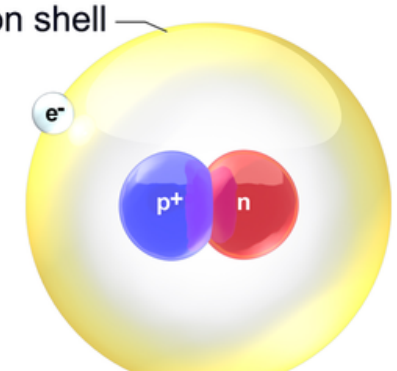

Hydrogen-2, mass number: 2

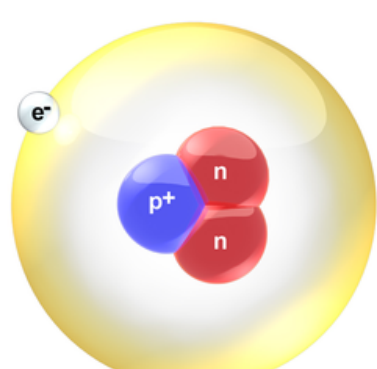

Hydrogen-3, tritium

mass number: 3

FIGURE 2.1: The hydrogen atom protium $\left({ }^{1} \mathrm{H}\right)$ and its two isotopes, the stable deuterium $\left({ }^{2} H\right)$ and the unstable isotope tritium $\left({ }^{3} H\right)$ (Source: Wikimedia Commons, Bruce Blaus (2014)

DOI:10.15347/wjm/2014.010. ISSN 2002-4436).)

Due to the development of the isotopic ratio mass spectrometry, H.C. Urey (1893-1981) received the 1934 Nobel Prize in chemistry for the discovery of the heavier isotope of hydrogen, the deuterium (Urey, Brickwedde, and Murphy, 1932). The group of students and collaborators of Urey, later called the "Chicago Group" included prominent names, such as S. Epstein, H. Craig, J. McCrea, C. Emiliani and H. Lowestam, that represented the group of founders of the isotopic geochemistry as we know it today. For example, the concept of the isotopic thermometer, that is considered as one of the most important achievements of the scientific community involved in isotopic studies during the $\mathrm{X} \mathrm{X}^{\circ}$ century, was discovered by this group (Urey et al., 1948; Epstein et al., 1951; Urey et al., 1951). In hydrology the theory of stable isotopes is used to understand the distribution and the dynamics of water isotopologues throughout the water cycle. Isotopologues are molecules with the same chemical structure but, due to the different isotopic composition, with different molecular mass. In theory up to 9 different "isotopic types" of water can co-exist in nature, each with a different atomic configuration, although most of these theoretical molecules have not been directly measured yet. Stable isotope hydrology uses the most abundant water isotopologues listed in table 2.1

Heavy isotopologues have higher (lower) boiling (freezing) point and, at the same temperature of the solution, they have lower vapor pressure in respect of lighter isotopologues (Rumble, 2019).

In the last 50 years technological progresses contributed to an increasing use and application of stable isotopes in a large number of research fields. Nowadays some analysis, like the measurement of the isotopic composition of rainfall and water vapor, are included in routine monitoring networks, 
TABLE 2.1: Relative abundance of isotopic water and principal physical properties

\begin{tabular}{lcc}
\hline Molecule & abundance & amu $^{* *}$ \\
\hline$H_{2}^{16} O$ & $99.78 \%$ & 18 \\
$H_{2}^{18} O$ & $0.20 \%$ & 20 \\
$H_{2}^{17} O$ & $0.03 \%$ & 19 \\
$H^{2} H^{16} O^{*}$ & $0.0149 \%$ & 19 \\
\hline${ }^{*}{ }^{2} H$ or $D$ stands for Deuterium \\
${ }^{* *}$ atomic mass unit
\end{tabular}

allowing a better understanding of the processes in context of the global atmospheric circulation patterns. Furthermore, other research fields took advantage of the new laser-based technologies for the isotopic measurements due to the benefit of requiring comparatively small sample amounts. Some of these fields are plant physiology, soil geochemistry and animal biogeochemistry.

\subsection{Isotopic ratio and $\delta$-notation}

In general, all applications using stable isotopes rely on the fact that heavier isotopologues react slower than lighter ones during chemical reactions or during phase changes. The process that causes the repartition of isotopologues in contiguous phases or between products and reagents is known as isotopic fractionation and it expresses the ratio between the concentration of heavy (and less abundant) and lighter isotopes in a sample (Dawson and Brooks, 2001; Kendall and McDonnell, 2012).

Formally fractionation is measured using the isotopic ratio (equation 2.1), which is the ratio between the concentration of heavier and lighter isotopes in a sample. For example, the isotopic ratio of deuterium and oxygen-18, the most common isotopes of water, are written as follows:

$$
R_{2} H=\frac{\left[{ }^{2} H\right]}{\left[{ }^{1} H\right]} \quad \text { and } \quad R_{18} O=\frac{\left[{ }^{18} \mathrm{O}\right]}{\left[{ }^{16} \mathrm{O}\right]}
$$

Absolute isotopic abundances (concentrations) are not easy to determine and also not practical to use due to the small proportion of heavier isotopologues in natural reservoirs (see table 2.1). In isotopic geochemistry it is therefore convention to specify the isotopic ratio of the targeted isotope in a sample, to the isotopic ratio of a known standard (Pinti, 2011), a convention known as " $\delta$-notation" (Coplen, 2011) and first introduced by (McKinney et al., 1950) using the following definition:

$$
\delta=\left(\frac{R_{\text {sample }}-R_{\text {standard }}}{R_{\text {standard }}}\right) \quad \text { also } \quad \delta=\left(\frac{R_{\text {sample }}}{R_{\text {standard }}}-1\right)
$$


where $\delta$ is reported in "\%o". In eq. 2.2, $R_{\text {standard }}$ stands for the isotopic ratio of a reference material of known isotopic composition and $R_{\text {sample }}$ the isotopic ratio of the measured sample. The choice of the proper reference material depends on the geochemical cycle of interest (Jochum et al., 2005). In hydrology the international standard in use is V-SMOW2 (Craig, 1961; Araguás-Araguás, Froehlich, and Rozanski, 2000; Gröning, Duren, and Andreescu, 2006) a laboratory-created water that recently substituted the original V-SMOW (out of stock). From the definition of " $\delta$-value" it follows that the values of $\delta D$ and $\delta^{18} O$ of the V-SMOW2 standard are $0 \%$ for both the deuterium and oxygen-18 isotopologues as it reports the average isotopic composition of all the oceans water. In terms of absolute isotopic ratio of VSMOW2 the values of $R_{18 O}$ is $(2005.20 \pm 0.45) \times 10^{-6}$ (Baertschi, 1976) and the value of $R_{2} H$ is $(155.95 \pm 0.1) \times 10^{-6}$ (Wit, Straaten, and Mook, 1980).

Stability and supply of the reference material are constantly checked by the International Atomic Energy Agency (IAEA) in Vienna, Austria and by the National Institute for Standard and Technology (NIST) in Gaithersburg, USA. These institutions are also in charge for supplying reference material to the scientific community. Furthermore, IAEA also promotes inter-laboratory comparison studies like the International Water Isotope Inter-Comparison Test ((Wassenaar et al., 2012; Wassenaar et al., 2018)) to test and certify laboratories measuring performances (figure 2.2).

Combined Accuracy Score for WICO Core Set
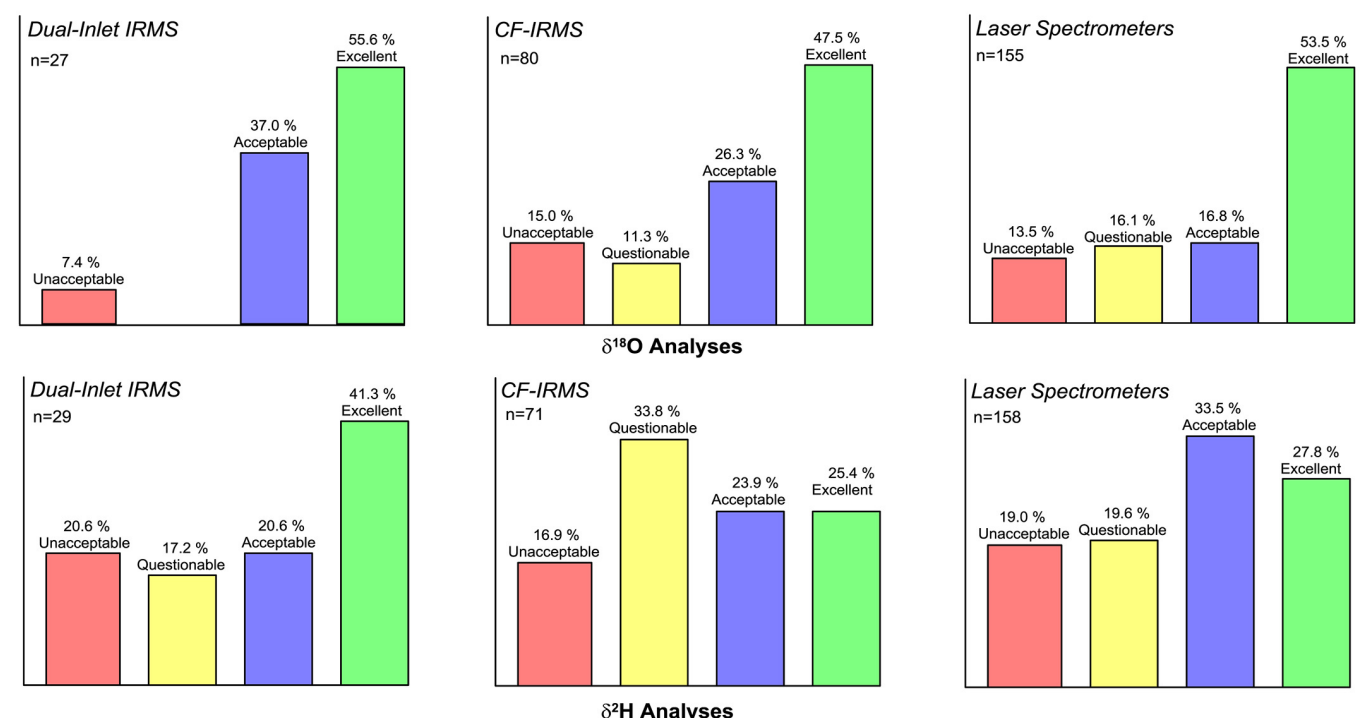

FIGURE 2.2: Combined cumulative performance scores for the WICO1-4 core samples using a "collected point' 'scoring criteria based on laboratories measurement accuracy (Wassenaar et al., 


\subsection{Isotopic fractionation in hydrology}

As in all geochemical cycles, also the hydrological cycle is constituted by reservoirs and fluxes. In the specific case of the water cycle the main reservoirs are the oceans containing approximately the $96 \%$ of the Earth's water. However there are other minor fresh water reservoirs that are relevant for the stable isotopic hydrology, as they yield information of the repartition and the water pathways from a source (the ocean) to the sites of deposition (Gat, 1983; Masson-Delmotte et al., 2008; Steen-Larsen et al., 2013).

TABLE 2.2: Range of isotopic composition values in different water reservoirs. After Mook and Rozanski (2000)

\begin{tabular}{lcc}
\hline Reservoir & $\delta D(\% \mathbf{\%})$ & $\delta^{18} O(\% \mathbf{0})$ \\
\hline Ocean & $-28 \ldots+10$ & $-6 \ldots+3$ \\
Groundwater & $-110 \ldots+10$ & $-15 \ldots-1$ \\
Greenland & $-150 \ldots-100$ & $-39 \ldots-25$ \\
Antarctica & $-200 \ldots-100$ & $-60 \ldots-25$ \\
Marine moisture & $-110 \ldots-75$ & $-15 \ldots-11$ \\
\hline
\end{tabular}

The flow of water, moisture and ice through the global water cycle (figure 1.1) is generated by temperature, air humidity, pressure gradients, by the friction exerted from wind on wet surfaces and by its momentum in the atmosphere. Moreover, at finer scale, plants control the water flux to the troposphere via the stomatal apertures. The variability observed in the $\delta$ values among different reservoirs, reported in Table 2.2 (Mook and Rozanski, 2000), depends on the isotopic fractionation that occurs during these movements.

The condensation of water vapor during droplets formation (AraguásAraguás, Froehlich, and Rozanski, 2000; Froehlich, Gibson, and Aggarwal, 2002; Pfahl and Sodemann, 2013), evaporation of seawater from the ocean surface (Brutsaert, 1975a; Merlivat, 1978; Merlivat and Jouzel, 1979; Benetti et al., 2014), vapor deposition onto ice particles in clouds (Jouzel, Merlivat, and Roth, 1975; Federer, Brichet, and Jouzel, 1982; Ciais and Jouzel, 1994) or sublimation of vapor from surface snow (Sokratov and Golubev, 2009; Münch et al., 2019) are all physical processes generating an isotopic fractionation between the gaseous and the fluid phase. In general the isotopic fractionation between two substances or phases (A and B) of a substance is expressed by the following:

$$
\alpha_{A-B}=\frac{R_{A}}{R_{B}}=\frac{\left(N_{i} / N_{j}\right)_{A}}{\left(N_{i} / N_{j}\right)_{B}}
$$

where $N_{i}$ and $N_{j}$ are the concentration of heavy and light isotopes (Gat, 1996). Following the definition of $\delta$, equation 2.3 then becomes:

$$
\alpha_{A-B}=\frac{1+\frac{\delta_{A}}{1000}}{1+\frac{\delta_{B}}{1000}}=\frac{1000+\delta_{A}}{1000+\delta_{B}}
$$


In general $\alpha$ is close to unity so a good approximation (for $\Delta<10 \%$ ) is represented by the:

$$
\Delta_{A-B}=\delta_{A}-\delta_{B} \approx 10^{3} \ln \alpha_{A-B}
$$

Heavier (and less abundant) isotopes reacting slower in equilibrium reactions, concentrate in the lower energy phase. For example, during evaporation, heavier isotopes remain in the liquid and lighter and more volatile isotopes form the gas phase. The same principle, at lower temperatures, applies also for ice sublimation.

An alternative way to express isotopic fractionation, for example in plant physiological researches, is through the enrichment factor, $\epsilon$, defined as follow:

$$
\epsilon_{A-B}=\left(\alpha_{A-B}-1\right)
$$

where $\epsilon_{A-B}$ is the isotopic composition difference between two phases $\mathrm{A}$ and $\mathrm{B}$. The enrichment factor gives in $\%$ the relative enrichment (or depletion) of a product (or a phase) in respect of the source. The nature of isotopic fractionation depends among various factors and conditions but it is mainly classified in equilibrium and kinetic (Majoube, 1971; Cappa, 2003; Ellehoj et al., 2013).

\subsubsection{Equilibrium fractionation}

Equilibrium isotopic fractionation occurs during chemical equilibrium reactions and it depends only on the equilibrium reaction temperature. In nature, a typical equilibrium reaction is represented by condensation. Within clouds, condensation of water vapor into liquid droplets starts only when the relative humidity approaches saturation conditions, namely when $\mathrm{RH}$ is close or equal to $100 \%$. Under certain conditions, when the concentration of condensation nuclei (dust or aerosols) is lower that the amount necessary for all the water vapor to condense and form ice crystals, super saturation conditions $(R H>100 \%)$ might occur (Galewsky et al., 2011).

The equilibrium reaction of water condensation is:

$$
\mathrm{H}_{2} \mathrm{O}_{v} \rightleftharpoons \mathrm{H}_{2} \mathrm{O}_{l}
$$

where subscripts " $\mathrm{v}$ " and " 1 " stand for vapor and liquid respectively. In this specific equilibrium reaction, at any given time, the number of molecules evaporating from the liquid phase equals the number of molecules condensing on the vapor/liquid interface. If follows that, when the equilibrium is reached, the different isotopologues vapor pressure leads to isotopic fractionation (Bigeleisen, 1961; Horita and Wesolowski, 1994). From the definition of fractionation factor (equation 2.3): 


$$
\alpha_{l-v}=\frac{\text { prod }}{\text { reac }}=\frac{R_{l}}{R_{v}}=\frac{\left({ }^{18} O /{ }^{16} O\right)_{l}}{\left({ }^{18} O /{ }^{16} O\right)_{v}}=\frac{p H_{2}^{18} O}{p H_{2}^{16} O}
$$

where $p$ stands for vapor pressure. Since isotopic fractionation occurs at equilibrium, it follows that:

$$
\alpha_{l-v}=\frac{1}{\alpha_{v-l}}
$$

The fractionation factor has an inverse temperature dependency, meaning that at higher temperatures the isotopic fractionation between liquid and vapor is lower than at cooler temperatures. At higher temperatures, when molecular internal energies are higher, heavier isotopes evaporate faster, reducing the difference with the amount of lighter isotopes in the evaporated phase (Majoube, 1971). Below freezing temperatures, the vapor pressure difference between lighter and heavier isotopes increases, therefore lighter isotopes sublimate faster, partially explaining the pronounced negative isotopic composition of the polar snow and ice (Table 2.2).

The temperature dependency of the isotopic fractionation factors (for ${ }^{2} \mathrm{H}$ and ${ }^{18} \mathrm{O}$ ) between liquid and vapor (equations 2.10 and 2.11) determined by Majoube, 1971 and between vapor and ice (equations 2.12 and 2.13) determined by Ellehoj et al., 2013 are the following:

$$
\begin{gathered}
\ln ^{18} \alpha_{v-l}(T)=2.0667 \times 10^{-3}+\frac{0.4156}{T}-\frac{1.137 \times 10^{3}}{T^{2}} \\
\ln ^{2} \alpha_{v-l}(T)=-52.612 \times 10^{-3}+\frac{76.248}{T}-\frac{24.844 \times 10^{3}}{T^{2}} \\
\ln ^{18} \alpha_{v-i}(T)=0.0831-\frac{49.192}{T}+\frac{8312.5}{T^{2}} \\
\ln ^{2} \alpha_{v-i}(T)=0.2133-\frac{203.10}{T}+\frac{48888}{T^{2}}
\end{gathered}
$$

where the subscripts " $\mathrm{v}$ ", "l" and i"" stand for vapor, liquid and ice respectively. The first set of equations is valid for the temperature range from the freezing point to the boiling points, whilst the second set is valid in the range $-40^{\circ} \mathrm{C}$ to $0^{\circ} \mathrm{C}$ due to the water phase change at the water triple point.

\subsubsection{Batch and Rayleigh processes}

The evolution of the isotopic composition of a binary system can be interpreted in essentially two ways. The first and simplest one is the batch process that describes the evolution of the isotopic composition of a system composed only by the liquid and by the vapor in equilibrium with it. The formalization of a batch process is: 


$$
(F) * \delta_{v}+(1-F) * \delta_{l}=\delta_{t w}
$$

where $F$ is the fraction of vapor and $\delta_{t w}$ is the isotopic composition of the system that in this case remains constant (equation 2.14).

In a batch process the system is a two-phase system where there isn't exchange of matter with the surrounding ambient. The description of the batch condensation is based on a constant isotopic fractionation factor, as the variation of this other parameter would result in further complication. In the initial state, the system is entirely formed by vapor $(\mathrm{F}=$ fraction of vapor $=$ 1) and the liquid is completely absent. As the condensation starts, the isotopic composition of firstly formed liquid is determined by the enrichment factor (equation 6.6) corresponding to the isotopic enrichment of liquid at the condensation temperature. As the condensation proceeds further the liquid phase remains enriched in respect of the vapor by virtue of the fractionation factor (equation 2.8). Since there is not exchange of matter with the environment, the isotopic composition of the system remains constant and the isotopic composition of the liquid and vapor decrease progressively. Once the entire vapor is condensed, the isotopic composition of the liquid equals the isotopic composition of the initial vapor (figure 2.3).

The isotopic composition of liquid and vapor as function of the vapor fraction parameter, is calculated using the:

$$
\delta_{l}=\frac{\alpha * \delta_{t w}+1000 * F(\alpha-1)}{\alpha *(1-F)+F}
$$

and the,

$$
\delta_{v}=\delta_{l}-1000 *(\alpha-1)
$$

where $\mathrm{F}$ is the fraction of the remaining vapor in the system.

The batch process is considered as a theoretical case and never occurs in nature because a certain degree of exchange between the system and the environment occurs. To describe the evolution of the isotopic composition in the open-system scenario, the effect of this exchange needs to be accounted for. A better theoretical description is provided by the Rayleigh process:

$$
\left(\frac{R}{R_{i}}\right)=F^{\alpha-1}
$$

where the subscript $i$ stands for the isotopic ratio of the initial water vapor. Using the delta notation equation (2.17) gives,

$$
\delta_{v}=\left[\delta_{v, i}+1000\right] * F^{\alpha-1}-1000
$$

and,

$$
\delta_{l}=\alpha *\left(\delta_{v}+1000\right)-1000
$$




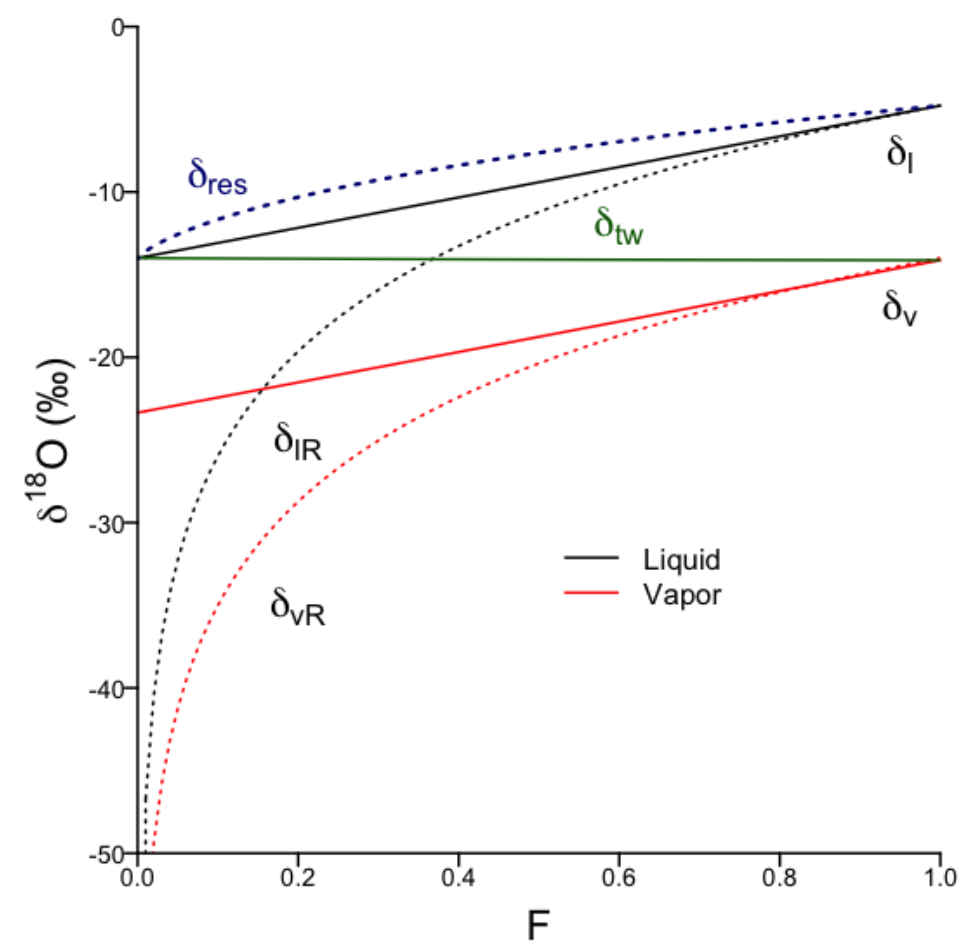

FIGURE 2.3: The theoretical evolution of the isotopic composition of vapor and liquid during a batch process $\left(\delta_{l}\right.$ and $\delta_{v}$, solid lines) and during a Rayleigh condensation $\left(\delta_{l R}\right.$ and $\delta_{v R}$, dashed lines). The dotted-dashed green horizontal line represent the isotopic composition of the initial vapor and of the system $\left(\delta_{t w}\right)$.The solid blue line represent the reservoir isotopic composition in the case of an open Rayleigh process $\left(\delta_{\text {res }}\right)$. F denotes the fraction of vapor in the system.

for the vapor and the liquid respectively. In this case $\delta_{v R}$ and $\delta_{c R}$ represent the isotopic composition of the fractionating vapor and condensing liquid at each step of the condensation process (dotted lines in figure 2.3). Isotopic fractionation causes heavier isotopes to condense faster, thus reducing their concentration in the remaining vapor. The newly formed liquid at each condensation step is added to the system reservoir (solid blue line in figure 2.3), which represents the isotopic composition of all the removed liquid of the system.

The open Rayleigh process is widely used to model the evolving isotopic composition of moisture and rainfall in air masses. Further complications arise however due to the temperature dependency of isotopic fractionation factor (figure 2.4). In the real case, the isotopic composition of air parcels propagating in the atmosphere needs to account for multiple condensation 
stages and rainouts, mixing between air masses with different isotopic composition and reintroduction, within the same air mass, of re-evaporated vapor from rain falling through sub-cloud unsaturated layers. Indeed, the isotopic composition of rain samples collected at some point in space and time provides information about the "history" of the air masses.

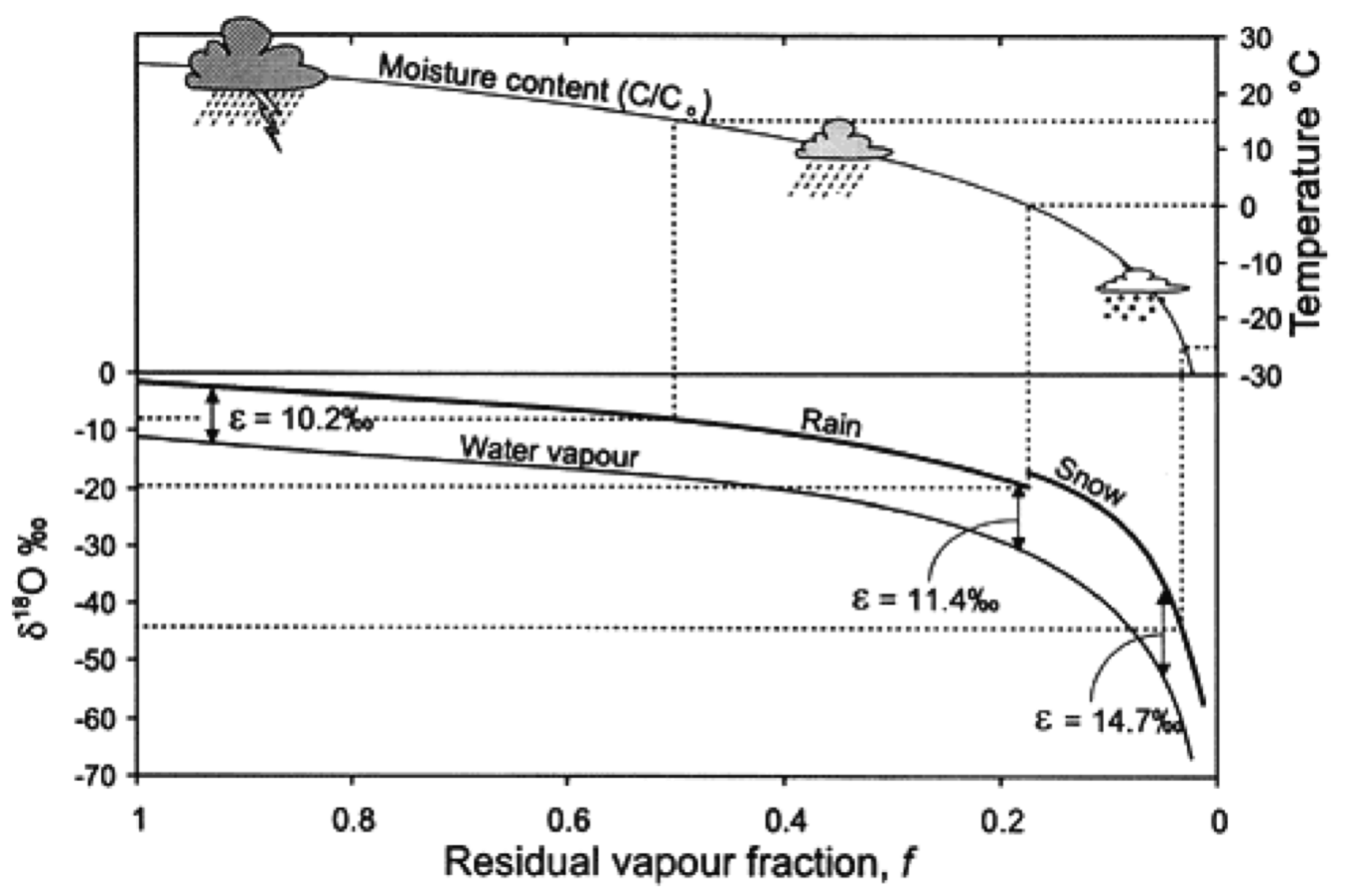

FIGURE 2.4: Evolution of the $\delta^{18} O$ of the vapor and of the condensed phases (rain and snow) according to a Rayleigh distillation. It is important to observe the change in the curves steepness at the water freezing point. Here the temperature dependency of the liquid-vapor fractionation factor changes due to the shift from condensation to sublimation. Dashed lines link $\delta^{18} O_{p}$ with the condensation temperature. (Clark and Fritz, 1997)

\subsubsection{Kinetic fractionation}

While condensation is mostly an equilibrium process, evaporation is normally occurring at non-equilibrium conditions. Under these circumstances isotopic fractionation assumes also a kinetic behavior, determined by the different molecular diffusions of isotopologues (Merlivat, 1978; Cappa, 2003, see table 2.3).

At sub-saturation conditions the isotopic fractionation between the evaporating liquid and the vapor increases due to the higher diffusivity of lighter in respect of heavier isotopes (Merlivat, 1978). Furthermore, the effective diffusion coefficients for water isotopologues are significantly different from those calculated using the kinetic gas theory because evaporation is not a 
TABLE 2.3: Ratio of molecular diffusivities of the main water isotopologues in air

\begin{tabular}{lcc}
\hline Isotopologues & Diffusivity ratio & Reference \\
\hline$D_{H D O} / D_{H_{2} O}$ & 0.9755 & (Merlivat, 1978) \\
& 0.9839 & (Cappa, 2003) \\
$D_{H_{2}^{18} \mathrm{O}} / D_{\mathrm{H}_{2} \mathrm{O}}$ & 0.9723 & (Merlivat, 1978) \\
& 0.9691 & (Cappa, 2003) \\
\hline
\end{tabular}

monomeric but rather a reaction involving small chains of 5 molecules (Dansgaard, 1964). This means that the final isotopic composition of the initial water vapor leaving the liquid surface is normally more depleted in heavy isotopes as predicted by the theory. Moreover the kinetic effect during water isotopic fractionation affects the oxygen isotopologue to a larger extent than the hydrogen isotopologues because in the first the mass difference is larger (Dansgaard, 1964; Sharp, 2017). These effects are measurable in a parameter called deuterium excess (see below) that reflects the deviations from the equilibrium conditions occurring in precipitation during condensation and in water vapor during evaporation.

Influences on the kinetic isotopic fractionation are controlled by temperature, in that it has an effect on evaporation, however its main driver is the relative humidity of the air above the evaporating surface (Dansgaard, 1964; Jouzel and Merlivat, 1984; Pfahl and Sodemann, 2013) and the wind speed due to friction velocity (Merlivat and Coantic, 1975). For example, the initial water vapor evaporating from the ocean surface has a lower isotopic composition in respect of its theoretical equilibrium value due to the fact that the ocean skin layer is almost always saturated in relation to the ocean surface temperature (Merlivat and Jouzel, 1979).

\subsection{Global Meteoric Water Line}

The relationship between $\delta^{18} O$ and $\delta D$ observed in global precipitation is defined through a linear regression having the following equation:

$$
\delta D=8.13 * \delta^{18} O+10.8
$$

This regression equation is known as the "Global meteoric water line" (GMWL) because it was extrapolated from a set of precipitation samples collected at various sites around the Globe (Craig, 1961). The GMWL outlines the average characteristics of the isotopic composition of the worldwide rainfall and despite the spatial heterogeneity of the sampling points it expresses a consistent relationship between different latitudes and climates (figure 2.5). 


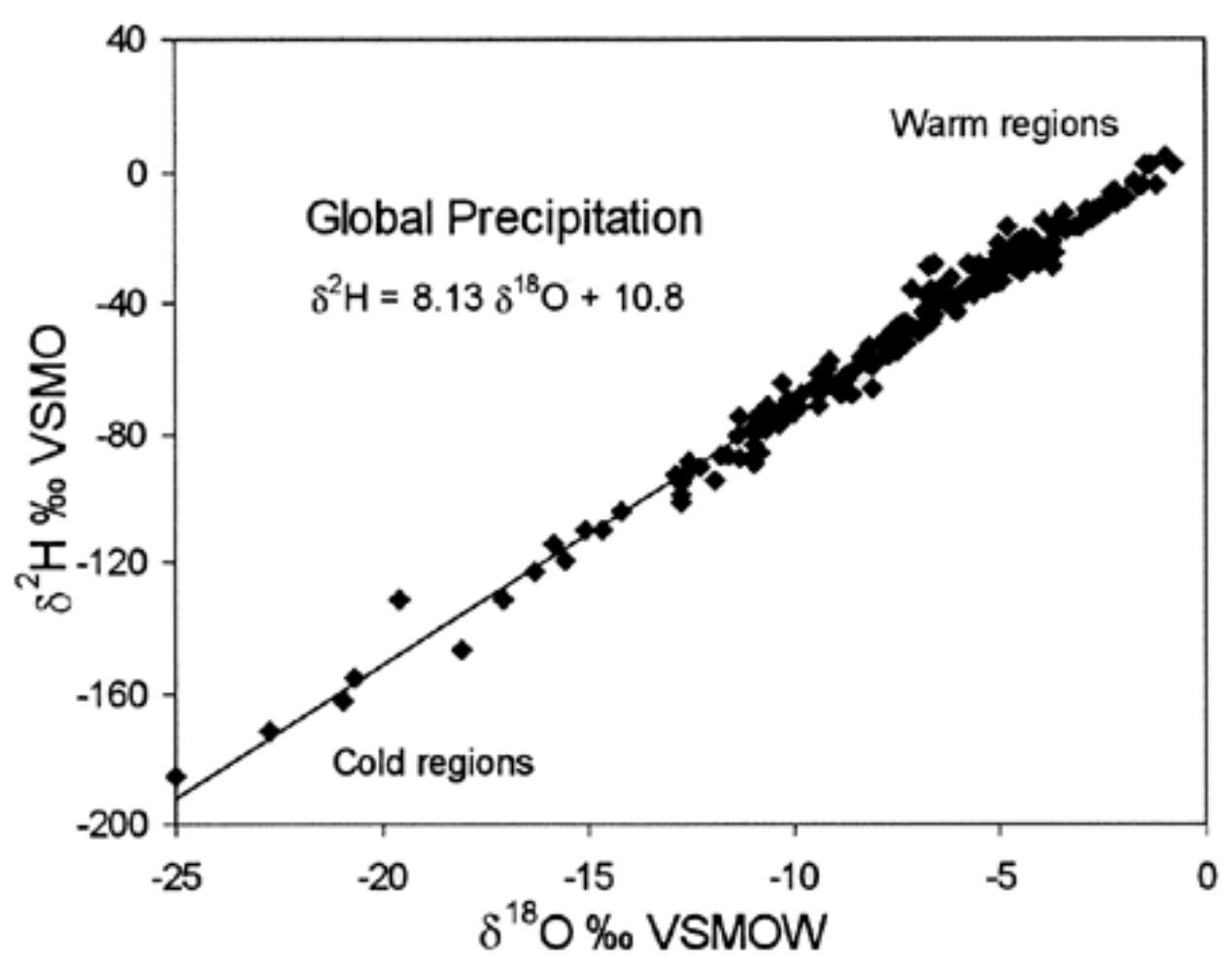

FIGURE 2.5: The correlation between global collected samples in a wide range of latitudes establish a regression line called the Global Meteoric Water Line that has equation $\delta D=8.13 * \delta^{18} O-$ 10.8. After (Rozanski, Araguas-Araguas, and Gonfiantini, 1992) adapted from (Clark and Fritz, 1997).

Moreover the slope of the GMWL, which is nearly 8, represents the ratio between the molecular diffusivities of the water isotopologues at the equilibrium, in fact

$$
{ }^{2} \epsilon_{l-v} /{ }^{18} \epsilon_{l-v} \approx 8
$$

for the temperature range $0^{\circ} \mathrm{C}$ to $40^{\circ} \mathrm{C}$. Furthermore the value of the intercept $(\approx 10)$ is known as deuterium excess (Dansgaard, 1964) and it depends on the relative humidity during water vapor formation. The coefficients of the GMWL, representing global average values, reflect the fact that, while precipitation is mostly an equilibrium process (the majority of points lay on the regression with slope close to 8 ), the ocean evaporative flux occurs mainly at sub-saturation conditions. Using these coefficients we can estimate that the global average surface layer $\mathrm{RH}$ is $\approx 80 \%$ and the air temperature $\approx$ $20^{\circ} \mathrm{C}$. Thus, a water vapor formed only at saturation would lead to an intercept of 0 .

At local and regional level the oxygen18-deuterium relationship defines the isotopic regimes through "local meteoric water lines" (LMWL) that are 
specific for each catchment area as they depends from the local climatology and moisture transport (Breitenbach et al., 2010; Wu et al., 2015; Wirmvem et al., 2017).

\subsubsection{Deuterium Excess}

The value of the intercept of each LMWL defines the "local" deuterium excess (Dansgaard, 1964) in precipitation. This parameter is calculated following the:

$$
d_{e x c}=\delta D-8 * \delta^{18} O
$$

and its applications are not limited to precipitation (Froehlich, Gibson, and Aggarwal, 2002; Pfahl and Sodemann, 2013) but instead gives important information about the kinetic processes affecting water vapor formation (Uemura et al., 2008; Benetti et al., 2014; Steen-Larsen et al., 2014), transpiration, soil evaporation and moisture recycling (Lai and Ehleringer, 2011; Welp et al., 2012; Aemisegger et al., 2014) and it is also an important value to identify the moisture source areas (Delattre, Vallet-Coulomb, and Sonzogni, 2015; Steen-Larsen et al., 2015; Stenni et al., 2016).

Following the theory seen in the Craig and Gordon model (see below) for the isotopic composition of the evaporative flux, it follows that, as discussed in the kinetic fractionation paragraph, the value of the $d_{e x c}$ depends on the relative humidity, on the temperature and on the wind speed above the water surface. A disadvantage represented by the determination of this secondary order parameter is represented by its higher sensitivity to error propagation as it depends simultaneously on $\delta^{18} O$ and $\delta D$ measurements. Therefore care must be taken during its determination.

While higher $d_{e x c}$ values normally occur in colder seasons (the fractionation is an inverse relationship in respect of temperature and relative humidity) and at higher latitudes, lower values are associated with warmer and drier conditions (figure 2.6).

\subsubsection{The Craig-Gordon Model}

A modeling approach for the determination of the isotopic composition of the newly formed water vapor above the ocean surface was formulated by (Craig and Gordon, 1965). This model considers the air layer above the sea surface, where the isotopic fractionation occurs, consisting in 3 sub-layers where the dynamic of water vapor transport differs. This classification is based on the laminar or the turbulent airflow above the surface.

At the sea-air interface the relative humidity is at saturation (the thickness of this layer is in the order of $\mathrm{mm}$ ), therefore, within this sublayer, the equilibrium isotopic fractionation, which depends only on the air temperature, dominates. The model assumes that above the interface layer the water vapor molecules diffuse through the unsaturated atmospheric surface layer. 


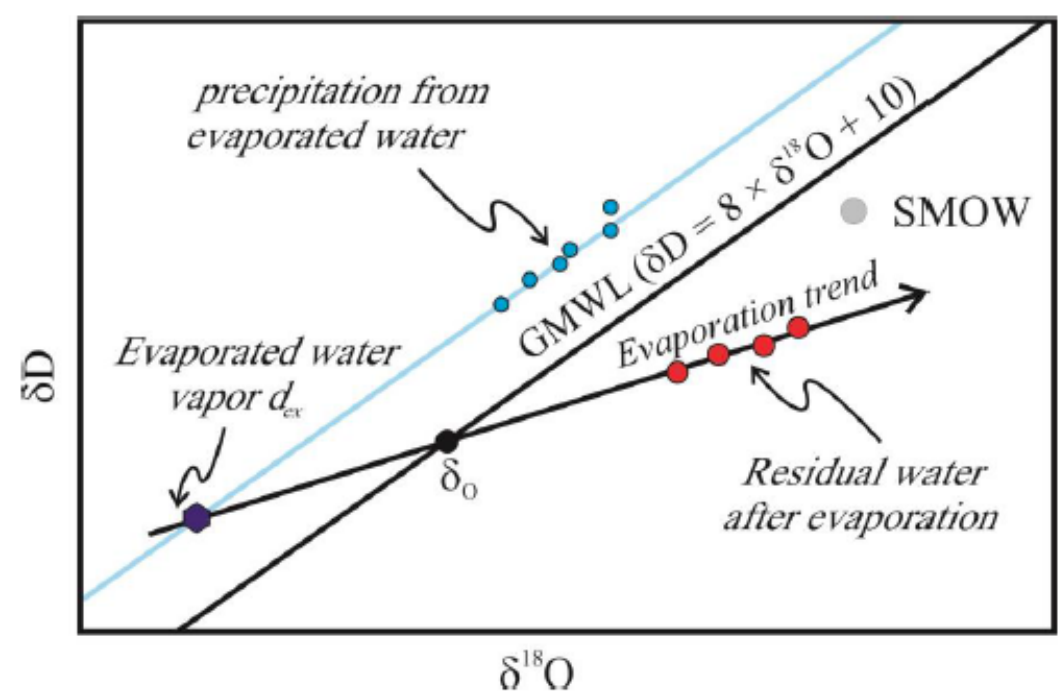

FIGURE 2.6: Isotope effect of evaporation into dry air. Water evaporation under dry conditions is affected by a kinetic fractionation due to the higher volatility of deuterium in respect of oxygen-18. Blue dots represent precipitation and the dark blue diamond the vapor in equilibrium. $\delta 0$ is the liquid isotopic composition (a lake water). Under dry conditions where kinetic effect is larger the isotopic composition of vapor will decrease increasing also the $d_{e x c}$ while the remaining liquid will be more enriched and with a lower $d_{e x c}$ (Sharp, 2017).

Here the diffusion velocity is strongly controlled by the humidity gradient $\Delta h$ between the interface and the free atmosphere. It is important to note that the model considers the relative humidity normalized to the sea surface temperature (SST) as calculated in equation 2.24, as the main parameter controlling the fractionation above the liquid/vapor interface. In this way not only the air temperature is important for the isotopic exchange, but also the temperature of the surface where the water is evaporating. Within the diffusive sublayer the kinetic fractionation factor controls the water vapor isotopic composition.

Above the diffusive sublayer turbulence becomes the main driver of water vapor transport and no isotopic fractionation occurs. The isotopic ratio of the evaporative flux $R_{e}$ in the atmospheric boundary layer according to the model is calculated using the:

$$
R_{e}=\alpha_{k} * \frac{R_{l} / \alpha_{l-v}-h * R_{a}}{1-h}
$$

where $h$ is the relative humidity normalized to the SST as it follows:

$$
h=R H * \frac{e_{s}\left(T_{a i r}\right)}{e_{s}(S S T)}
$$




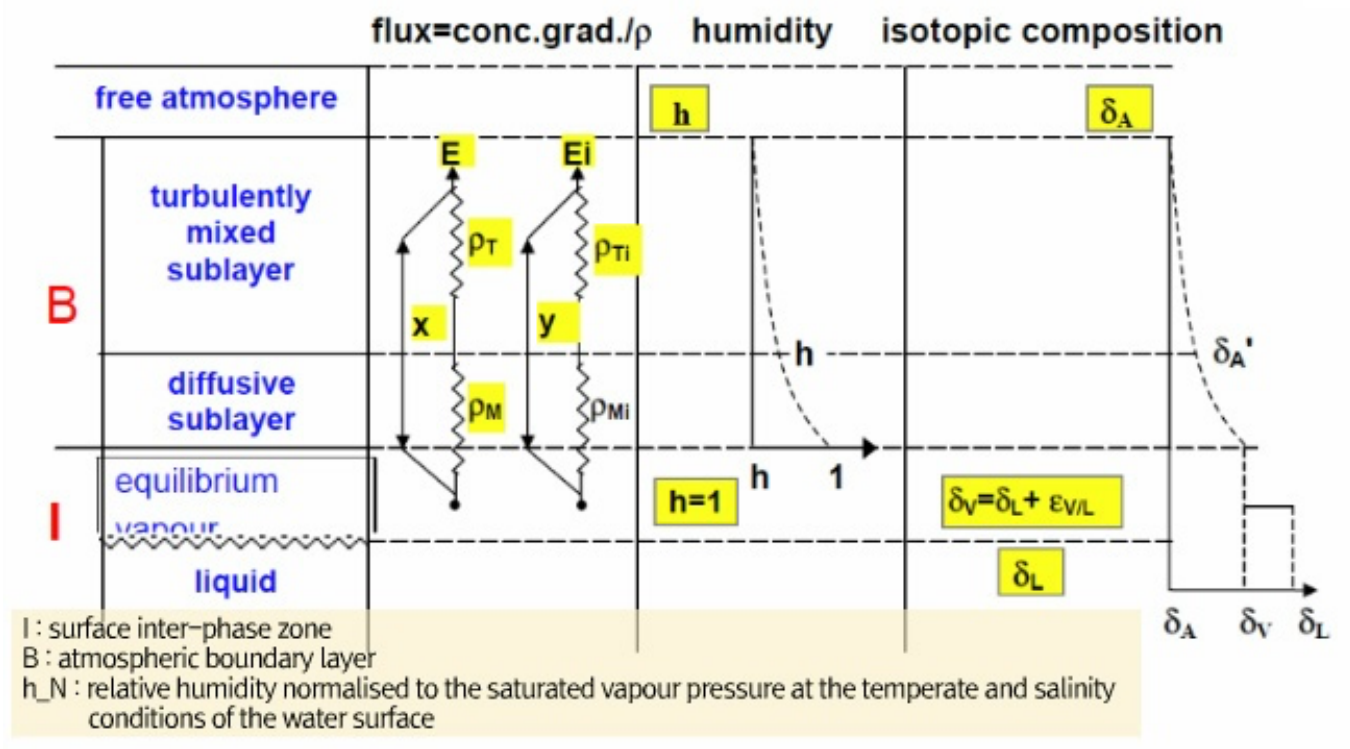

FIGURE 2.7: The Craig-Gordon model for isotopic fractionation during evaporation of an open water body into the free atmosphere (Craig and Gordon, 1965). The model divides the atmospheric boundary layer into 3 layers. A saturated layer at the water/air interface dominated by equilibrium conditions. A diffusive layer where molecular diffusion dominates and an upper turbulent mixed layer where no isotopic fractionation occurs. 
The Craig and Gordon model formulation using the $\delta$-notation is instead,

$$
\delta_{e}=\frac{\left(\delta_{l}-\epsilon\right) / \alpha_{l-v}+h \delta_{a}-\epsilon_{k}}{1-h+\epsilon_{k}}
$$

where $\epsilon$ stands for the equilibrium enrichment factor (eq.6.6), $\delta_{a}$ is the isotopic composition of the water vapor in the boundary layer and $\epsilon_{k}=$ $\left(\alpha_{k}-1\right) * 1000$ is the kinetic fractionation factor (see below). The kinetic enrichment factor depends on the molecular and turbulent resistances $\left(\rho_{M}\right.$ and $\left.\rho_{T}\right)$, schematically represented in figure 2.7 .

\subsubsection{Global closure assumption}

One limitation of the Craig and Gordon model for evaporation was the direct observation of the atmospheric water vapor isotopic composition above the marine turbulent layer because few direct measurements of this quantity existed (Uemura et al., 2008; Benetti et al., 2014; Benetti et al., 2017). A possible solution to this problem has been solved using isotope-enabled global circulation model such as ECHAM5-wiso (Werner et al., 2011), LMDZ-iso (Risi et al., 2010), or remote sensing measurements like the Tropospheric Emission Spectrometer (TES) sensor installed onboard the AURA satellite that measured the isotopic composition of the water vapor in the lower troposphere (Worden et al., 2011). However, even before the existence of these measuring techniques, a solution was found using an approximation known as the Global closure assumption (Merlivat and Jouzel, 1979). This assumption, valid only when considering large evaporative surfaces such as the oceans, assumes that the whole global evaporative flux (and its isotopic composition) is only produced by the evaporation of the sea surface, thus neglecting the contributions from evapotranspiration or small water bodies evaporation.

When using the global closure assumption in the application of the Craig and Gordon model, the isotopic composition of the initial water vapor leaving the ocean surface is determined by the following:

$$
\delta_{v 0}=\frac{\alpha_{v-l} *\left(\delta_{l}+1\right) *\left(1-\epsilon_{k}\right)}{1-\epsilon_{k} * h}-1
$$

where the values of the kinetic fractionation factors $1-\epsilon_{k}$ depend on the ratio between the molecular diffusivities of water isotopologues in air and on the type of wind regime blowing over the ocean surface 2.3. It is possible to observe, from the equation 2.26, that the $\delta_{a}$, that is the atmospheric water vapor isotopic composition term, has been removed.

The expression used to calculate the kinetic fractionation factors is:

$$
\epsilon_{k}=\frac{\left(1+\left(D / D_{i}-1\right)\right)^{n}-1}{\left(1+\left(D / D_{i}-1\right)\right)^{n}+\left(\rho_{T} / \rho_{M}\right)}
$$

where " $\mathrm{n}$ " is assumed as $2 / 3$ during smooth wind conditions $\left(w s_{10}<7\right.$ $\left.\mathrm{ms}^{-1}\right)$ and $1 / 2$ during rough wind conditions $\left(w s_{10}>7 \mathrm{~m} \mathrm{~s}^{-1}\right)$. The term 


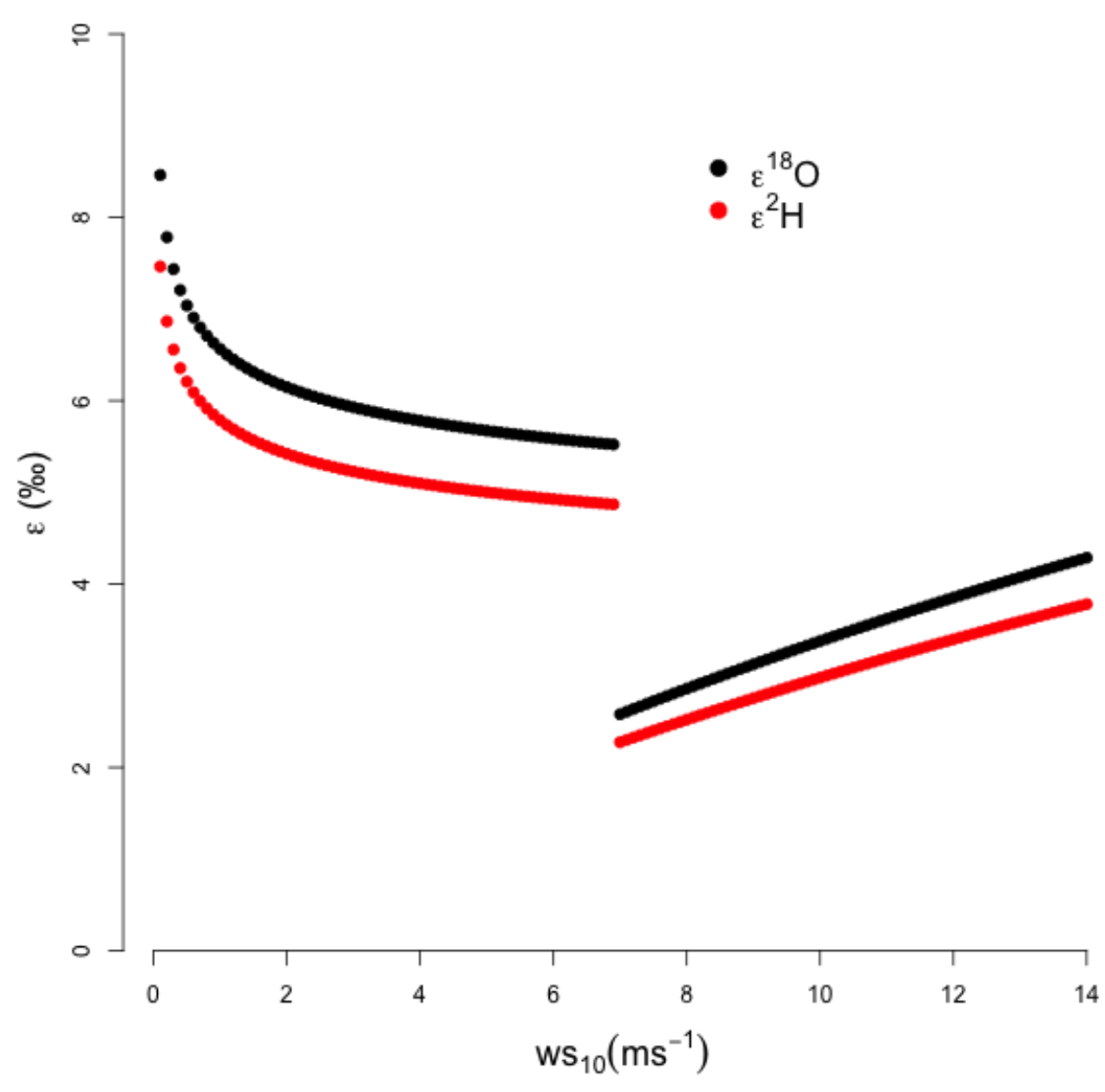

FIGURE 2.8: Kinetic enrichment factors of oxygen-18 and deuterium calculated using the diffusivities coefficient of (Merlivat, 1978) as a function of the average wind speed at $10 \mathrm{~m}$ a.s.l. The surface roughness for the smooth regime was selected as $z_{0}=0.1 \mathrm{~mm}$ and $0.5 \mathrm{~mm}$ for the rough conditions. The discontinuity in the function is coincident with the transition from a wind speed $<7$ to $>7 \mathrm{~m} \mathrm{~s}^{-1}$

$\rho_{T} / \rho_{M}$, standing for the ratio between the turbulent and molecular resistances, is calculated following the evaporation model proposed by (Brutsaert, 1975b; Brutsaert, 1975a) as follows:

$$
\begin{aligned}
\frac{\rho_{T}}{\rho_{M}} & =\frac{1}{\chi} \ln \frac{u_{*} z}{30 \nu} / 13.6\left(\frac{\nu}{D}\right)^{2 / 3} \\
\frac{\rho_{T}}{\rho_{M}} & =\frac{1}{\chi} \ln \frac{z}{z_{0}}-5 / 7.3 R_{e s}^{1 / 4}\left(\frac{\nu}{D}\right)^{1 / 2}
\end{aligned}
$$

where $\chi=0.4$ is the Von Karman constant, $\nu=12.71 \times 10^{-6} \mathrm{~m}^{2} \mathrm{~s}^{-1}$ is the 
kinematic air viscosity, $D=24.0 \times 10^{-6} \mathrm{~m}^{2} \mathrm{~s}^{-1}$ is the diffusivity of water vapor in air (at $300 \mathrm{~K}), u_{*}$ in $\mathrm{m} \mathrm{s}^{-1}$ is the friction velocity and $z_{0}$ in $\mathrm{m}$ the roughness length. The values assumed by this last parameter is usually assumed as $0.1 \mathrm{~mm}$ over an open calm ocean and can increase to a maximal $15 \mathrm{~mm}$ over an ocean with a rough surface during strong wind regimes 2.8.

It is important to observe that using this relationship it is now possible to calculate the isotopic composition of the water vapor evaporating from the sea surface using a function that depends only on the sea surface temperature (SST), from the relative humidity (through the parameter $h$ ) and from the wind speed regime $\left(\epsilon_{k}\right)$. The dependency of the deuterium excess parameter on the relative humidity at source, on the evaporation temperature and on the wind speed regime is shown in figure 2.9.

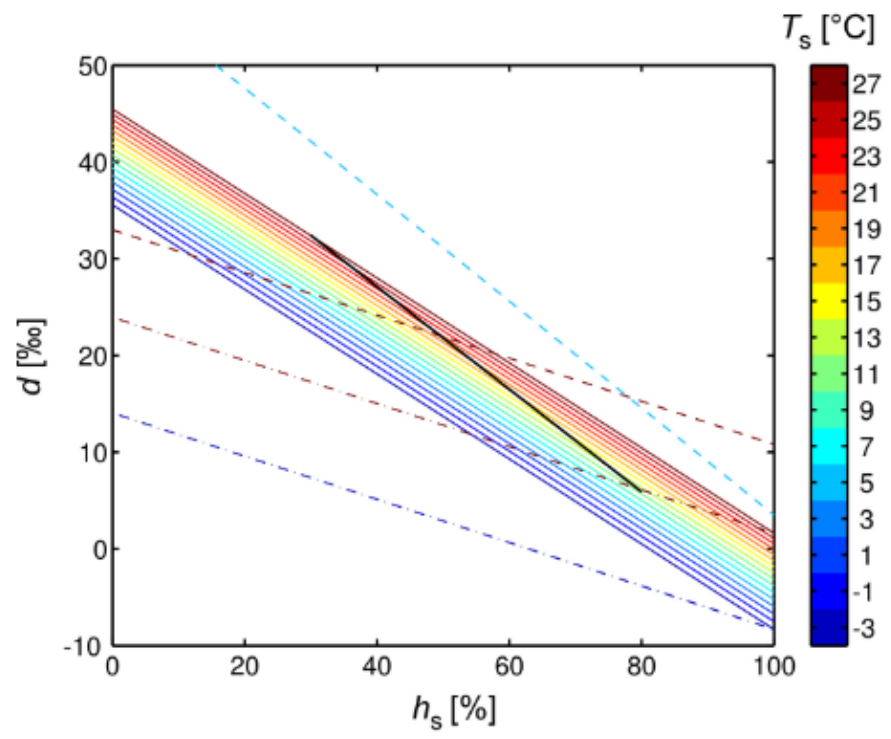

Theoretical relation using Craig and Gordon, 1965 and global closure:

- Merlivat and Jouzel, 1979

$\equiv \mathrm{u}_{10 \mathrm{~m}}=5 \mathrm{~m} / \mathrm{s}$

:::: Merlivat and Jouzel, 1979 $\mathrm{u}_{10 \mathrm{~m}}=10 \mathrm{~m} / \mathrm{s}$

Pfahl and Wernli, 2009 $100 \%$ soil evaporation

-.- Pfahl and Wernli, 2009 $40 \%$ soil evaporation $60 \%$ transpiration

Empirical relation

- Pfahl and Wernli, 2008

FIGURE 2.9: Parametrization of the deuterium excess dependency on relative humidity, air temperature, wind speed and different non-equilibrium fractionation factors using the global closure assumption of (Merlivat and Jouzel, 1979). Relative humidity $h_{s}$ is normalized to the sea surface temperature. $d_{e x c}$ values are calculated assuming the 2.26. (Aemisegger et al., 2014). 


\subsection{Factors controlling the isotopic composition}

In 1961, originally motivated by the atmospheric monitoring of thermonuclear fallouts, the International Agency for Atomic Energy (IAEA) and the World Meteorological Organization (WMO) established the Global Network for Isotope in Precipitation (GNIP). The aim of this project was to determine the spatial and temporal variability of stable isotopes $\left(\delta D\right.$ and $\left.\delta^{18} O\right)$ and tritium in natural waters across the Globe (figure 2.10).

\section{IAEA/WMO/GNIP Stations (183 stations in 53 countries)}

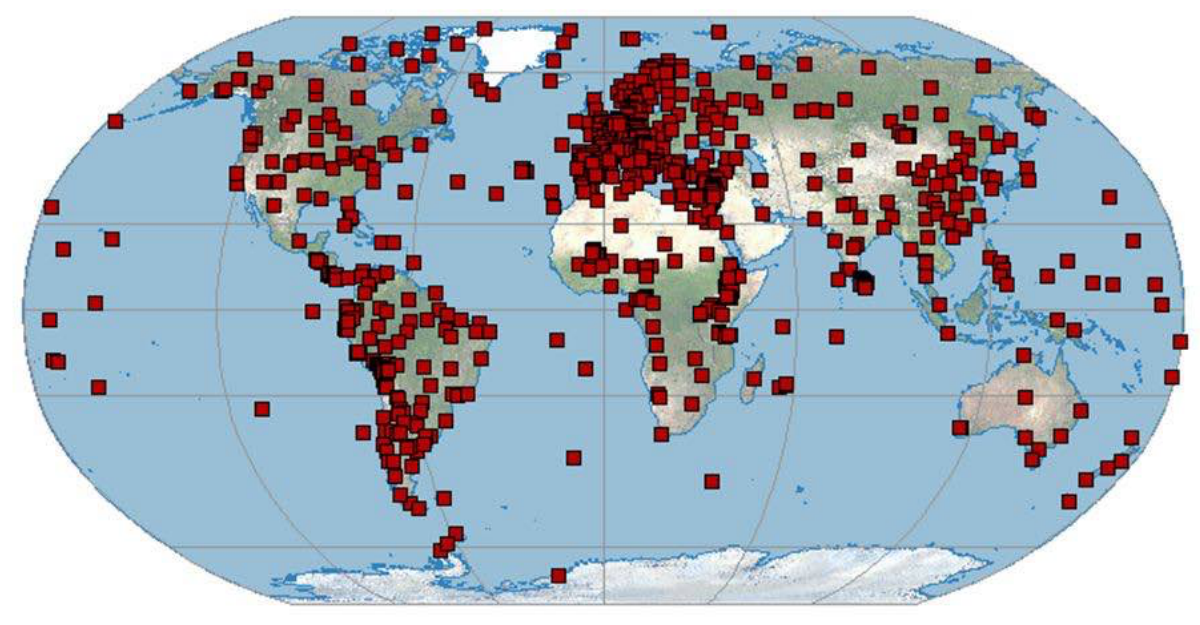

FIGURE 2.10: Map showing the location of the IAEA/WMO precipitation sampling stations belonging to the Global Network for Isotopes in Precipitation program. Note the density of sampling points in Europe and in America and the sparseness of station in Asia, Africa and Oceania.

The distribution of sampling stations across all latitudes has allowed the identification of common drivers of the rainfall isotopic composition (Craig, 1961; Panarello et al., 1998; Bowen and Wilkinson, 2002). All these factors, affecting moisture transport from the oceanic sources to the continents, are related to the average surface temperature (Dansgaard, 1964).

Moreover, the GNIP dataset, due to the number of measurements available (135.000 isotopic records see Terzer et al., 2015), has been extensively used for the sensitivity analysis and validation of isotope-enabled Global Circulation Models (Jouzel et al., 1987; Jouzel et al., 1991; Terzer et al., 2013). 


\subsubsection{Altitude Effect}

In regions close to mountain ranges, like the Himalaya, the Andes, the Alps and so on, the isotopic composition of precipitation depends strongly on the steepness of the elevation gradient (Ambach et al., 1968). Air masses carrying moisture and traveling over land are forced to uplift, vapor condensation occurs faster and heavier precipitation falls on the windward side. The interaction between the local topography and the increase of the amount of precipitation determines a steeper gradient of the rainfall isotopic composition (Gonfiantini et al., 2001; Windhorst et al., 2013).

\subsubsection{Latitudinal Effect}

The area on the Earth where the largest amount of water vapor is released to the atmosphere is the Equator, in proximity of the Inter Tropical Convergence Zone (ITCZ). Here at the doldrums, an area of constant low atmospheric pressure, moisture is forced to rise to the upper layer of the atmosphere by converging winds, in a Hadley cell circulation type. This moisture propagates towards higher latitudes transported by the Ferrel-Polar circulation cells. This latitudinal transport and the decreasing average surface temperature cause a latitudinal gradient in the precipitation isotopic composition (figure 2.11).

This effect, known also as "isotopic thermometer" is expressed by two relationship for $\delta D$ and $\delta^{18} O$ (Dansgaard, 1964):

$$
\begin{gathered}
\delta^{18} O=0.69 * T_{\text {avg }}-13.6 \\
\delta D=5.6 * T_{\text {avg }}-100
\end{gathered}
$$

where $T_{\text {avg }}$ stand for mean annual surface temperature.

\subsubsection{Continentality}

This effect is not linked to the condensation temperature at which precipitation formations occurs, but rather to the reduced moisture recharge that influences air masses traveling from the ocean to the continents (SánchezMurillo et al., 2016). Most of the moisture uptake occurs during air masses transport over the oceans, therefore when they reach the continents they progressively lose moisture due to the progressive rainout. From this point onwards, the air parcel moisture content significantly decreases due to the lower moisture recharge from the lower atmosphere. In this way air parcels are more depleted as they move towards the internal part of continents. An exception to these phenomena is observed within air masses that are transported above rainforests, where the vapor originated from evapotranspiration can exceed the tropospheric vapor (Moreira et al., 1997). Here the water vapor derived from soil, but largely the transpired water vapor deriving from leaves (Jasechko et al., 2013; Wei et al., 2017), contributes substantially to the vapor recharge of the lower troposphere. 


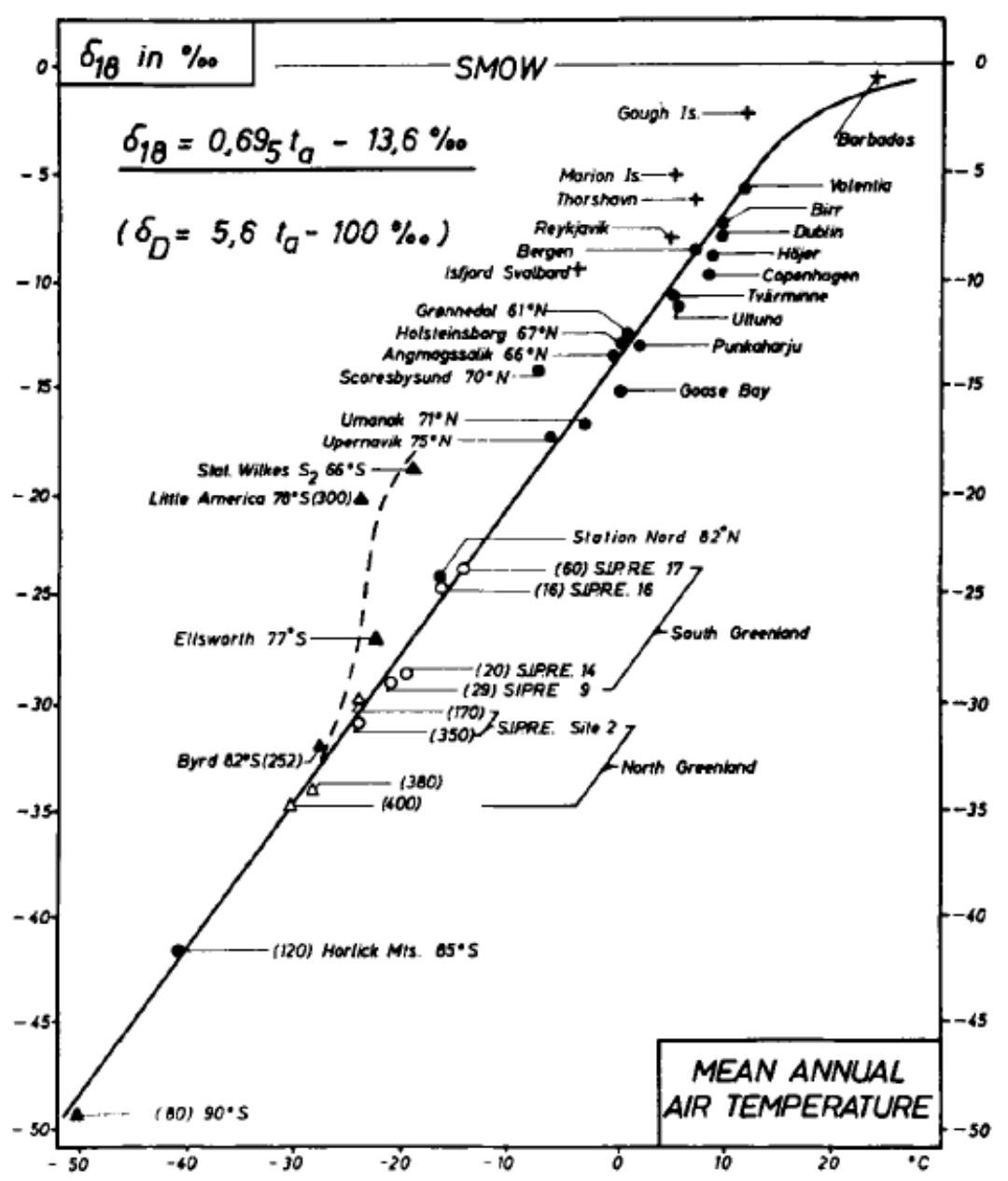

FIGURE 2.11: The latitudinal gradient in the precipitation isotopic composition is extremely stable due to the atmospheric global circulation activity. Long term rainfall sampling allowed the formulation of a relationship called the isotopic thermometer that links the average isotopic composition of precipitation to the average surface temperature in one location (Dansgaard, 1964).

\subsubsection{Amount Effect}

This effect occurs mainly in tropical regions, where heavy rainfall events characterize the rainy season. During these intense events an inverse relationship between the amount of rainfall and its isotopic composition is observed (Cobb et al., 2007; Tindall, Valdes, and Sime, 2009; Kurita, 2013). This phenomenon, also known as "amount effect", depends on the drop size and on the level of isotopic exchange between falling raindrops and surrounding ambient vapor (Dansgaard, 1964; Lee and Fung, 2008; Moore, Kuang, and Blossey, 2014). During heavy rainfall events in hot and humid climates, raindrops pass through an unsaturated sub-cloud layer during their fall to the ground. In this time an exchange of lighter isotopes with the ambient air occurs. The exchange intensity depends on the drop size, in that it is less 
pronounced during heavy storms because raindrops are larger and are affected by a relatively smaller isotopic exchange with the surrounding vapor in respect of lighter rainfall.

\subsection{Stable isotopes in the water vapor}

Until a decade ago the Isotopic Ratio Mass Spectrometry (IRMS) was the only available technique to perform measurements of the isotopic composition. Despite being a very precise and reliable measuring technique, it allowed water vapor isotopic composition measurements only of discrete samples. Therefore air was collected in sampling flasks (Moreira et al., 1997; Krishan and Rao, 2014) or in U-shaped tubes immersed in a cryogenic solution like nitrogen and ethanol (Uemura et al., 2008; Midhun, Lekshmy, and Ramesh, 2013). Recently, after the development of laser-based spectrometers, water vapor sampling can be performed continuously and in remote areas due to the portability of these analyzers. This possibility has allowed new insight in the study of water vapor isotopic composition (Galewsky et al., 2016).

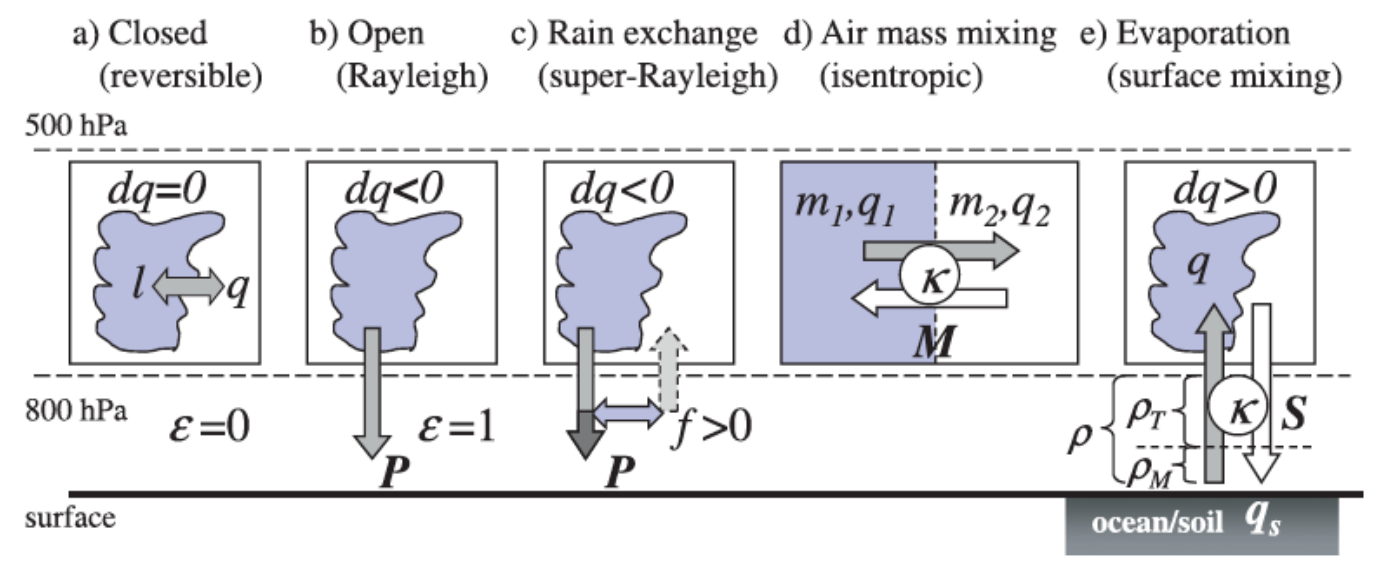

FIGURE 2.12: The possible mechanisms of water vapor formation are here displayed imagining an air parcel that: a) doesn't exchange moisture with the surrounding vapor (closed Rayleigh), b) A typical Rayleigh distillation where at each cooling step, the newly formed condensate is readily removed from the parcel, c) A super-Rayleigh distillation were part of the falling rain reevaporated and the resulting water vapor return into the original air mass, d) An isotopic mixing between two air masses with distinct mixing ratios $\left(q_{1}, q_{2}\right)$ and isotopic composition and finally e) An air mass that exchange isotopically distinct moisture with the lower level of the troposphere and with the earths surface (Noone, 2012)

Similarly to precipitation, the atmospheric water vapor isotopic composition variability depends on a variety of dynamic factors.

Source areas (Araguás-Araguás, Froehlich, and Rozanski, 2000; Bonne et al., 2014; Delattre, Vallet-Coulomb, and Sonzogni, 2015), which vary in space 
and time due to seasonality and mesoscale weather phenomena (ENSO, MJO to mention a few), determine the isotopic composition of the initial vapor forming above the ocean surface. As seen previously, the Rayleigh process describes the evolution of a bi-phase system isotopic composition in nonequilibrium conditions. However, whilst precipitation depletion normally follows this theoretical framework as consequence of the progressive continental rainout, water vapor isotopic composition is affected by further complications. Firstly any air parcel, with its original newly formed water vapor, traveling from the ocean towards the continents internal areas can receive a continental vapor updraft from evapotranspiration (Brown, Worden, and Noone, 2008; Risi et al., 2013) in a process called continental recycling. Furthermore, air parcels are subject to mixing with other air masses having different isotopic composition, provenience and moisture content. Another important source of variability for the water vapor isotopic composition is the falling rain re-evaporation in cloud and sub-cloud tropospheric layers.

For example, water vapor generated from the re-evaporation of falling raindrops would be more depleted than the vapor in equilibrium with precipitation, thus following a typical Rayleigh distillation (RH equals $100 \%$ ) as shown in figure 2.13. When measuring the atmospheric water vapor isotopic composition it is necessary to combine the mixing ratio $q$ with the $\delta D$ or $\delta^{18} \mathrm{O}$ in order to get more insights about the processes affecting the formation, transport and mixing of water vapor to the measurement site (Noone et al., 2011; Noone, 2012).. The observations distribution in the $\delta(q)$ space (figure 2.13) allows the identification of the possible mechanisms that contribute to the final water vapor isotopic composition(figure 2.12).

\subsubsection{Distillation and mixing model for the water vapor iso- topic composition}

The formalization of the model for the interpretation of the water vapor isotopic composition as a function of the mixing ratio (Noone, 2012), starts with the definition of a mass balance of an air parcel formed from the sea surface evaporative flux, assuming an average isotopic composition of the sea water as $0 \%$ (for both $\delta^{18} O_{s w}$ and $\delta D_{s w}$ ). The isotopic composition of the initial water vapor formed above the ocean surface is calculated using the CraigGordon model for the evaporative flux above a water surface following equation 2.25 or, using the global closure assumption (Merlivat and Jouzel, 1979), equation 2.26. The general mass balance equation for the air parcel moisture is:

$$
\frac{d q}{d t}=\dot{q}=M+S-C+X
$$

where $\dot{q}$ stands for the time evolution of the air parcels mixing ratio. The terms on the right-hand side of the equation define a set of parameters for which a variation of the parcels mixing ratio occurs. These are the mixing between two air masses $(M)$, the moisture uptake from the ocean or land 


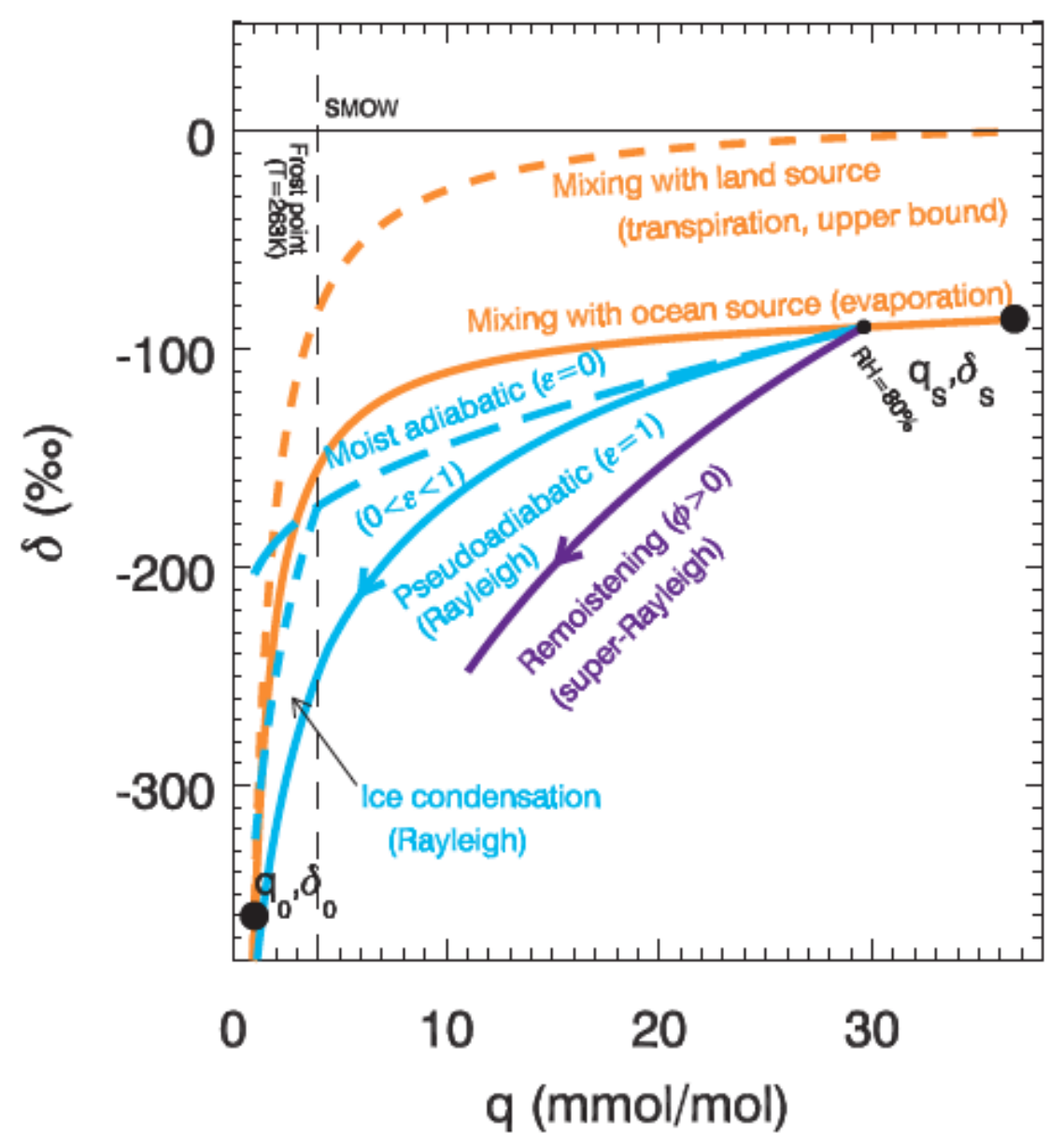

FIGURE 2.13: Theoretical evolution of the water vapor isotopic composition as a function of the vapor mixing ratio. Cyan solid curve represents the typical Rayleigh distillation 2.17 for an air parcel in equilibrium with an ambient relative humidity of $80 \%$. Dashed cyan represents an open Rayleigh distillation where at each cooling step the condensed phase remains within the air parcel as cloud liquid (super saturation). The difference between these two processes depends on the precipitation efficiency term ( $\epsilon$ that has not to be confused with the enrichment factor). Purple solid line represent the case of a rain reevaporation process where the falling precipitation evaporates and return in the cloud. Yellow curves represent isotopic mixing between two air masses with different isotopic composition and mixing ratio. The solid yellow curve describes the mixing between a moist and enriched sea evaporative air parcel and an upper air (upper tropospheric) end member while the dashed line is the response of the isotopic mixing with a contribution of a land moisture uptake (transpiration contribution) (Noone, 2012)

evaporative sites $(S)$, the loss of vapor as consequent to condensation and 
rainout process $(C)$ and finally the moisture uptake following a partial reevaporation of the falling rain drops through the sub-saturated atmospheric layers $(X)$.

\section{Condensation}

The mass balance equation where only condensation is taken into account is:

$$
d q+d l+d r=0
$$

where " $\mathrm{q}$ " stands for vapor mixing ratio, " 1 " for the liquid in suspension within the air parcel and " $\mathrm{r}$ " for the condensed liquid that leaves the air parcel as precipitation. The single terms are calculated only as a function of condensation and precipitation using the following system:

$$
\begin{cases}d q & =-C \\ d l & =C-P \\ d r & =P\end{cases}
$$

The amount of precipitation produced during each cooling step is controlled by the precipitation efficiency term $\epsilon$ that is multiplied for the condensation rate term $P=\epsilon C$ leading to $d l=-(1-\epsilon) d q$. Substituting these terms in equation 2.33 gives the evolution of the liquid fraction as function of the air mass mixing ratio through the:

$$
l=l_{0}+(1-\epsilon)\left(q_{0}-q\right)
$$

The form of the equation 2.33 for the different isotopic species is written as follow (here for the deuterium):

$$
d q_{D}+d l_{D}+d r_{D}=0
$$

and the isotopic composition of the liquid that condenses at each cooling step is controlled by the equilibrium fractionation factor $\alpha$. The description of the evolution of the isotopic composition of an air mass as function of the mixing ratio during a condensation process, after the initialization of the $\delta$ value of the water vapor at source is:

$$
\delta-\delta_{0} \approx \ln \left(\frac{R}{R_{0}}\right)=\left[\frac{\alpha * \epsilon}{1-\alpha(1-\epsilon)}-1\right] * \ln \left[\frac{\alpha l_{0}+q-\alpha(1-\epsilon)\left(q-q_{0}\right)}{\alpha l_{0}+q_{0}}\right]
$$

that, for a maximal precipitation efficiency $(\epsilon=1)$ it is simplified to the open Rayleigh fractionation process (figure 2.12-b):

$$
\delta-\delta_{0} \approx \ln \left(\frac{R}{R_{0}}\right)=(\alpha-1) \ln \left(\frac{q}{q_{0}}\right)
$$

This process described by a logarithmic curve in the $\delta D(q)$ space (figure 2.13 , solid cyan curve). If the precipitation efficiency is smaller than 1 some newly formed condensate is retained in the cloud. Due to the incomplete 
equilibrium fractionation, a small amount of heavier isotopes remains in the vapor phase, thus resulting, compared to the open process, in an enriched residual water vapor. Therefore, since the maximal precipitation efficiency is a boundary condition for the amount of heavy isotopes that could be removed from the air parcel at each cooling step, reduced rainfall efficiency contributes to feed the moisture with heavy isotopes, producing enriched clouds. This process, known as "closed-system" is described by the following (Jouzel, 1986):

$$
\delta-\delta_{0}=\left(\alpha_{e}-1\right) *\left[\frac{q-q_{0}}{q-\alpha_{e}\left(q-q_{0}\right)}\right]
$$

where $\alpha_{e}$ is the equilibrium fractionation factor at the dew point temperature. This equation describes a discontinuous curve in the $\delta D(q)$ space (Fig. 2.13 dashed cyan curve) due to the non-linearity of the equilibrium fractionation factor at the freezing point (equations 2.10, 2.11 and 2.12, 2.13).

\section{Rain reevaporation}

The rain reevaporation process, as illustrated in figure $2.12-c$, occurs when the precipitation falling from a cloud cross a sub-saturated air layer. During their fall, raindrops are affected by evaporation and, due to the light isotopes higher vapor pressure, contribute to the enrichment of the residual rain and a negativization of the surrounding vapor (amount effect). This mechanism occurs mostly in tropical rainfall where a significant relationship between the rain amount and its isotopic composition is observed. The isotopic composition of rain re-evaporation flux occurring during the exchange conditions between the falling raindrops and the surrounding vapor is calculated through (Jouzel, 1986; Lee and Fung, 2008; Noone, 2012):

$$
\frac{X_{D}}{X}=\alpha_{k}\left(\frac{\alpha_{e}^{-1} R_{r}-h_{r} R_{b}}{1-h_{r}}\right)
$$

where $h_{r}$, similarly to $h$ (equation 2.24), stands for the relative humidity near the raindrop. $\alpha_{k}$ is the kinetic fractionation factor that depends on the different molecular diffusivities of water isotopologues and $R_{r}$ and $R_{b}$ are the isotopic ratios of the raindrop and the boundary layer vapor. These terms are not easy to determine, therefore it is common to use an equilibrium fractionation factor parametrization:

$$
\alpha=(1+\phi) \alpha_{e}
$$

where $\phi$ reflects the deviation of $\alpha$ from the equilibrium. Super-Rayleigh curves that describe a reevaporation process are steeper (fig. 2.13 solid purple curve) than the open Rayleigh curve and the degree of rain reevaporation depends on their slopes. 


\section{Air mass mixing}

The general equation that describes the evolution of the mixing ratio of a well-mixed air mass $(\hat{q}, \hat{\delta})$ originated from two different air parcels with their own initial masses and mixing ratios is (Noone et al., 2011; Noone, 2012):

$$
\hat{q}=\left(\frac{m_{1} q_{1}+m_{2} q_{2}}{m_{1}+m_{2}}\right)
$$

which is a weighted averaged contribution of the 2 air masses to the final mixed volume (figure 2.12-d). The evolution of the mixed isotopic state instead, needs to account for the different diffusivities in air of water isotopologues. Thus, the instantaneous condition of an air parcel with a constant mass can be described by the following system of equations:

$$
\begin{cases}q & =q_{0}+q_{F} \\ R_{q} & =R_{0} q_{0}+R_{F} q_{F}\end{cases}
$$

with

$$
\left\{\begin{array}{l}
q_{F}=\left(\hat{q}-q_{0}\right)\left(1-e^{K t}\right) \\
R_{F}=\frac{\hat{R} \hat{q}-R_{0} q_{0}}{\hat{q}-q_{0}}
\end{array}\right.
$$

where $F$ stands for the flux into the mixed air parcel volume and $\mathrm{K}$ is the eddy-diffusivity term. This set of equations, describing a budget equation after full mixing, are converted into delta notation giving the expression for the isotopic mixing model:

$$
\delta=\frac{R}{R_{s}}-1=q_{0}\left(\delta_{0}-\delta_{f}\right) \frac{1}{q}+\delta_{f}
$$

which is described by a hyperbolic curve in the $\delta(q)$ space (figure 2.13 solid and dashed orange curves. These curves follow the Keeling approach for the determination of the isotopic composition of a source in a mixed model (Keeling, 1958). Furthermore, multiplying the isotopic composition for the mixing ratio and plotting the results in the $q \delta(q)$ space leads to the linearization of the hyperbolic curves. In this case the intercept between the linearized line and the $y$-axis determines the isotopic composition of the water source $\delta_{F}$

The mixing model can be also applied to determine the isotopic mixing between atmospheric air masses and oceanic or ecosystem moisture contributors such as, for example, during sea surface evaporation or during continental recycling (figure 2.12-e). In the first case the determination of the oceanic vapor initial-point of the mixing model needs to account for the molecular and turbulent diffusivity terms $\left(\rho_{T}\right.$ and $\left.\rho_{M}\right)$. In a similar manner, when the source is the ecosystem, appropriate terms, such as leaf boundary layer, stomatal resistance and canopy resistance need to be accounted for (Noone, 2012). 


\subsection{Ecosystem water flux partitioning}

The study of the ecosystems water cycle and its interaction with the atmosphere involves the problem of flux partitioning. This requires knowledge of both the isotopic composition of ecosystems water pools and that of fluxes (Dawson and Ehleringer, 1993; Ehleringer, Hall, and Farquhar, 1993; Yakir and Sternberg, 2000; Wen et al., 2008; Lai and Ehleringer, 2011; Wei et al., 2015).

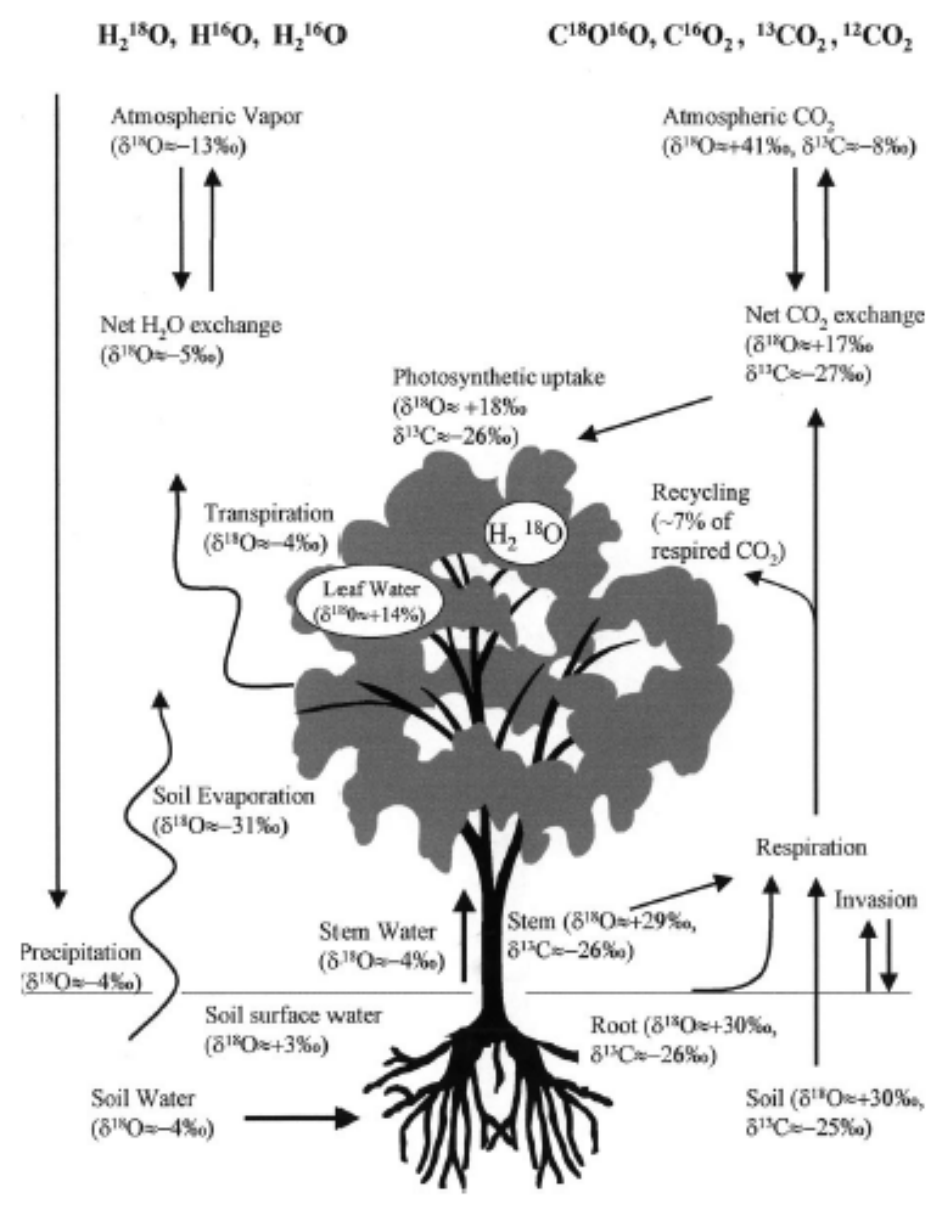

FIGURE 2.14: Values of ecosystem water and carbon dioxide pools and fluxes (Yakir and Sternberg, 2000)

The ecosystems water cycle of a vegetated area consists of inputs, such as rainfall and advected moisture, and outputs such as evaporation and transpiration. The net sum of these two fluxes together represents the ecosystem evapotranspiration flux.

Measuring the isotopic composition of the water fluxes in the ecosystem is challenging because not only environmental factors such as temperature, relative humidity and wind speed change constantly but they also influence the plants response to these changing factors (Day, 2000; Hetherington and 
Woodward, 2003; Buckley, 2005), thus rapidly influencing the isotopic composition of the water pools (Kahmen et al., 2008; Still et al., 2009; Ripullone et al., 2008). With the development of laser-based measuring systems, providing higher frequency sampling, better estimates of the ecosystems water vapor fluxes can be achieved (Wen et al., 2008; Wang et al., 2010; Kool et al., 2014). However, the advantages of high frequency laser based measurements are confounded by intrinsic uncertainties arising from i.e. heated intake tubes, chambers, temperature-controlled manifolds and pumping systems need to be accounted for.

For the determination of the isotopic composition of the evapotranspiration flux three methods can be used, the Keeling plot approach, the flux gradient method, which consists in the measurement of the isotopic species vertical gradient between two inlet placed above the canopy (Lee et al., 2005; Welp et al., 2008; Good et al., 2012) and the eddy covariance method, which uses the co-variations of high frequency vertical wind speed and isotopic composition measurements (Zhang et al., 2010; Griffis et al., 2010; Dubbert et al., 2014; Braden-Behrens, Markwitz, and Knohl, 2019).

\subsubsection{Keeling plot approach for $\delta_{E T}$ determination}

The Keeling plot approach (Keeling, 1958; Keeling, 1961) for the determination of the isotopic composition of evapotranspiration $\delta_{E T}$, relies on the measurement of atmospheric water vapor $\delta_{v}$ along a vertical profile. This method was originally developed for $\mathrm{CO}_{2}$ but it can be applied to any scalar (Moreira et al., 1997; Pataki et al., 2003; Maher, Santos, and Tait, 2014; Wolf et al., 2015).

The principle of this method is based on the following mass conservation law (Harwood et al., 1999; Yakir and Sternberg, 2000; Yepez et al., 2005):

$$
\begin{cases}q_{a} & =q_{E T}+q_{b} \\ \delta^{18} O_{a} q_{a} & =\delta^{18} O_{E T} q_{E T}+\delta^{18} O_{b} q_{b}\end{cases}
$$

where "ET", "a" and " $b$ " stand for evapotranspiration, atmospheric water vapor and background isotopic composition (Good et al., 2014). The solution (here for $\delta^{18} O$ ) of this system of equation is:

$$
\delta^{18} O_{a}=q_{b}\left(\delta^{18} O_{b}-\delta^{18} O_{E T}\right)\left(\frac{1}{q_{a}}\right)+\delta^{18} O_{E T}
$$

where the isotopic composition of the $\delta^{18} O_{E T}$ is determined by the value of the intercept in the $\delta^{18} O\left(1 / q_{a}\right)$ space. When using this method it is necessary to assume that there is no water vapor loss outside the ecosystem other than the one exchanged with the atmosphere and that only two sources with different isotopic composition exist. The Keeling plot approach (2.15) can be affected by large uncertainties in the determination of the intercept that is sensitive to even small measurement errors (Yakir and Sternberg, 2000; Zobitz et al., 2006). 


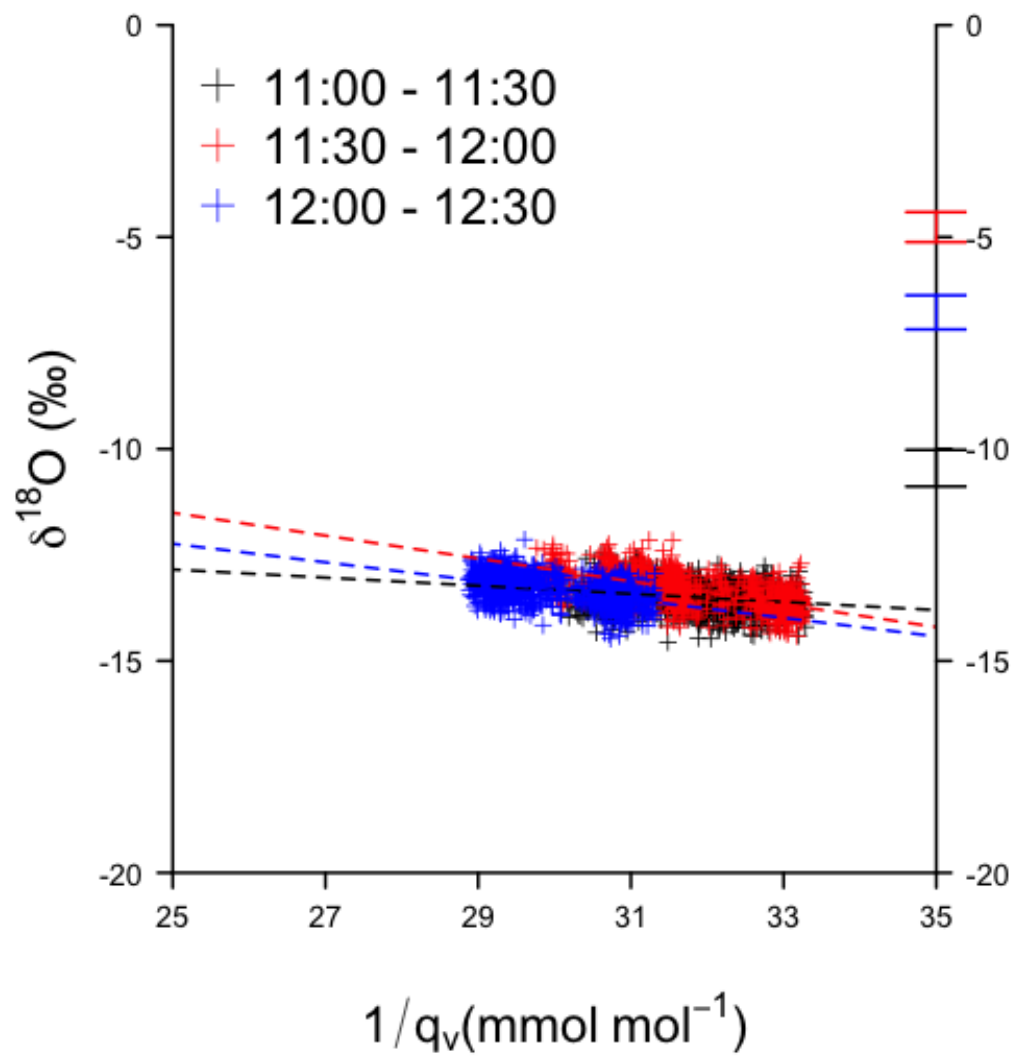

FIGURE 2.15: Example of $\delta^{18} O_{E T}$ determined using the Keeling plot approach (using OLS regression) on 3 different and consecutive high frequency $(0.5 \mathrm{~Hz})$ measurements along a vertical profiles. The right axis shows the standard error of the intercept.

\subsubsection{Soil water isotopic composition}

Following the determination of the isotopic composition of evapotranspiration it is necessary to estimate the $\delta D$ and $\delta^{18} O$ of the components of the surface moisture flux calculated as (Wang et al., 2010; Good et al., 2014; Wang et al., 2015):

$$
f_{T / E T}=\frac{F_{T}}{F_{E T}}=\frac{\delta_{E T}-\delta_{E}}{\delta_{T}-\delta_{E}}
$$

where ET, T and E stand for the isotopic composition in \%o of evapotranspiration, transpiration and evaporation, $\mathbf{F}$ the fluxes in $\left(\mathrm{g} \mathrm{m}^{-2} \mathrm{~s}^{-1}\right)$ and $\mathbf{f}$ the ratio between the transpiration and evapotranspiration fluxes. Soil evaporation flux isotopic composition $\delta_{E}$ can be directly measured using soil chambers (Rothfuss et al., 2010; Dubbert et al., 2013; Dubbert et al., 2014) or by 
sampling soil at different depths, extract the water content using an extraction line and estimate the isotopic composition of the evaporative flux using the Craig and Gordon model (Horita, Rozanski, and Cohen, 2008; Wang et al., 2010; Dubbert et al., 2013; Good et al., 2014) using the:

$$
\delta_{E}=\frac{\alpha \delta_{s}-\delta_{a} h-\epsilon_{k}-\epsilon^{*}}{(1-h)+10^{-3} \epsilon_{k}}
$$

where $\delta_{s}$ and $\delta_{a}$ are the isotopic compositions of the "bulk" soil liquid water and water vapor in the air layer above the soil surface, $\alpha$ is the temperaturedependent equilibrium fractionation factor which depends on the soil temperature (Majoube, 1971); $\epsilon^{*}$ is the isotopic enrichment factor and $\epsilon_{k}$, the kinetic fractionation factor, which depends on the wind speed. The parameter $h$ is the relative humidity normalized to soil temperature calculated as:

$$
h=R H * \frac{e_{s}\left(T_{\text {air }}\right)}{e_{s}\left(T_{\text {soil }}\right)}
$$

Depending on the hydrological regime of the area, soil water isotopic composition can change according to the frequency and intensity of precipitation and, in upper soil levels are usually enriched in heavier isotopes due to moisture with the lower boundary layer. However it is important to consider that no fractionation during water uptake by roots occurs (Zimmerman, Ehhalt, and Münnich, 1967; Gat, 1996; Edwin et al., 2014).

\subsubsection{Leaf water isotopic composition}

In the global water cycle leaf transpiration is the largest surface contributor to the total land flux (Jasechko et al., 2013; Evaristo, Jasechko, and McDonnell, 2015), but the direct and precise determination of the transpiration flux isotopic composition $\delta_{T}$ suffers from many technical issues (Sutanto et al., 2014). These issues are similar to the problematic affecting the determination of the evapotranspiration isotopic composition, but in addition they emerge due to the plant physiology and to the small dimension of the leaf boundary layer where isotopic fractionation occurs. This last parameter is a specie-specific physiological trait that depends on the leaf shape, its surface roughness, its orientation and on the friction velocity exerted by the wind speed on its surface (Jarvis and McNaughton, 1986; Brenner and Jarvis, 1995; Daudet et al., 1998).

Moreover the isotopic composition variability within leaf tissues is a highly dynamic process depending on the endogenous assimilation rate but also on exogenous environmental forcing, such as vapor pressure deficit or photosynthetically active radiation (Farquhar and Cernusak, 2005; Cuntz et al., 2007; Wang et al., 2012). From the isotopic point of view, on longer time scales, the leaf mass balance is considered in "Steady State" (SS), however studies have reported that the SS conditions are normally reached only during mid-day or early afternoon (depending on the season) when leaf transpiration reaches its maximum and isotopic fractionation at the stomata level do 
not occurs (Dongmann et al., 1974; Cernusak, Pate, and Farquhar, 2002; Dubbert et al., 2013; Wen et al., 2016; Cernusak et al., 2016). At sub-daily scales the transpiration isotopic composition is mainly driven by the difference between the atmospheric vapor $\delta_{v}$ and the leaf isotopic enrichment resulting from the deviation from leaf steady-state conditions.

In steady state conditions the isotopic composition of transpiration $\delta_{T}$ equals that of vapor at the equilibrium with xylem water $\delta_{x}$ because the water vapor enclosed in the stomatal cavity is assumed at saturation conditions (Cernusak et al., 2016). When steady state condition occurs, a modified version of the Craig-Gordon model for the evaporation from a water body, adapted to the leaf internal environment (Farquhar and Lloyd, 1993), can be used to determine the isotopic leaf enrichment:

$$
\delta_{L, e}=\delta_{T}+\epsilon_{e q}+\epsilon_{k i n}+h\left(\delta_{v}-\epsilon_{k i n}-\delta_{T}\right)
$$

The underlying principle controlling leaf isotopic enrichment is common in both models but the latter one considers the resistances, modulated by physical factors, to the water diffusion occurring from the site of water evaporation within the leaf mesophyll, to the free ambient (Dubbert et al., 2013; Cernusak et al., 2016). Thus the equilibrium fractionation factor $\epsilon_{e q}$ depends on the leaf surface temperature (Majoube, 1971) and the stomatal and leaf boundary layer resistance (inverse of the conductance) determine the kinetic fractionation factor $\epsilon_{\text {kin }}$ such as (Farquhar et al., 1989):

$$
\epsilon_{k i n}=\frac{32 r_{s}+21 r_{b}}{r_{s}+r_{b}}
$$

here reported for $\delta^{18} O$. Assuming steady state conditions $\left(\delta_{T}=\delta_{x}\right)$ the modified Craig and Gordon model can be written using the following equation. In both cases the parameter $h$ refers to the above leaf relative humidity normalized to the leaf temperature, in a similar shape as observed in equation 2.24. Thus:

$$
\delta_{L, s}=\delta_{x}+\epsilon_{e q}+\epsilon_{k i n}+h\left(\delta_{v}-\epsilon_{k i n}-\delta_{x}\right)
$$

The measure of the deviation of the leaf isotopic composition from the steady-state conditions can be expressed using the:

$$
\delta_{L, e}-\delta_{L, s}=\left(\delta_{T}-\delta_{x}\right)(1-h)
$$

In field conditions it is necessary to carefully remove the central vein from sampled leaves, because it contains the photosynthetic products that have a different isotopic composition. Once the water is extracted cryogenically the resulting water is called the "Bulk leaf water" and its isotopic composition is therefore $\delta_{L, b}$ modeled as follows:

$$
\delta_{L, b}-\delta_{x}=\frac{\left(\delta_{L, e}-\delta_{x}\right)\left(1-\mathrm{e}^{-\wp}\right)}{\wp}
$$


Due to the leaf isotopic mass balance, the diurnal pattern of $\delta_{T}$ leads to more depleted (in respect of $\delta_{x}$ ) values in early morning when $\delta_{L, b}$ increases due to the preferential diffusion of lighter isotopes through the stomata. In the late afternoon the relationship is normally in the opposite direction, with lighter isotopic composition of the xilematic water $\left(\delta_{x}\right)$ and heavier $\delta_{T}$ due to the source water recharge from the root system (Cernusak et al., 2016; Wen et al., 2016).

$$
\wp=\frac{E_{T} L_{e f f}}{C D}
$$

A better agreement between the observed $\delta_{L, b}$ and the non-directly observable $\delta_{L, e}$ is reached using the model proposed by (Farquhar and Lloyd, 1993) that takes in account the relationship between the isotopic enrichment at the site of leaf evaporation and transpiration. These terms are related via $\wp$, that is the dimensionless Péclet number shown in equation 6.12. In the $\wp$ equation, $E_{T}$ is the transpiration rate of the leaf in $\mathrm{mol} \mathrm{m}^{-2} \mathrm{~s}^{-1}, L_{e f f}$ is the species-specific effective water diffusion length within the mesophyll in $\mathrm{m}, \mathrm{C}$ is the molar density of water and D the diffusivity of $\mathrm{H}_{2}^{18} \mathrm{O}$ in water (Cuntz et al., 2007). 



\section{Chapter 3}

\section{Methods in water stable isotopes analysis}

\subsection{Introduction}

The measurement methods for the determination of the isotopic composition of a sample applied in hydrological geochemistry can be summarized in two categories (Galewsky et al., 2016; Sharp, 2017; Bowen et al., 2019). Isotopic ratio mass spectrometry (IRMS), that exploits the separation of isotopically different molecules moving at the same speed under the effect of a constant deflecting force. Optical-based methods like cavity ring-down spectrometry (Berden, Peeters, and Meijer, 2000; LaFranchi, 2003) or Off-Axis Integrated Cavity Output Spectroscopy (Baer et al., 2002; Baer et al., 2012), using the light absorption strenght of different molecules when stimulated from a highly energetic light source.

\subsection{Isotopic Ratio Mass Spectrometry}

As previously discussed, the isotopic composition of a sample is not determined by the absolute abundance of different isotopes in a sample, but rather by the ratio between the abundances between heavier and lighter isotopes. This ratio can be precisely determined using the different weights of isotopically different molecules.

An Isotopic Ratio Mass Spectrometers (IRMS) consists of an ion source, where the gas with the unknown isotopic composition is introduced and ionized, a "U-shape" high vacuum flying tube, positioned under a magnet that generates an intense magnetic field and a series of collectors (the Faraday cups), that transform the intensity of molecular collision into voltage and then into isotopic abundance (figure 3.1). In order to measure the isotopic composition of a sample, it needs to be preliminarily converted into a gas, therefore interfaces placed before the IRMS are specifically designed. It is possible to convert solid and liquid samples in gas using an element analyzer (Total Combustion interface) and introduce the combusted and purified gas to the mass spectrometer. 
In order to achieve the high measurement precision characterizing this method, IRMS are equipped with 2 low vacuum pumps capable of reaching a vacuum pressure of $10^{-3}$ mbar coupled with 1 or 2 turbo vacuum pumps that reduce this pressure up to $10^{-7}$ mbar.

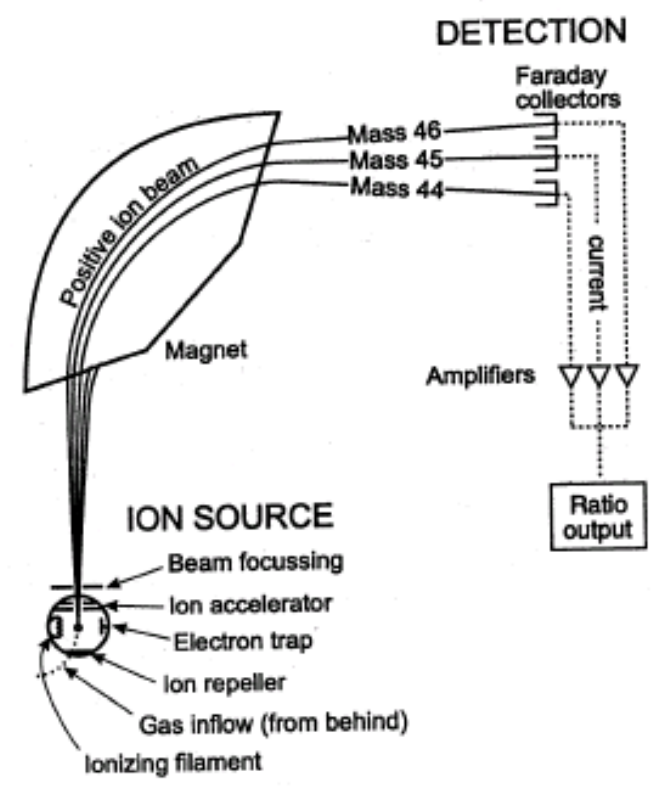

FIGURE 3.1: Simple schematics showing the main components and the measuring principle of an Isotopic Ratio Mass Spectrometer.

The gas entering the source is ionized and accelerated by a tungsten filament (heated by a voltage of $3 \mathrm{kV}$ ) that reaches a temperature of $\approx 1.4 \times 10^{3}$ ${ }^{\circ} \mathrm{C}$. Here a set of metal plates (the focus lenses) are used to direct the ionized beam into the correct path, in order to prevent it to collide with the walls of the flying tube. In the middle part of the flying tube the different isotopic molecules are separated in order of increasing mass by the action exerted from a magnetic field generated by a set of high voltage magnets. The physical principle governing the trajectory radius as a function of the mass of the isotopologues is:

$$
\frac{m}{z}=\frac{B^{2} r^{2}}{2 V}
$$

where $\mathrm{m}$ is the mass $\mathrm{u}, \mathrm{z}$ is the electric charge, $\mathrm{B}$ is the magnetic field strength in $\mathrm{T}, \mathrm{r}$ the trajectory radius $\mathrm{m}$ and $\mathrm{V}$ the accelerating voltage in $\mathrm{V}$. Following this relationship (equation 3.1) heavier species have smaller curvature radius when the magnetic field and the accelerating voltage are kept constant. Mass spectrometry is based on this principle and theoretically, it is possible to measure the isotopic composition of many gasses by combining the intensity of the accelerating voltage and magnetic field. 


\subsection{Wavelength Scanned Cavity Ring-Down Spec- troscopy}

A major limitations of the mass spectrometry measurement techniques are represented by the non-portability of the equipment in the field, by the need for highly trained technical manpower to perform high precision analysis and by the elevate energy demand of these analyzers. In the last decade some companies introduced on the market a new type of easy-functioning, reliable and affordable optical laser-based isotopic analyzers. The measuring principle of the Picarro analyzer (Cavity Ring-Down Spectrometer, WSCRDS, L2120-i, Picarro Inc. (R), Santa Clara, CA, USA), which was used in this research, is based on the Lambert-Beer extinction law expressed by the following equations:

$$
\begin{aligned}
I & =I_{0} e^{-\alpha L} \\
\alpha & =n \sigma(\lambda)
\end{aligned}
$$

where I stands for the light intensity (and $I_{0}$ denotes its initial state), $\mathrm{L}$ in $m$ is the length of the laser beam path, $n$ is the concentration of the considered chemical species, $\sigma$ denotes the decay time that depends on the absorption frequency $(\lambda)$ of the considered compound. From equation 3.2 the cell ringdown time, that is the time-based laser intensity decay from its initial intensity is determined using the following relationships:

$$
\begin{aligned}
\sigma(\lambda) & =\frac{1}{c}\left[\frac{1}{\tau}-\frac{1}{\tau_{0}}\right] \\
\sigma(\lambda) & =\epsilon(\lambda) C
\end{aligned}
$$

where c stands for the speed of light, $\tau$ represent the ring-down time with the empty and filled detection cavity, and $C$ is the concentration of the gas in the path of the laser beam. The cavity of the analyzer $(25 \mathrm{~cm}$ long, $32 \mathrm{cc})$ is equipped with 3 high reflectivity mirrors (reflectance of 99.995\%), therefore the laser beam is reflected multiple times (for a total path length of $\approx 10$ $\mathrm{km}$ ) during an analysis. At each passage in the cavity the laser loses part of its intensity due to the vibro-rotational absorption by the molecules, thus the higher the concentration of the targeted chemical species, the shorter the laser extinction time. This technique allows fast and accurate measurements of the concentration and, due to the different absorption spectra of isotopically different molecules, their isotopic composition expressed in delta notation.

The drawback of this kind of measurements is represented by the fact that one instrument can only scans a short wavelength range, meaning that these instruments can measure the isotopic composition of only one substance. Thus, for particular applications involving multiple chemical molecules, such as water, carbon dioxide and other gasses, the laboratory should purchase an analyzers for measuring each of them. It is however noteworthy that the 


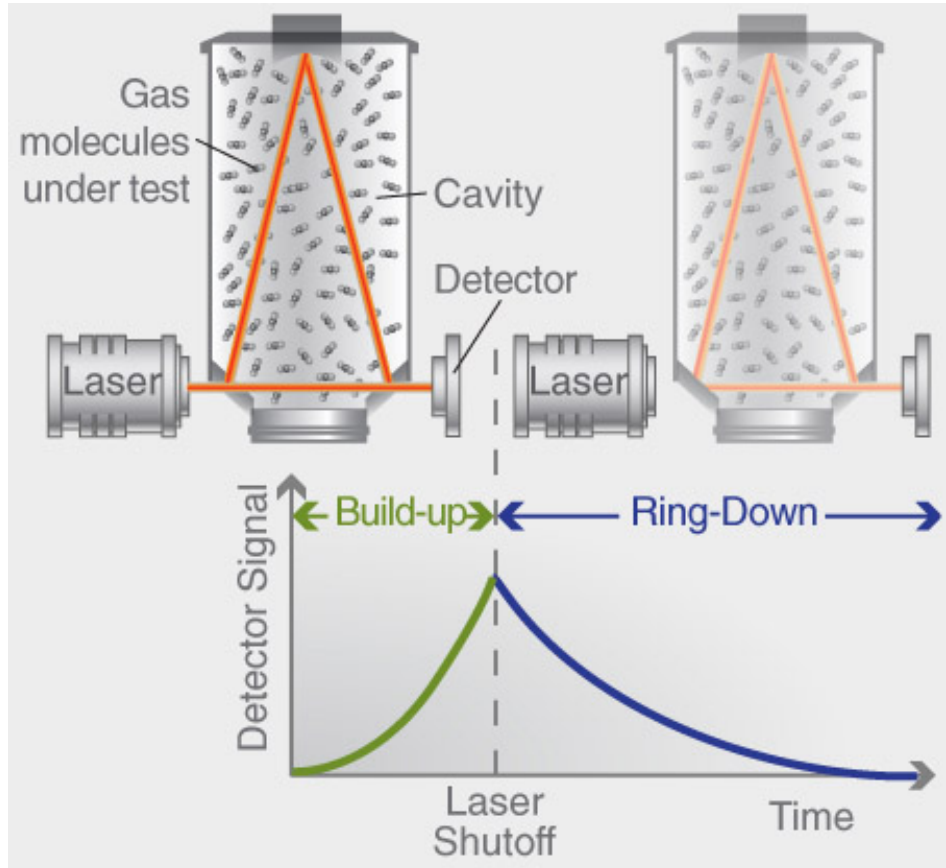

FIGURE 3.2: Illustration of the optical cavity of a laser spectrometer. On the left the gas has been injected in the moderate vacuum cavity where the laser beam is introduced. On the right the laser is turned off and the speed of the laser beam extinction depends on the isotopic composition and quantity of the sample introduced in the cavity. Figure from www.picarro.com

production of this analyzers has contributed to increase the number of studies and application regarding the isotopic composition of the most important chemical species. The main benefit of this methods relies on the simplicity of operations, the possibility of deploying the analyzers in the field for long times, if the temperature stability can be guaranteed, with reduced need for human intervention and the reasonable costs.

\subsection{Calibration}

As mentioned in the introduction, the most important phase to consider in order to produce reliable and robust results in all kind of measurements is the careful calibration of the measuring devices. Both methods (IRMS and CRDS) use similar calibration procedures, consisting in the determination of standard material with a known isotopic composition during each measurement session. However the CRDS technique differs from IRMS when water vapor continuous measurements need to be calibrated. 


\subsubsection{Discrete IRMS and WS-CRDS}

During liquid water analysis vials containing the reference standards are measured during sequential injection of samples in the analyzer. Normally laboratories are equipped with secondary and working standards that are routinely compared against the international reference material (Table 3.1).

TABLE 3.1: International standards for water isotopic measurements reference

\begin{tabular}{lcccc}
\hline Reservoir & $\delta D(\%)$ & $\mathrm{sd}$ & $\delta^{18} O(\boldsymbol{\% 0})$ & $\mathrm{sd}$ \\
\hline V-SMOW2 & 0 & 0.3 & 0 & 0.02 \\
GISP & -189.5 & 1.2 & -24.76 & 0.09 \\
SLAP2 & -427.5 & 0.3 & -55.50 & 0.02 \\
\hline
\end{tabular}

* Water is now out of stock

Due to the cost and the availability of these primary (or international) standards laboratories need to produce and stock their own standard for dayto-day use. It is considered a good practice to provide the instrument with standards bracketing the range of possible values assumed for the study of interest. For example, using very depleted standard water (similar to SLAP2) is considered not suitable if the study focuses on the precipitation isotopic composition in tropical areas.

In both methods vials containing the standard material have to be alternated with the vials containing the samples and they have to be repeated at regular intervals in order to build a robust regression calibration curve for the correction of the isotopic composition and for the instrumental drift.

Moreover, during an analysis run, multiple injection of liquid are required for each vial due to the "memory effect" affecting the isotopic composition shift between two consecutive. Procedural experience and analytic evidence suggest that the first 4 to 5 injection should be removed from the analysis when samples are analyzed for their water isotopic composition using the WS-CRDS equipped with auto-sampler and vaporizer (Godoy, Godoy, and Neto, 2012; Penna et al., 2012). The number of injections that needs to be reduced in the case of liquid IRMS analysis largely depends on the type of interface that is used to prepare the gas prior its delivery to the ion source. An example of configuration used in the determination of the isotopic composition of liquid samples in a CRDS setup is showed in figure 3.3.

\subsubsection{Continuous WS-CRDS}

One of the main advantages introduced by the development of laser spectrometer for the determination of the isotopic composition of gasses, is the possibility to conduct continuous measurement of water vapor. To perform 


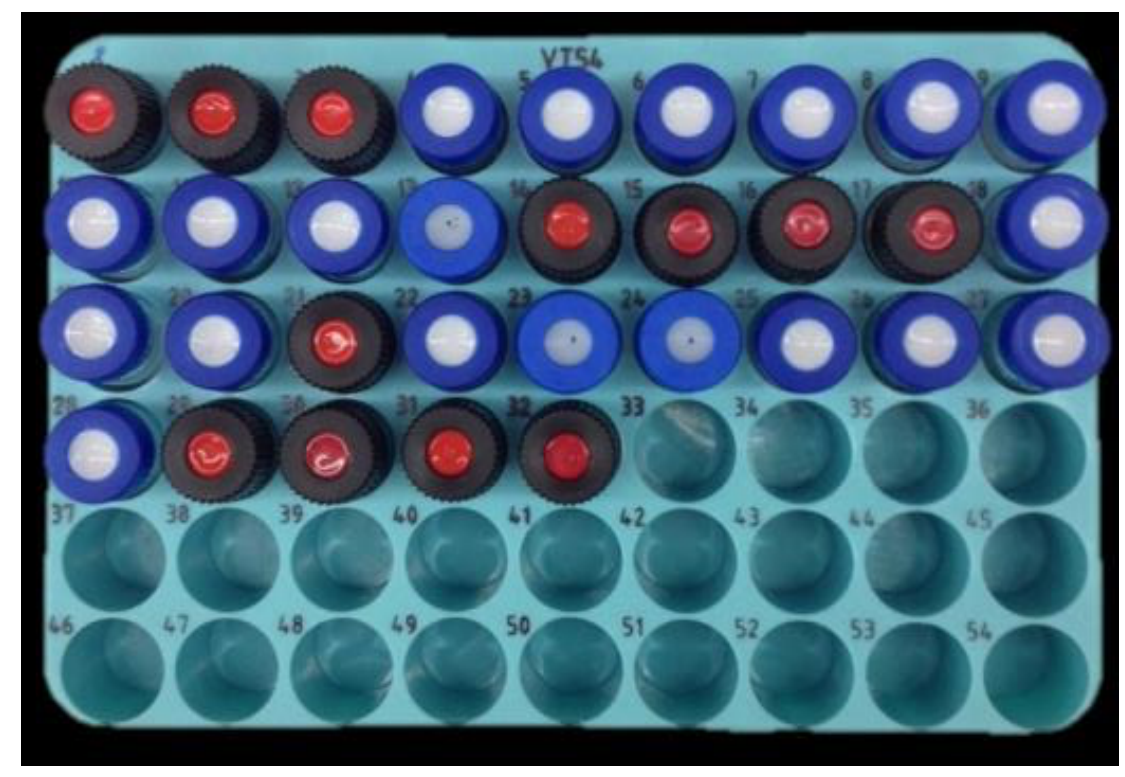

FIGURE 3.3: A possible sequence of sample vials (white septa) and standard vials (red septa) on a routine water analysis. Reference material vials are alternated with sample vials in order to provide a robust regression line. The vial number 1 can eventually be used as "dummy" to prepare the cavity for the measuring task. Source IAEA.

the calibration during this type of measurement the Picarro laser spectrometer is equipped with a dedicated peripheral. The standard delivery module (SDM) allows the WS-CRDS to be calibrated during the water vapor measurements using an automatic procedure. The SDM is schematically shown in figure 3.4

The SDM consists of a two aluminum bags where the reference material is stored (DW and YEKA in figure 3.4). Using a dedicated software application the SDM can be initialized, switched routinely on and off and the concentration of the standard within the cavity changed. The SDM delivers a precise stream of liquid water to the injector head positioned above the analyzer into the vaporizer assembly (consisting in a precisely heated chamber that creates a homogeneous vapor stream). Here the needles carrying the water are introduced to the vaporized under a stream of dry air that can be delivered from a pressurized cylinder (Part B figure 3.4) or collected by means of a pump from the ambient air (Part A figure 3.4). In this last setup a Drierite canister (an air desiccant) needs to be placed upstream to the injection head to remove the ambient moisture that could interfere with the vapor generated from the standard bags. The advantage of using the SDM is that, by the combination of the fixed air stream and by the precise regulation of the water delivered by the step motor a precise and long-lasting flux of standard water can be delivered to the cavity for the calibration. A possible problem that could occur during the calibration consists in the clogging of the small capillaries, therefore the standard water needs careful filtration from salts or small particles. 


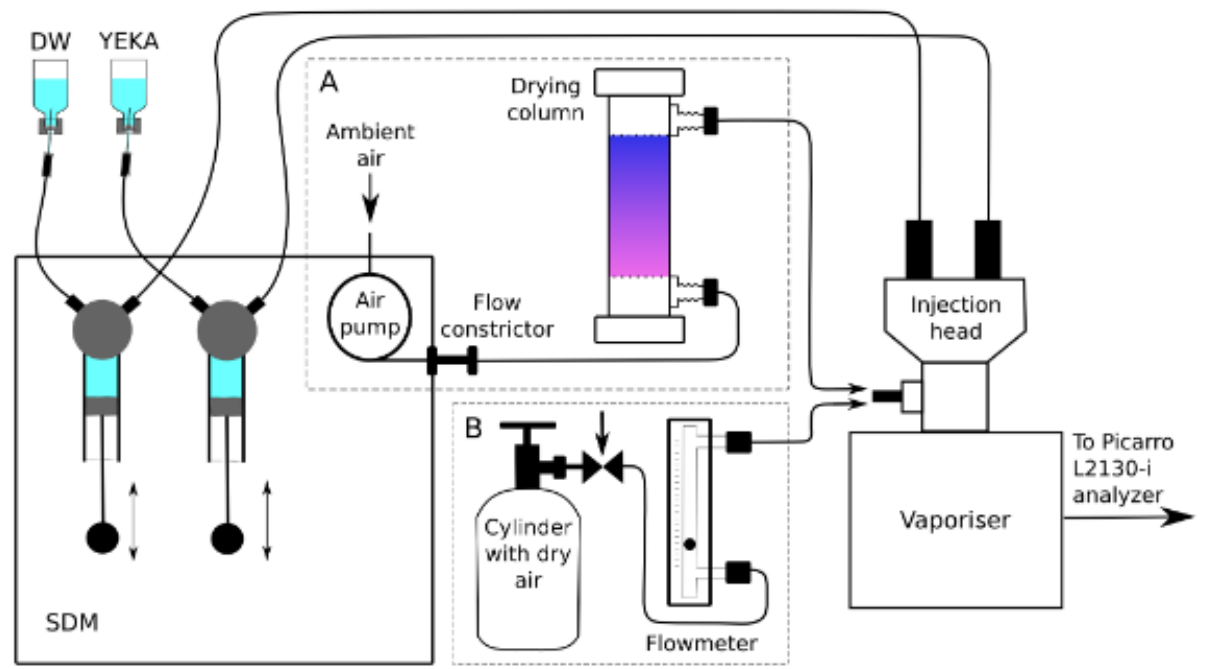

FIGURE 3.4: Schematic representation of the SDM used for the calibration of water vapor isotopic composition measurements. Here the standards were not stored in the provided aluminum bags but in glass vials (DW and YEKA). (Bastrikov et al., 2014)

\subsection{Sample collection and preparation}

\subsubsection{Rainfall collection}

Large uncertainties can affect measurements in the sample collection phase as well as during extraction of water samples from a matrix (where a matrix can be a leaf, a soil sample or any other material where the water is bonded to), therefore procedural guidelines for the correct sampling of water exist.

For hydrological studies the IAEA provides exhaustive guidelines to minimize the errors when collecting rainfall using pluviometers (IAEA, 2014). Many possibilities were tested, for example by burying the pluviometer in the soil in order to reduce temperature excursions, or using high purity liquid paraffin to prevent evaporation loss. For our studies we used a simple but proven method for collecting rainfall as shown in figure 3.5. It consisted of a funnel, where a table tennis ball was inserted in the inlet to prevent evaporation and a polyethylene bottle. The funnel was also equipped with a long cannula reaching the lower part of the bottle. This method for collecting rainfall was chosen due to difficulty in finding high quality paraffin in the area of our study. The pluviometers were then placed in shade and samples were collected after every rain event. After collecting the event sample, the pluviometer and the cannula were carefully cleaned and dried in order to prevent any cross contamination. The funnel was also cleaned and any particle (dust, leaf or small insects) removed before reestablish the pluviometer in the original location. 


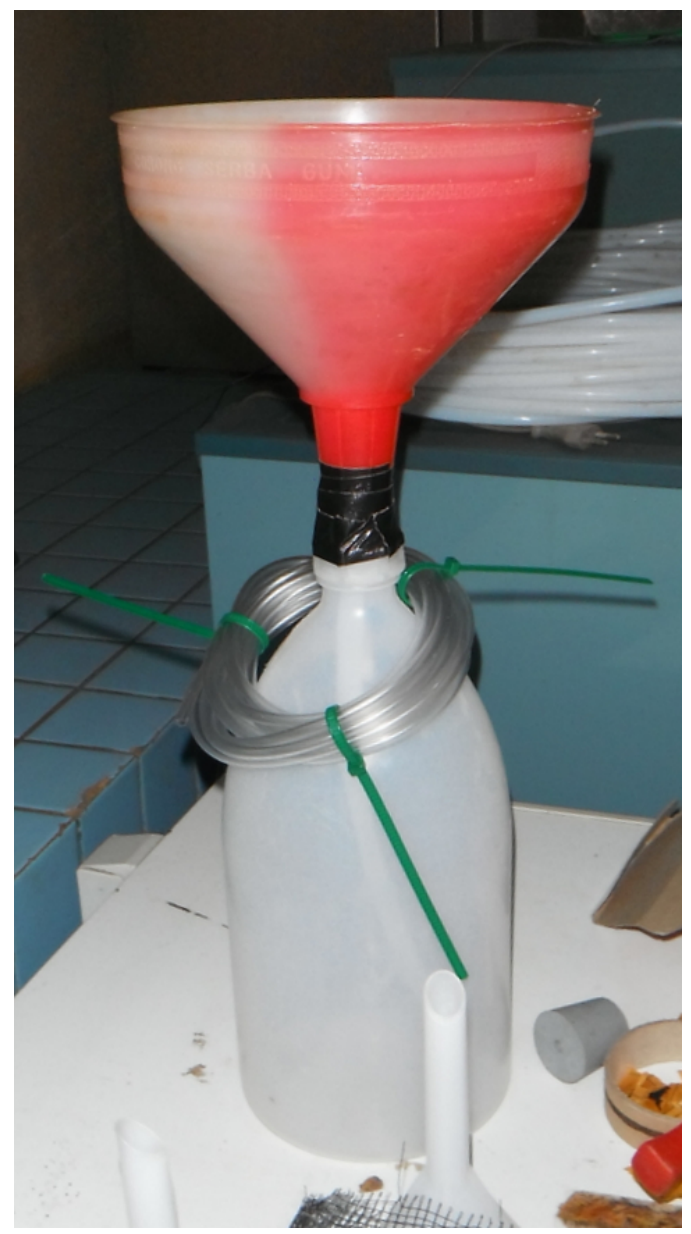

FIGURE 3.5: The rain event collector used in this study. The table tennis ball was placed at the top of the funnel inlet. The long tube twisted around the bottleneck is a pressure dumper. It allows the pressure equilibration between the ambient air and the bottle space avoiding any fractionation. The pluviometer was built following the IAEA guidelines for hydrological sampling.

\subsubsection{Water vapor sampling}

Sampling water vapor for isotopic studies requires a careful selection of the pumping system and tubing material. The tubes, manifolds and fittings need to be selected according to their retention and affinity to water vapor because this can increase the possibility of moisture condensation on the tube walls. Fractionation occurring within the tubing system can lead to false results of the water vapor isotopic composition measured in the cavity of the instrument. Moreover the tubes need to be relatively light in weight (depending on the distance between the sampling point and the analyzer), flexible (for bending and line displacement) but also they need to have a high thermic transmittance to allow the application of electric heating traces that can be useful to prevent condensation in the tubing especially at freezing temperatures or in high humidity environments.

One example of application is shown in figure 3.6. In this case we used a 


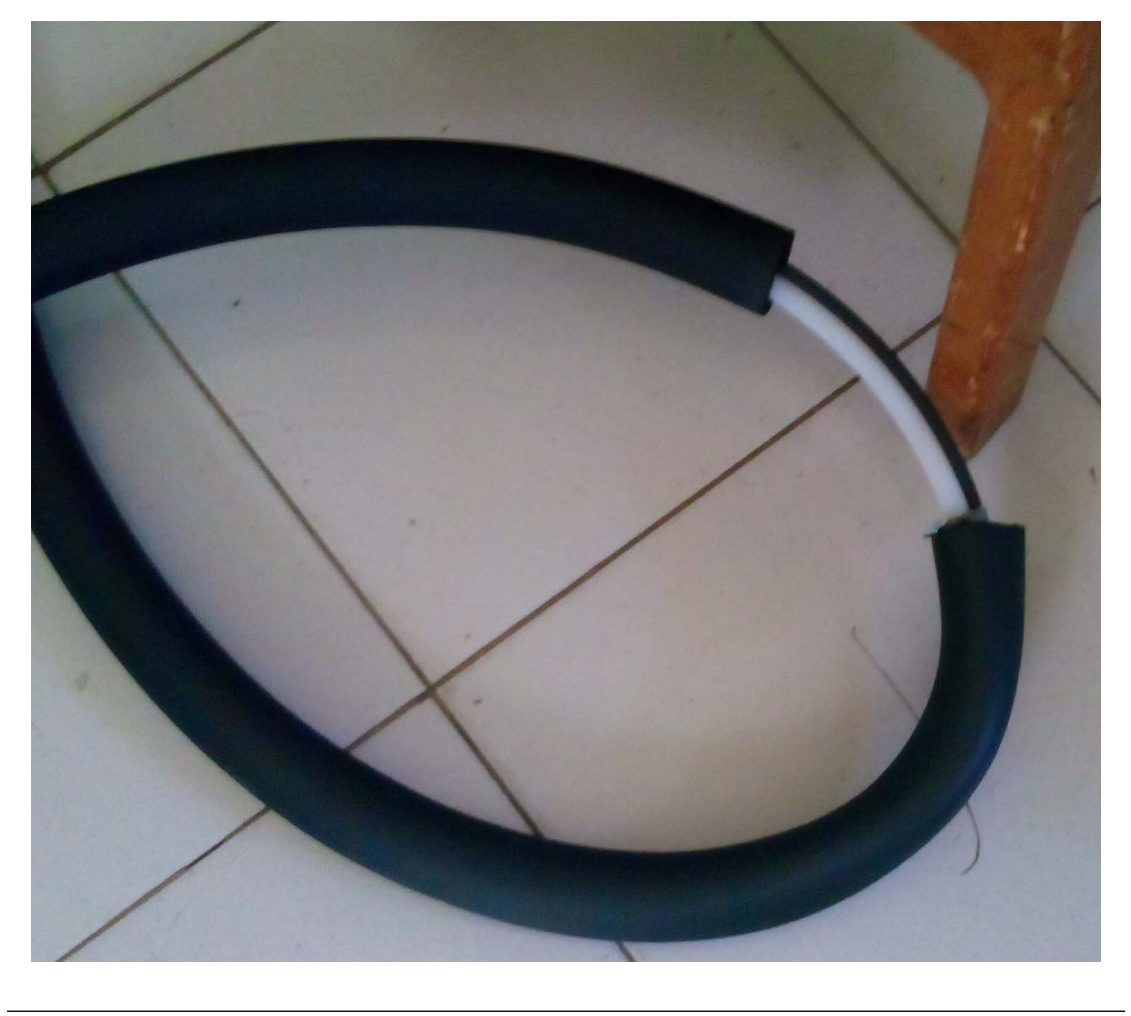

FIGURE 3.6: The sampling system setup used in this study consisted in a teflon tube (in white with o.d. 1/2 Inch), a selfregulating heating trace (in black) and a foam insulation (encapsulating both).

Teflon tube with a inner diameter of $1 / 2$ Inch, that was preferred to the Synflex tube for the lower water vapor retention time (Sturm and Knohl, 2010), a self regulating heating trace (Raychem $($, Pentain Inc., Houston U.S.A.) and a commercial foam thermal insulator. The self-regulating heating trace was places along the teflon tube in order to avoid condensation on the tube walls by keeping the temperature of the tube always above air temperature.

Another important aspect to consider is the air sampling pumping system design. It is important to keep the internal flow of the gas turbulent because in case of a laminar flow a fractionation can occur. This condition is met combining the tube internal diameter and the air stream velocity (flow). In our field experiments, we sampled ambient air from 5 different heights along a flux tower. Air from each height was sampled using a low flow pump (4.2 $\left.1 \mathrm{~min}^{-1}\right)$. Before reaching the instrument, this line was subsampled in order to deliver to the instrument the desired flow. The other inlets were instead kept flushed, by means of a high flow pump $\left(28 \mathrm{l} \mathrm{min}^{-1}\right)$, in order to avoid air stagnation and possible condensation. 


\subsubsection{Extraction of water samples}

In ecosystems water exchange studies, together with rainfall and water vapor, samples consist of leaves, soil, roots and other organic material interacting with water (Kahmen et al., 2008; Hu et al., 2014; Kool et al., 2014; Cernusak et al., 2016). The determination of the isotopic composition trapped in these samples requires an additional step when compared to vapor and precipitation, in that the water content under investigation must first be separated from the matrix to which it is bound, whether it is an organic material such as a leaf or an inorganic material such as a soil particle (West, J. Patrickson, and Ehleringer, 2006; Goebel and Lascano, 2012; Orlowski et al., 2016).

In the case of transpiration, water isotopic fractionation occurs within the stomatal cavity and its magnitude depends on the time of the day, on the environmental conditions and on the status of the plant. A further complication is represented by the small sampling volume and by the proximity between xylem and phloem vessels. Therefore it is important to collect only the leaf tissues where fractionation determines the isotopic composition of the leaf bulk water (Welp et al., 2008; Cernusak et al., 2016). Similarly, isotopic fractionation affects the bulk soil water isotopic composition due to soil temperature, air relative humidity, soil texture and ventilation in the upper soil layers (Zhang et al., 2010; Zhao et al., 2014).

In order to maintain and preserve the isotopic information contained in these samples, particular attention should be paid to sampling, transfer, storage, and extraction of the aqueous content. This is to maintain the integrity and continuity of the isotopic composition that characterizes the samples. For example, after separating the leaf mesophyll from the larger veins, leaf samples need to be quickly folded, introduced in air tight vials and stored in fridge. The same applies to samples of soil.

In the laboratory the water content of the sample needs to be extracted and separated from the matrix to which it is bound. Different solutions have been developed to perform a water extraction from these type of samples, however in this study, we used the methodology showed in figure 3.7. The cryogenic vacuum extraction line (Ehleringer, Roden, and Dawson, 2000; West, J. Patrickson, and Ehleringer, 2006) has been used to extract the water content from oil palm leaves and soil samples. Each cryogenic water extraction line consists at least of two vials connected through a " $U$ " tube. One vial contains the sample to be extracted, and another one is empty and receives the water content from the first one after the cryogenic vacuum extraction.

The method consists in freezing with liquid nitrogen the vial with the bulk sample (this can be a leaf, a soil portion or any other material from which the water must be extracted). Once the entire content is frozen, a low vacuum $\left(10^{-4} \mathrm{mbar}\right)$ is applied, in the following order, to the sample, to the manifold and to the empty vial. Once the vials are "evacuated", that means that no ambient vapor is present in the whole line, the valve on the manifold side is closed, isolating the space of the sample and the empty vial. At this point a 


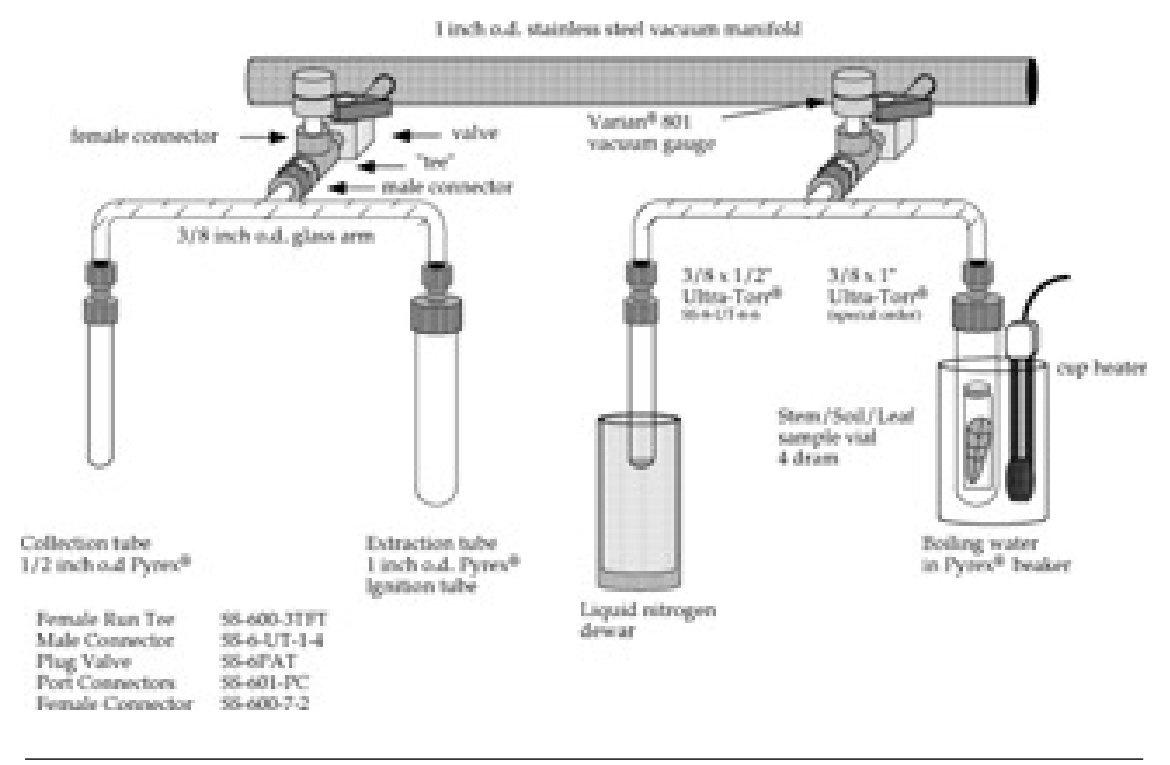

FIGURE 3.7: Illustration of the water cryogenic vacuum extraction line (West, J. Patrickson, and Ehleringer, 2006) used in this study.

closed system between the sample vials and the destination vial is establish. The water contents is then transferred to the empty vial by heating the sample vial and, at the same time, freezing the empty vial with liquid nitrogen in order to increase the temperature gradient between the sublimation and condensation end-points. Following the procedure correctly results in the complete transfer of the water content between the sample and the destination vial. 



\section{Chapter 4}

\section{Isotopic characterization of the precipitation regime in Central Sulawesi, Indonesia}

\subsection{Introduction}

The ratio between light and heavy isotopes (expressed as $\delta D$ and $\delta^{18} O$ in $\%$ against the VSMOW scale) of water in precipitation is well known as a powerful tracer of the history of the air masses moving through the atmosphere. It represents a useful tool for the investigation of the hydrological cycle from global (Aggarwal et al., 2012) to regional (Breitenbach et al., 2010) and local perspective (Wirmvem et al., 2017) as schematically represented in figure 1.1. Deuterium excess, moreover, is a measure of the relative proportion of deuterium and oxygen-18 in water vapor as well as in precipitation. Deuterium excess is defined as $d_{e x c}=\delta D-8 * \delta^{18} O$, and it mainly depends on the physical conditions prevailing at the moisture source areas during evaporation, often sea surface conditions (Dansgaard, 1964) Furthermore, physical conditions during raindrop formation, post-evaporation and remoistening (reintroduction of water vapor in clouds) contribute to the deuterium excess variability in the final precipitation (Froehlich, Gibson, and Aggarwal, 2002; Uemura et al., 2008; Benetti et al., 2014; Pfahl and Sodemann, 2013).

There are many factors that determine the final isotopic composition of a rainfall event occurring in a certain location. Air temperature (and sea surface temperature), relative humidity and wind speed affect the isotopic composition of the initial water vapor in the sea-air interface at the moisture source area above the oceans (Cole et al., 1999; Benetti et al., 2014; Bonne et al., 2014) whilst other factors (such as advection, entrainment, mixing to mention a few) affect the moisture isotopic ratio during the transport of air parcels in the troposphere (Aggarwal et al., 2016; Tharammal, Bala, and Noone, 2017; Gamache and Houze Jr, 1983). Moreover, in the boundary layer and in the lower layers of the atmosphere, where a strong interaction between air masses and land surface occurs, the moisture isotopic composition is further influenced by forced altitude uplift (Ambach et al., 1968; Gonfiantini et al., 2001), latitude (Yurtsever and Section, 1975; Araguas-Araguas and Froehlich, 
1998; Bowen and Wilkinson, 2002) and continentality (Rozanski, AraguasAraguas, and Gonfiantini, 1992). Finally, whereas the trajectories of the air masses are also constrained by large-scale climate phenomena, the precipitation isotopic ratio variability is also linked, in space and in time, to seasons (Belgaman et al., 2017) and other cyclic weather phenomena like El Niño Southern O (ENSO) (Qian, Robertson, and Moron, 2010), Madden-Julian Oscillation (Kurita et al., 2011; Berkelhammer et al., 2012), Monsoons (Lekshmy et al., 2014; Araguas-Araguas and Froehlich, 1998) and to occasional perturbations like typhoons (Lawrence, 2004) and storms (Celle-Jeanton et al., 2004). While at higher latitudes the precipitation isotopic composition is strongly correlated with the average surface air temperature (Johnsen et al., 1972; Ciais and Jouzel, 1994; Stenni et al., 2004) at lower latitudes it is largely controlled by the "amount effect" (Dansgaard, 1964; Kurita et al., 2009), an empirical relationship that relates the amount of rainfall to the increasing depletion (lighter rainfall) of its isotopic composition. This relationship is often used in paleoclimatological studies, such as leaf waxes retrieved in sediment cores (Contreras-Rosales et al., 2014; Niedermeyer et al., 2016), in stalagmites (Dykoski et al., 2005; Partin et al., 2007) and ice cores (Masson-Delmotte et al., 2003; Küttel et al., 2012), in that it reveals changes of the rainfall patterns in the past.

In 1961, the International Atomic and Energy Agency (IAEA) initiated the Global Network of Isotopes in Precipitation (GNIP) program in cooperation with the World Meteorological Organization (WMO) to monitor the isotopic composition of precipitation (and the tritium abundance) at monthly resolution (and even at rainfall event frequency) across the globe. This program includes data from over 1000 weather stations in more than 125 countries and it represents the most extensive collection of water isotopic measurements worldwide (IAEA/WMO, 2019). The data are freely available and have been used in a broad spectrum of research topics, from climatology and global circulation models calibration (Werner et al., 2011; Torri, Ma, and Kuang, 2017) to animal migration (Levin et al., 2006; Viljoen, Luckins, and Naletoski, 2016). Furthermore, the program provides guidelines and protocols concerning the methods for the correct handling of precipitation samples (IAEA/GNIP precipitation sampling guide V2.02 September 2014, (IAEA, 2014)). Although the GNIP program runs nowadays with the contribution of a large number of partners and it represents almost all the different climatic zones of the Earth, the dataset still suffers from large spatial gaps (Vuille et al., 2005; Yoshimura et al., 2008). North America, Europe, and Australia are densely covered by land and marine stations, while Africa, Asia (except for China) and South America are largely underrepresented (Rozanski, AraguasAraguas, and Gonfiantini, 1992; Terzer et al., 2013).

Among these regions, there is Indonesia, a country in the tropics characterized by a large geographical extension with the complex morphology of an archipelago. The Indonesian archipelago (also known as "The maritime continent") has an extension similar to the surface of the United States but 
it is composed by a mosaic of almost 17000 islands, some of them being the largest on Earth (e.g. Borneo, Sumatra and Papua New Guinea). Raised over the "Ring of Fire" (an area of the Pacific with a high volcanic concentration), Indonesia was entirely originated as the consequence of volcanic activity and therefore many of the highest mountains in the area are active volcanoes (e.g. Mt. Krakatoa, Mt. Merapi, Mt. Agung). A large number of mountains in the archipelago is higher than $2000 \mathrm{~m}$ a.s.l. with some of these being close to the coastline. This geomorphological complexity, together with the geographical position (across and along the Equator) of the archipelago and the high moisture supply provided by the Indo-Pacific Warm Pool determine a large variability in the pattern, amount and isotopic composition of rainfall across Indonesia (Suwarman et al., 2013; As-syakur et al., 2013). For example, using the datasets derived from 100 rain gauges displaced among the archipelago and a robust statistical method ("double correlation method") Aldrian and Dwi Susanto (2003) identified 3 main precipitation regimes. However, the identification of local rainfall regimes and characteristics are still affected by the scarcity of a widespread precipitation monitoring system and a detailed examination of the interactions between large-scale weather phenomena and local pressure gradients (Qian, Robertson, and Moron, 2010).

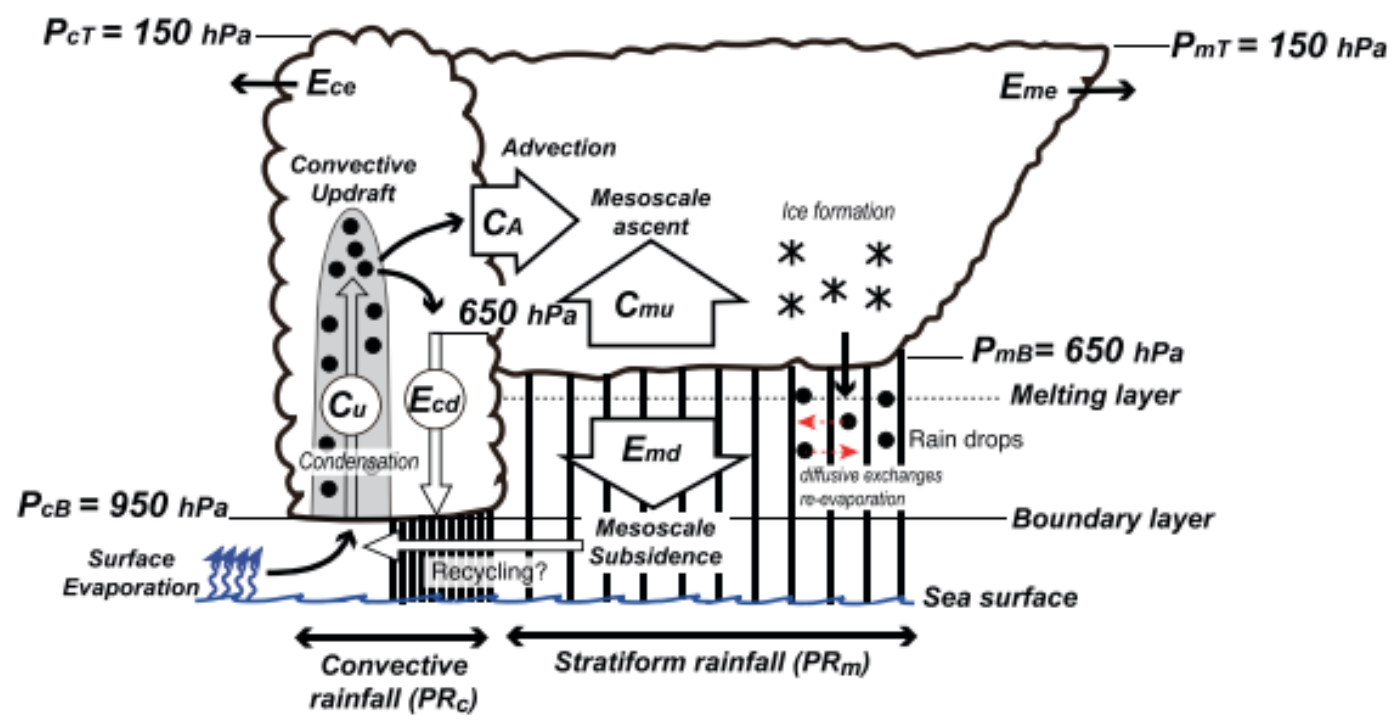

FIGURE 4.1: Schematic diagram of an idealized mesoscale system water budget (Kurita, 2013). The water budget parameters are referred to (Gamache and Houze Jr, 1983) with $C_{u}$ (Convective updraft), $E_{d c}$ (Evaporation in the convective downdraft), $E_{c e}$ (Evaporation in cumulonimbus environment), $C_{a}$ (Condensed water carried to the adjacent stratiform cloud), $C_{m u}$ (Condensed mesoscale ascent in stratiform cloud), $E_{m d}$ (Evaporated mesoscale downdraft), $E_{m e}$ (Evaporated mesoscale exit into the environment).

In tropical regions and mid-latitudes, precipitation is mainly produced 
from two different types of clouds, i.e. convective and stratiform. Together, these constitute the so-called mesoscale systems (Gamache and Houze Jr, 1983; Kurita, 2013; Tharammal, Bala, and Noone, 2017). Convective clouds are highly energetic, vertically developed and the moisture motion is dominated by the convective updraft of surface-generated water vapor. Therefore convection-produced rainfall is intense, rapid and isotopically enriched due to the limited exchange between falling raindrops and sub-cloud moisture. Stratiform clouds, on the other hand, are less energetic, they develop on average at higher altitudes and, most importantly, they receive an large amount of moisture from convective clouds $\left(C_{A}\right.$, figure 4.1$)$. In comparison, stratiform precipitation is less intense and therefore the isotopic exchange between droplets and atmospheric moisture is more pronounced. Rainfall reevaporation, moisture deposition and lower descending velocities contribute to the depletion of the isotopic composition of stratiform clouds precipitation (Kurita, 2013).

The microphysical processes characterizing convective and stratiform clouds are very different and hence the isotopic composition of rainfall and water vapor responds to this variability accordingly (Aggarwal et al., 2016; Konecky, Noone, and Cobb, 2019). A large number of studies involving observations (Lekshmy et al., 2014; Moerman et al., 2013), satellite data (Kurita, 2013) and atmospheric circulation models (Vuille 2003; Risi, 2008; Tindall, 2009) investigated the mechanisms and formulated hypothesis trying to explain the microphysical mechanisms that are involved in the process known as amount effect. This effect characterizes mainly tropical precipitation and it is determined by a progressive decrease of the precipitation isotopic composition as a result of the increase in precipitation intensity (Dansgaard, 1964).

The factors contributing to the amount effect can be summarized (Tharammal, Bala, and Noone, 2017) as (I) the isotopic composition decreases with increasing precipitation amount due to the increased condensation and rainout with heavy precipitation (Vuille et al., 2003), (II) the precipitation reevaporation and the enhanced recycling of this isotopically depleted vapor in unsaturated downdrafts during intense convection (Risi, Bony, and Vimeux, 2008), (III) the partial equilibration of raindrops below the cloud base which depends on the droplet size (Lee and Fung, 2008), (IV) The dependence of isotope ratios of precipitation on the converged vapor, with the increased moisture convergence during the convective events, then on the vapor from the local evaporation (Lee et al., 2007; Moore, Kuang, and Blossey, 2014), $(\mathrm{V})$ the increased rain amount and the reduced proportion of reevaporation of falling raindrops in the convective systems (Sutanto et al., 2015) and, (VI) the post-condensational processes in the unsaturated downdrafts (Lawrence, 2004; Risi, Bony, and Vimeux, 2008) through environmental subsidence and mixing during the organized convective events (Lekshmy et al., 2014; Kurita, 2013).

The dependence of the rainfall isotopic composition variability as a consequence of the increasing surface of stratiform clouds was recently found 


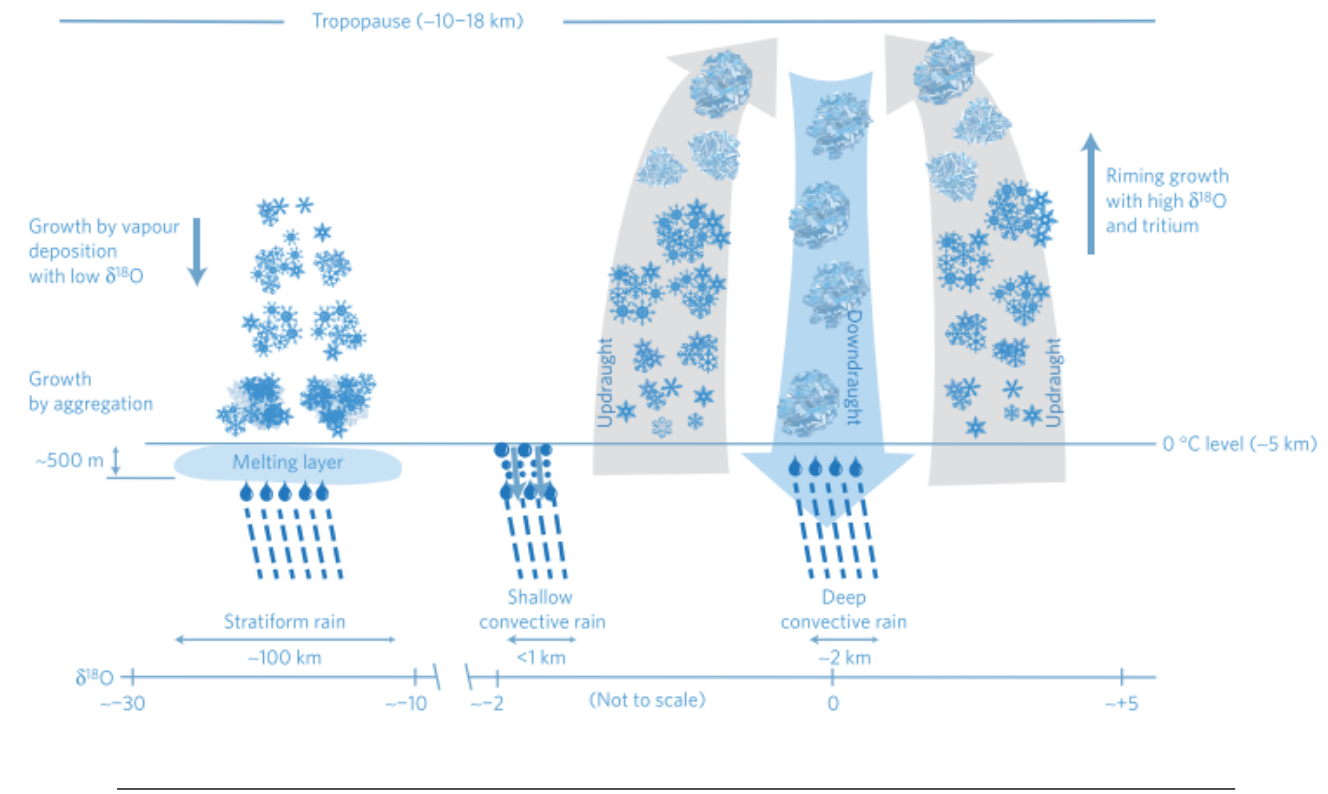

FIGURE 4.2: Schematic representation of differences in dynamical and microphysical processes in convective and stratiform precipitation resulting in isotopic variations (Aggarwal et al., 2016).

comparing observations and satellite retrieved data for a set of stations in the tropical area (Munksgaard et al., 2019) . Due to the lower condensation temperatures and the conditions for a co-existence of liquid and solid water particles, a correlation between the increasing stratiform cloud surface average and depleted rainfall isotopic composition was found (figure 4.2, Aggarwal et al. (2016)).

As mentioned before in the introduction, Indonesia is still characterized by a poor detailed network of sampling station that monitor the evolution of the characteristics of rainfall isotopic composition. Many important questions associated to the interaction between the large-scale weather phenomena and local constrains are still yet unresolved. Therefore, motivated by these questions, here we present the results of our research activity conducted in Central Sulawesi along a North-South elevation transect in the Bay of Palu region. We investigated the effect of elevation, the seasonality effect and whether a clear amount effect was statistically significant at the three sites showing different precipitation characteristics (marine, land and mountain). To support our results we compared our data both against a highfrequency dataset from Mulu in Malaysia, not far from our region of interest and against the GNIP dataset (at monthly resolution). 


\subsection{Methods}

\subsubsection{Site description}

The study was carried out in Central Sulawesi, Indonesia along a NorthSouth elevation transect in the Bay of Palu. (figure 4.3).

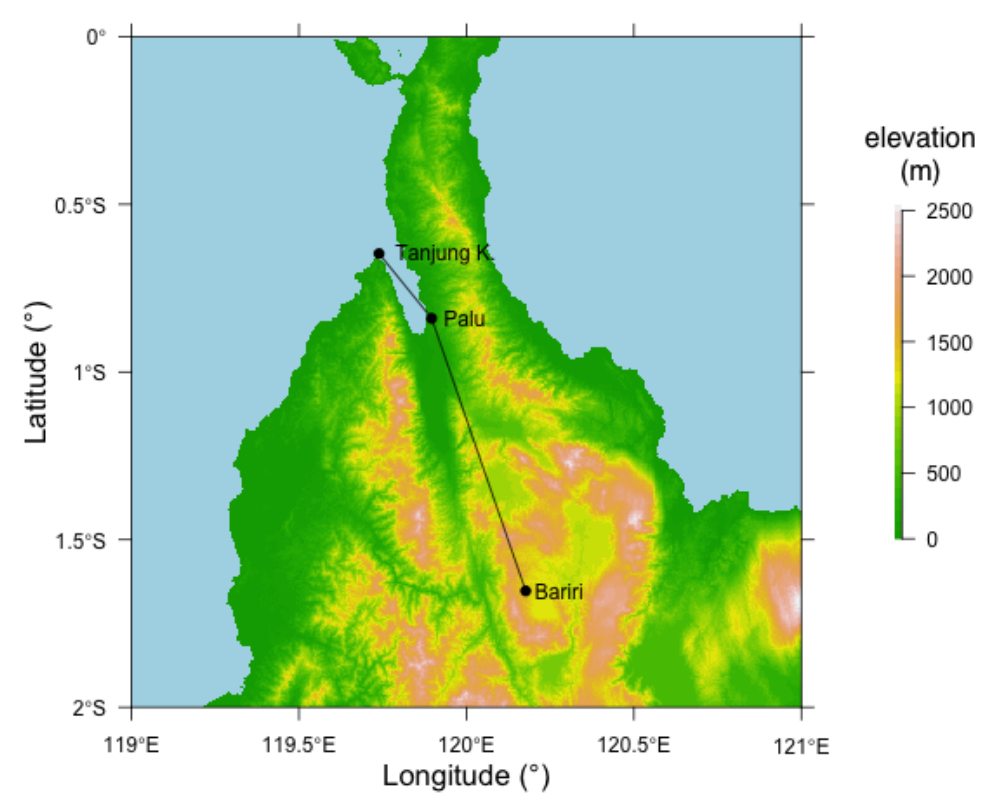

FIGURE 4.3: Topographical map of Central Sulawesi with data from Hole-filled SRTM digital elevation $250 \mathrm{~m}$ resolution (Jarvis et al., 2008). Black solid line indicates the transect between the selected measuring stations.

We selected 3 sampling stations:

- Tanjung Karang $\left(\right.$ Latitude $=0.647^{\circ} \mathrm{S}$, Longitude $=119.739^{\circ} \mathrm{E}$, elevation $=10 \mathrm{~m}$ a.s.l.), on the northernmost tip of the bay of Palu, classified as "marine" station due to the influence of the air masses coming from the Makassar Strait.

- Palu (Latitude $=0.84^{\circ} \mathrm{S}$, Longitude $=119.896^{\circ} \mathrm{E}$, elevation $=70 \mathrm{~m}$ a.s.1.) at the campus of the Tadulako University, near the city and classified as "land/marine" station due to its proximity to the coast but more inland in respect of the Tanjung Karang station.

- Bariri $\left(\right.$ Latitude $=1.653^{\circ} \mathrm{S}$, Longitude $=120.177^{\circ} \mathrm{E}$, elevation $=1230 \mathrm{~m}$ a.s.l.), was located on the border of the primary tropical rainforest in the Lore Lindu National Park, classified as "montane". 
Additionally, in order to compare our observations with those of a longlasting sampling station in the area, we retrieved the precipitation isotopic composition data from the Mulu station (Latitude $=4.05^{\circ} \mathrm{N}$, Longitude $=$ $114.81^{\circ} \mathrm{E}$, elevation $=32 \mathrm{~m}$ a.s.l.) located in Sarawak, Malaysia.

According to the Köppen-Geiger climate classification (Peel, Finlayson, and McMahon, 2007) Tanjung Karang and Palu both belong to the "Tropical Rainforest" (Af) climate zone (Af), whilst Bariri, located on a high plateau in the centre of the island shows a better agreement to the "cold, no dry season and hot summer climate" category (Dfa). In terms of precipitation pattern Central Sulawesi is located at the border between two distinct pluviometric regions (A and C, Aldrian and Dwi Susanto (2003)) and thus shows a different respond to large-scale climate phenomena like ENSO and monsoon. Region $\mathrm{A}$ is characterized by 1 peak and 1 trough due to the influence of the wet (winter) and dry (summer) monsoon respectively and covers the area of south Indonesia encompassing south Sulawesi and Kalimantan, whilst Region $\mathrm{C}$, features a 1 peak and 1 trough pattern, but their occurrence is lagged as compared to region A and covers the area of Maluku and north Sulawesi. The Indonesia Through-flow, a stream that carries waters from the Pacific to the Indian Ocean through the Makassar Strait, influences rainfall in region C which tends to show a higher sensitivity, in respect of region A, to sea surface temperature fluctuations in the Indo-Pacific Warm Pool.

\subsubsection{Isotopic measurements}

From May 2014 to August 2015 we collected precipitation samples at event frequency using a set of custom-made pluviometers. For each sample we measured the rainfall amount and later analyzed the isotopic composition $\left(\delta^{18} O\right.$ and $\left.\delta D\right)$, reporting the results in \%o using the "delta" scale after calibration against the international standards.

Following the guidelines provided by the IAEA (IAEA/GNIP precipitation sampling guide V2.02 September 2014), rain samples were collected using custom made pluviometers (option 2 and 3). At each location, we placed an event pluviometer using a 2.5 liters polyethylene bottle (figure 3.5) equipped with a plastic funnel (diameter $19.5 \mathrm{~cm}$, sampling surface $\approx$ $300 \mathrm{~cm} 2$ ) equipped with a table tennis ball and a "tube-dip-in-water" to minimize evaporation and sample loss. Rain collectors were placed in the shade and carefully cleaned after each rain event to prevent cross-sample contamination. Subsamples were collected in amber glass vials $(2.5 \mathrm{~mL})$ carefully minimizing the headspace after the volumetric measure. Where possible (Tanjung Karang and Palu), vials were stored in the fridge $\left(-4^{\circ} \mathrm{C}\right)$. In Bariri, due to a lack of a constant power supply, vials were stored underground. Caps of all vials were double-sealed through a septum and Parafilm (R. After storage, samples were air-transported to Europe and analyzed at the IAEA Isotope Hydrology laboratory and the University of Göttingen through Wavelength Scanned Cavity Ring-Down Spectroscopy (WS-CRDS 


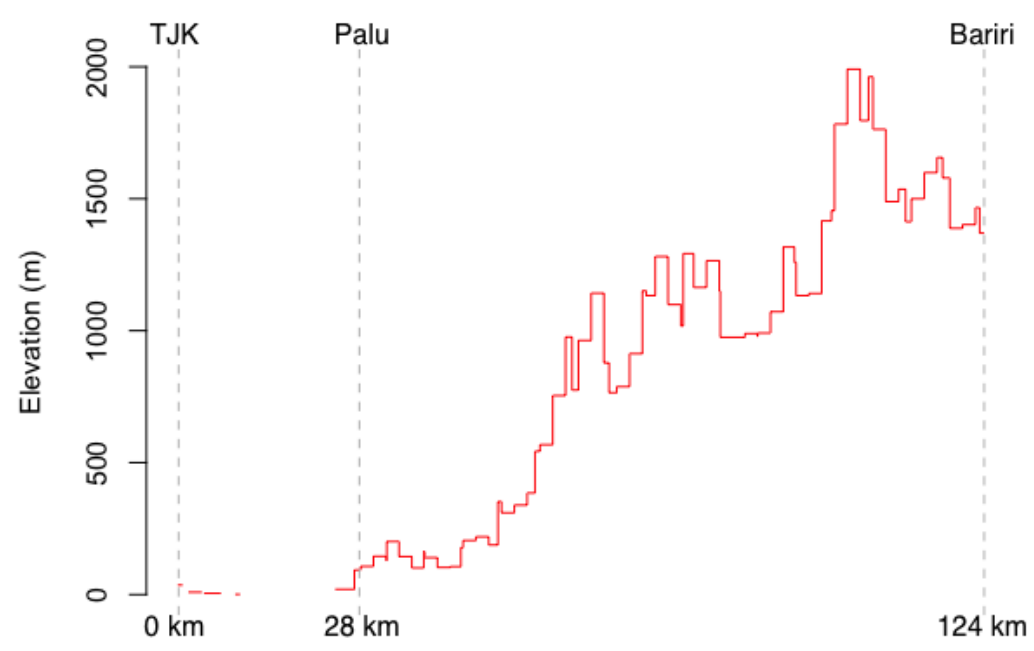

Distance along transect $(\mathrm{Km})$

FIGURE 4.4: Elevation profile in $m$ along the North-South transect. The vertical profile was extracted from the ETOPO $1^{\prime}$ Global Relief Model (Amante and Eakins, 2009).

Picarro R, mod. L 2120-i).

Measurements accuracy and precision obtained from analysis of the calibration standards was $0.37 \pm 1.14 \%$ for $\delta D$ and $0.18 \pm 0.15 \%$ for $\delta^{18} O$ at IAEA and $1.4 \pm 3.72 \%$ for $\delta D$ and $0.12 \pm 0.8 \%$ for $\delta^{18} O$ at University of Göttingen.

\subsubsection{Meteorological data}

For Palu and Tanjung Karang direct meteorological measurements were not available and we thus, used data from TerraClimate database that provides monthly historical data for the whole globe with a fine spatial resolution of $\approx 4 \mathrm{~km}\left(1 / 24^{\circ}\right)$ covering the period from 1958-2018 (Abatzoglou et al., 2018). In order to increase the consistency between datasets we retrieved and used the TerraClimate data for the Bariri site.

\subsection{Results and discussion}

\subsubsection{Local meteorology}

Air temperature and relative humidity (Table 4.1) were characterized by a common patter at all three sites with warmer and drier conditions during the boreal spring and summer due to the effect of the southwest monsoon. Cooler and wetter conditions predominated instead during the boreal autumn and winter due to the effect of the northeast monsoon (figure 4.5 left). 
In general the air temperature at Palu and Tanjung Karang was on average $\approx$ $6^{\circ}$ higher than in Bariri reflecting the elevation difference.
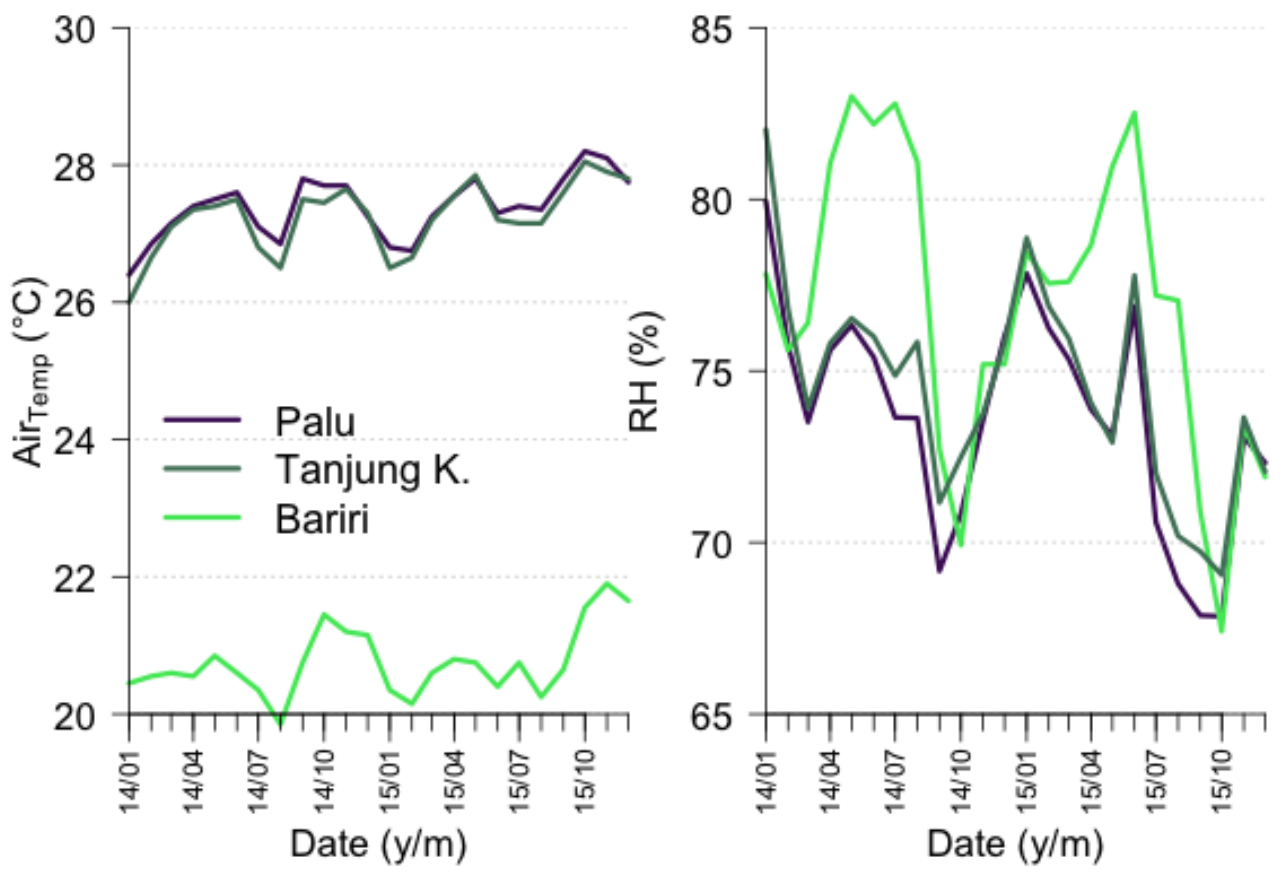

FIGURE 4.5: Left: Monthly average air temperature $\left({ }^{\circ} \mathrm{C}\right)$; right: Monthly average air relative humidity (\%) in Palu (purple), Tanjung Karang (dark green) and Bariri (light green). Data from TerraClimate (Abatzoglou et al., 2018)

Furthermore the position of Bariri, at the edge of the montane rainforest above $1000 \mathrm{~m}$ a.s.l., resulted in generally higher air relative humidity during the wetter months. During drier months, instead, the relative humidity was similar in all 3 sites (figure 4.5 right).

TABLE 4.1: Average (2014-15) values with $\pm 1 \sigma$

\begin{tabular}{lll}
\hline Station & Air temperature $\left({ }^{\circ} \mathrm{C}\right)$ & Air relative humidity $(\%)$ \\
\hline Palu & $27.4 \pm 0.44$ & $73.63 \pm 3.17$ \\
Bariri & $20.7 \pm 0.5$ & $76.94 \pm 4.30$ \\
Tanj & $27.4 \pm 0.5$ & $74.51 \pm 3.05$ \\
\hline
\end{tabular}

\subsubsection{Precipitation regime}

In total we collected 249 rainfall samples, across Palu $(\mathrm{N}=99$, total volume $=879 \mathrm{~mm})$, Bariri $(\mathrm{N}=73$, total volume $=1820 \mathrm{~mm})$ and Tanjung Karang $(\mathrm{N}$ $=77$, total volume $=1833 \mathrm{~mm}$ ). In Palu the fieldwork was slightly longer because it was the place where the first rain collector was installed, whilst in the other locations the setup, training and site accessibility resulted in a shorter 
campaign.

During the entire sampling period Palu received almost $50 \%$ less precipitation compared to Tanjung Karang and Bariri. This difference could be explained considering the topography of the Bay of Palu (figure 4.3), where a high mountain range (elevations up to $2000 \mathrm{~m}$ a.s.l.) separates the Makassar Strait from the internal shallow waters. Westerly winds, carrying moisture from the Makassar Strait and from long-range transport, encounter on their route the mountain range. This forces air masses uplift triggering rainfall on the windward side, and Föhn winds on the leeward side resulting in more abundant precipitation in the yearly rainfall amount in the south-west sector of Central Sulawesi (figure 4.6).

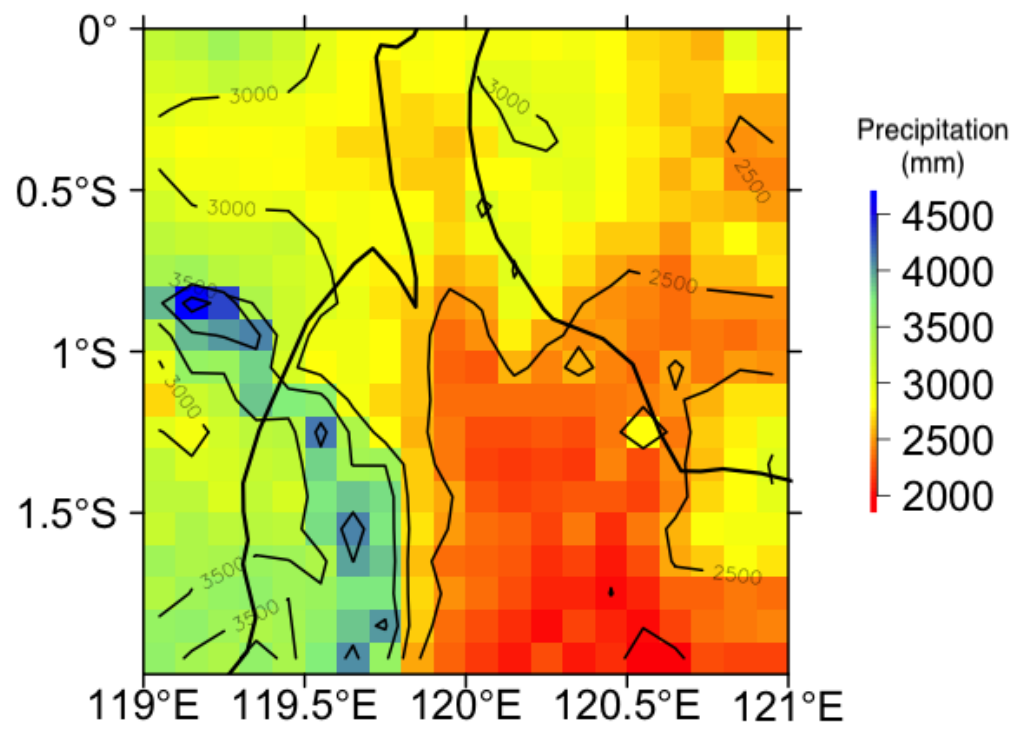

FIGURE 4.6: Contour plot of the yearly (2014-15) rainfall amount $(\mathrm{mm})$ in the region of interest. Data derived from daily GPM data (Huffman et al., 2019).

Moreover in the same study period one of the strongest El Niño Southern Oscillation event (ENSO) of the last decades occurred (Santoso, Mcphaden, and Cai, 2017). ENSO is known to affect the regional and local rainfall variability (Qian, Robertson, and Moron, 2010; Wu et al., 2015) with negative rainfall anomalies in Indonesia (Permana, Thompson, and Setyadi, 2016) resulting in severe consequences for agriculture (Meijide et al., 2018) and the environment (Stiegler et al., 2019). According to the Multivariate ENSO Index (MEI) ranking (Wolter and Timlin, 1998), 2014-2016 was characterized by an increasing ENSO activity, as revealed by the Nino 3.4 index (Trenberth and Stepaniak, 2001). The Nino 3.4 index reached its maximum at the end of 
2015. All our sites showed a clear decrease in precipitation in the second half of 2015 suggesting a similar influence of ENSO on the precipitation as seen in other station in the region during the previous ENSO strong event.

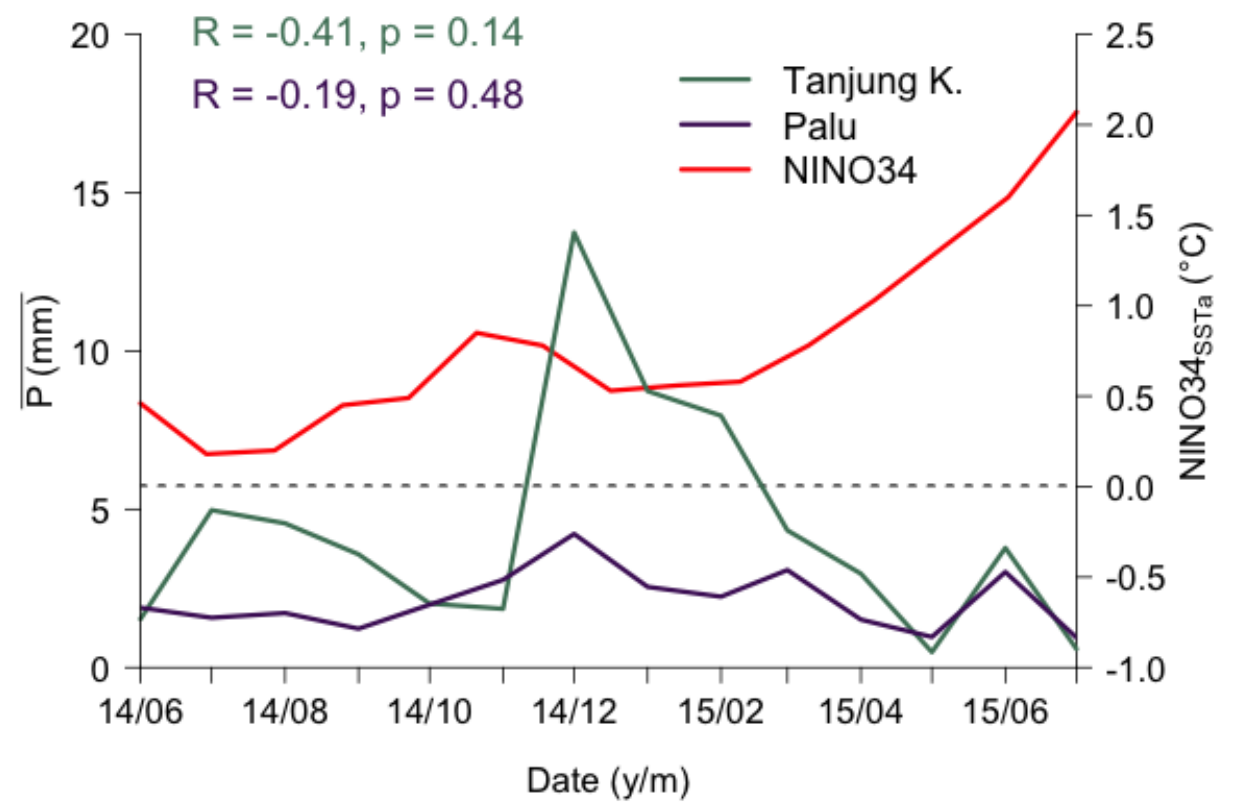

FIGURE 4.7: Monthly average precipitation amount in Palu (purple) and Tanjung Karang (dark green) and Nino 34 sea surface temperature anomaly index $\left({ }^{\circ} \mathrm{C}\right)$. Upper left: Person's product correlation and significance value of precipitation at Palu and Tanjung Karang with the Nino 3.4 index

In Mulu (Sarawak, Malaysia) measurements of the isotopic composition of precipitation reported a similar anti-correlation between the amount of rainfall and the Southern Oscillation Index (SOI), Nino3 and Nino 4 indexes (Moerman et al., 2013). Moreover a comparison between our data and the dataset provided from the GNIP network (Bangkok and Kinabalu here reported) revealed a similar trend consistent with the climatological occurrences (figure 4.8) among all stations in the area. The anti-correlation $(R=$ $-0.41, p=0.14$ ) between the rainfall amount collected in Tanjung Karang and the Nino 3.4 index (sea surface anomaly in the central equatorial Pacific), suggests an influence of ENSO also on the Central Sulawesi precipitation regime. We observed a similar but weaker correlation for Palu $(R=-0.19$, $\mathrm{p}$-value $=$ 0.48 ) that might be related to the attenuation effect exerted by the topography on the local circulation (figure 4.7).

The monthly cumulative precipitation amount observed in Tanjung Karang was fairly similar to the trend reported for Kinabalu site, a site in Malaysia that belongs to the GNIP network and relative close to Mulu (figure 4.8-a). Whilst in Indonesia the winter northeast monsoon, characterized by the stationary high-pressure system located in central Asia carries moisture and heavy rain due to the north blowing winds, in Bangkok the same is 


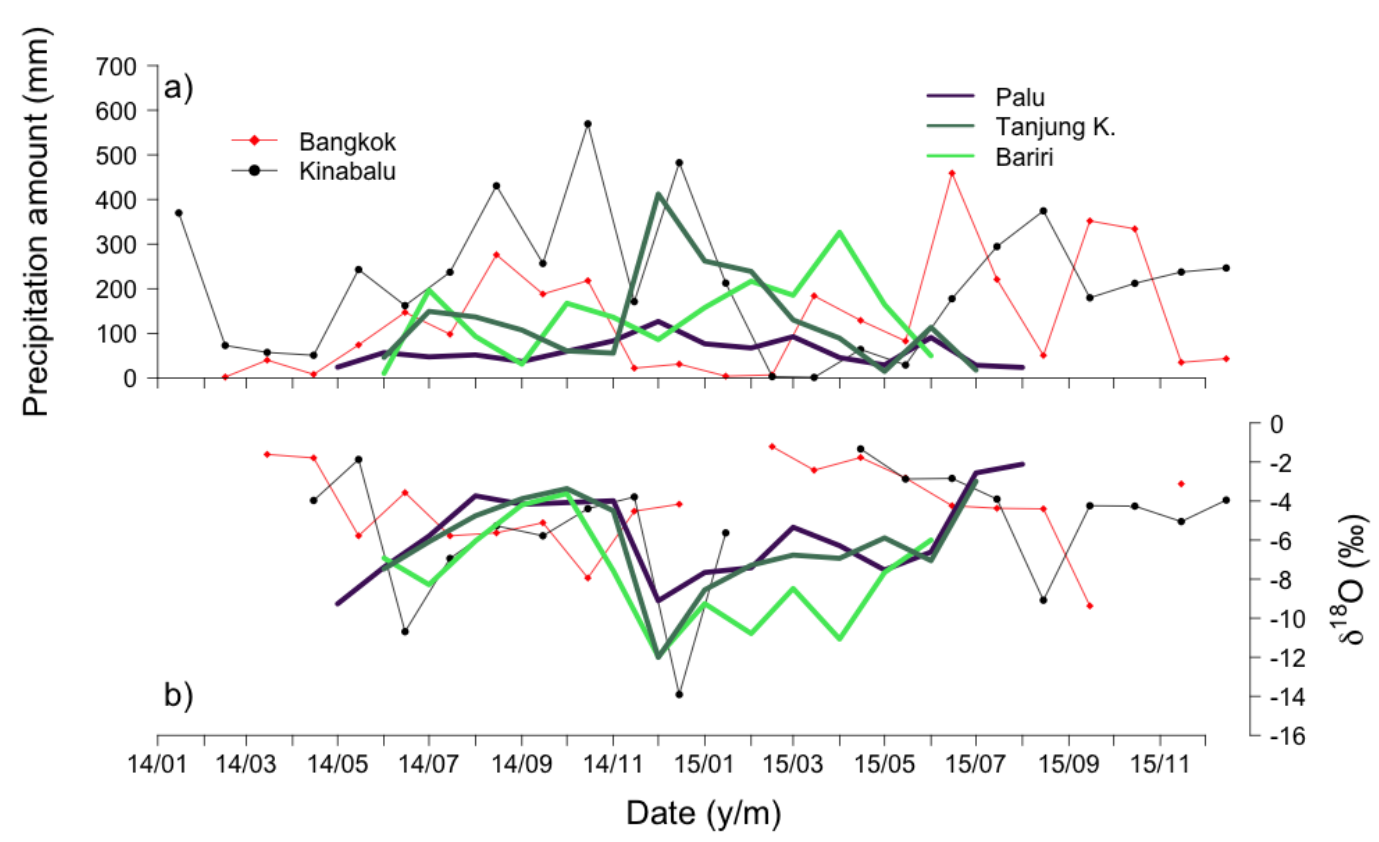

FIGURE 4.8: a) Monthly cumulative precipitation amount (mm) recorded in the GNIP stations in South-East Asia and compared to the amount recorded at our sampling sites. b) Average monthly $\left(\delta^{18} O\right)$ of the same stations.. Data from the GNIP station available from (https://nucleus.iaea.org/wiser/)

responsible for reduced rainfall activity and dry conditions.

A singular peak characterizes the pluviometric region " $\mathrm{A}$ " rainfall amount during the wet northwest (NW) monsoon (DJF) that define the wet season and a trough during the dry boreal summer (JJA) influenced by the SE monsoon (Aldrian and Dwi Susanto, 2003). In Bariri, the station at the edge of the rainforest, this "single peak" pattern is not as evident as in Palu and in Tanjung Karang. In these coastal sampling stations the higher precipitation intensity in April is distinguishable from the rainfall episodes distributed during the whole year (figure 4.9). This precipitation intensity pattern might be related to the position of Bariri that, according to the classification of Aldrian and Dwi Susanto (2003), is identified at the boundary between the pluviometric region $\mathrm{A}$ and region $\mathrm{C}$. This behavior in tropical area occurs when Intertropical Convergence Zone (ITCZ) fluctuation triggers the convective activity (Cobb et al., 2007). Thus, water vapor recycling in the convective updraft (figure 4.1) contributes to the depletion of the co-existing liquid phase, which undergoes to evaporation during rainfall. Moreover, other processes are competing when convective cells loose energy and turn into stratiform clouds, like advection, moisture mixing and changes in the air masses trajectories and origin (Breitenbach et al., 2010; Gao et al., 2011). 

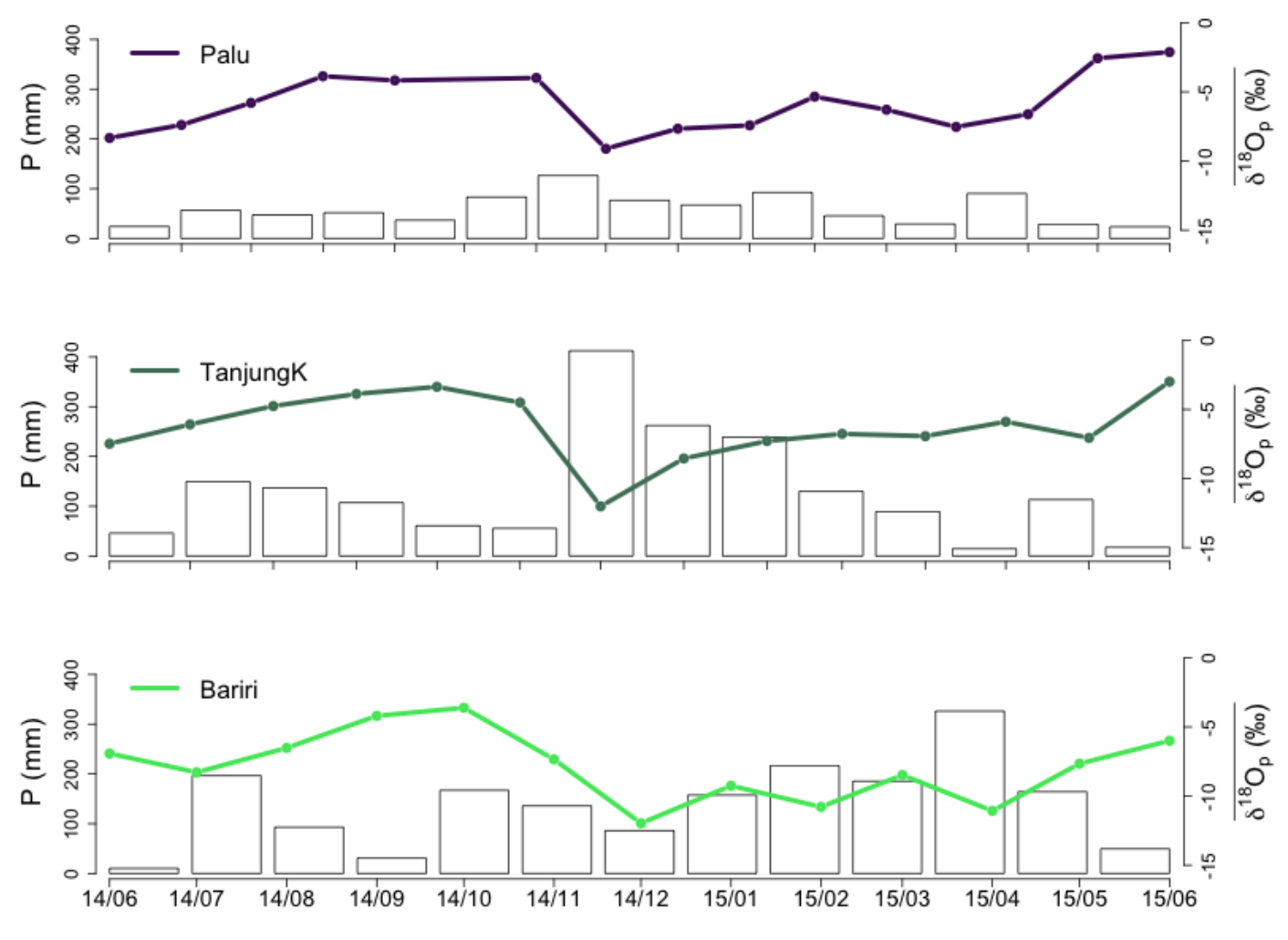

FIGURE 4.9: Monthly cumulative precipitation amount in $\mathrm{mm}$ (bars) and monthly average precipitation $\delta^{18} O$ (lines) for each station. Palu (purple), Tanjung Karang (dark green), Bariri (light green).

\subsubsection{Rainfall isotopic composition $\delta^{18} \mathrm{O}$}

From Tanjung Karang at the northern tip of the bay of Palu to the Bariri site in the mountains the precipitation isotopic composition was progressively depleted (Table 4.2) in heavy isotopes, following a Rayleigh distillation process. Factors contributing to the progressive decrease in the isotopic composition of precipitation (figure 4.10) were most likely related to the effect of the increasing distance from the coast (continentality) and progressive moisture condensation and rainout and to the increasing elevation (figure 4.11).

TABLE 4.2: Precipitation event isotopic composition $\delta^{18} O$ median and inter-quartile range

\begin{tabular}{lllll}
\hline & Tanjung Karang & Palu & Bariri & Mulu $^{*}$ \\
\hline $25^{t h}$ percentile $\% 0$ & -8.08 & -8.45 & -10.18 & -8.51 \\
median $\% 0$ & -5.60 & -5.93 & -7.98 & -5.92 \\
$75^{t h}$ percentile $\% 0$ & -4.05 & -3.79 & -6.05 & -3.60 \\
\hline
\end{tabular}

* used for comparison later in the results. 
Elevation effect depending on the forced air masses uplift due to the topographical constrains was quantified with the following least-square regression between $\delta^{18} O$ and elevation in $\mathrm{km}$ :

$$
\delta^{18} O=-(1.61 \pm 0.35) z-(6.17 \pm 0.24)
$$

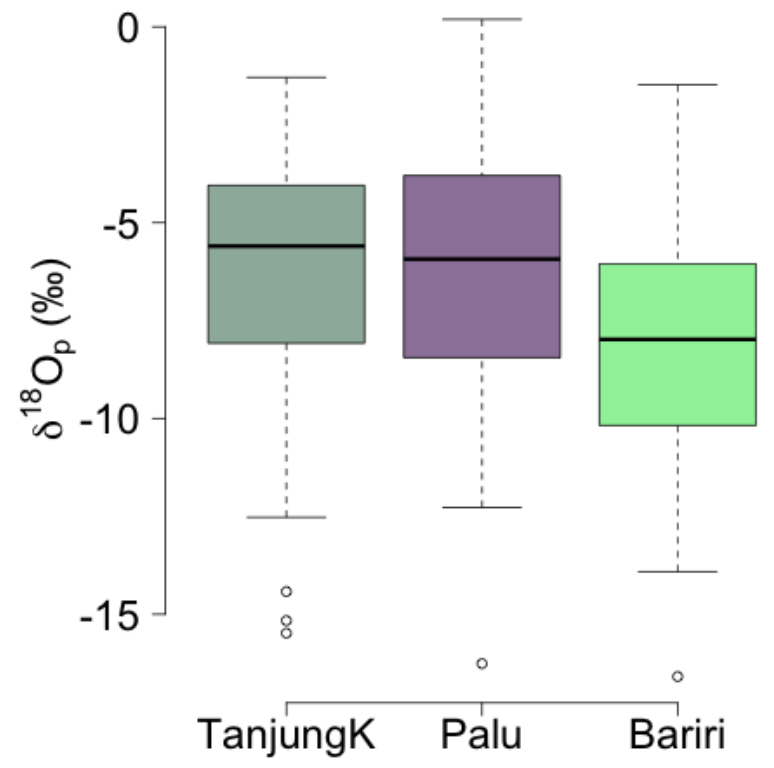

FIGURE 4.10: Boxplot of the precipitation oxygen isotopic composition $\left(\delta^{18} O\right)$ at the 3 sampling sites. Whiskers represent minimum and maximum values, solid black bar the median value and boxes the $25 \%-75 \%$ inter-quantile range.

Similar isotopic lapse rates were found at Mount Cameroon (-1.5 to $2.4 \% * \mathrm{~km}^{-1}$ in Gonfiantini et al. (2001)), in Puerto Rico $\left(-1.2 \%\right.$ \% $\mathrm{km}^{-1}$ in Scholl and Murphy (2014)), in Ecuador $\left(-2.2 \% 0 * \mathrm{~km}^{-1}\right.$ in Windhorst et al. (2013)) and in Papua New Guinea $\left(-2.4 \% 0 * \mathrm{~km}^{-1}\right.$, Permana, Thompson, and Setyadi (2016)). The precipitation isotopic composition showed a similar trend among the 3 sampling sites with minimum values recorded during the winter monsoon (nov-jan) "wet" season, concurrently with the most intense precipitations (figure 4.9). Maximum values were instead detected during the end of the dry summer monsoon season. This behavior, quite usual in tropical precipitation (figure 4.8), finds its explanation in the empirical "amount effect" relationship (Dansgaard, 1964).

Outgoing long-wave radiation (OLR) measured from satellites is an indicator of convective activity (Liebmann and Smith, 1996). Convective clouds are generally colder than stratiform clouds. Thus OLR is commonly used as proxy for convection where smaller outgoing radiation values $\left(\mathrm{W} \mathrm{m}^{-2}\right)$ correspond to higher convective activity. Results from Tanjung Karang indicate 


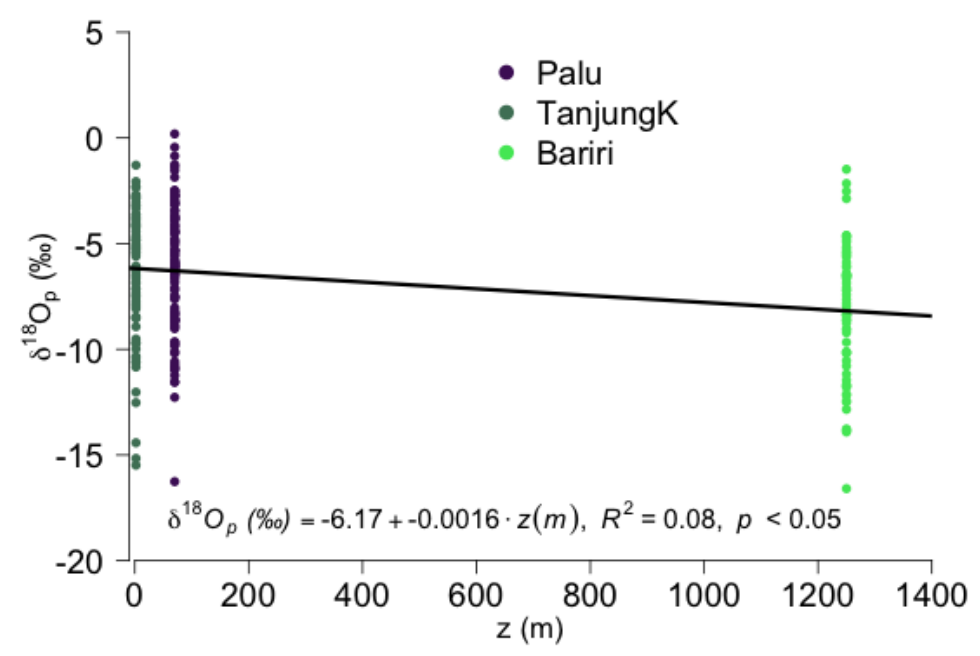

FIGURE 4.11: Precipitation isotopic composition dependency on the elevation (in $\mathrm{m}$ ) along the transect and for all samples.

a significant correlation ( $R=0.48, p<0.01$ for 10-days running average, figure 4.12) between precipitation isotopic composition at this site with the daily OLR values for the station grid point. A similar relationship was also found for Palu ( $R=0.49, p<0.001$, not shown) and Bariri $(R=0.39, p<0.01$, not shown). The lower correlation coefficient in Bariri might be due to the above discussed elevation effect. This implies that despite local effects depending on the topography and on the elevation, convection characterizes not only the type of precipitation falling in this region but also it controls its isotopic composition.

\subsubsection{Rainfall deuterium excess $\left(d_{e x c}\right)$}

Average $d_{e x c}$ in Tanjung Karang and in Bariri was higher than average $d_{e x c}$ in Palu (figure 4.13). Considering that Palu was the driest of our sites with a cumulative precipitation $<50 \%$ compared to the other sites and with a low relative humidity, this low $d_{e x c}$ value is likely related to secondary effects on raindrops falling through a dry air layer. Under these conditions, lighter molecules (HDO) with lower bounding energies evaporate from the liquid phase preferentially, decreasing the deuterium excess of the condensate (raindrops), and contemporary feeding the lower atmospheric layer with a higher $d_{e x c}$ water vapor (Moerman et al., 2013; Guan et al., 2013). This process can be depicted by looking at the linear regression between $\delta^{18} O$ and $d_{\text {exc }}$ in precipitation (figure 4.14). As $d_{e x c}$ is principally sensitive to the ambient relative humidity (Kurita, 2013; Pfahl and Sodemann, 2013) and secondarily to temperature, a change in the slope of $d_{e x c}$ vs. $\delta^{18} O$ indicates an effect of postcondensation evaporation and moisture exchange with ambient air in the subcloud layer. In Palu the $d_{e x c}$ vs. $\delta^{18} O$ ordinary least-square regression is characterized by a higher slope $\left(-0.49 \pm 0.11 \%, R_{P a l u}^{2}=0.17, \mathrm{p}<0.05\right)$ than 


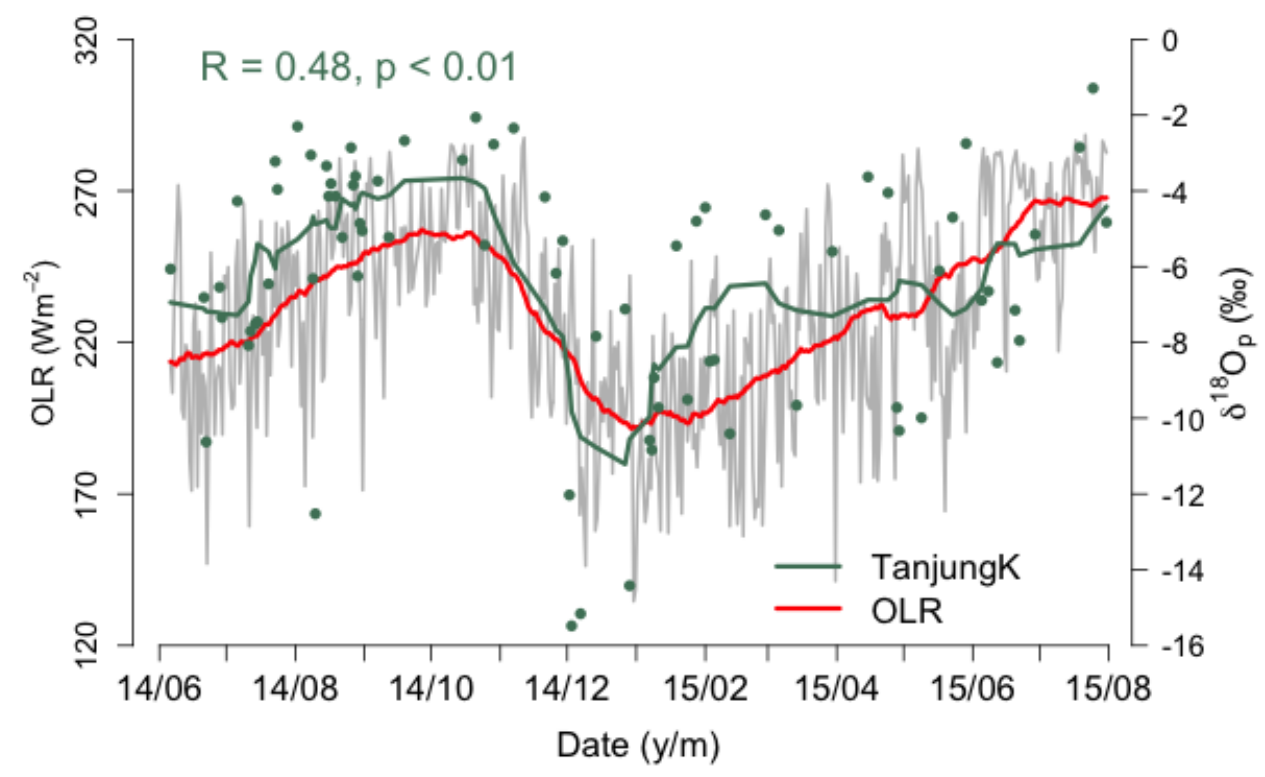

FIGURE 4.12: NOAA daily interpolated Outgoing Longwave Radiation (grey) and 2 months running average (red) for the area of interest (Liebmann and Smith, 1996). Tanjung Karang (dark green points) event precipitation isotopic composition $\left(\delta^{18} \mathrm{O}\right)$ and 10 days running mean with Pearson correlation product between OLR and isotopic composition reported.

in Tanjung Karang $\left(-0.11 \pm 0.09 \%, R_{\text {TanjungKarang }}^{2}=0.02, \mathrm{p}=0.27\right)$ and Bariri $\left(-0.20 \pm 0.11 \%\right.$, $\left.R_{\text {Bariri }}^{2}=0.04, \mathrm{p}=0.07\right)$ probably in virtue of the role of ambient humidity and the prevalent drier environment condition in determining the precipitation isotopic composition of Palu.

In our study, due to the relatively small geographical separation between our 3 stations we argue that the effect determining the $d_{e x c}$ variability in our precipitation samples most likely depends not from the differences in the moistures sources, but rather it depends mainly on the post-condensation process occurring to the precipitation falling through the sub-cloud layer.

\subsubsection{Amount effect and its drivers}

The "amount effect" is the inverse relationship between the amount and the isotopic composition of precipitation (Dansgaard, 1964) and is one of the main sources of variability in tropical precipitation $\delta^{18} O, \delta D$ and $d_{e x c}$. To better quantify the variability of the local amount effect among the monitored stations we compared our results with a dataset from the station of Mulu, in Malaysia, where samples were collected almost daily and for a longer period of time ( 5 years) thus providing a more systematic and consistent approach for the identification of the controlling factors of the amount effect (Cobb et al., 2007; Moerman et al., 2013; Belgaman et al., 2016; Munksgaard et al., 


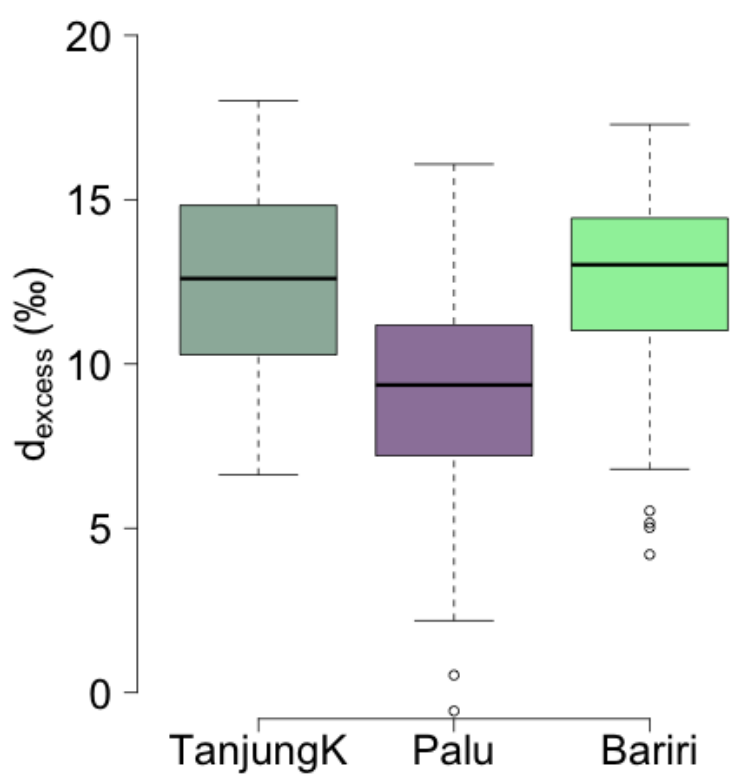

FIGURE 4.13: Boxplot of the precipitation deuterium excess composition $\left(d_{e x c}\right)$ at the 3 sampling sites. Whiskers represent minimum and maximum values, solid black bar the median value and boxes the $25 \%-75 \%$ inter-quantile range.

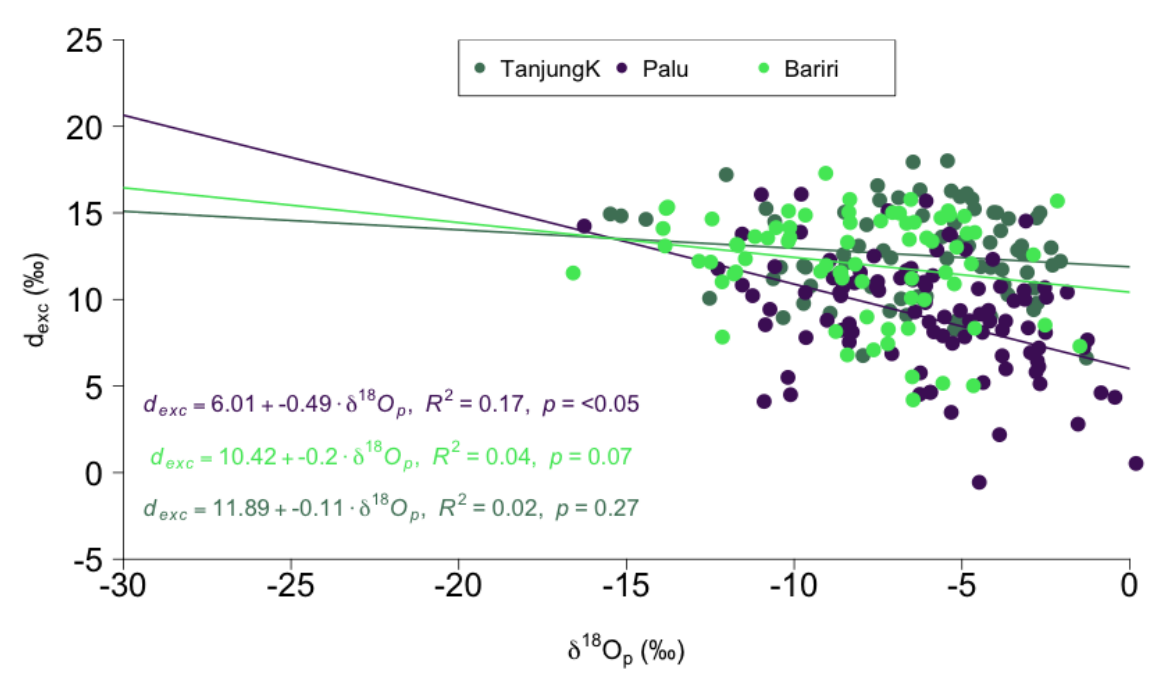

FIGURE 4.14: OLS regression between precipitation isotopic composition $\delta^{18} O_{p}$ and deuterium excess $d_{e x c}$.

2019). The precipitation isotopic composition fluctuation in our sites seems to mimic the observations of Mulu. Furthermore the $\delta^{18} O$ median at Mulu for the interval of our measurements is $-5.92 \%$ and also the inter-quantile range $(-8.51 \%$; $-3.61 \%$ ) were very close to the values recorded in Palu and 
Tanjung Karang suggesting a strong influence of the oceanic moisture to the rainfall isotopic composition in Palu and Tanjung Karang (Table 4.2).

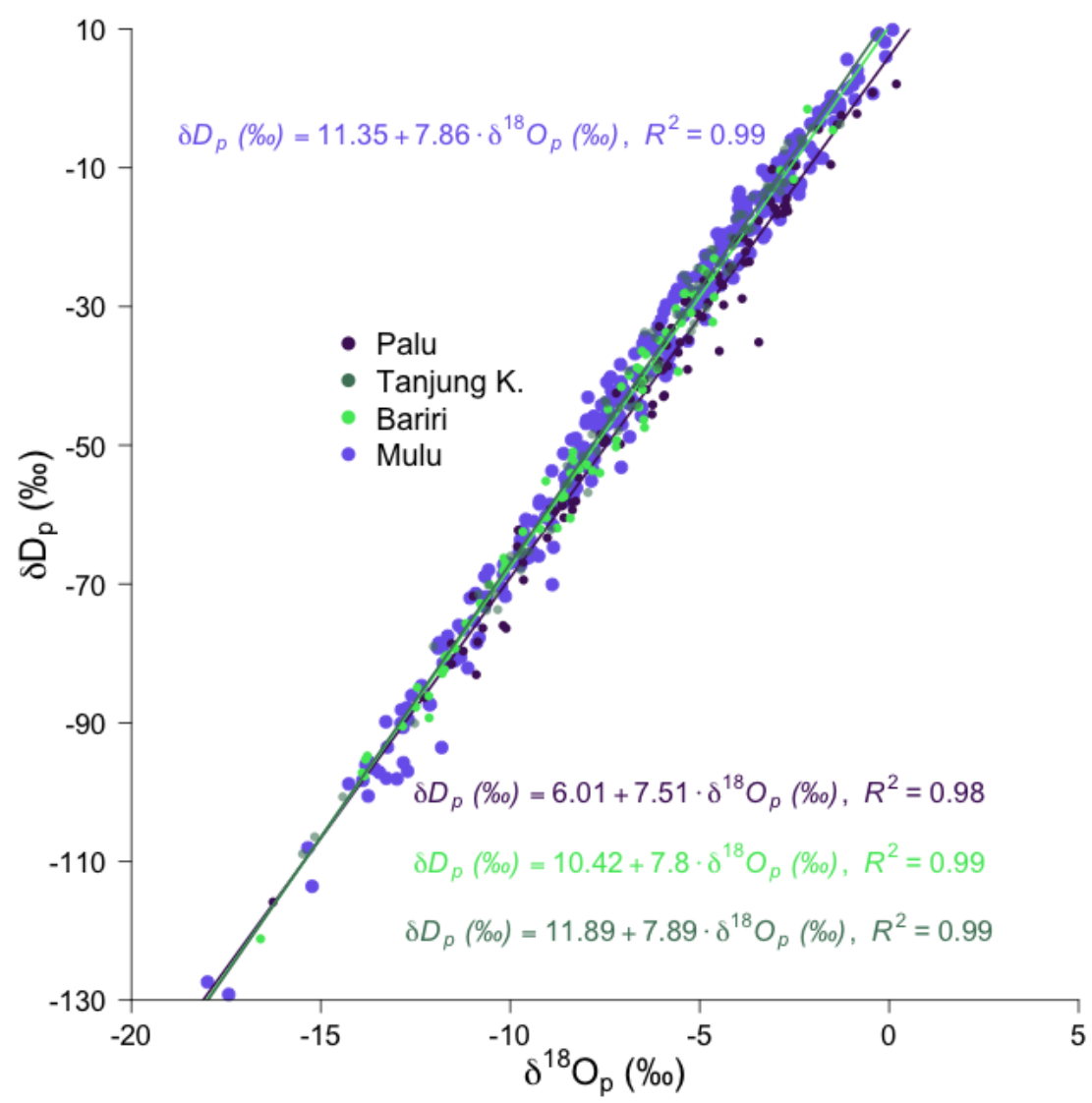

FIGURE 4.15: Local meteoric water lines for the stations along the Central Sulawesi transect with the addition of the Mulu station in Malaysia (light purple).

The similarity of the precipitation stable isotopic composition between the stations in the area is also shown by the sites local meteoric water line (LMWL, figure 4.15) derived from the regression between the $\delta D$ and $\delta^{18} O$ (Craig, 1961). Values of LMWLs slope and intercept depend from the prevailing temperature and humidity conditions during moisture transport, descent through the sub-cloud layer and air masses mixing, therefore suggesting similar conditions during rainfall formation and transport. The only significantly difference, depending on the average $d_{e x c}$ as discussed before, was the value of the LMWL intercept for Palu, with a value of $6 \%$ confirming the post-condensation effect determined by the persistent drier conditions. Having successfully benchmarked the results between stations, we found the following regression coefficients for the daily amount effect:

$$
\delta^{18} O_{\text {Palu }}=-(0.11 \pm 0.02) * P-(5.11 \pm 0.36), R^{2}=0.18, p<0.001
$$




$$
\begin{gathered}
\delta^{18} O_{\text {Bari }}=-(0.04 \pm 0.02) * P-(7.2 \pm 0.63), R^{2}=0.05, p<0.05 \\
\delta^{18} O_{\text {Tanj }}=-(0.05 \pm 0.01) * P-(5.13 \pm 0.41), R^{2}=0.23, p<0.001
\end{gathered}
$$

Relationships were all significant $(p<0.05)$ but with low explained variability $\left(R^{2}<0.23\right)$. A possible explanation is that our sampling interval was too coarse and short in comparison to the sampling performed at Mulu. Therefore we weren't able to exclude additional sources of variability that could have been possible with a more intense and systematic sampling strategy. We found the most robust relationship for the Tanjung Karang coastal site, the station most exposed to the impact of the oceanic moisture, not affected by the effect of elevation, distance from the coast or mountain shadowing. However the high scatter in our results might highlight the complex mechanism involved when looking at the daily amount effect.

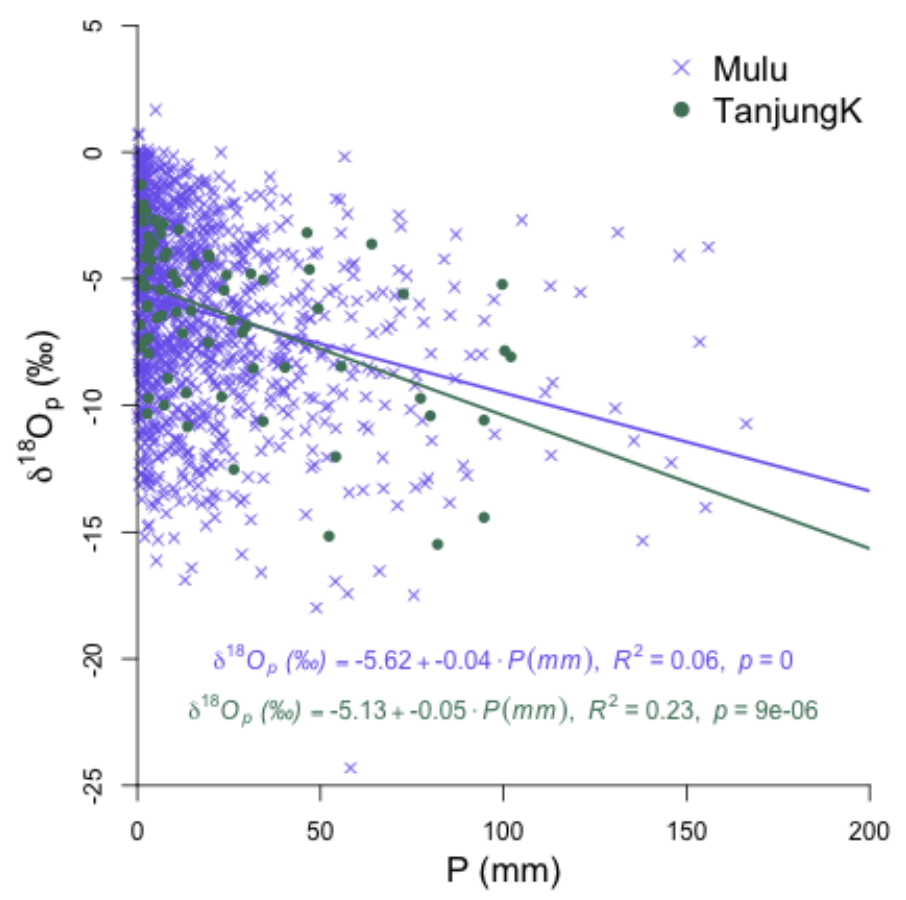

FIGURE 4.16: Precipitation amount effect estimated from daily or event frequency and comparison between daily Mulu (purple) and Tanjung Karang (green).

Determining a daily amount effect is challenging because of the uncertainties associated with the measurements of individual rain event and of the variability in terms of trajectories and atmospheric conditions. A more robust measure is a monthly weighted average amount effect, calculated according to equation 4.5 (Dansgaard, 1964): 


$$
\delta_{w}=\frac{\sum_{i=1}^{n} P_{i} \delta_{i}}{\sum_{i=1}^{n} P_{i}}
$$

The weighted amount effect reflects averaging monthly conditions, in that it dampens the high frequency fluctuations that are very difficult to track when the measurements are based on cumulative event sampling, like in our case. In order to catch these fast fluctuations a sub-daily (hourly and faster) sampling strategy could be helpful. Using equation 4.5 we found the following regression coefficients for the monthly weighted average amount effect (figure 4.17):

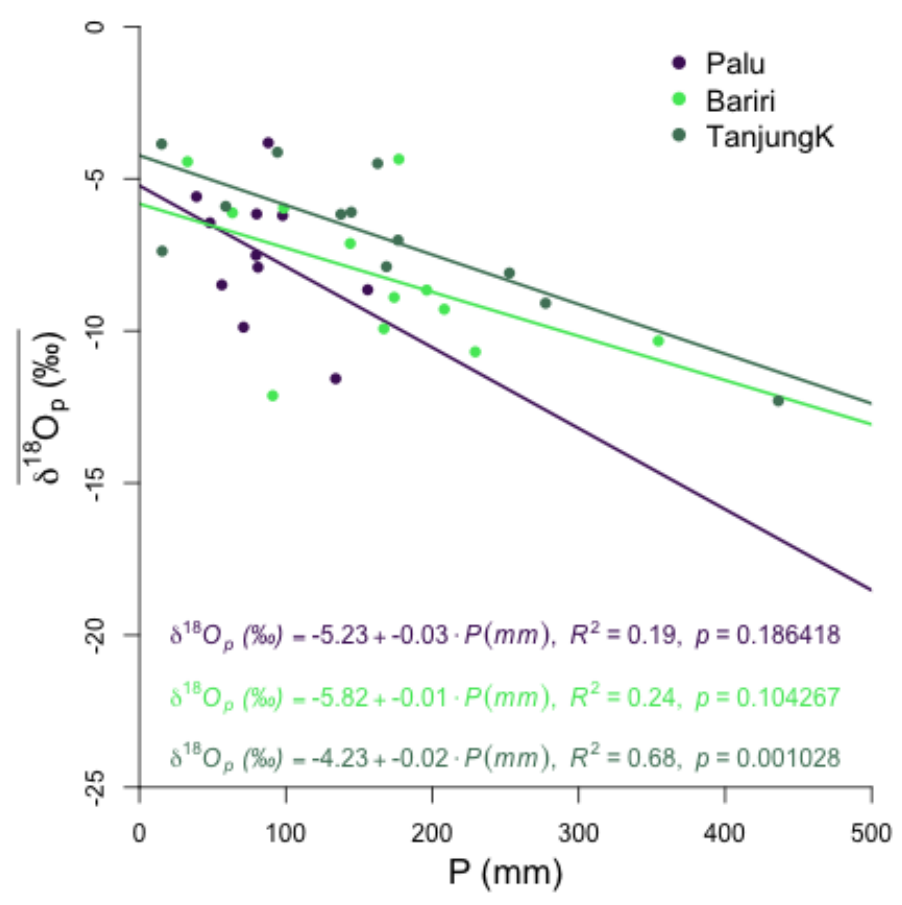

FIGURE 4.17: Monthly weighted amount effect for all stations in Sulawesi (Mulu excluded).

We observed reduced scatter in the relationship, but at the expenses of the significance, probably due to the decrease in the data points. Similarly to the daily amount effect, we find the strongest relationship at Tanjung Karang showing most directly the oceanic moisture contribution.

$$
\begin{gathered}
\delta^{18} O_{\text {Palu }}=-(0.03 \pm 0.02) * P-(5.23 \pm 1.69), R^{2}=0.19, p<0.2 \\
\delta^{18} O_{\text {Bari }}=-(0.01 \pm 0.01) * P-(5.82 \pm 1.47), R^{2}=0.24, p<0.2 \\
\delta^{18} O_{\text {Tanj }}=-(0.01 \pm 0.003) * P-(4.23 \pm 0.71), R^{2}=0.68, p<0.001
\end{gathered}
$$


Finally, due to the significant amount effect relationship observed in Tanjung Karang, we hypothesize that this site allows testing the effect that stratiform clouds have in determining the degree of isotopic depletion of rainfall (Lekshmy, Midhun, and Ramesh, 2018). For testing this hypothesis we use the Mulu dataset, where an algorithm for estimating the fractional area of stratiform versus convective clouds was already available (Munksgaard et al., 2019). We found this relationship:

$$
\begin{gathered}
\delta^{18} O_{\text {TanjungK }}=-11.83 * F_{s}-0.17, R^{2}=0.02, p=0.23 \\
\delta^{18} O_{\text {Mulu }}=-31.86 * F_{s}+10.53, R^{2}=0.26, p<0.05
\end{gathered}
$$

with $F_{s}$ denoting the area fraction covered by stratiform clouds. We found that this relationship, despite showing an overlap in the cluster of points of the two stations, was not significant for Bariri (figure 4.18). Nevertheless we should also consider that: a) The fractional area function was calculated over a $5^{\circ} \times 5^{\circ}$ grid point centered on Mulu and not centered on Tanjung Karang, therefore the relationship for our station might improve after an horizontal shift or a time lag (The time series in Mulu was 5 years long) and b) Our dataset was too coarse and randomized in comparison to the record of Mulu and therefore, a more regular and robust sampling strategy might lead to better and more consistent results.

However, due to the vicinity and similarity of the two sites (both close to the coast and at sea level), as already confirmed by the amount effect, by the Local Meteoric Water Line and by the similar temporal evolution of the precipitation isotopic composition, we expect a similar influence of the stratiform originated precipitation on the isotopic composition both in Mulu as well as in Tanjung Karang, in Palu and possibly also in Bariri.

\subsection{Conclusion}

In 2014-15 we conducted a precipitation isotopic characterization study along a transect in Central Sulawesi, an area in Indonesia without any GNIP sampling station. The sampling sites were chosen in order to represent unique hydrological conditions and thus we selected a coastal site, at the tip of the bay of Palu (Tanjung Karang), a land-coastal site at the campus of Tadulako University in Palu and a montane rainforest site in Bariri, at the edge of the Lore Lindu National Park.

We observed that, despite the 2014 -15 ENSO intensification (Santoso, Mcphaden, and Cai, 2017), the precipitation regime of this area well represents the classification give for Region A (Aldrian and Dwi Susanto, 2003). Therefore winter months (October to January), influenced by the north-west Monsoon, were characterized by an intensification of the precipitation regime. 


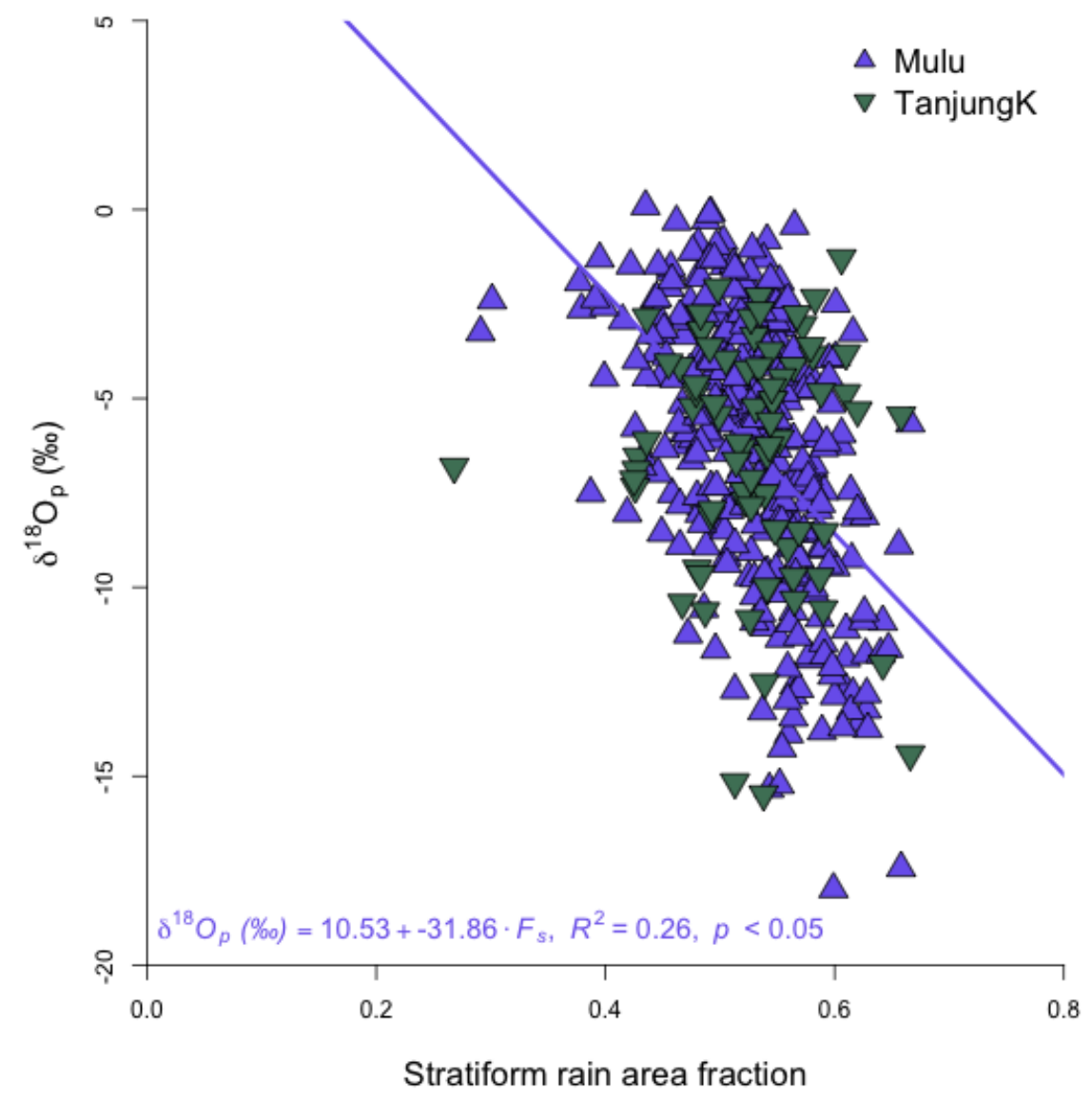

FIGURE 4.18: Rainfall isotopic composition dependency on the stratiform area fraction comparison between Mulu (purple) and Tanjung Karang (green)

Conversely summer months (July to September), due to the south-east Monsoon effect, were prevalently dry with occasional heavy showers especially in the coastal site. The position at the end of the bay and the presence of high mountains on both sides of it, have determined the lowest amount of precipitation in Palu station. This fact was also confirmed from the smaller precipitation deuterium excess values.

Samples isotopic composition $\left(\delta^{18} O\right)$ reached its minimum values during winter months in all three sites. Thus, not only the intensification of the convective activity, associated to the winter monsoon, promoted an increase in the precipitation amount but also caused the precipitation to be more depleted in heavier isotopes. This effect, known as the isotopic amount effect, is characteristic of tropical precipitation and it is caused by the evaporation of falling raindrops through unsaturated sub-cloud layers (Dansgaard, 1964; Kurita et al., 2009). We have observed this effect at all measurement sites, but the most significant was found at the coastal site. The particular topography 
and local circulation in the Palu site and the altitude and different location of the Bariri site may explain the different incidence of this effect.

Despite the limited resources and the short transect we were able to catch significant differences in both the precipitation regime and in the rainfall isotopic composition. It is important to note that a significant step forward in this study was made after the publication of some recent articles that allowed us to benchmark and compare our measurements (Munksgaard et al., 2019). Our results show that, despite the relatively small extension of our research area, the 3 sites are characterized by a clear different response in the rainfall isotopic composition due to the influence exerted from the strong 2015 ENSO, elevation and stratiform cloud cover. This study yields valuable insights into a region shaped by a high geomorphological complexity, that has been the focus of climate change studies in the recent past, i.e. due to the observation of a nearly 2-fold expansion of the warming pool with consequences for the Madden-Julian Oscillation and the Earths climatology and hydrological cycle (Roxy et al., 2019). 



\section{Chapter 5}

\section{The influence of the MJO on the isotopic composition of the land-surface water vapor and precipitation in Sumatra, Indonesia.}

\subsection{Introduction}

The Madden-Julian Oscillation (MJO) is the most important intra-seasonal climate oscillation occurring in the tropics and it is characterized by a periodicity of 30 to 90 days (Madden and Julian, 1971; Madden and Julian, 1972). The MJO is a global periodic perturbation that envelops the equatorial belt. It includes ensembles of clouds called Mesoscale Convective Systems (MCS) formed by clouds having different life stages and scales. These cloud systems, reaching extensions of up to $2000 \mathrm{~km}$, move eastwards along the equator at an approximate speed of $5 \mathrm{~m} \mathrm{~s}^{-1}$ due to the development of consecutive clusters east of the mature-stage ones (Nakazawa, 1988; Zhang, 2005). Across the Indian and the western Pacific Ocean the MJO evolves through a series of stages driven by wind circulation, moisture uptake, sea surface temperature and the interaction between the lower atmosphere and the maritime continent (Zhu and Wang, 1993; Wang and Li, 1994; Maloney and Sobel, 2004; Peatman, Matthews, and Stevens, 2014).

The MJO evolution, also known as the MJO discharge-recharge mechanism (Benedict and Randall, 2007), is characterized by an active phase that begins with the intensification of the convective instability induced by an enhanced sea evaporative flux occurring due to the enhanced sea surface temperature of the "warm pool" (Zhang, 2005). Here the boundary layer progressively moistens and deepens, and cumulus congestus moisten progressively the lower free troposphere, preconditioning the atmosphere to convection (Tian et al., 2006; Benedict and Randall, 2007; Riley, Mapes, and Tulich, 2011; Del Genio et al., 2012). At this stage, occurring approximately 15 days before the MJO maximum, the development of shallow cumuli and clouds 
congestus over the central Indian Ocean results in a non-aggregated convective activity that gradually increases the precipitation intensity (Tobin et al., 2013). In the days preceding the MJO precipitation maximum, the troposphere experiences a progressive moistening due to 1) the strong updraft of warm and moist air from the boundary layer, 2) the upper cloud detrainment and 3) the subcloud precipitation and the aggregation of the isolated convective cumuli into a more organized convective structure (Benedict and Randall, 2007). At the peak of the MJO active phase, when the rainfall intensity is at its maximum, the lower and mid troposphere are well moistened, organized convection reaches its maximum vertical development and air column reaches stable conditions (Riley, Mapes, and Tulich, 2011; Del Genio et al., 2012). In the suppressed (dry) phase of the MJO, deep convective clouds evolve in anvil and stratiform clouds progressively dry the lower troposphere due to the mesoscale subsidence and, at the end of the suppressed phase, convection dissipates in the central Pacific (Wang and Rui, 1990; Hendon and Salby, 1994; Kurita et al., 2011).

The features associated to the MJO are highly relevant for the climatology of Indonesia and particularly for the island of Sumatra because it modulates the rainfall regime of the whole region (Wu et al., 2017). Additionally, the MJO variability also depends on its interaction with other large-scale oscillations like El-Niño Southern Oscillation (ENSO) (Hendon, Wheeler, and Zhang, 2007). While the MJO has been intensively studied over the last decades, understanding it impacts on atmospheric water vapor over the Indonesian Islands still remain a challenge due to a lack of observational data.

Stable isotopes of water are powerful tools to understand processes related to atmospheric water vapor and to precipitation formation. They are used in climatological studies because they contain information regarding the physical processes that occur throughout the hydrological cycle (Gat, 1996). The isotopic compositions $\delta D$ and $\delta^{18} O$ (defined as the isotopic ratios ${ }^{2} \mathrm{H} /{ }^{1} \mathrm{H}$ and ${ }^{18} \mathrm{O} /{ }^{16} \mathrm{O}$ against a reference, respectively) of precipitation and water vapor are influenced by both the conditions at the evaporative site (Merlivat and Jouzel, 1979; Pfahl and Wernli, 2008) and those at the site where rain formation occurs. Furthermore, the isotopic composition of the water vapor in the boundary layer depends on the interaction between free tropospheric water vapor and surface fluxes (Bailey, Toohey, and Noone, 2013; Benetti et al., 2015; Guilpart et al., 2017), and can also be influenced by the interaction between air masses and local topography (Moore et al., 2016). For this reason, water stable isotopes are useful tools to describe the effects of large-scale weather phenomena on the local climatology.

So far, a large number of isotope-based studies have been conducted in the Northern hemisphere (Aemisegger et al., 2014; He et al., 2015; SteenLarsen et al., 2014) or during oceanographic campaigns (Benetti et al., 2014; Benetti et al., 2017; Uemura et al., 2008) but fewer have been performed 
within the complexity of the Indonesian archipelago (Conroy et al., 2016; Kurita, 2013; Kurita et al., 2011; Moerman et al., 2013). Consisting of more than 17000 islands located along the Equator between the Indian and the Pacific oceans, Indonesia is characterized by a large spatial heterogeneity due to the large number of island and also due to the topography. While the variability of the isotopic composition of water vapor and precipitation above the ocean surface has already been investigated in this area, much less is known about its variability in the internal part of major islands like Sumatra. Sumatra is the westernmost island of the archipelago and the first to be impacted by the climatic variability associated with the increasing rainfall intensity caused by the active phase MJO (Wu et al., 2017).

In the last decade, the application of stable water isotopes in atmospheric research strongly benefited from the introduction of optical-based laser spectrometers (Crosson, 2008), which enabled in situ, continuous and high frequency measurements of the water vapor isotopic composition (Gupta et al., 2009). These measurements helped to evaluate the performances of isotopeenabled general circulation models (Aemisegger et al., 2015; Steen-Larsen et al., 2017), provided useful tools to validate remote sensed water vapor isotopic measurements (Worden et al., 2011; Herman et al., 2014; Dyroff et al., 2015) and helped to formulate isotopic models extending previous knowledge about distillation, mixing between air masses and the isotopic signature of reevaporation of falling precipitation (Noone, 2012). Here, in order to provide additional understanding of the effects of the MJO on the land surface water vapor isotopic composition, we want to make use of such highfrequency measurements and investigate continuously the evolution of the isotopic composition of water vapor and precipitation in Eastern Sumatra during an active phase of the MJO.

The main objectives of the present study were to obtain the first record of water vapor isotopic composition on the island of Sumatra and to evaluate if and how the MJO, during its active phase, affects the variability of the water vapor and precipitation isotopic composition. The campaign took place from the $12^{\text {th }}$ to the $26^{\text {th }}$ in 2016 at a meteorological tower in a mature oil palm plantation close to the city of Jambi in Sumatra, Indonesia. We continuously measured the isotopic composition of water vapor and collected precipitation samples at event resolution.

Our results show that the MJO active phase represents a source of variability for the isotopic composition of both the precipitation and the surface layer water vapor. Before and during the onset phase of the MJO the analysis of the backward trajectories identified a predominant moisture source in the South China Sea. During this time the air trajectories travelled at lower altitudes keeping the atmospheric surface layer moistened and enriched in heavy isotopes. In the second half of March 2016 a convective cluster originated in the Indian Ocean. This cluster evolved and intensified during the onset stage of the $\mathrm{MJO}$, peaking on the $21^{\text {st }}$ March off the coasts of western 
Sumatra. The convective activity of the windward side of the island produced an unsaturated downdraft towards the eastern side of the Island that manifested in our measurement site as the driest and most depleted water vapor in the surface layer of the oil palm plantation at PTPN VI. After the dissolution of the convective cluster, the predominant winds returned from the West, rapidly remoistening and enriching the atmospheric surface layer.

\subsection{Materials and Methods}

\subsubsection{Site description}

The measurement campaign took place from the $12^{\text {th }}$ to the $26^{\text {th }}$ March 2016 in a mature and productive oil palm (Elaeis guineesis Jacq.) plantation approximately $30 \mathrm{~km}$ west of the city of Jambi, Sumatra, Indonesia $\left(01^{\circ} 41^{\prime} 34.8^{\prime \prime} \mathrm{S}\right.$, $103^{\circ} 23^{\prime} 27.6^{\prime \prime} \mathrm{E} ; 70 \mathrm{~m}$ a.s.l.; plantation extension 2186 ha, see 5.1). The plantation (PTPN VI) belongs to the PT. Perkebunan Nusantara oil palm production national company and it is one of the sites of the research project Ecological and Socioeconomic Functions of Tropical Lowland Rainforest Transformation Systems (EFForTS) (Drescher et al., 2016). At the time of the present study, oil palm trees were $\approx 14$ years old, average canopy height was $12 \mathrm{~m}$ and the average leaf area index was $3.64 \mathrm{~m}^{2} / \mathrm{m}^{-2}$ (Fan et al., 2015). The terrain in the plantation was generally flat with relatively small depressions $(\approx$ $15 \mathrm{~m}$ deep) (Meijide et al., 2017) that were dry during the whole campaign.

\subsubsection{Water vapor and precipitation measurements}

Surface-layer air was sampled along a $22 \mathrm{~m}$ tall tower located in the oil palm plantation using 1/2 inch PTFE tubes (as in Sturm and Knohl (2010)) of equal length that were warmed by means of self-regulating heating cable to prevent water vapor condensation on tube walls (Raychem $R$, Mod BTV2, Pentair, TX, USA). Inlets (located at 21, 16, 9, 3 and $0.5 \mathrm{~m}$ height) were equipped with plastic shields to prevent insects, large dust particles or raindrops from entering the tubes. A Cavity Ring-Down Spectrometer (WS-CRDS, L2120-i, Picarro Inc. (R, Santa Clara, CA, USA) was placed inside a concrete hut, located next to the tower. Air pumps, a tube manifold and an inlet switching system were also stored inside the hut, where room temperature was kept at $27^{\circ} \mathrm{C}$ using a commercial air conditioner. We used a high flow pump (28 $\left.1 \mathrm{~min}^{-1}\right)$ to drag air from the inlets to the manifold and a low flow pump (4.2 $1 \mathrm{~min}^{-1}$ ) from the manifold to the analyzer. With this configuration, all tubes were continuously flushed avoiding water vapor stagnation. Air from each inlet was sampled for 6 minutes providing a complete vertical profile every half hour.

WS-CRDS mixing ratio was calibrated using a portable dew point gener-

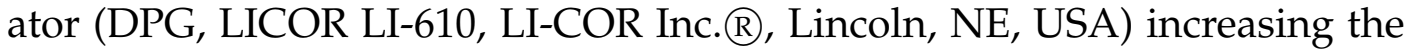
mixing ratio linearly from 5 to $30 \mathrm{mmol} \mathrm{mol}^{-1}$ at $5 \mathrm{mmol} \mathrm{mol}^{-1}$ steps and applying the following equation 5.1: 


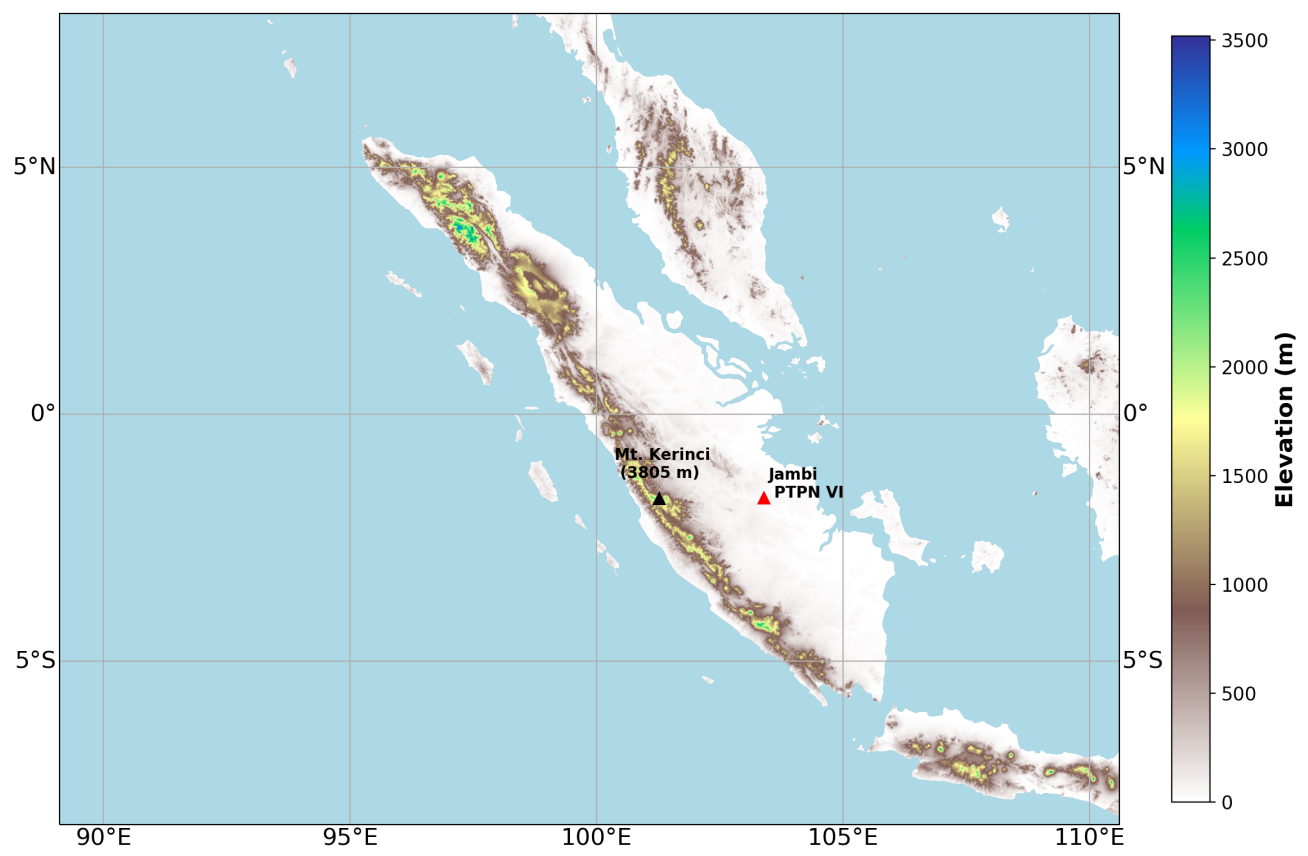

FIGURE 5.1: Digital elevation map of the island of Sumatra showing the position of the meteorological tower in the mature oil palm plantation (red triangle) and the position of Mt. Kerinci (black triangle). The data for the DEM are from the Global Multi-resolution Terrain Elevation Data 2010 (GMTED 2010) at 30-arc-second resolution (Danielson and Gesch, 2011).

$$
\mathrm{H}_{2} \mathrm{O}_{\mathrm{CRDS}}=0.9457 * \mathrm{H}_{2} \mathrm{O}_{D P G}-1.595
$$

to the WS-CRDS configuration file.

The calibration of the WS-CRDS for stable isotopes was routinely performed every $6 \mathrm{~h}$ using the Standard Delivery Module (SDM A0101, Picarro

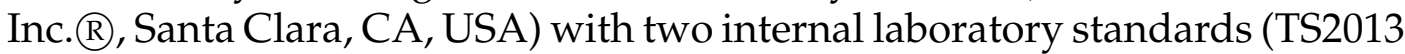

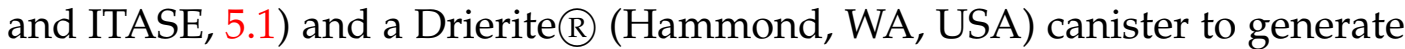
a dry air stream. The SDM injected the two standards into the dry air stream at three different volumes $\left(0.06,0.07\right.$ and $\left.0.08 \mu \mathrm{min}^{-1}\right)$ for $\approx 10 \mathrm{~min}$. Every calibration cycle took $\approx 1 \mathrm{~h}$. WS-CRDS instrumental accuracy was 1.35 and $0.02 \%$ and precision, reported as the standard error of the mean $\frac{\sigma}{\sqrt{n}}$, was 0.25 and $0.04 \%$ for $\delta D_{v}$ and $\delta^{18} O_{v}$ respectively. The total error for $\operatorname{dex} c_{v}$ was $0.251 \%$ calculated using error propagation. Furthermore, no significant ( $\mathrm{p}$ $>0.05$ ) drift of the standard isotopic composition was observed during the campaign.

Precipitation samples were collected after each rainfall event using a custom made pluviometer installed on the top of the tower to avoid possible canopy interception. To prevent evaporation of the precipitation samples, we closed the funnel drain with a table tennis ball and used a dip-in sampler 

land-surface water vapor and precipitation in Sumatra, Indonesia.

TABLE 5.1: Mean and standard deviation (sd) of the working standard measured with an IRMS (Delta Plus, Thermo Fisher

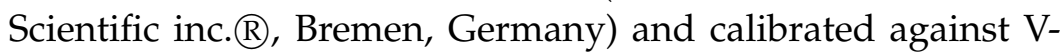
SMOW; TS 2013 and ITASE were used for calibration of water vapor and STD A, B, C for precipitation samples and leaves extracted water respectively.

\begin{tabular}{lcc}
\hline Standard & $\begin{array}{c}\delta^{18} O \pm \mathbf{s d} \\
\mathbf{\%}\end{array}$ & $\begin{array}{c}\delta D \pm \mathbf{s d} \\
\mathbf{\%}\end{array}$ \\
\hline TS2013 & $-8.08 \pm 0.04$ & $-51.73 \pm 0.64$ \\
ITASE & $-34.89 \pm 0.11$ & $-277.06 \pm 1.32$ \\
STD A & $-0.23 \pm 0.04$ & $-2.03 \pm 0.32$ \\
STD B & $-8.24 \pm 0.05$ & $-54.50 \pm 0.92$ \\
STD C & $-18.69 \pm 0.09$ & $-138.43 \pm 1.20$ \\
\hline
\end{tabular}

method as suggested by IAEA/GNIP precipitation guidelines (IAEA/GNIP precipitation sampling guide V2.02 September 2014). After measuring the precipitation volume, samples were transferred into amber glass vials with silicone screw caps, sealed with Parafilm and sent to Germany for the analysis. Analyses were performed with a WS-CRDS (WS-CRDS L2120-i, Picarro Inc. $\AA$, Santa Clara, CA, USA, the same model as the one used for the onsite measurements in Jambi) and measurements were calibrated using three working standards (STD A, STD B and STD C, 5.1). Isotopic composition of water vapor and precipitation expressed in $\delta$ notation (Coplen, 2011) is reported in \%o against the international standard V-SMOW following eq. 2.2 (Araguás-Araguás, Froehlich, and Rozanski, 2000; Craig, 1961).

For the precipitation measurements, the accuracy was 0.12 and $0.02 \%$ and precision (sd) was \pm 0.99 and $\pm 0.12 \%$ for $\delta D$ and $\delta^{18} O_{p}$ respectively. Additionally, since our measuring campaign was too short to cover the entire evolution of an MJO event, which has a periodicity varying between 30 to 90 days (Zhang, 2005), we verified the precipitation trend at our site with the data from the ombrometers permanently installed on the meteorological tower.

\subsubsection{Synoptic data}

Meteorological parameters were measured as explained in Meijide et al. (2017) and included air temperature and relative humidity (Thermohygrometer, type 1.1025.55.000, Thies Clima $\AA$, Göttingen, Germany) at 6 different heights along the tower $(22,16.3,12.4,8.1,2.3,0.9 \mathrm{~m})$, atmospheric pressure, wind speed and wind direction (Thies Clima $₫$, Göttingen, Germany) at $22 \mathrm{~m}$. Precipitation amounts were measured by two ombrometers (Thies Clima $₫$, Göttingen, Germany). These parameters were averaged at $10 \mathrm{~min}$ resolution and stored in a DL16 Pro data logger (Thies Clima ${ }^{\circledR}$, Göttingen, Germany). 
The evolution of the active phase of the MJO was determined using the all-season real-time multivariate index (RMM1 and RMM2, (Wheeler and Hendon, 2004)). The RMM index provides the position and the intensity of the active phase of the MJO using NCEP/NCAR 850-hPa, 200-hPa zonal wind fields between $15^{\circ} \mathrm{N}$ and $15^{\circ} \mathrm{S}$, and outgoing long-wave radiation (OLR) data (Liebmann and Smith, 1996). We calculated 72 hours backward trajectories using the ARL-HYSPLIT particle dispersion model (Stein et al., 2015) based on $1^{\circ}$ data from the Global Data Assimilation System (GDAS). Trajectories were generated every 6 hours (at UTC 00:00, 06:00, 12:00 and 18:00) from four different starting points aligned above the tower at 500,1000, 1500 and $2000 \mathrm{~m}$ a.s.l. These trajectories provided the information about the evolution of the air parcels in latitude, longitude and height plus additional parameters such as rainfall, specific humidity and atmospheric pressure calculated along the trajectories path. For the along-path statistics and for plotting the trajectories we used a PySPLIT Python-based package for HYSPLIT (Cross, 2015).

\subsubsection{Isotopic distillation and mixing model}

In order to understand which were the factors controlling the isotopic composition of the water vapor in the lower boundary layer, we used the isotopic distillation and mixing model described in 2.37. Using this set of equations we built the theoretical curves relative to the Rayleigh distillation, the isotopic mixing between two air masses, the closed Rayleigh distillation (batch process) and the rain re-evaporation process. Afterwards we plotted our observations in the $\delta D_{v}\left(q_{v}\right)$ space and evaluate "best" process describing our dataset.

\subsection{Results}

\subsubsection{MJO index}

The real-time multivariate $\mathrm{MJO}$ index shows the position and the intensity of the MJO equatorial oscillation during March 2016 (5.2). From the beginning of the month the MJO lost intensity (expressed as the distance from the centre of the plot) during its propagation from Western Africa to the Indian Ocean (phases 1 and 2). Then, it gained intensity during its propagation from the Indian Ocean (phase 3) to the Indonesian Archipelago (phase 4), where it reached its maximal intensity (phase 5) during the second half of the month $\left(19^{\text {th }}-22^{\text {nd }}\right.$ March 2016). At the maximum development of the convective cluster characterizing the active phase of the $\mathrm{MJO}$, the perturbation decreased consistently its eastward propagation velocity (smaller distance between days), assuming a temporarily stationary behavior over the maritime continent. This perturbation, after reaching its maximal intensity south of Sumatra, gradually dissolved while propagating towards the Pacific Ocean and evolved into the suppressed phase of the MJO. Moreover the propagation speed of the disturbance increased again but, at the same 
time, lost much of its intensity. Our measurement campaign was carried out during the transition from phase 3 to 6 , a period characterized by an increasing convective activity in the Indian Ocean (see figure 7 ) that peaked on the $21^{\text {st }}-22^{\text {nd }}$ March off the coast of the island on Sumatra, subsequently followed by a decrease in its intensity and the propagation of the perturbation center towards the Pacific Ocean.

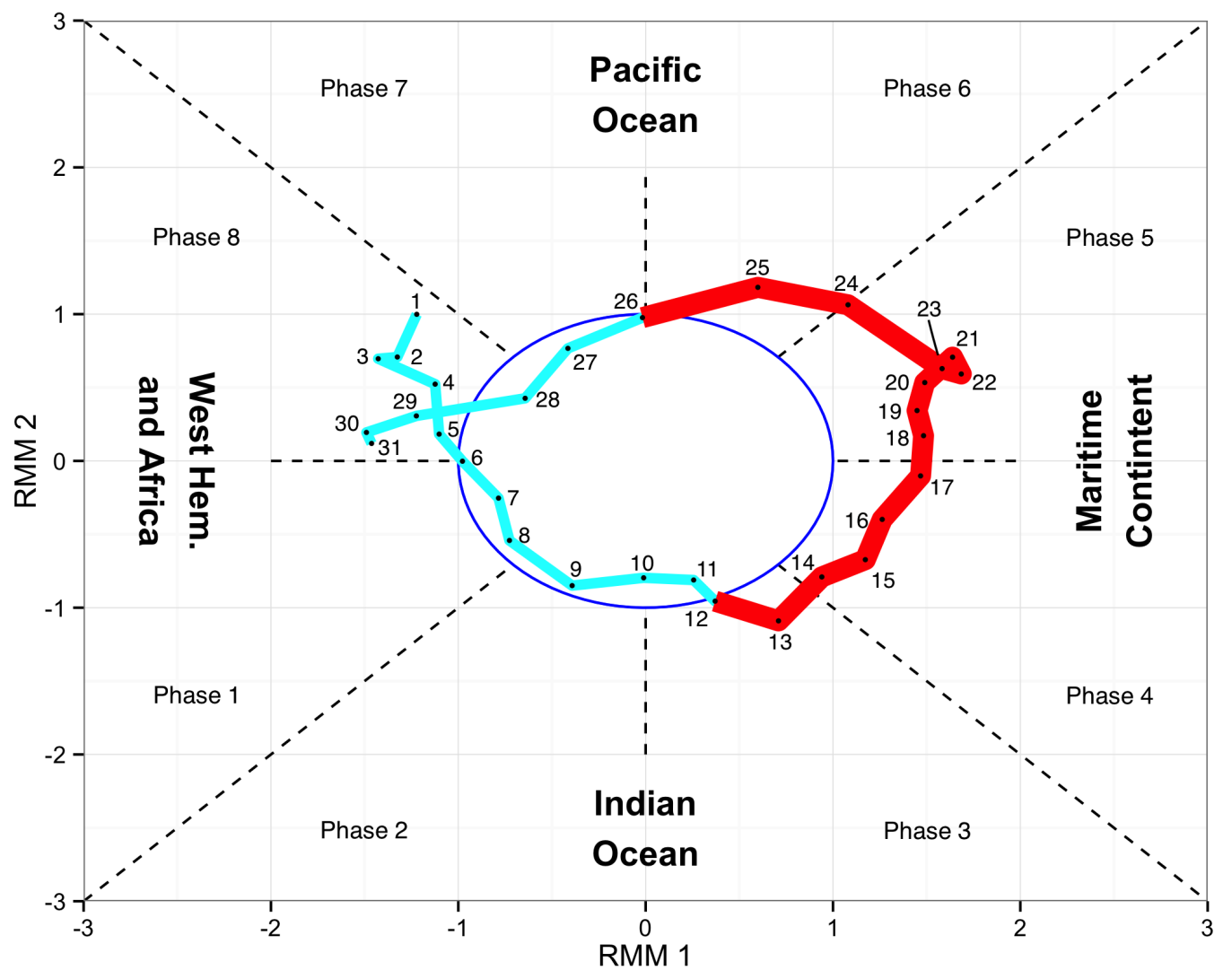

FIGURE 5.2: Phase space plot of the Madden-Julian Oscillation (MJO) from 1 to 31 March 2016 (number at the colored line indicate the day). The red solid segments correspond to the time interval of our measurement campaign. The location of the MJO perturbation is indicated by bold text. RMM1 and RMM2 are the real-time multivariate (RMM) MJO index. The MJO intensity is displayed as the distance from the centre of the plot. The inner blue circle indicates an area where the index uncertainty is too high to determine the effective strength of the perturbation. Subdivision with dashed lines reflects the different MJO phases. 


\subsubsection{Precipitation trend and isotopic composition}

A non-parametric Mann Whitney U-test revealed a statistically non-significant difference ( $p$-value $=0.325$ at $95 \%$ confidence interval) between the precipitation amount measured with the ombrometer and collected with the custom made pluviometer. Moreover, despite our campaign was shorter that the whole MJO development, the results from the ombrometer revealed that, during this time, we were able to catch most of the features of this particular event (figure 5.3).

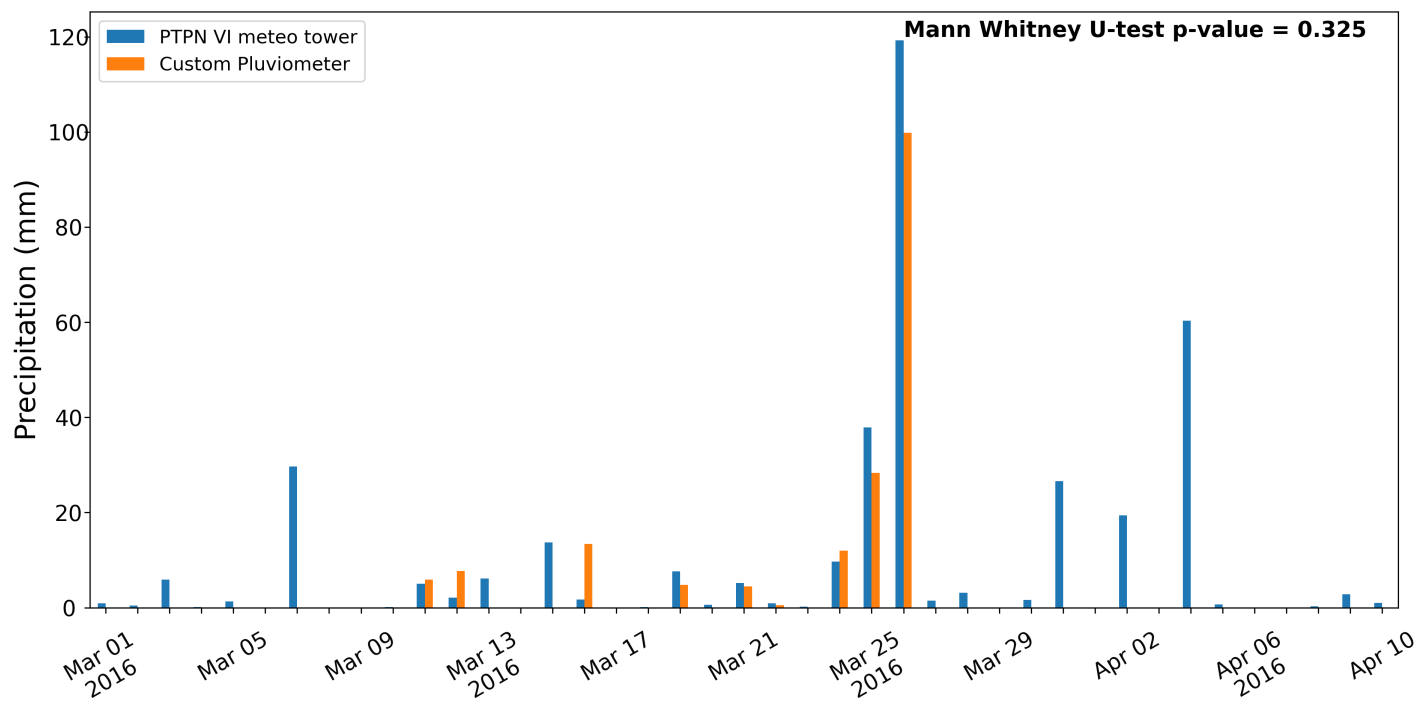

FIGURE 5.3: Precipitation amount mm comparison between the custom made pluviometer (orange) used for the sampling of rainfall for the isotopic analysis and the ombrometer (blue) installed on the meteorological tower at Jambi PTPN VI. On the top right the p-value of the Mann Whitney U-test between the 2 set of samples.

We collected in total $176.8 \mathrm{~mm}$ of rain distributed in 9 precipitation events (Table 5.2). The rainfall isotopic composition ranged from -20.16 to -90.46 $\%$ and from -3.64 to $-12.94 \%$ for $\delta D_{p}$ and $\delta^{18} O_{p}$, respectively. It showed a significant negative trend from the $21^{\text {st }}$ to the $24^{\text {th }}$ March 2016 shifting from -20.16 to $-90.46 \%$ in $\delta D_{p}$ and -3.6 to $-12.94 \%$ in $\delta^{18} O_{p}$. After the isotopic minima, rainfall was gradually more enriched and the rainfall amounts increased steadily. The rainfall deuterium excess $\left(\operatorname{dex}_{p}\right)$ showed the higher values $\left(\operatorname{dexc}_{p}>13 \%\right)$ during events characterized by an amount higher than $10 \mathrm{~mm}$.

\subsubsection{Water Vapor Isotopic Composition}

The $\delta D_{v}$ and $\delta^{18} O_{v}$ (subscript stands for vapor) ranged from -72.0 to -161.8 $\%$ and from -8 to $-22.2 \%$, respectively. Mean and standard deviation were $-110.27 \pm 21.09 \%$ and $-15.04 \pm 2.91 \%$ for the $\delta D_{v}$ and $\delta^{18} O_{v}$ respectively. The deuterium excess for water vapor $\left(\operatorname{dexc}_{v}\right)$ ranged from 23 to $-2 \%$ with mean 

land-surface water vapor and precipitation in Sumatra, Indonesia.

TABLE 5.2: Date of the rainfall event, amount and isotopic composition $\left(\delta^{18} O_{p}, \delta D_{p}\right)$ and deuterium excess $\left(d_{p}\right)$ of the rain collected in 2016.

\begin{tabular}{lcccc}
\hline Date & $\begin{array}{c}\text { Amount } \\
\mathrm{mm}\end{array}$ & $\begin{array}{c}\delta^{18} O_{p} \\
\%_{0}\end{array}$ & $\begin{array}{c}\delta D_{p} \\
\%_{0}\end{array}$ & $\begin{array}{c}d_{p} \\
\%_{0}\end{array}$ \\
\hline 11 Mar & 5.9 & -4.65 & -29.61 & 7.59 \\
12 Mar & 7.7 & -6.04 & -38.62 & 9.70 \\
16 Mar & 13.4 & -6.70 & -40.01 & 13.59 \\
19 Mar & 4.8 & -5.54 & -36.34 & 7.98 \\
21 Mar & 4.5 & -3.64 & -20.16 & 8.96 \\
22 Mar & 0.5 & -9.12 & -61.86 & 11.10 \\
24 Mar & 12.0 & -12.94 & -90.46 & 13.06 \\
25 Mar & 28.3 & -10.56 & -71.38 & 13.10 \\
26 Mar & 99.8 & -7.96 & -50.31 & 13.37 \\
\hline
\end{tabular}

and standard deviation of $10.16 \pm 3.78 \%$. Water vapor mixing ratio ranged from 39.73 to $25.59 \mathrm{mmol} \mathrm{mol}^{-1}\left(32 \pm 1.7 \mathrm{mmol} \mathrm{mol}^{-1}\right.$, mean \pm standard deviation).

During the course of the measurement campaign, we observed a distinctive transition towards lighter water vapor from the $21^{\text {st }}$ to the $24^{\text {th }}$ March. The beginning of this consistent depletion of the isotopic composition $(\approx-60$ $\%$ shift in $\delta D_{v}$ in just 3 days) of the surface-layer water vapor took place during the maximum amplitude of the MJO index (Figure 5.4). Despite being dominated by the diurnal variability, the average $\operatorname{dexc}_{v}\left(\operatorname{dexc}_{v}=\delta D_{v}-8 *\right.$ $\delta^{18} O_{v}$, (Dansgaard, 1964)) increased during the active phase of the MJO but reached the maximum on the $22^{\text {nd }}$ March at the beginning of the suppressed phase of the MJO.

\subsubsection{Meteorology}

Long-term atmospheric pressure (not shown) reflected closely the evolution of the MJO showed in figure 5.4. During the intensification and the approach of the MCS to the coast of Western Sumatra, the pressure was characterized by a negative trend with the minima recorded during the transition from the active to the suppressed phase ( $22^{\text {nd }}$ March). The trend observed in the atmospheric pressure was inverted during the last days of the campaign. Predominant wind direction at the site ranged from North-East to South-West with low wind speed $\left(96 \%\right.$ of the times wind speed $\left.<3 \mathrm{~m} \mathrm{~s}^{-1}\right)$. Air temperature ranged from $20.9^{\circ} \mathrm{C}$ and $31.9^{\circ} \mathrm{C}$ at the top of the canopy and relative humidity from $56.5 \%$ to $100 \%$ reaching saturation conditions during nighttime. 


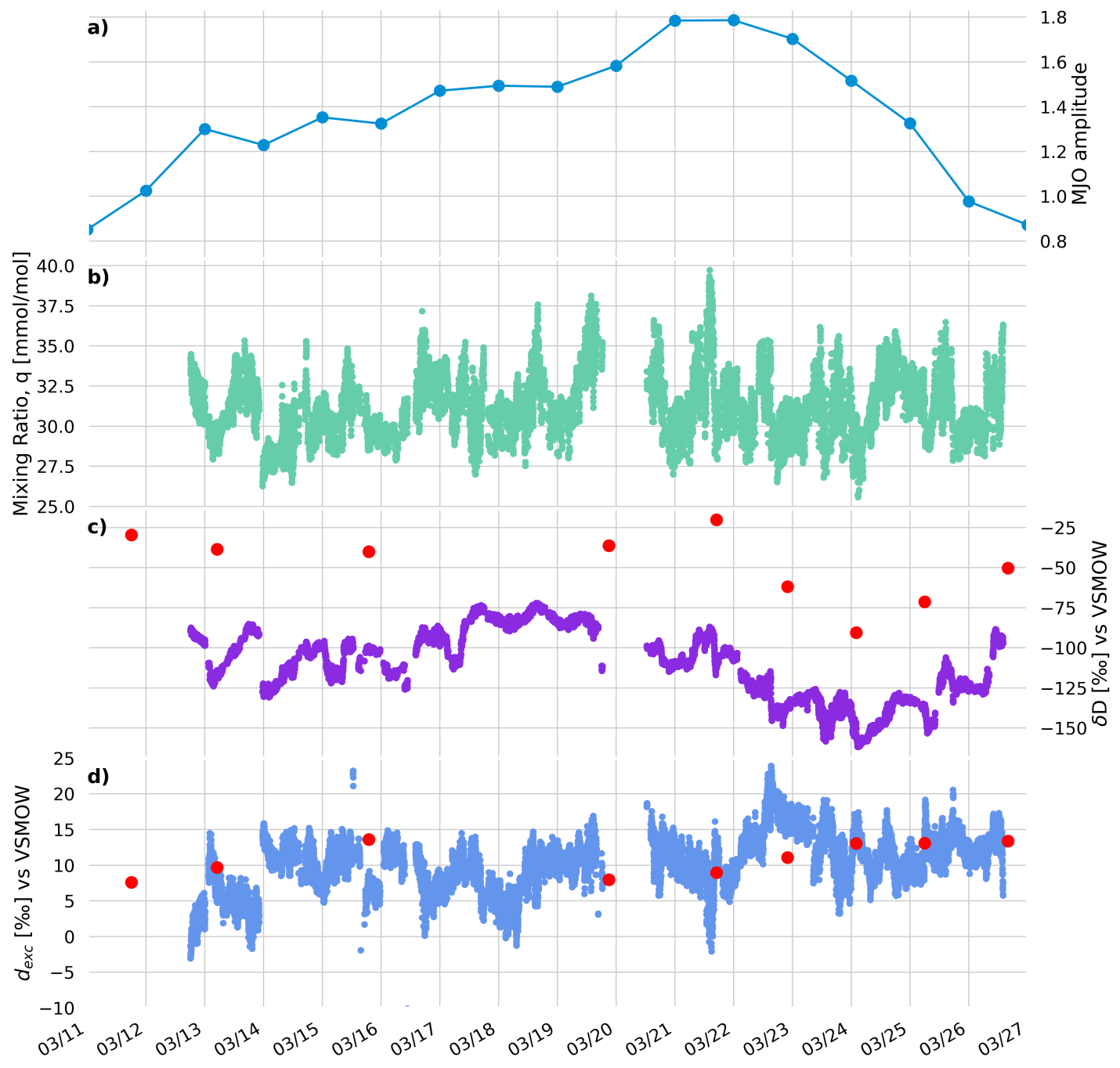

FIGURE 5.4: Madden Julian Oscillation (MJO), water vapor and rainfall isotopic composition variability from the $11^{\text {th }}$ to the $27^{\text {th }}$ March 2016 at the PTPN VI station, Jambi (Sumatra). a) MJO amplitude calculated using the RMM index shown in figure 5.2. b) 1 minute average water vapor mixing ratio in $\left(\mathrm{mmol} \mathrm{mol}^{-1}\right)$, c) 1 minute average $\delta D$ (\%o vs V-SMOW) of water vapor (purple dots) and rainfall (red dots) and d) 1 minute average dexc (\%o vs V-SMOW) of water vapor (blue dots) and rainfall (red dots). 


\subsection{Discussion}

In order to provide additional evidence of the mesoscale processes that influenced the surface water vapor and the precipitation isotopic composition, we investigated the relationships among the in-situ observations and external sources of data, such as Outgoing Longwave Radiation (OLR, Liebmann and Smith (1996)) and Tropical Rainfall Measurement Mission (TRMM, Huffman et al. (2010)). Furthermore, in order to investigate the reasons that determined the observed isotopic shift during the transition from the convective to the stratiform type of clouds, we show the horizontal and vertical trajectory of the incoming air parcels using the ARL-Hysplit backward trajectory model. Finally, using the isotopic distillation and mixing model developed by Noone (2012), we compared the distribution of our observations in the $\delta D_{v}\left(q_{v}\right)$ space together with the theoretical lines that predict the water vapor isotopic composition under different transport processes.

\subsubsection{Relationship Between $\delta D_{p}, \delta D_{v}$, dexc $c_{p}$ and Meteorolog- ical Variables}

Following the application of a double correlation method to the multi-year rain gauge observations among the Indonesian archipelago, eastern Sumatra was identified in the pluviometric region B, a region categorized by a weak dependency between SST and rainfall variability (Aldrian and Dwi Susanto, 2003). The closest GNIP (Global Network of Isotopes in Precipitation, IAEA (2018), https: / / nucleus.iaea.org/Pages/GNIPR.aspx) station to our site (also belonging to the pluviometric region $\mathrm{B}$ ), providing data for the same period, was Kuala Lumpur, MY (MINT). The average isotopic composition reported for precipitation in March 2016 at this GNIP station was -10.2 and -2.49\% $\%$ for $\delta D_{p}$ and $\delta^{18} O$ respectively. The $d e x c_{p}$ was $9.72 \%$, thus resulting in an enriched precipitation for this site located nearly $550 \mathrm{~km}$ from our measurement station. The range of the precipitation isotopic composition was similar to former studies conducted in the same area (Belgaman et al., 2016; Kurita et al., 2009). A commonly observed characteristic of tropical precipitation is the inverse relationship between the amount of precipitation and its isotopic composition, a relationship known as the "amount effect" (Dansgaard, 1964). This effect depends on various factors including, but not limited to the size of falling raindrops and the degree of rainfall re-evaporation through the unsaturated atmospheric surface layer (Dansgaard, 1964; Moerman et al., 2013; Rozanski, Araguas-Araguas, and Gonfiantini, 2013; Conroy et al., 2016). Consequently, in a region where most of the precipitation occurs due to the convective activity, the amount effect recorded at one side can be influenced by the intensity and the propagation of convective clouds clusters such as those characterizing the evolution of the MJO (Lekshmy et al., 2014). 


\subsubsection{Analysis of the Air Parcels Backward Trajectories}

In order to evaluate the factors determining the isotopic composition of precipitation and water vapor at our site and identify the synoptic moisture source area, we calculated the 72 hours backward trajectories reaching 4 receptors located above the meteorological towers (500, 1000, 1500, $2000 \mathrm{~m}$ a.s.l.) using the ARL-Hysplit Lagrangian particle dispersion model. The simulations covered the entire sampling period and backward trajectories were launched every 6 hours. In total we simulated 240 backward trajectories (60 for each receptor). We used Global Data Assimilation System (GDAS $1^{\circ}$ resolution and 23 pressure levels meteorological archived dataset) meteorological fields to calculate the hourly position of the air parcels, their altitude and some other parameters such as rainfall rate and specific humidity along the track.

During our sampling campaign the backwards air parcels trajectories were characterized a bimodal frequency distribution with a predominant Northeast and a secondary Southwest components (figure 5.5). We grouped the trajectories by selecting an arbitrary bounding box around our site and determined the corresponding cluster of each trajectory according to its bounding box crossing direction (Xia, Butorovic, and Yu, 2020).

The number of trajectories reaching our site from the northeast, thus originating in the South China Sea, was considerably higher (186 occurrences, $77.5 \%$ ) than those reaching our station from the west/southwest and originating in the Indian Ocean (54 occurrences, 22.5\%). Albeit the lower number of occurrences, the distribution of the air parcels elevation along the trajectories revealed that the air masses reaching our site from the Indian Ocean travelled at a considerable higher altitude in comparison to those arriving from the South China Sea (figure 5.6). To link the observed local moisture and precipitation isotopic composition variability with the synoptic-scale weather pattern we analyzed the relationship between outgoing longwave radiation (OLR) and rainfall with the wind domain as determined from the trajectories clustering.

\subsubsection{Large-scale convective patterns and their effect on the surface layer moisture and precipitation}

The position and the intensity of the MJO are commonly expressed in terms of phases that identify the position of the MCS along the Equator by means of the Real-time Multivariate MJO index (Wheeler and Hendon, 2004) as seen in figure 5.2.

However, from a hydrological perspective, the eastward propagation of the MJO towards the Pacific Ocean is best described defining the different stages of the cloud development (Benedict and Randall, 2007). According to this classification, stage I is defined by the enhanced solar radiation that promotes sea surface evaporation and the production of shallow cumuli. During 

land-surface water vapor and precipitation in Sumatra, Indonesia.

stage II convection is responsible for an increase in rainfall intensity, especially near the Sumatran coast. During stage III the atmosphere undergoes a complete rain discharge and a period of suppressed convection is responsible for generally dry conditions at the land surface. Since the MJO phases are expressed using the RMM index, which is built by the combination of outgoing long-wave radiation (OLR) with upper and lower atmospheric wind fields, we used the OLR dataset to evaluate the dependency between cloud type and observed water vapor isotopic composition. Convective clouds normally occur when OLR values fall below $220\left(\mathrm{~W} \mathrm{~m}^{-1}\right)$ (Waliser, Graham, and Gautier, 1993).

The evolution of the OLR during March 2016 is displayed using a Hovmoller diagram in figure 5.7 using the NOAA $1^{\circ}$ daily average OLR data (Liebmann and Smith, 1996). As seen in figure 5.2, starting on the $12^{\text {th }}$ March, the intensity of the MJO significantly increased during its eastward propagation from the Indian Ocean towards the maritime continent. Initially a cluster of convective clouds appeared and gained intensity between $80^{\circ}$ and $100^{\circ} \mathrm{E}$ and, after a momentary weakening on the $17^{\text {th }}$ March, it gained again intensity. From the $20^{\text {th }}$ March onwards, a large area of deep convection, a so-called active phase of the MJO, moved eastwards from the Indian Ocean

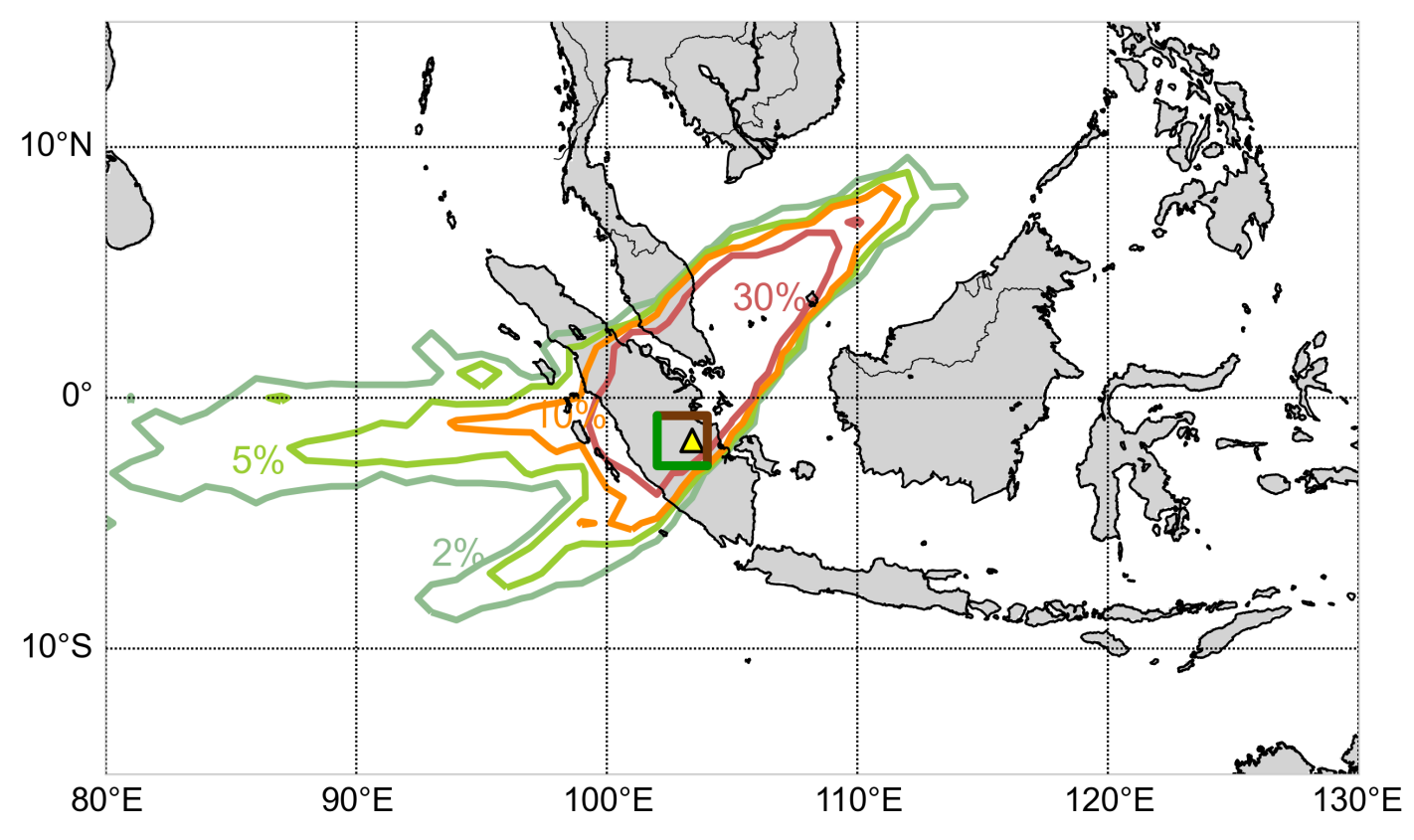

FIGURE 5.5: Map of the air parcels trajectory frequency for the period between the $11^{\text {th }}$ to $26^{\text {th }}$ March 2016. Trajectories were launched 72 hours back in time from 4 different heights (500, $1000,1500,2000 \mathrm{~m}$ a.s.l.) above the meteorological tower (yellow triangle) every 6 hours. The trajectories were clustered in northeast domain (brown solid line) and south-west domain (green solid line) using a bounding boxes around the measurement site. 
towards the Pacific Ocean but it rapidly dissipated (figure 5.7). The mentioned rainfall intensification off the coast of West Sumatra was consistently observed also in the daily cumulative precipitation data from Tropical Rainfall Measurement Mission (TRMM 3B42 RT 3-hourly $0.25^{\circ}$ ). The rain events followed consistently the propagation of the convective cluster associated to the MJO active phase. Furthermore, the location of the most intense and widespread rainfall event in the area (especially on the $21^{\text {th }}$ March), suggests and is consistent with previous observations (Wang and Rui, 1990; Wang and Li, 1994; Maloney and Sobel, 2004; Peatman, Matthews, and Stevens, 2014) that the Barisan mountain range, located on the West of Sumatra and reaching up to $3700 \mathrm{~m}$ with Mt. Kerinci, might have triggered the rainfall discharge on the windward side of the island of Sumatra (Figure 5.8).

The influence exerted from the intense convection of the active phase of the MJO was revealed by the analysis of the along-path accumulated precipitation and cumulative humidity uptake (not shown) simulated with the backward trajectories. As the trajectory frequency map (figure 5.5) revealed, most of the air parcels reaching our site originated in the South China Sea and travelled at a lower altitude in comparison to the fewer trajectories starting in the Indian Ocean. However these results didn't reveal the time and the reason that produced more depleted precipitation and surface layer water vapor. The along-path cumulative amount instead display clearly that, from the beginning of our sampling campaign, on the $11^{\text {th }}$ March until the $22^{\text {nd }}$ March most of the moisture and rainfall occurring at our site was originated from the north-eastern sector. As soon as the convective cluster started

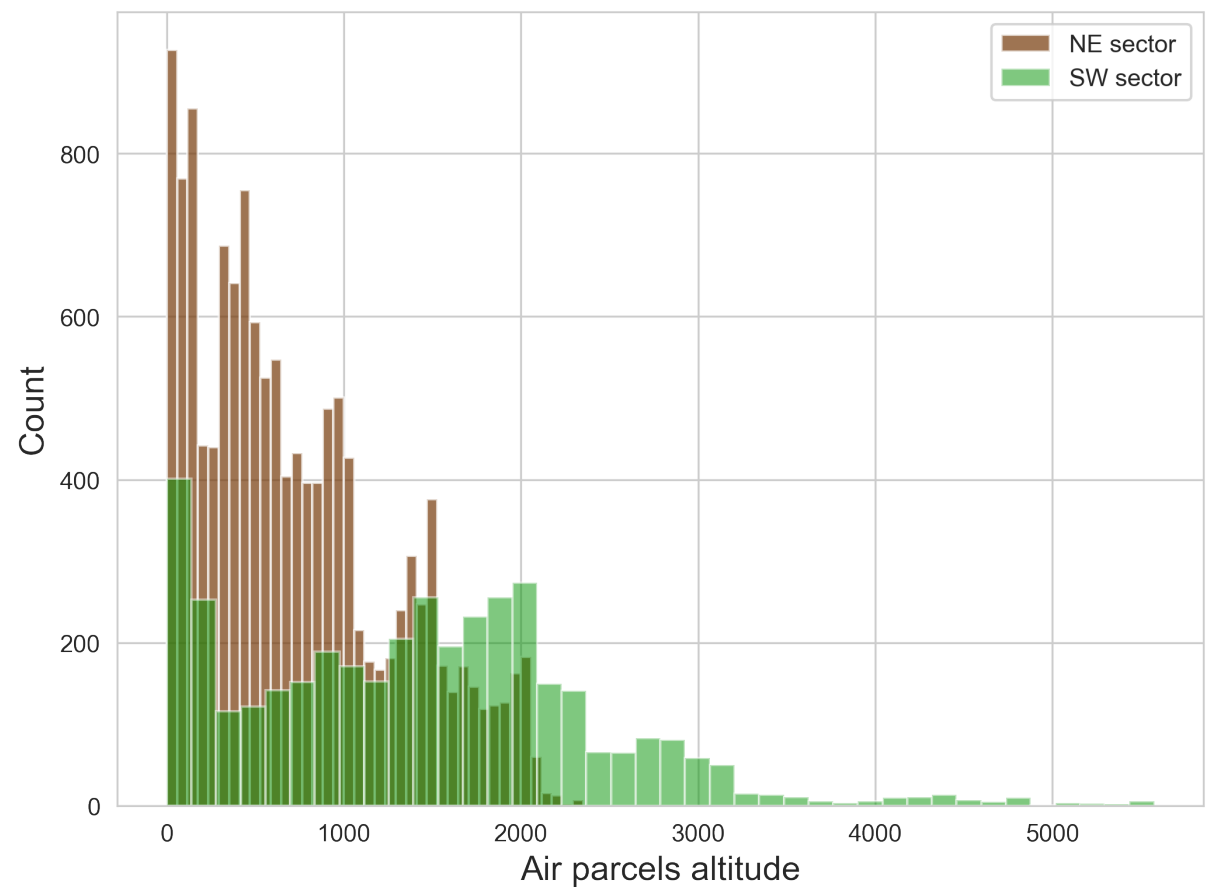

FIGURE 5.6: Histogram of the air parcels elevation along the backward trajectories sorted for each cluster. 

land-surface water vapor and precipitation in Sumatra, Indonesia.

to develop around $80^{\circ} \mathrm{E}$ on the $18^{\text {th }}$ March, the proportion of south-westerly air parcels reaching our site gradually increased. During the same time the South China Sea moisture contribute decreased until it become absent on the $22^{\text {nd }}$ March when the surface moisture isotopic composition started to decrease drastically. At the peak of the MJO active phase, not only the air masses were predominantly from the South-West sector, a change consistent with the typical MJO pattern (Zhang, 2005), but also they were associated to the highest cumulated along-path precipitation indicating that these air

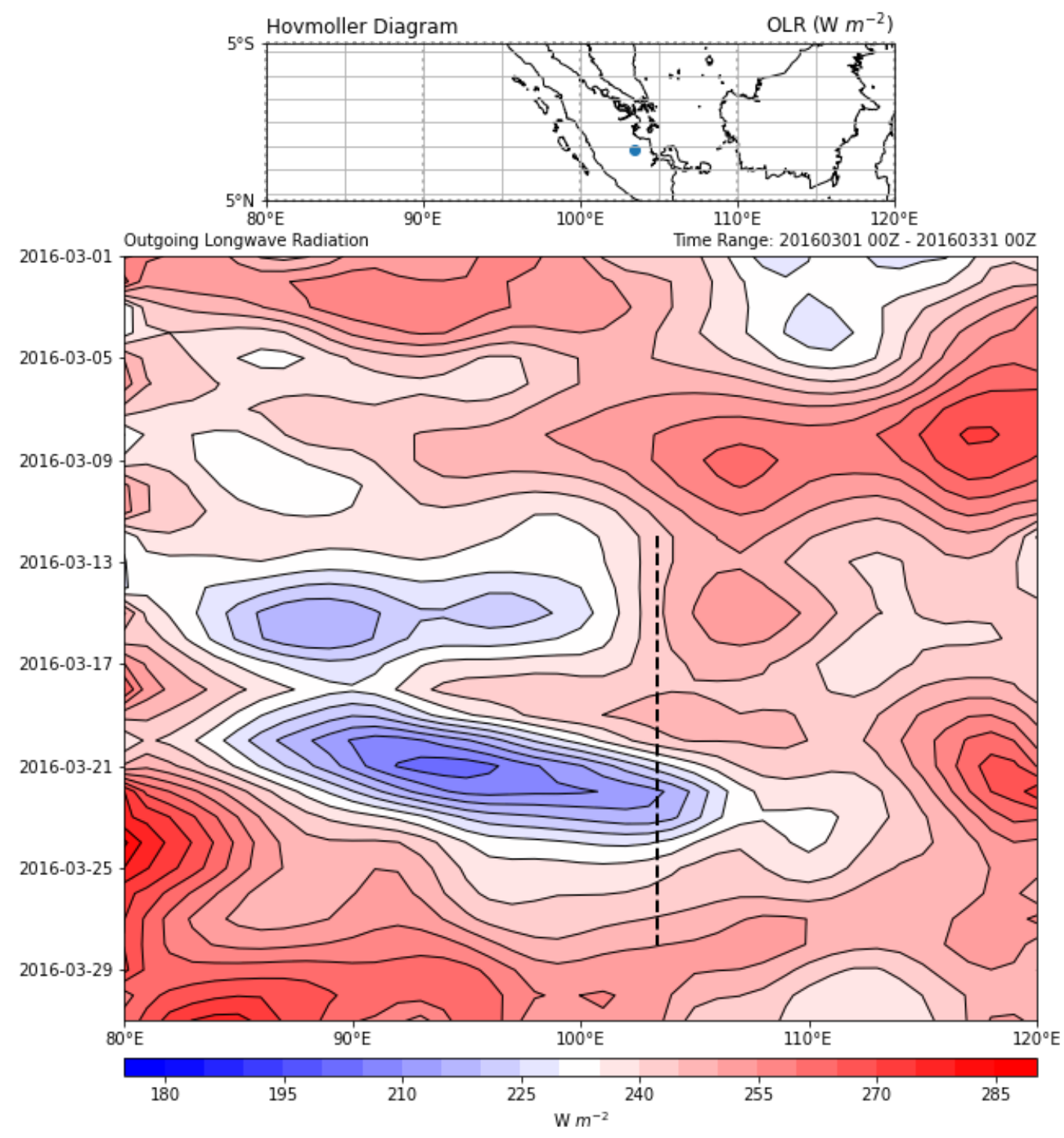

FIGURE 5.7: Hovmoller diagram of the outgoing longwave radiation (OLR $\left(\mathrm{W} \mathrm{m}^{-1}\right)$, Liebmann and Smith (1996)) during March 2016 between $80^{\circ} \mathrm{E}$ and $120^{\circ} \mathrm{E}$. The upper map displays the position of the PTPN VI meteorological tower (blue dot). The filled contour was calculated averaging the OLR between $10^{\circ} \mathrm{N}$ and $10^{\circ} \mathrm{S}$. The longitude of our station $\left(103^{\circ} \mathrm{E}\right)$, as well as the period of our sampling campaign, is shown as vertical black dashed line 
masses were influenced by the intense convective activity occurring off the coasts of Sumatra (figure 5.9).

The 3 days lag between the peak of the MJO active phase and the minimum isotopic composition recorded at our site in both the precipitation and moisture has been elsewhere motivated in terms of competitive factors involving the interference of the landmasses and the associated reduced moisture convergence feeding the lower portion of the convective clouds (Tuinenburg et al., 2015). Therefore under the influence of the active phase of MJO air masses were preferentially transported from the Indian Ocean (figure 5.9). The high mountains range might have played a crucial role in the migration

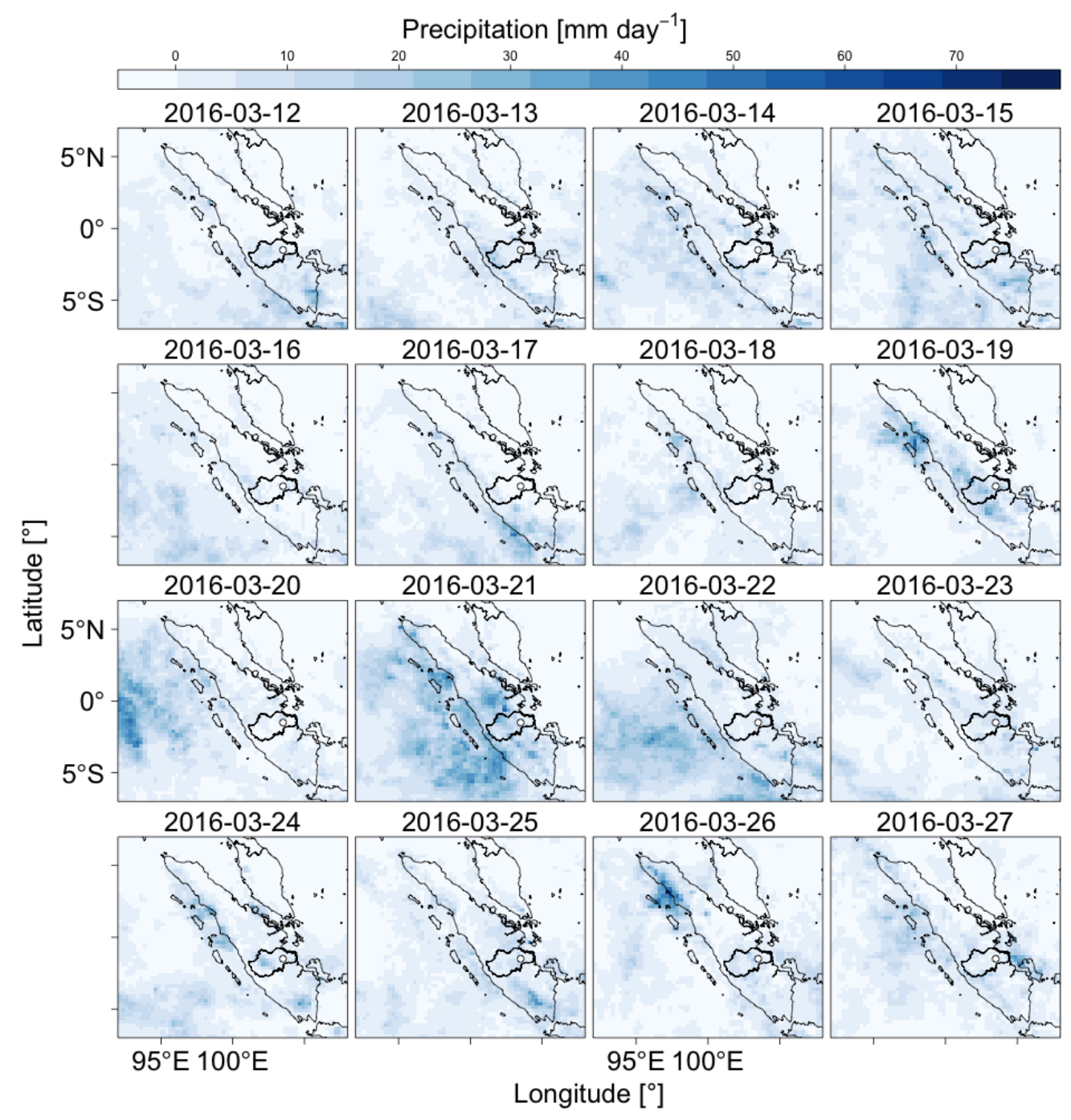

FIGURE 5.8: Daily cumulative precipitation for the domain of interest during the measurement campaign derived from $0.25^{\circ}$ resolution Tropical Rainfall Measurement Mission (TRMM 3B42 RT 3-hourly ( $\mathrm{mm} \mathrm{d}^{-1}$, Huffman et al. (2010))). The solid black line represents the administrative boundary of the Jambi province and white point the location of the tower. 
of the peak rainfall intensity (Mori et al., 2004). During this MJO event, the elevation triggered a rapid rainout on Western Sumatra promoting the transition of the convective non-organized convective cluster first in its organized form and then into stratiform cloud with a consequent depletion of precipitation, due to lower condensation temperature and air subsidence (Kurita et al., 2011).

Despite being indicative of processes occurring at timescales longer than precipitation events (Vimeux et al., 2005), we observed a similar relationship between $\delta D_{p}$, dexc $c_{p}$ and precipitation amount at our site (figure 5.10). As observed by Risi, Bony, and Vimeux (2008) $\delta D_{p}$ (and probably also $d e x c_{p}$ ) provide information on the convective activity that occurred 3 to 4 days before the precipitation event and not on the instantaneous convective maxima. The subcloud layer vapor isotopic composition reacts slower than the convective activity and therefore the $\delta D_{p}$ temporally integrates the convective activity that occurred in the past days (Risi, Bony, and Vimeux, 2008). This explains why we observed a 3 days delay between the peak of the MJO active phase intensity ( $21^{\text {st }}$ March) and the most depleted water vapor and precipitation. However, despite the lag, the information carried in the precipitation reflected the different hydrological history of the air parcels arriving at our site from the 2 opposed sectors, in that both relationships $\left(\delta D_{p}\right.$ and $d e x c_{p}$ vs.

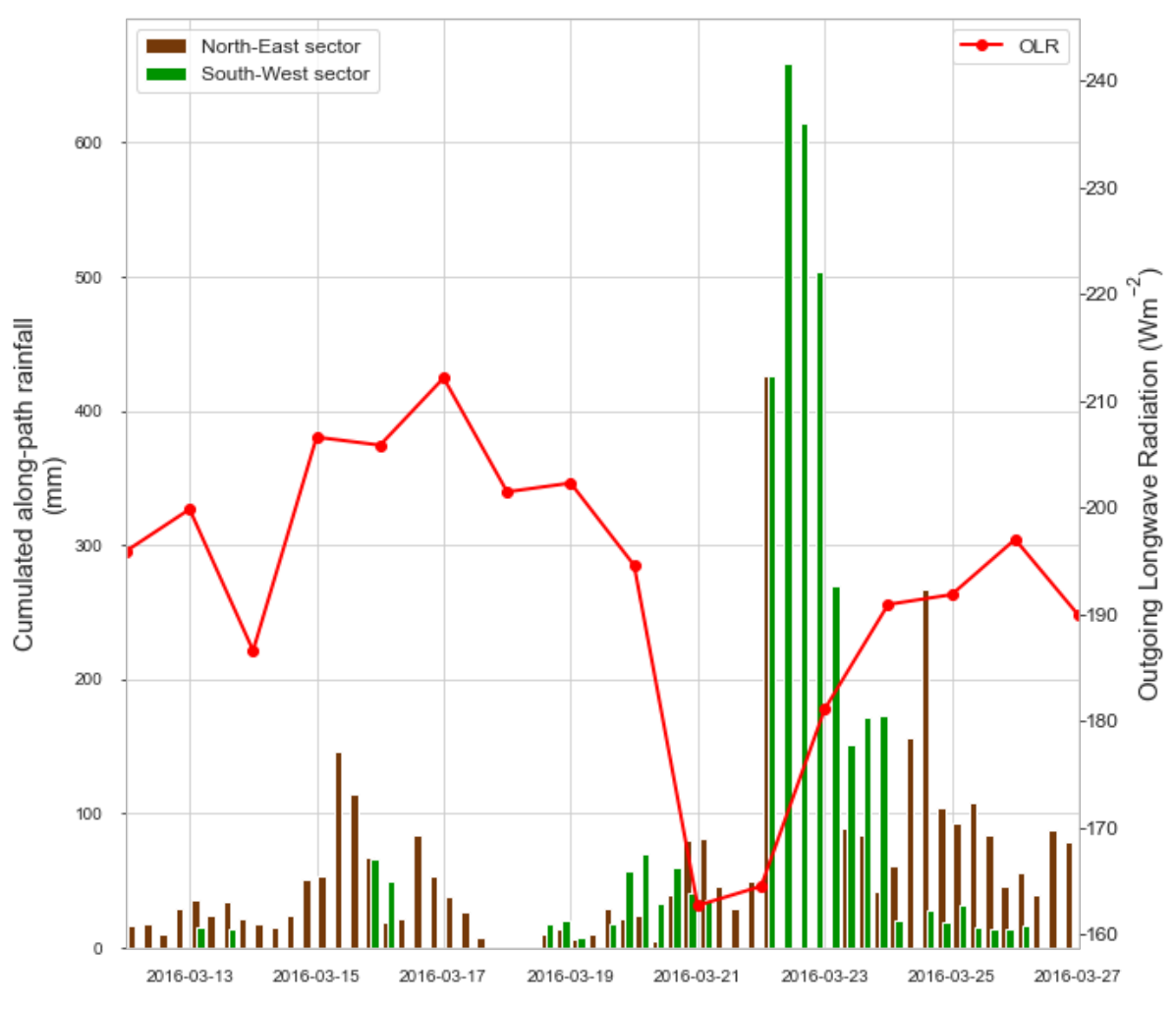

FIGURE 5.9: Along trajectory path cumulative precipitation for the north-east (brown bars) and south-west (green bars) sectors. The red line represents the OLR $\left(\mathrm{W} \mathrm{m}^{-1}\right)$ for the $1^{\circ} \times 1^{\circ}$ grid cell corresponding to the location of our measurement site. 
precipitation amount $(\mathrm{mm})$ ) were similar but the slope of the air parcels experiencing the strongest convection (those originated in the Indian Ocean) was steeper than the slope of the air parcel originating in the South China Sea. Moreover, despite the small number of precipitation events recorded, the Indian Ocean precipitation was significantly more depleted, due to the convection activity with air parcels that travelled at a considerable higher altitude as compared to parcels that originated in the Northeastern sector (figure 5.6).

The distribution of the rainfall isotopic composition in the $\delta D\left(\delta^{18} O\right)$ space was represented by the Local Meteoric Water Line (LMWL). At our site and for the duration of our sampling campaign the slope and the intercept of this line $(7.41 \%$ and $6.53 \%$ respectively were very close to the coefficients of the Global Meteoric Water Line (GMWL, Craig (1961)) represented by the dot-dashed black line in figure 5.11.

The distribution of the moisture isotopic composition at the measuring site in the $\delta D\left(\delta^{18} O\right)$ space revealed that, on average, the more depleted values were recorded when the south-western sector dominated the transport of moisture to the site. However the ordinary least-square coefficients (7.12\% and $-3.04 \%$ vs. $7.30 \%$ and $-0.01 \%$ for slope and intercept of north-eastern and south-western cluster, respectively) were not significantly different between the two clusters. More depleted values may indicate mesoscale (Risi et al.,
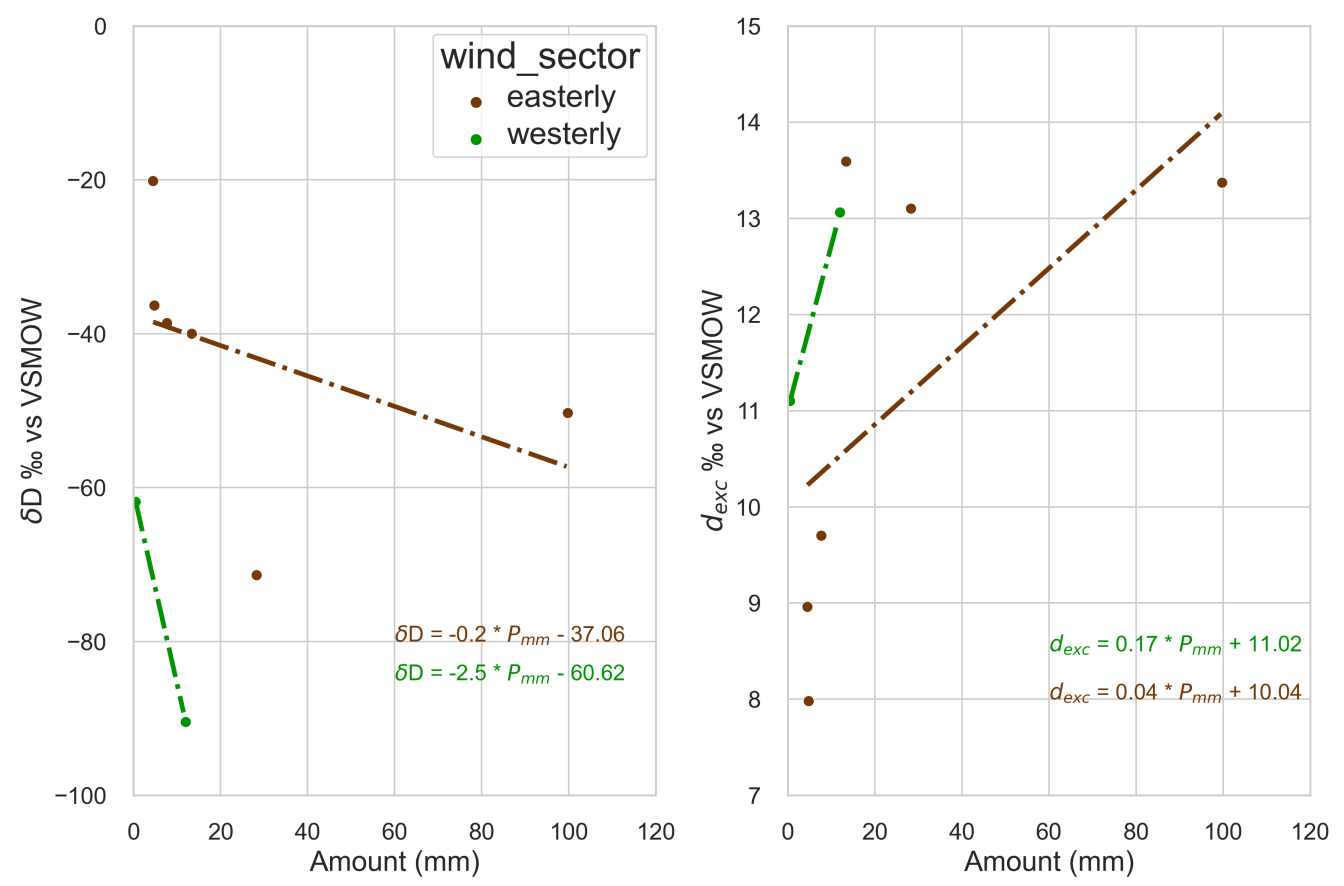

FIGURE 5.10: Amount effect relationship between left) amount of rainfall $(\mathrm{mm})$ and $\delta D_{p}$ and right) amount of rainfall $(\mathrm{mm})$ and $\operatorname{dexc}_{p}$. The relationships were calculated for the precipitation clustered according to the results of the backward trajectories. 
Chapter 5. The influence of the MJO on the isotopic composition of the land-surface water vapor and precipitation in Sumatra, Indonesia.

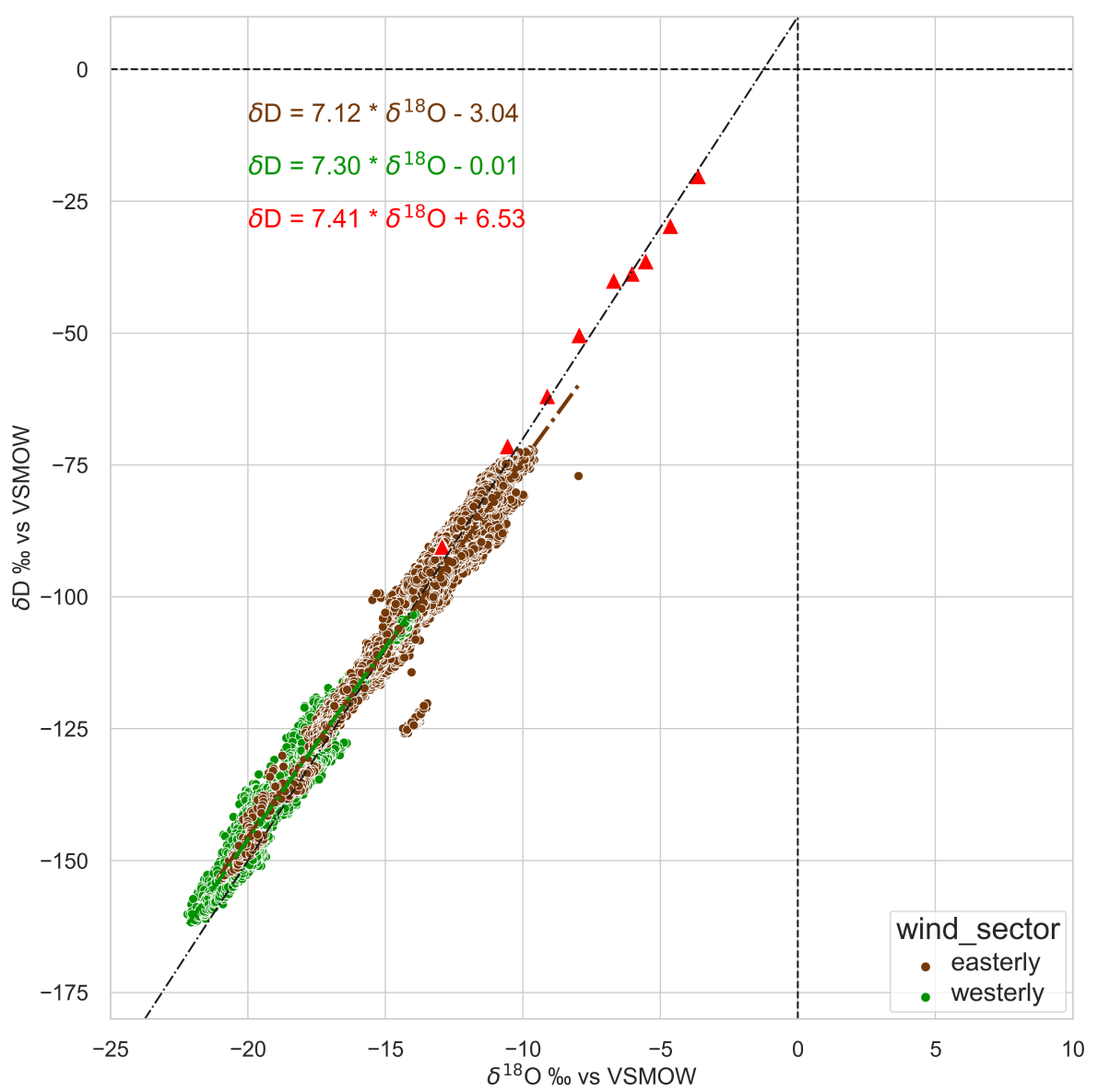

FIGURE 5.11: $\delta D-\delta^{18} O$ plot for 1 minute averaged water vapor isotopic composition associated to the backward trajectory clusters (brown dots for north-eastern and green dots for southwestern sector), and precipitation samples (red triangles). Black dot-dashed line represents the Global Meteoric Water Line and the brown and green dot dashed lines represent the ordinary least square regressions for each group of points. The regression line for the precipitation data was omitted for clarity. The respective OLS coefficients are displayed on the upper part of the plot.

2010; Kurita, 2013) or convective scale subsidence (Risi, Bony, and Vimeux, 2008). Furthermore other mechanisms contributing to the depletion of the isotopic composition of rainfall and moisture include rainfall re-evaporation that feeds the below cloud moisture (Worden et al., 2007; Field, Jones, and Brown, 2010) and the rainfall re-equilibration with the surrounding water vapor (Gedzelman et al., 2003). A possible explanation concerning these mechanisms can be obtained considering the joint evolution of the mixing ratio and the moisture isotopic composition (Worden et al., 2007) as described in the next paragraph. 


\subsubsection{The influence of rain re-evaporation on the surface layer water vapor $\delta D_{v}$}

The surface water vapor isotopic composition $\left(\delta D_{v}\right.$ or $\left.\delta^{18} O_{v}\right)$ at one location is mainly indicative of the temporal evolution of the sites conditions (i.e. daily and seasonal air temperature fluctuations, wetter or moister conditions, etc.) and can give further information about the source conditions through the secondary order parameter deuterium excess (Merlivat and Jouzel, 1979; Pfahl and Wernli, 2008). However, it is not enough to fully understand the mechanisms involved in the moisture production and transport. Therefore, in order to fully understand these processes, we need to use the paired information provided by the isotopic composition and the mixing ratio $\left(q_{v}\right)$. A theoretical framework describes the evolution of the water vapor isotopic composition as a function of the mixing ratio (Noone et al., 2011; Noone, 2012). Here, we applied the same framework to our observations aiming at understanding the physical processes that characterized the water vapor transport at our site (figure 5.12).

The curves plotted in fig. 5.12 represent the theoretical evolution of the isotopic composition of an air parcel under different distillation conditions as explained in the methods section.

We simulated both the distillation and the isotopic mixing by choosing common end members for the 2 clusters. The wet oceanic end member $\delta D_{v}$ $=-72 \%$ and $q_{v}=43.8 \mathrm{mmol} \mathrm{mol}^{-1}$ were calculated assuming an air parcel at saturation $(\mathrm{RH}=100 \%)$ and in isotopic equilibrium with the air temperature above the sea surface at $30^{\circ} \mathrm{C}$ (Majoube, 1971). Despite the backward trajectories simulation showed that the moisture originated partly in the South China Sea and partly in the Indian Ocean, we observed that, on average, the Indian Ocean was not more depleted than the South China Sea. This justifies the choice of an arbitrary starting point of the curves in figure 5.12. For example, using ERA-INTERIM data, the air temperature difference between the 2 domains was smaller than $1^{\circ} \mathrm{C}$ during our observation period. The landenriched member of the isotopic mixing model (yellow dashed curve) was arbitrarily chosen as representative of the moisture contribute from evapotranspiration. The second end member of the isotopic mixing model, assumed equal for both the land and the sea members, corresponding to a dry and depleted air mass with the characteristics of a high tropospheric air parcel, was estimated with a $\delta D_{v}=-360 \%$ and a $q_{v}=1 \mathrm{mmol} \mathrm{mol}^{-1}$. Since oceanevaporating moisture is not immediately at saturation with the ambient air, we chose an ambient relative humidity of $85 \%$ (red point) as starting point of the Rayleigh distillation (solid cyan curve). The dashed cyan curve also represents a Rayleigh distillation but in this case, the water vapor is enriched in heavy isotopes because during every cooling step (represented by the $\mathrm{x}$-axis as decreasing mixing ratio) the condensing vapor is retained in the air parcel, thus it is not removed from the parcel itself. 
The distribution of our measurements, clustered in northeast and southwest sectors, on the $q_{v}-\delta D_{v}$ diagram shows that, before and during the onset on the MJO active phase, when air parcels arrived at the site from the northeast, the abundant moisture supplied from the South China Sea and transported from the westerlies resulted in wetter conditions on the lowland of East Sumatra. In these conditions, the advection of depleted marine moisture mixed with the enriched moisture derived from the evapotranspiration producing the final isotopic composition measured in the oil palm plantation (distant roughly $100 \mathrm{~km}$ from the coast). At the peak of the MJO active phase instead, the convective cluster formed in the Indian Ocean produced an unsaturated and depleted moisture downdraft on the leeward side on Sumatra, that introduced depleted and dryer moisture in the atmospheric surface layer producing a shift towards lighter and dryer moisture in the $q_{v}-\delta D_{v}$ diagram (figure 5.12). Following the $q_{v}$ and $\delta D_{v}$ minima the dominant wind direction turned to West and the surface layer was remoistened with less depleted water vapor. In the Indian Ocean the phasing between the mixing ratio and the isotopic composition has a clock-wise pattern and is characterized by four distinct phases, moistening, depletion, then drying and finally remoistening and enrichment (Tuinenburg et al., 2015) similar to the phasing observed at our site. This means that, in certain cases, the MJO phasing might extend more to the east than what previously thought.

During this MJO event, the most intense precipitations occurred on the west coast of Sumatra (figure 5.8) followed by a rapid decline of the active phase convective cluster. As suggested by Tuinenburg et al. (2015), it is probable that over the maritime continent, the MJO inter-event variability depends both on the actual synoptic activity and on the interaction between the convective clouds and the continents. By looking at the TRMM data we suggest that in this particular case, due to the distribution of the convective cluster on the $21^{\text {st }}$ March, the Barisan Mountains might have accelerated the precipitation rate, thus limiting the extension and the duration of this particular MJO active phase.

In both cases however, the principal mechanism determining the surface layer moisture isotopic composition, after the initial Rayleigh distillation was the precipitation re-evaporation (Berkelhammer et al., 2012). As observed in Worden et al. (2007), rainfall evaporation in the tropics contributes up to the $50 \%$ to the lower tropospheric humidity. This, together with the distribution of the $\delta D_{v}$ vs. the mixing ratio, suggests that a large fraction of moisture reaching our site, both from the South China Sea as well as from the Indian Ocean sector, might have been re-evaporated precipitation that was subsequently advected to our site.

\subsubsection{Summary and conclusion}

The Madden-Julian Oscillation (MJO) is one of the important weather fluctuations affecting the tropics. The MJO consists of a sequence of mesoscale 
convective clusters that slowly propagates eastwards, determining the precipitation regime and consequently the isotopic composition of the moisture along the whole atmospheric vertical profile.

From the $12^{\text {th }}$ to $26^{\text {th }}$ March 2016 we conducted a surface water vapor and precipitation isotopic composition measuring campaign in Eastern Sumatra, close to the city of Jambi. Water vapor isotopic measurements were performed using a WS-CRDS stored in a temperature-controlled hut next to a flux tower. Additionally the tower was equipped with a set of meteorological sensors. Precipitation samples were collected in-situ but their isotopic composition was measured with an identical analyzer in a laboratory in Germany. During the sampling campaign, we observed a significant and rapid negative shift in both the water vapor and rainfall isotopic composition. This shift started after the peak of an intense Madden-Julian Oscillation (MJO) event and the lower values of the mixing ratio and $\delta D$ were recorded 3 days after the peak of the MJO active phase. Combining the information of the isotopic composition of the hydrological tracers, with the data gathered from external sources such as outgoing longwave radiation and the tropical rainfall measuring mission, the results of the ARL-Hysplit particle dispersion model and an isotopic distillation and mixing model, we investigated the influence of the active and the suppressed phases of the MJO exerted on our site.

The principal moisture source of the Jambi area during our sampling campaign were identified in the South China Sea and in the water bodies close to the Malaysian Peninsula due to the predominant westerly winds. Under these conditions air parcels elevations, simulated through the particle dispersion model, travelled in the lower portion of the troposphere carrying large amounts of isotopically enriched moisture. Within the later half of March 2016 a convective cluster, associated to the active phase of the MJO perturbation, formed in the middle of the Indian Ocean and propagated eastwards towards the coasts of the island of Sumatra. The peak of the MJO active phase intensity, confirmed by the OLR minima and the TRMM maxima, was reached on the $21^{\text {st }}$ of March off the coast of Sumatra. This perturbation was characterized by drier condition and isotopically depleted water vapor to our site and the $q_{v}$ and $\delta D_{v}$ minima recorded at our site had a lag of 3 days in respect of the MJO active phase maxima.

The isotopic amount effect, considered at event resolution, increased in air masses experiencing the convection associated to the MJO. However, during the active phase, we recorded the lower precipitation amount at our site. We hypothesize that, in this particular case, the propagation of the convective cloud cluster might have interfered with the Barisan Mountain range, triggering the rainfall intensification on the coasts of west Sumatra and injecting dryer and depleted water vapor to the east. In this case the clock-wise phasing of the $q_{v}$ and $\delta D_{v}$ might be observable further east than previously thought. 

land-surface water vapor and precipitation in Sumatra, Indonesia.

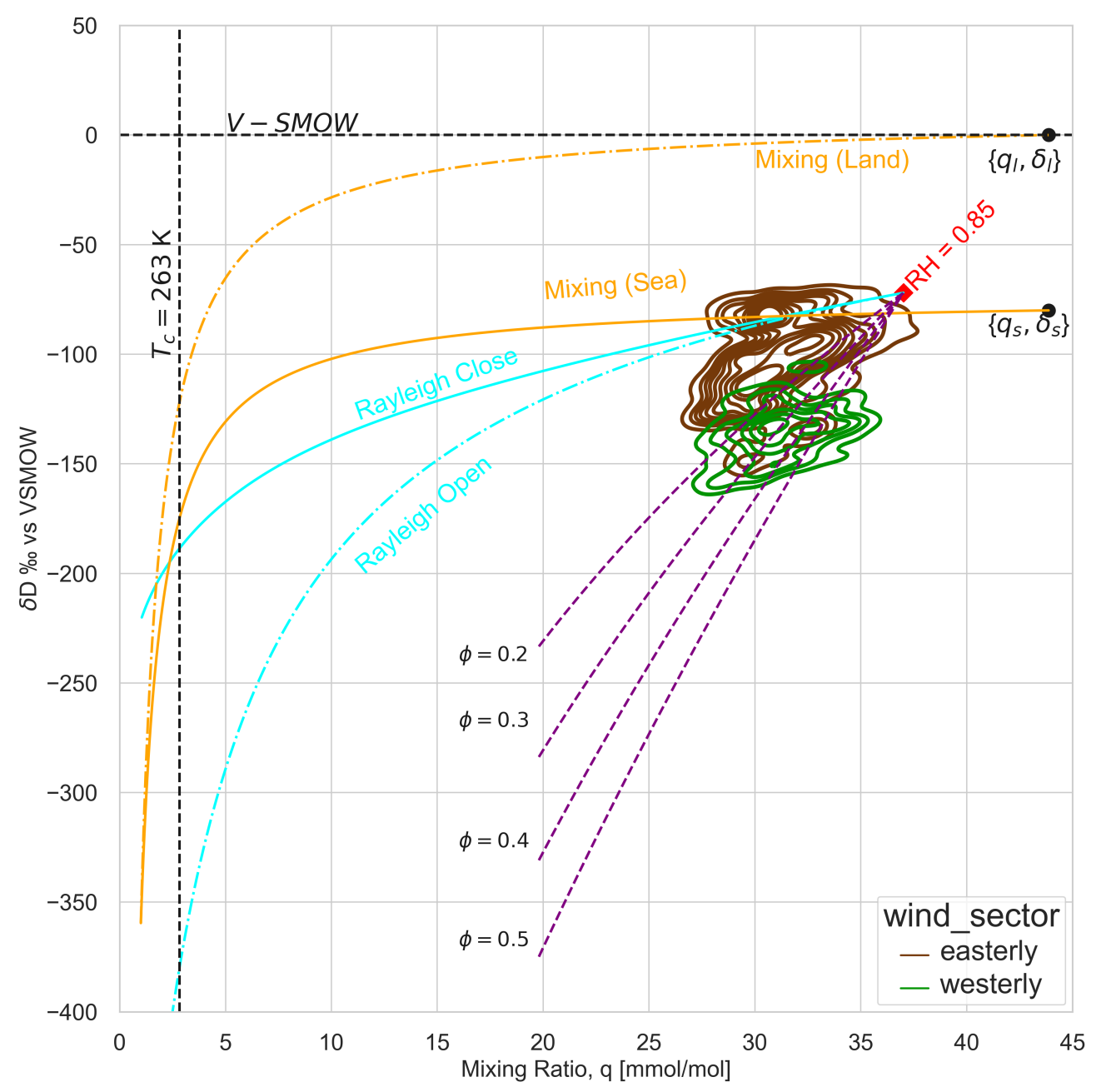

FIGURE 5.12: Theoretical evolution of $\delta D_{v}(\%)$ as a function of the mixing ratio $\mathrm{q}\left(\mathrm{mmol} \mathrm{mol}^{-1}\right)$ under different distillation of the air mass moisture. 1-minute average $\delta D_{v}$ and $q_{v}$ are clustered according to the backward trajectory origin and grouped using Kernel Density Estimation. Mixing lines (orange) represent the evolution of the isotopic composition of vapor due to the mixing of two air masses. Solid orange represents the isotopic mixing between an oceanic source and a dry upper tropospheric air mass, dashed orange results from the mixing of a dry air mass and a land (enriched) moisture source (contribution from evapotranspiration). Solid cyan represents a Rayleigh distillation with maximal precipitation efficiency $(\epsilon=1)$, whilst cyan dashed represents the case where all condensate remains in the cloud (supersaturation $\epsilon=0$ ). The purple dashed lines represent the boundary layer moisture isotopic composition during different rain reevaporation stages. Each dashed purple line corresponds to a different fraction (denoted with the parameter $\phi$ ) of the total rainfall that re-evaporates. Wet oceanic member was calculated assuming global closure equation and using 6 hourly ERA-Interim climatological fields for the considered region with air temperature above the ocean $(\mathrm{t} 2 \mathrm{~m})$ at 303 


\section{Chapter 6}

\section{Partitioning water fluxes in a mature oil palm plantation in Jambi province, Sumatra.}

\subsection{Introduction}

Water vapor released at ecosystem level contributes to the global water cycle budget mainly via soil evaporation $(E)$ and canopy transpiration $(T)$, that together form the evapotranspiration flux $(E T)$ moistening the near-surface atmosphere. While direct estimates of the evapotranspiration flux can be determined using micrometeorological data from eddy-covariance towers (Shi et al., 2008; Meijide et al., 2017), i.e. using the Penman-Monteith equation, more difficult is to measure its isotopic composition $\left(\delta_{E T}\right)$. To date few direct measurements of $\delta_{E T}$ exist (Griffis et al., 2010; Griffis et al., 2011; BradenBehrens, Markwitz, and Knohl, 2019) and these were possible due to the application of laser-based spectrometers in the study of ecosystems moisture flux exchange. The relative contribution of plant transpiration to the total evapotranspiration flux, known also as the $T / E T$ ratio, depends on a multitude of factors, i.e. on the season (Ferretti et al., 2003; Robertson and Gazis, 2006), on the precipitation regime (Brubaker, Entekhabi, and Eagleson, 1993; Lauenroth and Bradford, 2012) and it also varies across regions (Jordan and Heuveldop, 1981) and biomes (Jasechko et al., 2013; Coenders-Gerrits et al., 2014; Schlesinger and Jasechko, 2014; Fatichi and Pappas, 2017).

The isotopic composition of evapotranspiration is a mixture of the isotopic composition of transpiration from leaves and evaporation from the soil (Yepez et al., 2005; Good et al., 2014). Thus, the analysis of water stable isotopes is a useful tool to investigate the $T / E T$ ratio and quantify the water flux partitioning at the ecosystem scale (Yakir and Sternberg, 2000; Wang et al., 2010; Zhang et al., 2010; Dubbert et al., 2013). Heavier water isotopes, $D$ and ${ }^{18} \mathrm{O}$, can be used as tracers of the ecosystems water cycle, in that their distribution in time and space depends on the variability of the atmospheric inputs (i.e. air temperature, precipitation amount and frequency) as well as the interactions occurring between inputs and environment (Harwood et al., 1999; Koster et al., 2004; Aemisegger et al., 2014).

The isotopic composition of soil water $\left(\delta_{s}\right)$, for example, not only depends 
on the isotopic composition of precipitation $\delta_{p}$ but it also changes with depth and time in relation to the soil texture, composition and the temperature of the soil surface layer (Williams and Ehleringer, 2000; Shim et al., 2013). As no isotopic fractionation occurs at root level (Zimmerman, Ehhalt, and Münnich, 1967; Ehleringer and Dawson, 1992; Dawson and Ehleringer, 1993), xylem water isotopic composition $\left(\delta_{x}\right)$ inherits the signal of the average isotopic composition of the soil water at the root uptake depth (Ehleringer and Dawson, 1992; Zencich et al., 2002).

Bulk-leaf water isotopic composition $\left(\delta_{L, b}\right)$, namely the water extracted from a whole leaf (Cernusak et al., 2016), changes instead during the day as it depends on the fractionation occurring within the sub-stomatal cavity and thus on the stomatal activity (Gonfiantini, Gratziu, and Tongiorgi, 1965; Dongmann et al., 1974; Förstel, 1978). In addition, the water flux directed from the leaf to the atmospheric surface layer (transpiration) depends on the humidity gradient between the sub-stomatal cavity and the atmosphere, wind conditions and the leaf geometry and roughness. All these factors combine to increase the isotopic composition of bulk-leaf water that is normally enriched compared to xylem or soil water at the root uptake depth (Farquhar and Cernusak, 2005; Ripullone et al., 2008; Kahmen et al., 2008).

The Craig and Gordon model (Craig and Gordon, 1965) can be used to predict the isotopic composition of soil evaporation and transpiration fluxes (Yakir and Sternberg, 2000; Wang et al., 2010; Hu et al., 2014; Wen et al., 2016). However, to reduce the uncertainties in the determination of the T/ET ratio, some of the models environmental inputs need to be characterized (Dubbert et al., 2013). For soil evaporation the temperature at the evaporative site, which varies along a depth profile, is crucial to estimate the isotopic fractionation factor and therefore the isotopic composition of the evaporating water $\left(\delta_{E}\right)$ and moisture at the evaporative front (Yakir and Sternberg, 2000; Wang et al., 2010; Lai et al., 2006). Furthermore, soil water is almost never in isotopic steady state due to continuous underground water movement, mixing of precipitation and variation of the soil moisture content (Dawson, 1993; Dawson and Ehleringer, 1993; Marshall, Brooks, and Lajtha, 2007). Similarly for leaves, this model can be used to predict the isotopic composition of the transpiration flux $\left(\delta_{T}\right)$, knowing the isotopic compositions of the xylem water $\left(\delta_{x}\right)$, atmospheric moisture $\left(\delta_{a}\right)$ and the environmental conditions surrounding the leaf (Horita, Rozanski, and Cohen, 2008; Dubbert et al., 2013)

Some limitations in its application are represented by leaf physiological parameters that are difficult to measure directly, such as the leaf boundary layer conductance and the effective path length (Kahmen et al., 2009; Song et al., 2013; Roden et al., 2015). The first one is a measure of the aerodynamic resistance (expressed in $\mathrm{m}^{2} \mathrm{~s} \mathrm{~mol}^{-1}$ ) opposing the leaf moisture loss generated by the roughness of the leaf surface and depends on the wind speed and the leaf geometry (Baker and Myhre, 1969; Vesala, 1998). The second parameter (expressed in $\mathrm{m}$ ) instead is the average length of water movement inside the leaf mesophyll from the central veins to the sub-stomal cavity (Farquhar and Lloyd, 1993; Song et al., 2013) and therefore it depends on the tree species and 
the leaf physiological conditions (Barbour et al., 2000; Kahmen et al., 2008).

Commercial monocultures might offer the possibility to investigate the water cycle of an ecosystem, also in an isotopic context, with a high level of detail because they are fairly homogeneous in age, height and leaf area index. Since almost 2 decades Indonesia is experiencing a land use change due to the substitution of the native rainforest with intensive oil palm (Elaeis guineesis Jacq.) plantations (Margono et al., 2014). Due to its commercial value, the ease of its cultivation and the resistance to climatic perturbation, oil palm is shaping the Indonesian landscape with evident consequences for the environment (Barnes et al., 2014; Guillaume, Damris, and Kuzyakov, 2015; Kotowska et al., 2015; Carlson et al., 2012). These include effects on the water cycle due to the modification of the local radiative balance (Comte et al., 2012; Merten et al., 2016). However, despite the importance that this plant achieved in recent times, little is known about the isotopic water cycle and about oil palm physiological parameters related to the isotopic composition of transpiration and soil evaporation (Edwin et al., 2014). To our knowledge, values of leaf boundary layer conductance $\left(g_{b l}\right)$ and effective path length $\left(L_{e f f}\right)$ for oil palm do not exist in literature, therefore, in order to provide estimates for these parameters we investigated the water cycle of an oil palm plantation in Indonesia.

In 2016 we conducted a measurement campaign in a mature oil palm plantation in the province of Jambi, Sumatra, in the framework of the EFForTS CRC990 project (https:/ / www.uni-goettingen.de/en/310995.html). This project investigates the ecological and socio-economic impacts associated with the transition from rainforest to oil palm plantation. To contribute to the understanding of the local water cycle within a mature oil palm plantation we deployed a cavity ring-down spectrometer and measured the water vapor isotopic composition along a vertical profile across the canopy. Additionally we collected, over 3 consecutive days, soil samples at 3 different depths and leaves from 3 different oil palms at two different heights. We initially focused on the determination of the evapotranspiration isotopic composition $\left(\delta_{E T}\right)$ using the Keeling-plot approach (Keeling, 1958; Moreira et al., 1997; Zhang et al., 2010; Berkelhammer et al., 2016). Following we applied the Craig and Gordon model for the determination of the transpiration and evaporation isotopic composition using the water extracted from those samples. By fitting our results with different enrichment models we estimated the isotopic composition of the different water fluxes that were later used to calculate the $T / E T$ ratio.

\subsection{Methods}

\subsubsection{Site location}

The measurement campaign took place from $23^{\text {rd }}$ to $25^{\text {th }}$ March 2016 in a mature oil palm plantation approximately $30 \mathrm{~km}$ west of the city of Jambi, 


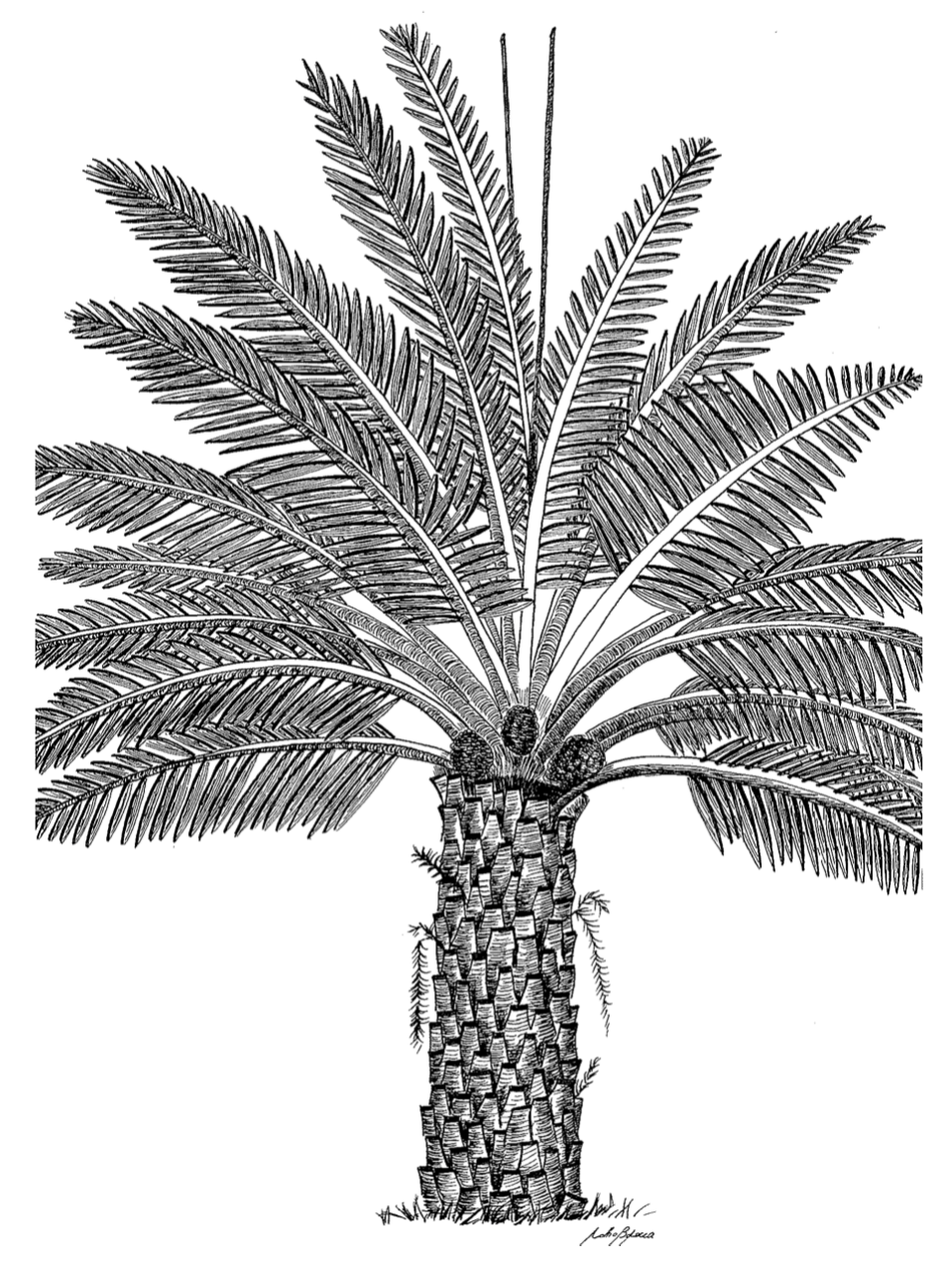

FIGURE 6.1: A graphical representation of a mature oil palm. New fronds grow from the top and gradually descend as new leaves are produced. The big bunches are mature fruits that are well known as palm oil source. The trunk is enveloped from the petiole bases that are removed during the fruit harvesting. This pockets are filled with organic matters, dusts and water that percolate during rainfall. The humidity and temperature characterizing these pockets create a favorable microclimate for the growth of epiphytes.

Sumatra, Indonesia $\left(01^{\circ} 41^{\prime} 34.8^{\prime \prime} \mathrm{S}, 103^{\circ} 23^{\prime} 27.6^{\prime \prime} \mathrm{E} ; 70 \mathrm{~m}\right.$ a.s.l.; plantation extension 2186 ha, figure 6.2). The plantation (PTPN VI) is owned by the PT. Perkebunan Nusantara oil palm production national company and it is one of the sites of the research project Ecological and Socioeconomic Functions of Tropical Lowland Rainforest Transformation Systems (EFForTS, Drescher et al., 2016). At the time of the present study, oil palm trees were $\approx 14$ years old and the average leaf area index was $3.64 \mathrm{~m}^{2} / \mathrm{m}^{-2}$ (Fan et al., 2015). 


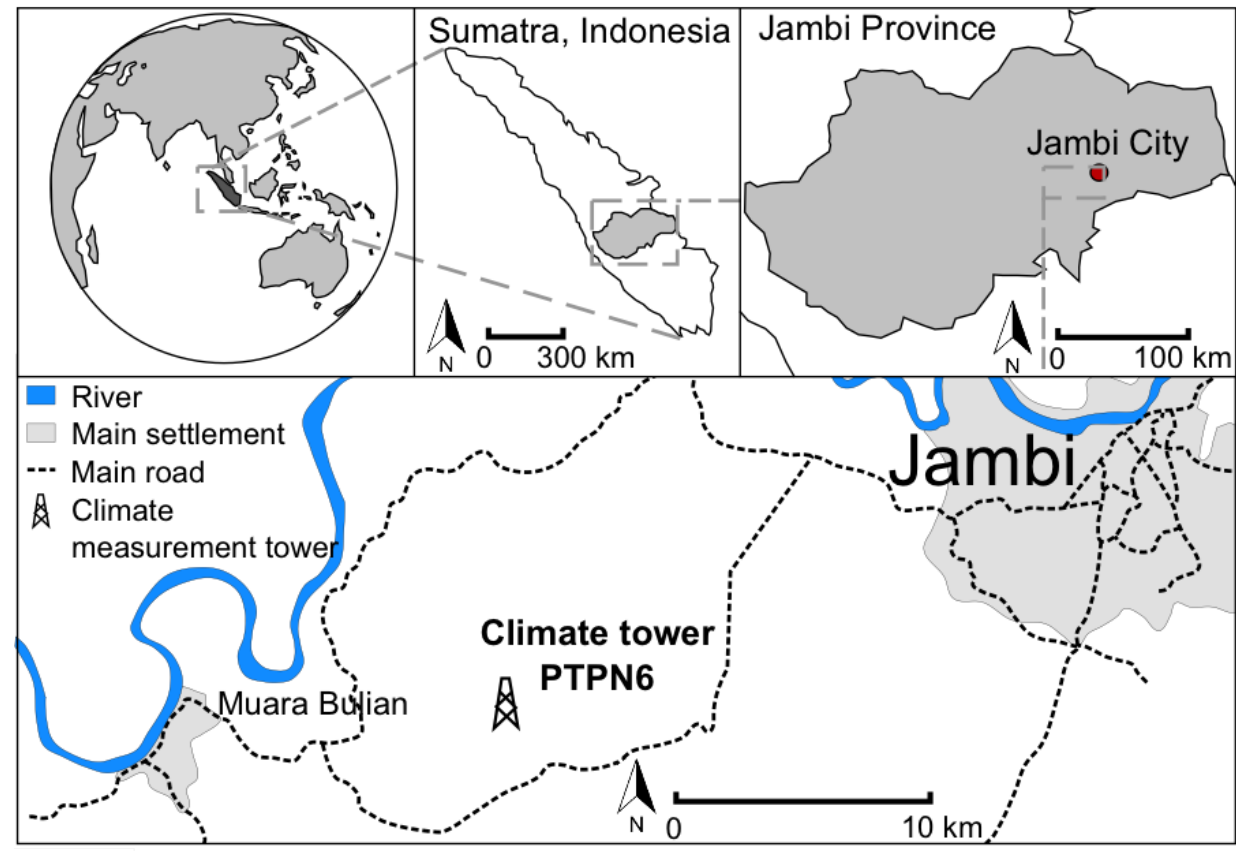

FIGURE 6.2: Map showing the exact location of the study site from Stiegler et al., 2019.

\subsubsection{Water vapor and meteorological measurements}

Air was sampled from a $22 \mathrm{~m}$ tall tower located in the oil palm plantation using 1/2 inch PTFE tubes (Sturm, Zhang, and Noone, 2010) of equal length

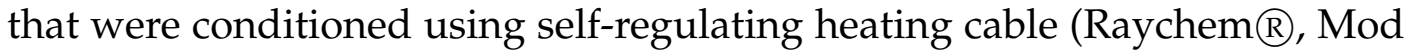
BTV2, Pentair, TX, USA) to prevent condensation on tube walls. Inlets, protected from insects and dust by means of plastic shields, were displaced along the tower at 21, 16, 9, 3 and $0.5 \mathrm{~m}$, to measure water vapor below, within and above the canopy. The Cavity Ring-Down Spectrometer (WSCRDS, L2120-i, Picarro Inc. (R, Santa Clara, CA, USA) was deployed inside a concrete hut next to the tower. The hut also housed air pumps, a manifold and an inlet switching system and kept at constant room temperature $27^{\circ} \mathrm{C}$ using a commercial air conditioner. We used a high flow pump $\left(28 \mathrm{l} \mathrm{min}^{-1}\right)$ to drag air from the inlets to the manifold and a low flow pump $\left(4.2 \mathrm{lmin}^{-1}\right)$ from the manifold to the analyzer, thus providing the necessary constant flow to the spectrometer. Due to this configuration all tubes were continuously flushed, thus avoiding water vapor accumulation and condensation on tube walls when inlets where not in use. Air from each inlet was sampled for 6 minutes providing a complete vertical profile every half hour.

Meteorological parameters, including air temperature and relative humidity (Thermohygrometer, type 1.1025.55.000, Thies Clima $®$, Göttingen, Germany) were measured at 6 different heights along the tower (22, 16.3, 12.4, 8.1, 2.3, $0.9 \mathrm{~m}$ ), atmospheric pressure, wind speed and wind direction

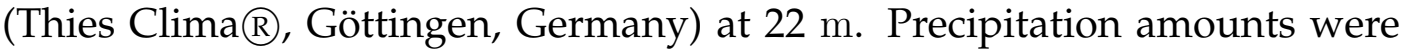
measured by two ombrometers (Thies Clima $\AA$, Göttingen, Germany) placed 
on two sides of the tower. These parameters were cumulated for 10 minutes and averaged between both instruments and stored in a DL16 Pro data logger (Thies Clima $®$, Göttingen, Germany).

The cavity ring-down spectrometer instrumental accuracy was 1.35 and $0.02 \%$ and precision, reported as the standard error of the mean, was 0.25 and $0.04 \%$ for $\delta D_{a}$ and $\delta^{18} O_{a}$ respectively.

\subsubsection{Evapotranspiration isotopic composition}

For the determination of the isotopic composition of the evapotranspiration $\left(\delta_{E T}\right)$ we adopted the "Keeling plot" approach (Keeling, 1958; Moreira et al., 1997; Wang et al., 2010; Dubbert et al., 2013; Berkelhammer et al., 2016). Using this approach, which assumes water vapor originating only from two sources, the determination of $\delta_{E T}$ is found from estimated intercept of the linear regression of water vapor $\left(\delta_{a}\right)$, sampled along a vertical profile throughout the canopy, against the inverse of the mixing ratio $\left(q_{a}^{-1}\right)$, thus using the:

$$
\begin{cases}q_{a} & =q_{E T}+q_{b} \\ \delta^{18} O_{a} q_{a} & =\delta^{18} O_{E T} q_{E T}+\delta^{18} O_{b} q_{b}\end{cases}
$$

where "ET", "a" and "b" stand for evapotranspiration, atmospheric water vapor and background isotopic composition (Good et al., 2014). The solution (here for $\delta^{18} O$ ) of this system of equation is:

$$
\delta^{18} O_{a}=q_{b}\left(\delta^{18} O_{b}-\delta^{18} O_{E T}\right)\left(\frac{1}{q_{a}}\right)+\delta^{18} O_{E T}
$$

The $\delta_{E T}$ was then used, after finding the values for $\delta_{T}$ and $\delta_{E}$ in the equation for calculating the $T / E T$ ratio:

$$
f=\frac{T}{E T}=\frac{\delta^{18} O_{E T}-\delta^{18} O_{E}}{\delta^{18} O_{T}-\delta^{18} O_{E}}
$$

We quantified the effect exerted by evapotranspiration on the atmospheric water vapor isotopic composition through the isoforcing, calculated as follows:

$$
I_{E T}=E T *\left(\delta_{E T}-\delta_{a}\right)
$$

with ET the evapotranspiration flux $\left(\mathrm{mmol} \mathrm{m}^{-2} \mathrm{~s}^{-1}\right)$. Values of $I_{E T}$ above zero suggest an enrichment of the surface layer isotopic composition due to ecosystems transpiration, which is normally enriched in heavier isotopes compared to the background atmospheric water vapor. Below zero $I_{E T}$ values, on the other hand, suggest the introduction of depleted moisture into the lower troposphere. Conditions driving $I_{E T}<0$ occur when soil evaporation predominate over transpiration, or when upper tropospheric moisture reaches the surface atmospheric layer (Lai and Ehleringer, 2011). 


\subsubsection{Leaves and soil sampling}

In order to measure the bulk leaves isotopic composition $\delta_{L, b}$ and model the leaf water isotopic enrichment, we collected oil palm leaf samples from three different trees, at two different heights, close to the flux tower. This dual height sampling was carried out in order to observe the effect of the different sun exposure on the water isotopic enrichment. Leaves were sampled every 3 hours from 06:00 to 19:00 and the operations were suspended during rain events. In addition, the condensation formed on the leaves during the early morning hours was carefully removed to avoid alteration of the final isotopic composition of the sample. From each oil palms branch we sampled 3 leaves with similar dimension, shape and health status. Before cutting and storing the leaves in glass vials we measured the leaf stomatal conductance $\left(g_{s}\right)$ and the leaf temperature $\left(T_{\text {leaf }}\right)$ using a portable leaf porometer (Mod.

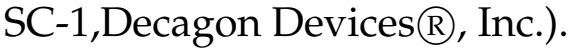

Analogously, for the determination of the isotopic composition of soil evaporation $\left(\delta_{E}\right)$ we sampled the soil in the plantation, right next to the oil palms selected for the leaf sampling, at two different depth $(0.3$ and $0.7 \mathrm{~m})$, using a $1 \mathrm{~m}$ long corer. In addition, for the analysis of the local water cycle, we included the weighted average isotopic composition used for the former study (Chapter 5). All samples were stored in glass vials sealed with Parafilm (R) (Bemis NA, WI, USA) and stored in shade until their arrival in Germany. Due to the local infrastructure and the particular logistic situation we were not in the condition to freeze the samples until they reached the destination.

The samples water content was extracted using a cryogenic vacuum extraction line at University of Göttingen. The extraction system was kept under vacuum at a pressure $<0.001$ mbar bar. The vial with the sample was then frozen with liquid nitrogen and, after its complete refrigeration, the vacuum was applied to the sample vial and the collecting water vial to avoid the contamination caused by ambient water vapor. After a sufficient vacuum condition was reached the sampled material was heated using an electric oven $(\approx$ $200^{\circ} \mathrm{C}$ ) and, due to the vacuum and temperature gradient, water vapor was transferred from the sample vial to the collecting vial (Ehleringer, Roden, and Dawson, 2000; West, J. Patrickson, and Ehleringer, 2006). The performance of the extraction was cross-validated using a precision scale, comparing the weight of the sampling vial with the sum of the water extracted and the organic material from where the water was extracted. Extracted water was analyzed using a WS-CRDS (Picarro $\AA$ mod. 12120-i) at University of Göttingen equipped with a Micro Combustion Module (MCM) that allowed the measurement of the isotopic composition of samples contaminated with organic compounds (as Methanol or Ethanol) produced during the extraction of samples. All measurements were calibrated against the internal standard listed in table 5.1. We also used the procedure described in (Martín-Gómez et al., 2015) to detect and remove the isotopic signal of the organic compounds from the extracted water. 


\subsubsection{Determination of $\delta_{T}$ and $\delta_{E}$}

Extracted water from leaves and soil material was used for the calculation of the isotopic composition of the transpiration and evaporation flux. The model for predicting the isotopic composition of moisture evaporating from a water surface is the Craig and Gordon model (Craig and Gordon, 1965) that in its general form is:

$$
R_{E}=\frac{1}{\alpha_{k} \alpha^{+} *(1-h)} *\left(R_{e}-\alpha^{+} h R_{a}\right)
$$

where $R_{E}$ is the isotopic ratio of the evaporating moisture, $R_{e}$ the isotopic ratio of water at the evaporative site, $\alpha_{k}$ and $\alpha^{+}$the kinetic and equilibrium (Majoube, 1971) fractionation factors respectively, $R_{a}$ the isotopic ratio of the ambient moisture and $h$ the relative humidity normalized to the temperature of the evaporating surface (Craig and Gordon, 1965). In the determination of the evapotranspiration constituents, this general form of the model was adapted according to the parameters defining the local evaporative conditions, thus for soil evaporation $\left(\delta_{E}\right)$ we used the isotopic composition (and then the isotopic ratio) of the soil water extracted at $30 \mathrm{~cm}$ below the surface because we estimated this to be the water source of the majority of the evaporation flux. Accordingly we used the meteorological data, including the soil temperature at $30 \mathrm{~cm}$ to estimate the equilibrium fractionation factor, the relative humidity at the soil atmosphere interface and thus $h$. For the kinetic fractionation factor we used a value of $\alpha_{k}=1.026$ corresponding to an averaged value that we found after a literature research (Merlivat, 1978; Cappa, 2003; Luz et al., 2009; Dubbert et al., 2013) as this parameter, depending on the different molecular diffusivities of water isotopologues and depending on the wind speed, was not determined at our field site. Moreover, since we sampled moisture at different heights we considered only the moisture collected from the lower inlet $(0.6 \mathrm{~m})$ as mostly representative of the evaporation flux.

The determination of the transpiration flux, generated in the substomatal cavity, was affected by large uncertainties. For example, since oil palm is a monocot plant with a particular morphology, we were not able to sample the xylem water because we could not separate the bark and thus sample the transpiring source water. We hypothesize that this source water could have had an isotopic composition similar to the deep soil that in turn depended on the weighted average precipitation isotopic composition measured during the entire field campaign. In addition, many physiological parameters where approximated, such as the effective path length $L_{e f f}$, indicating the length of the path that separates the water vein from the substomatal cavity, or the characteristic leaf dimension that depends on the leaf dimensions and shape. To reflect above described sources for uncertainty in the estimation of the isotopic composition of transpiration $\left(\delta_{T}\right)$ we applied a series of different isotopic enrichment models with an increasing complexity. 
Initially we converted all isotopic composition measurements to isotopic enrichment terms, applying the following:

$$
\Delta_{e}=\frac{\delta_{e}-\delta_{s}}{1+\frac{\delta_{s}}{1000}}
$$

where $\Delta_{e}$ is the isotopic enrichment of the liquid with isotopic composition $\delta_{e}$ at the evaporating site and $\delta_{s}$ is the isotopic composition of the generic water source. Using this equation all $\delta$ values were converted in $\Delta$ units (isotopic discrimination) and calculated as a function of a common water source (in this case the isotopic composition of the soil water collected and extracted at $70 \mathrm{~cm}$ ). Following we calculated the predicted leaf isotopic enrichment using the following (Farquhar, Cernusak, and Barnes, 2007):

$$
\Delta_{e}=\left(1+\epsilon^{+}\right) *\left[\left(1+\epsilon_{k}\right)\left(1-\frac{w_{a}}{w_{i}}\right)+\frac{w_{a}}{w_{i}} *\left(1+\Delta_{a}\right)\right]-1
$$

where $\epsilon^{+}$and $\epsilon_{k}$ were the equilibrium and kinetic enrichment factors respectively $(\epsilon=(\alpha-1) * 1000), \frac{w_{a}}{w_{i}}$ the ratio between the air and the leaf surface vapor pressure (depending on the leaf temperature) and $\Delta_{a}$ the isotopic discrimination of the atmospheric water vapor compared to the source water.

Next the predicted isotopic enrichment at the evaporating site included the steady-state regime assumption. This model assumes that the water vapor isotopic composition of transpiration can be directly determined from the source water (xylem) adding a parameter that includes the rate of diffusion of heavier water isotopes within the leaf mesophyll. The model is described using the following (Farquhar and Lloyd, 1993):

$$
\Delta_{L, s s}=\Delta_{e} *\left(\frac{1-e x p^{-\wp}}{\wp}\right)
$$

where the result of the predicted enrichment 6.8 was multiplied for the Péclet effect. This effect, used as second term of the equation 6.7, taking into account the transpiration flux (in $E_{t}$ in $\mathrm{mmol} \mathrm{m}^{-1} \mathrm{~s}^{-1}$ ) calculated as:

$$
E_{t}=\left(\frac{g_{s} g_{b l}}{g_{s}+g_{b l}}\right) *\left(\frac{e_{i}-e_{a}}{P_{a t m}}\right)
$$

where $g_{s}$ and $g_{b l}$ were the stomatal and boundary layer conductance respectively. While $g_{s}$ was directly measured using the portable leaf porometer, $g_{b l}$ was estimated using the following relationship (Bonan, 2015):

$$
g_{b l}=\frac{1}{0,147 * \sqrt{\frac{w s}{d}}}
$$

where $w s$ was the wind speed (in $\mathrm{m} \mathrm{s}^{-1}$ ) and $\mathrm{d}$ the leaf characteristic size (m) determined, using a oil palm paper replicate representing the average shape of a leaf samples collected in the field, as follows: 


$$
\sum_{i=1}^{n}=w_{i} * d_{i}
$$

with $w_{i}$ the width of the leaf at the section $i$ and $\mathrm{d}$ the length of the section and $n$ the number of section in which the replicate was segmented. After the determination of these parameters the Péclet effect was calculated using the following:

$$
\wp=\frac{L_{e f f} * E_{t}}{C * D}
$$

where D the molecular diffusivity of $\mathrm{H}_{2}^{18} \mathrm{O}$ in water (Cuntz et al., 2007), C the molar concentration of water $\left(\mathrm{mol} \mathrm{m}^{-2}\right)$ and $L_{\text {eff }}$ the effective path length, which for this study was assumed $0.01 \mathrm{~m}$.

Since the isotopic steady-state condition was reached only during midday, when the transpiration flux reached its maximum, we determined the leaf isotopic enrichment in non steady-state that considers the effect of isotopic back diffusion, using the following (Farquhar and Cernusak, 2005):

$$
\Delta_{L, n s s}=\Delta_{L, s s}-\frac{\alpha^{+} \alpha_{k}}{g_{t} * w_{i}} * \frac{1-e x p^{-\wp}}{\wp} * \frac{d\left(W \Delta_{L, n s s}\right)}{d t}
$$

with $W$ the mesophyll water concentration $\left(\mathrm{mol} \mathrm{m}^{-2}\right)$ calculated using the average leaf surface and the water volume extracted from each sample and $g_{t}$ the total conductance calculated as follows:

$$
g_{t}=\frac{g_{s} * g_{b l}}{g_{s}+g_{b l}}
$$

Through this model the estimates of bulk leaf enrichment not only took into account the Péclet effect, but also considered the temporal variability of the bulk enrichment multiplied for the water concentration within the leaf. This means that at each time step the non-steady state model includes the isotopic effect of unenriched source water entering the leaf lamina under the pressure potential generated by water evaporating from the stomata. This phenomenon is expressed by the equilibrium between the isoflux and the isostorage terms as follows (Farquhar and Cernusak, 2005):

$$
\frac{d\left(W \Delta_{L, b}\right)}{d t}=T *\left(\delta_{s}-\delta_{L, b}\right)
$$

The equation 6.15 describes the evolution of the isotopic composition within a leaf in terms of ratio of isotopes accumulation within the mesophyll, known as isostorage, and flux of isotopes in and out the leaves, known as isoflux (Dongmann et al., 1974; Farquhar and Cernusak, 2005).

Once we obtained the estimates for the bulk leaf water enrichment using these models described above we finally used the Crain and Gordon model to calculate the isotopic composition of transpiration and the $T / E T$ ratio. 


\subsection{Results and discussion}

\subsubsection{Meteorology}

The meteorological conditions at the PTPN VI site during our measurement campaign were characterized, except during rain showers, by low to moderate wind conditions, in that for over the $90 \%$ of the time, the wind speed was below $4 \mathrm{~m} \mathrm{~s}^{-1}$. During nighttime and before the sunrise the air moisture was almost always at saturation and this resulted in the deposition of dew on the oil palm leaves. In the early morning hours, before sunrise, the column of air along the tower was well mixed in that the gradients of the mixing ratio and of the oxygen-18 were, on average, $0.69 \mathrm{mmol} \mathrm{mol}^{-1}$ and $0.32 \%$ respectively.

In daytime, from early morning to dusk, we observed a progressive moistening of the air column as the mixing ratio increased, on average, by $\approx 4$ mmol mol ${ }^{-1}$ along the towers air column. The combined effect of the low wind speed and the high humidity regime below the dense foliage suggest an accumulation of moisture under the canopy that was reflected by the maximal mixing ratio increase $\left(\approx 5 \mathrm{mmol} \mathrm{mol}^{-1}\right)$ observed under the canopy at $3 \mathrm{~m}$ height. We noted also that the largest mixing ratio gradient $\left(2.17 \mathrm{mmol} \mathrm{mol}^{-1}\right)$ between the above and below canopy heights occurred in the late afternoon (06:00 p.m.) during sunset.

Similarly, the moisture isotopic composition (only $\delta^{18} O_{a}$ ) increased during the day from an average of $-17.17 \%$ above the top of the canopy in the early morning, to an average of $-12.99 \%$ in the late afternoon. The maximal gradient of the moisture $\delta^{18} O_{a}$ recorded along the profile was $1.15 \%$ between the bottom and the top of the canopy in the late afternoon. The variability of the moisture deuterium excess $\left(\operatorname{dexc}_{a}\right.$ ranged $\approx$ from 10 to 16 $\%$ along the entire profile, except for the profile in the late afternoon at 06:00 p.m.) hourly profiles was lower than that observed for the mixing ratio and the $\delta^{18} O_{a}$. However, consistent with the pattern of the air relative humidity (not shown), the $\operatorname{dexc}_{a}$ vertical profiles increased from early to late morning reaching the maximal values in the early afternoon $(16 \%$ ) when the surface layer reached the driest conditions (figure 6.3).

\subsubsection{Determination of $\delta_{E T}$ and isoforcing}

We determined the isotopic composition of evapotranspiration using the 1minute resolution record of water vapor mixing ratio and isotopic composition measured with the cavity ring-down spectrometer along the vertical profile. The dataset was aggregated into half hour intervals and for each interval the Keeling plot intercept was calculated using equation (6.2).

The eddy covariance derived ecosystem scale evapotranspiration flux (Meijide et al., 2017) ranged from $\approx 0.2\left(\mathrm{mmol} \mathrm{m}^{-1} \mathrm{~s}^{-1}\right)$ in the early morning to a maximum value of $10.87\left(\mathrm{mmol} \mathrm{m}^{-1} \mathrm{~s}^{-1}\right)$ at 13:30 (LT) on the $25^{\text {th }}$ March 2016. 

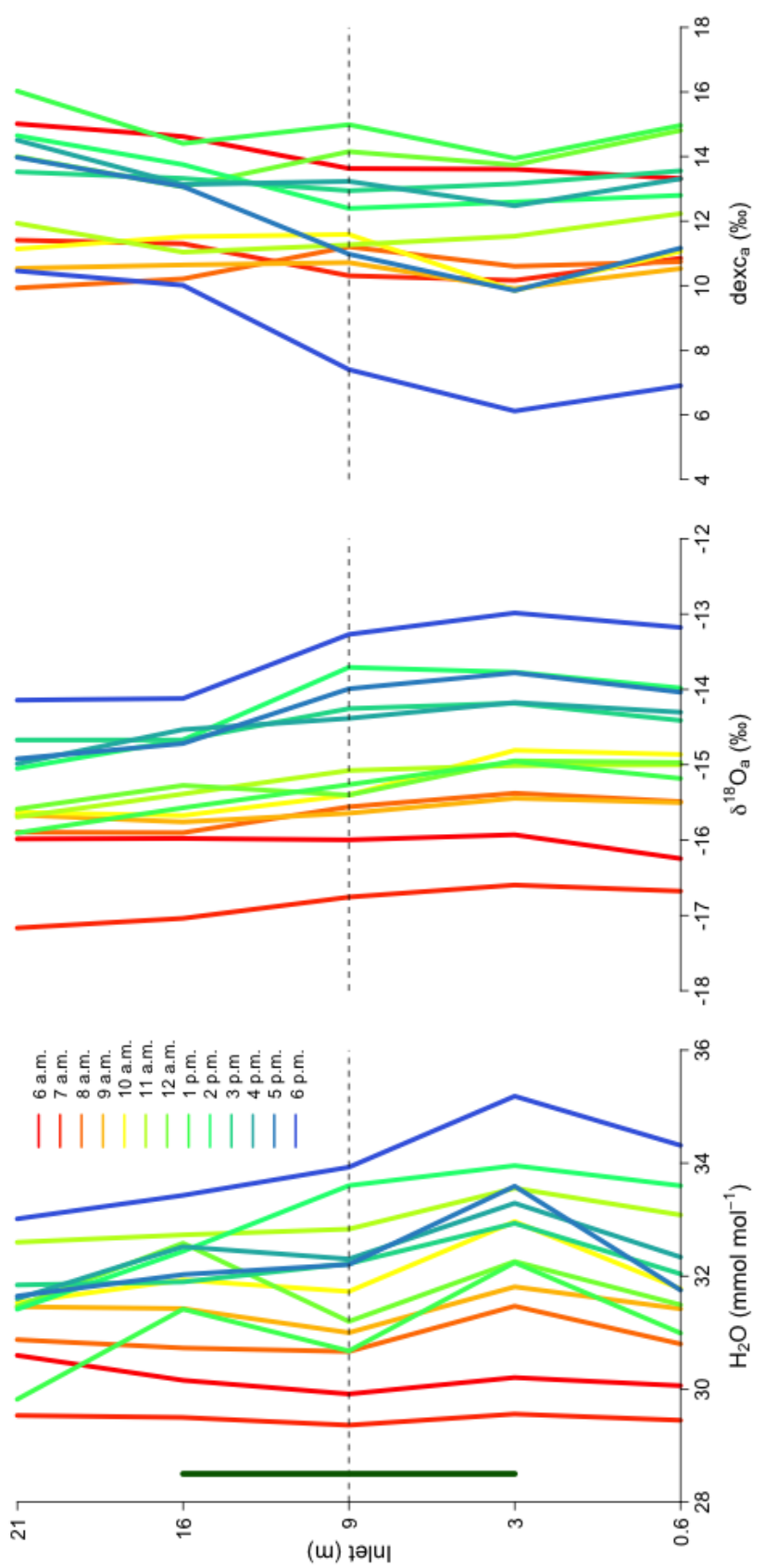

FIGURE 6.3: Daytime average hourly vertical profile of water vapor mixing ratio $\left(\mathrm{mmol} \mathrm{mol}^{-1}\right), \delta^{18} O(\%)$ and deuterium excess $(\%)$. Dotted line represents the average canopy height and the dark green vertical line on the left side the extension of the oil palm canopy.

During the morning of the March $24^{\text {th }}$ a thunderstorm occurred together with a dense cloud cover, which explains the lower ET values on that day. A large variability characterized the evapotranspiration isotopic composition determined via the Keeling plot approach, in fact the $R^{2}$ values of the 104 half-hourly linear regressions ranged from 0 to 0.95 . Higher determination 
coefficient values were typically obtained for daytime regressions whilst in the nighttime their values decreased substantially. Above described large variability was related to the water vapor sampling strategy, which did not involve the use of chambers for the measurement of evaporation and transpiration. Therefore, the absence of a pronounced vertical gradient made it impossible to distinguish the sources of the moisture fluxes in the lower part of the atmospheric boundary layer. However, we observed a daily fluctuation of $\delta_{E T}$ when running a 3-hourly moving average.

During nighttime, without the contribution of the evaporation and transpiration fluxes, the isotopic composition of evapotranspiration $\left(\delta_{E T}\right)$ was close to the isotopic composition of the atmospheric water vapor $\left(\delta_{a}\right)$. However, during the day we observed a systematically increasing enrichment of the atmospheric water vapor ranging from -18.7 to $-3.45 \%$ with the maximum values reached in the early afternoon (figure 6.4). Our results were comparable with the measurements (from -20.00 to $-5.00 \%$ ) obtained in summertime in an agricultural ecosystem in Minnesota (Griffis et al., 2010).

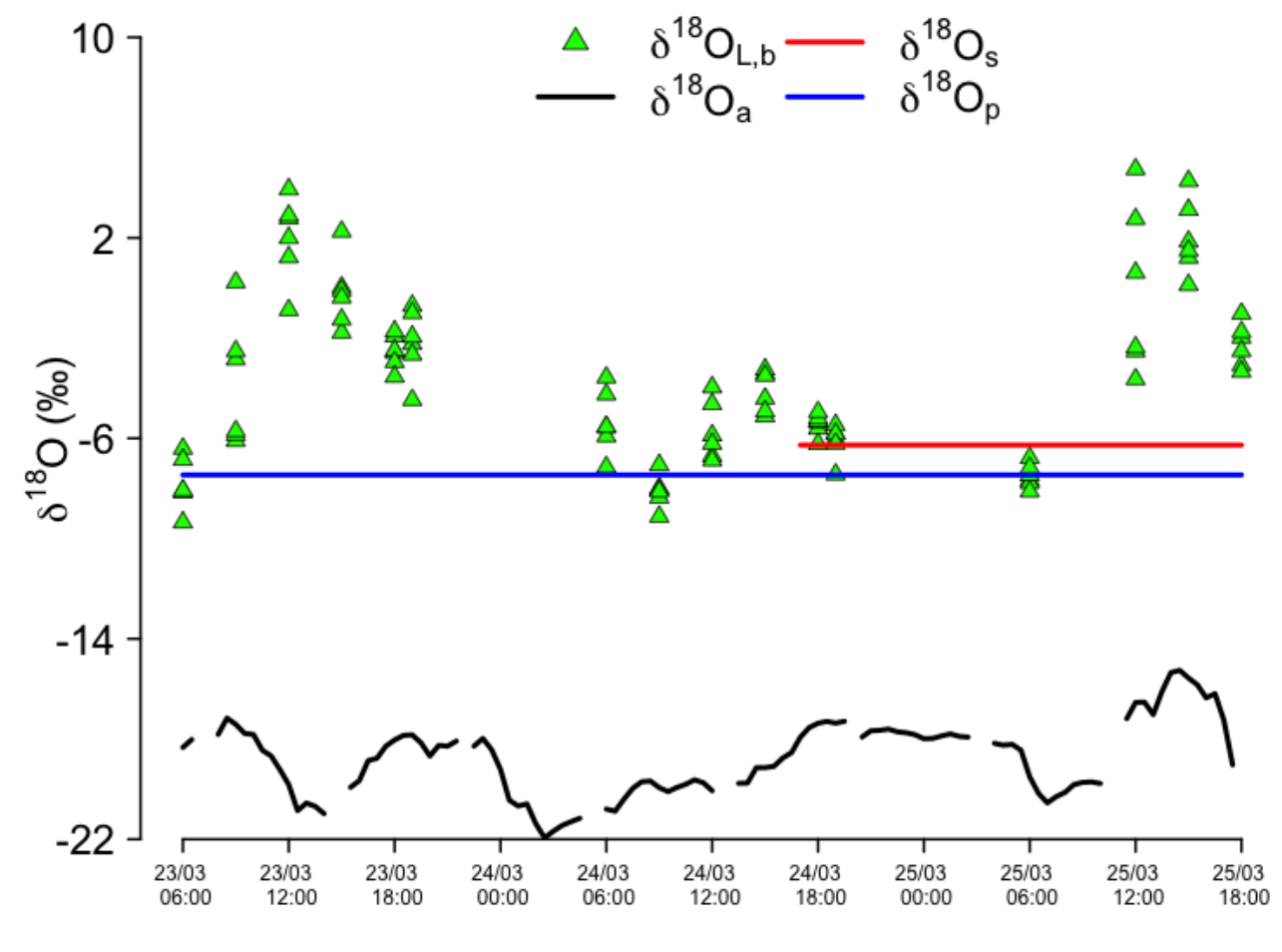

FIGURE 6.4: Top: Bulk leaf water isotopic composition. Black solid line surface layer water vapor isotopic composition. Blue solid line represents the weighted average rainfall isotopic composition and the red solid the average soil water isotopic composition at $0.7 \mathrm{~m}$ depth. Bottom: Dark-green diamonds are the half-hourly $\delta_{E T}$. Green and red solid lines represent the 3 and 6 hourly moving average respectively.

Moreover, the contribution given by the evapotranspiration isotopic composition to the background water vapor was estimated using the isoforcing 
equation 6.4. On average, from early morning to the late afternoon, we observed an $\approx 2 \%$ enrichment of the boundary layer water vapor as a consequence of the injection of enriched water vapor into the atmospheric surface layer (figure 6.5).

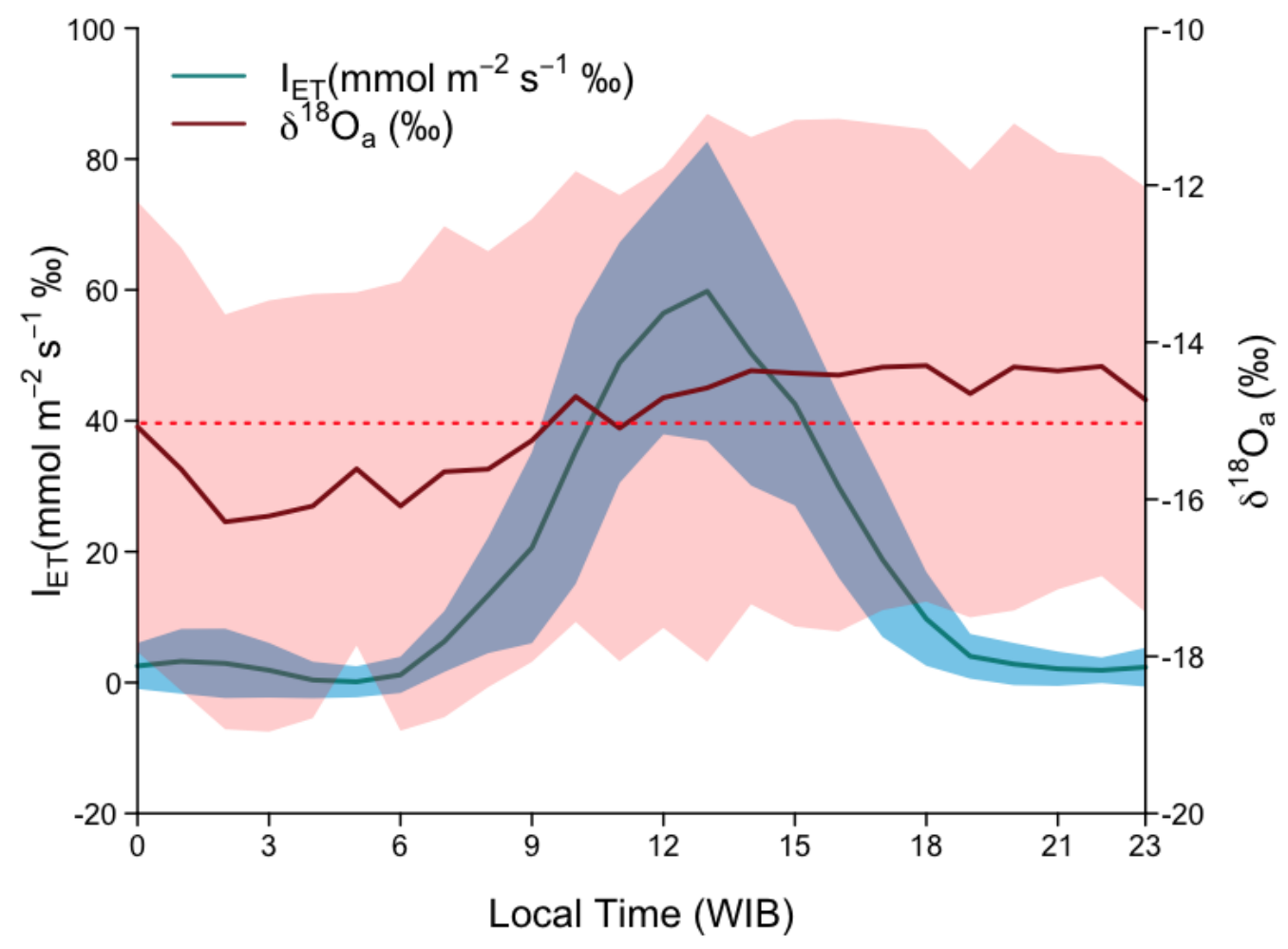

FIGURE 6.5: Hourly ensemble of evapotranspiration isoforcing (cyan solid line) and average atmospheric water vapor (red solid line). Red dashed line represents the average atmospheric water vapor isotopic composition during the measuring campaign. Shadings represent $\pm 1 \sigma$ of isoforcing and water vapor isotopic composition respectively.

\subsubsection{Isotopic composition of $\delta_{L, b}$ and $\delta_{s}$}

The observed isotopic composition of bulk leaf water $\left(\delta_{L, b}\right)$ had a range (for $\delta^{18} O$ ) between $-9.35 \%$ to $4.74 \%$ for the sun exposed leaves, and a range between $-8.36 \%$ and $4.27 \%$ for the shaded leaves. In all leaves the lower values were found in early morning and late afternoon when the stomatal conductance $\left(g_{s}\right)$ was close to zero. In the higher leaves, influenced by the strongest sun radiation the largest isotopic enrichment amplitude was observed.

Due to the faster radiative cooling occurring at the top of the canopy, in early morning and late afternoon the bottom leaves temperatures (24.4 ${ }^{\circ} \mathrm{C}$ and $\left.27.7^{\circ} \mathrm{C}\right)$ were slightly higher than the top leaves $\left(23.3^{\circ} \mathrm{C}\right.$ and 27.0 ${ }^{\circ} \mathrm{C}$ ) figure 6.6. On average we measured the higher stomatal conductance 

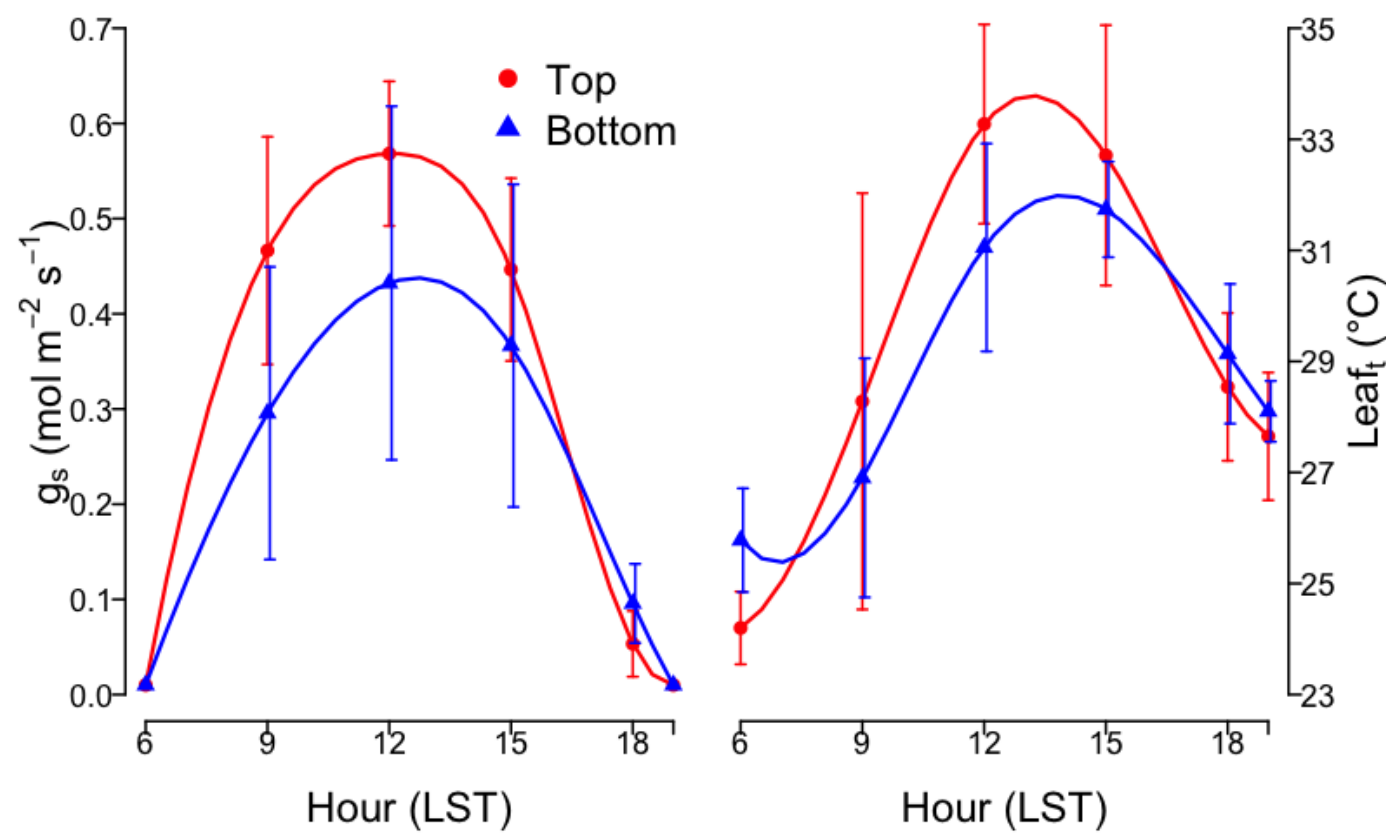

FIGURE 6.6: Left: Hourly ensemble of the average stomatal conductance $\left(\mathrm{mol} \mathrm{m}^{-1} \mathrm{~s}^{-2}\right)$. Right: Hourly ensemble of the average leaf temperature $\left({ }^{\circ} \mathrm{C}\right)$ for top (red solid line) and bottom leaves (blue solid line). The lines represent a polynomial fit and whiskers $\pm 1 \sigma$

$\left(0.568 \pm 0.076 \mathrm{~mol} \mathrm{~m}^{-1} \mathrm{~s}^{-2}\right)$ on the top leaves at midday, however, the $g_{s}$ of the bottom leaves $\left(0.432 \pm 0.186 \mathrm{~mol} \mathrm{~m}^{-1} \mathrm{~s}^{-2}\right)$ had a larger variability due to the fact that during our measurements some bottom leaves were also sun exposed and not entirely in shade. The observed daily stomatal conductance pattern observed in the mature oil palm at PTPN VI, with a maximum in early afternoon, was similar to the one observed in West Africa during the wet season where it was concluded that oil palms show this pattern when soil water availability is not limited (Rees, 1961).

Soil water had an isotopic composition ranging from $-10.51 \%$ to -3.34 $\% 0$ at $30 \mathrm{~cm}$ depth, meanwhile at $70 \mathrm{~cm}$ depth the range was from $-8.0 \%$ to $-4.48 \%$. The higher standard deviation $(1.91 \%$ for $30 \mathrm{~cm}$ and $0.98 \%$ for $70 \mathrm{~cm}$ ) that we found in the upper soil isotopic composition were related to the broader temperature and relative humidity excursions during daytime. These effects were evident from the values and range of the soil water deuterium excess (between -0.38 and $9.59 \%$ for the $30 \mathrm{~cm}$ layer and between 2.71 and $8.81 \%$ for the $70 \mathrm{~cm}$ layer) with extreme values for the most superficial layer.

The local meteoric water line (LMWL) calculated through the linear regression of the deuterium as function of the $\delta^{18} O$ contained in rainfall was defined by the: 


$$
\delta D=(7,41 \pm 0,2) * \delta^{18} O+(6,53 \pm 1,7)
$$

very close to the global meteoric water line (GMWL) and quite similar to Palu, in Sulawesi (Chapter 4, paragraph 4.3.5). The overlap between the rainfall and soil water isotopic composition shows that precipitation was indeed the source water for both the evaporation and transpiration flux (figure 6.7).

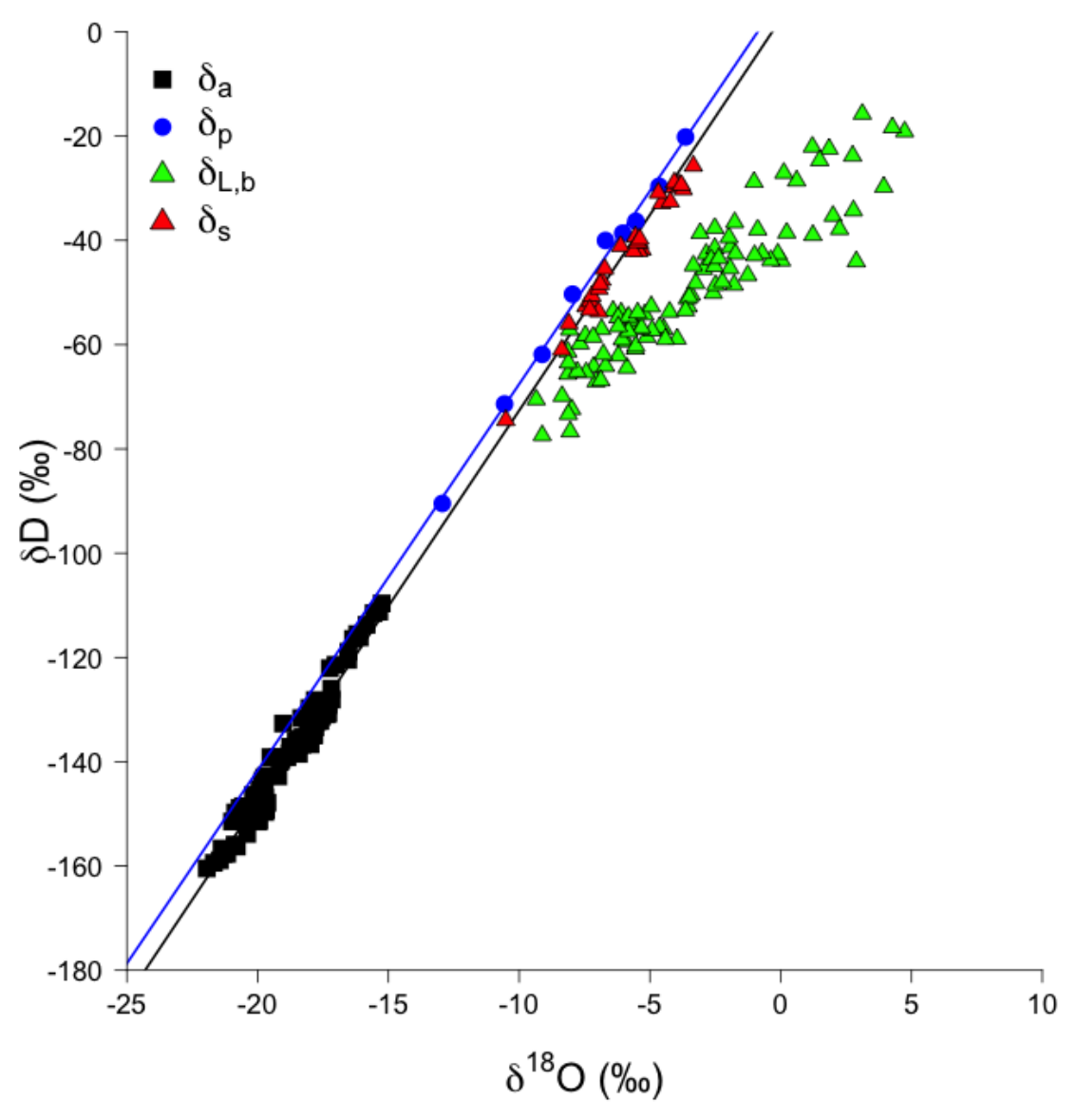

FIGURE 6.7: $\delta D\left(\delta^{18} O\right)$ plot of half-hourly surface layer water vapor (grey crosses), rainfall (blue diamonds) and bulk leaves (green triangles). Solid cyan line represents the GMWL and dark green solid line the bulk leaf water evaporative line.

The slope of the bulk leaf water isotopic composition instead showed the increasing leaf isotopic enrichment and the decreasing deuterium excess (between -67.14 and $4.31 \%$ for top canopy leaves and between -56.51 and 7.38 $\% 0$ for bottom shaded leaves) that was consistent with the evaporative character of the leaf enrichment under progressively dryer atmospheric conditions (Wen et al., 2008; Lai and Ehleringer, 2011; Berkelhammer et al., 2013; Aemisegger et al., 2014). 


\subsubsection{Modeling the bulk leaf water isotopic composition}

The bulk leaf water enrichment was calculated (equation 6.6), using as source water the average isotopic composition of the $0.7 \mathrm{~m}$ deep soil sample $\left(\delta^{18} O_{s}\right.$ $=6.52 \%$ ). Normally the largest portion of oil palm roots grows at a depth between 0 and $0.6 \mathrm{~m}$ (Carr, 2011). However, for the source water isotopic composition, we discarded the water extracted at $0.3 \mathrm{~m}$ due to its higher variability.

The observed leaf water enrichment had a range between $-2.85 \%$ and $11.33 \%$ compared to the source water and it was strongly influenced by air relative humidity. On the $24^{\text {th }}$ March we observed a strong decrease $(\approx 6.0$ $\%$ and $\approx 8.0 \%$ for top and bottom leaves respectively) of the leaf water enrichment, most likely driven by the meteorological conditions characterized by an intense rainfall event in the early morning and a thick cloud cover persisting during the whole day (figure 6.4 shows the $\delta_{L, b}$ ).

The isotopic enrichment at the evaporative site $\left(\Delta_{L, e}\right)$ was predicted using the Craig and Gordon model adapted for leaf transpiration. This model uses the enrichment of atmospheric water vapor $\left(\Delta_{a}\right)$ in respect of the source water, the ratio between the water vapor mole fraction in the air and in the leaf (normally at saturation), the equilibrium fractionation factor at leaf temperature and the kinetic fractionation factor (Dongmann et al., 1974; Farquhar and Lloyd, 1993; Flanagan, Comstock, and Ehleringer, 1991; Farquhar, Cernusak, and Barnes, 2007).

The average difference between the predicted water enrichment at the evaporative site $\left(\Delta_{L, e}\right)$ and the observations $\left(\Delta_{L, b}\right)$ was larger in the early morning (09:00 LT) for both the upper leaves and the lower leaves $(+3.96 \%$ and $+2.27 \%$ respectively) however this difference decreased during the day (Table 6.1 and figure 6.8).

TABLE 6.1: 3 hourly $\Delta_{L, b}-\Delta_{L, e}$ values in $\%$

\begin{tabular}{ccccc}
\hline & $09: 00$ & $12: 00$ & $15: 00$ & $18: 00$ \\
\hline Upper & 3,964 & 1,861 & 2,49 & 1,533 \\
Lower & 2,268 & 0,175 & $-0,311$ & $-0,378$ \\
\hline
\end{tabular}

The model predicting the leaf water enrichment however assumed the isotopic steady-state at the evaporation site within leaves, which means that it considers the water at the evaporative site having the same isotopic composition of the source water (xylem). The steady-state condition occurs very seldom in leaves because equilibrium between the flux of xylematic water from the central veins to the mesophyll cavity and the vapor flux exiting from the stomata must be established (Dongmann et al., 1974; Farquhar and Cernusak, 2005; Ogée et al., 2007; Welp et al., 2008; Dubbert et al., 2013). Fluctuations of the solar radiation, temperature and humidity could produce 
variations of the stomata aperture, thus moving the mesophyll ambient away from the isotopic equilibrium condition.
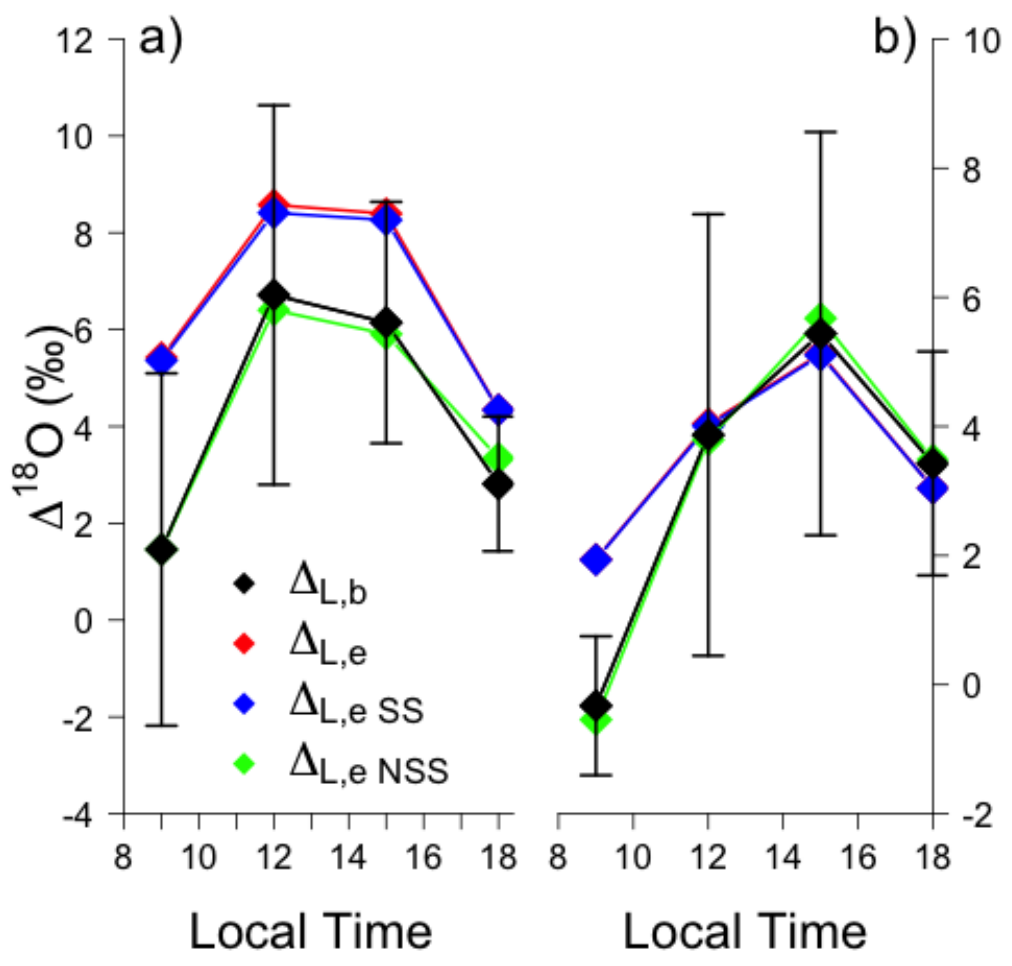

FIGURE 6.8: a) Observed average daytime hourly bulk top canopy leaf water isotopic composition (black diamonds) and simulated using the different enrichment models. Whiskers represent $\pm 1 \sigma$. b) Same for bottom canopy leaves.

In the upper leaves, more exposed to these fluctuations, the difference between observed and predicted leaf water enrichment was larger than in the lower leaves. To explain this deviation we applied a multiple linear regression model with $w a / w i$, the equilibrium (depending on leaf temperature) and the kinetic fractionation factors as predictors of the modeled leaf water enrichment. We found that these 3 parameters alone explained the $90 \%$ of the variance of the predicted enrichment and that, among these, the wa/wi ratio counted for approx. 50\% (followed by the $\alpha^{+}$with $42 \%$ and $\alpha_{k}$ with approx. $10 \%$ ) of the total variance. For this reason we could conclude that the difference observed between the modeled upper and lower leaves was most likely caused by the humidity gradient and by the leaf temperature that was higher on younger and sun exposed compared to the older sun-shaded leaves.

The next step was the introduction of the Péclet effect, where we tested the unknown and species-specific "leaf effective path length" $\left(L_{e f f}\right)$ parameter (equation 6.8 and 6.12). Since we did not find any $L_{e f f}$ value for oil palm in literature, we chose an arbitrary value of $10 \mathrm{~mm}$ to run the simulations; we performed a sensitivity analysis by varying this value in $5 \mathrm{~mm}$ 
increments around the selected value and we did not find any significant improvement of the steady-state enrichment model to simulate the observations, thus $10 \mathrm{~mm}$ was chosen for what follows. By plotting the proportional difference between $\Delta_{L e, s s}$ and $\Delta_{L, e}$ (calculated as $1-\Delta_{L e, s s} / \Delta_{L, e}$ ) as a function of the transpiration flux we didn't observe any relationship. A possible reason that could explain this phenomenon is the consideration that in oil palm leaves, as already observed in other species, the quantity $L_{e f f}$ is not fixed, but variable (symplastic or apoplastic movement) depending on the intensity of the water flow through the leaf tissues (Cernusak, Pate, and Farquhar, 2002; Kahmen et al., 2008; Song et al., 2013; Roden et al., 2015). In fact, if this were indeed true, it might explain, together with the effect of the larger humidity and temperature gradients, the larger deviation between $\Delta_{L e, s s}$ and $\Delta_{L, e}$ in the top leaves (figure 6.8-a).

We achieved the best agreement between observations and predictions with the introduction of the non steady state (NSS) leaf water enrichment model (equation 6.13). On average the NSS behavior of the leaf water followed the leaf bulk water enrichment closely because a temporal leaf water mass balance was added to previous models (Dongmann et al., 1974; Farquhar and Cernusak, 2005). In the lower leaves (figure 6.8) the application of the same set of models produced only a small difference between the observations and the predictions, whilst in upper leaves the difference was larger at each sampling time (Table 6.1). Considering equation 6.15 we can conclude that the observed difference between the two set of leaves relies on their different dynamics, driven by environmental and physiological variability, in storing heavier isotopes with the leaf lamina (Simonin et al., 2013). At the canopy height where upper leaves were harvested, the environmental conditions were hotter, drier and the wind speed higher as compared to the bottom of the canopy. Therefore, the leaves net isoflux, that is driven by transpiration and is responsible for the enrichment of the bulk leaf water, was counterbalanced by a higher and faster isostorage, thus decreasing the predicted leaf water enrichment due to the introduction of unenriched xylem water in the leaves lamina.

\subsubsection{Transpiration isotopic composition and flux partition- ing}

After determining the isotopic enrichment at evaporative site we calculated the isotopic composition of transpiration using the Craig and Gordon model for the evaporation flux of a water body (Craig and Gordon (1965), equation 6.5).

We observed a similar pattern of the average transpiration isotopic composition between the top and the bottom leaves (figure 6.9). In the morning time $\delta_{T}$ was depleted in heavy isotopes due to the lower stomatal conductance and transpiration flux $(-25.66 \%$ and $-24.46 \%$ for upper and lower leaves respectively). The $\delta_{T}$ steadily increased during the morning until the maximum isotopic composition was reached in the early afternoon (-18.57\%0 


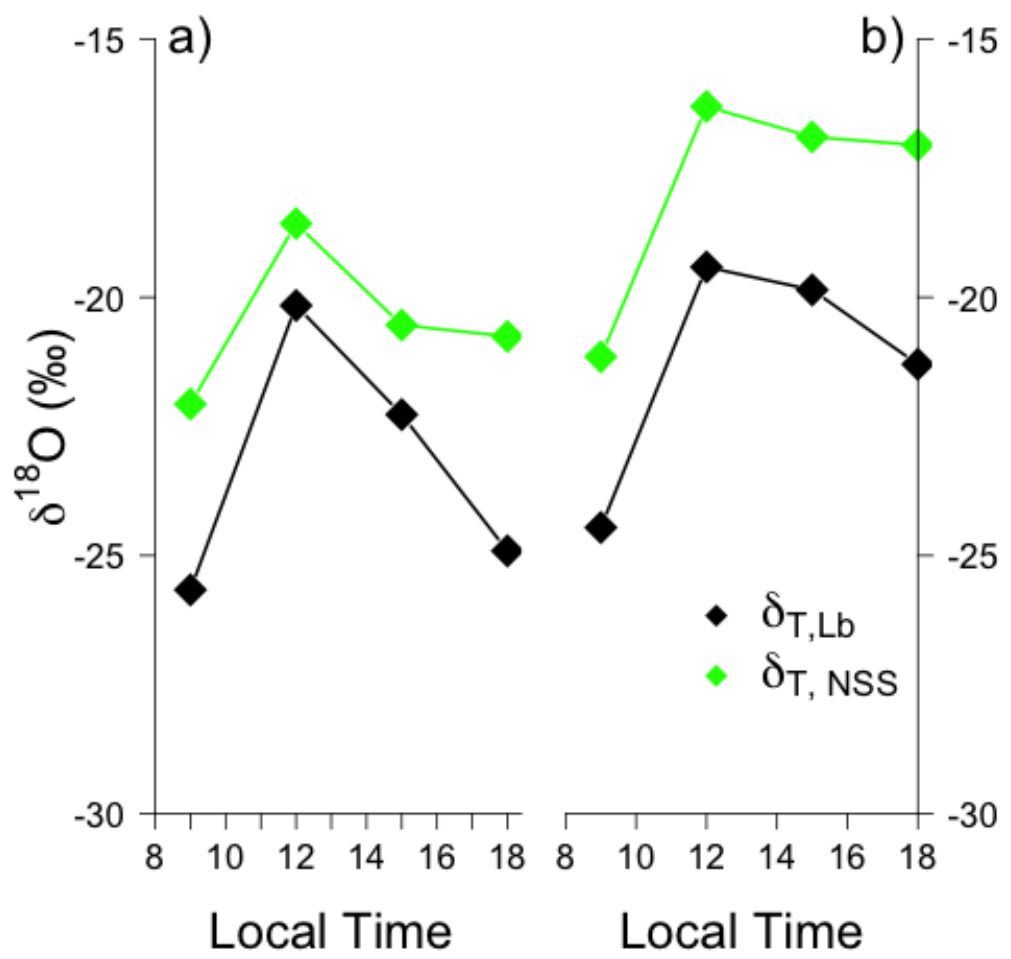

FIGURE 6.9: a) Average hourly transpiration isotopic composition from upper leaves calculated via the Craig and Gordon model (Craig and Gordon, 1965) using bulk leaf water isotopic composition (black diamonds) and the simulated enrichment at the evaporating site using the Non Steady State assumption (green diamonds). b) Same for lower leaves.

and $-16.30 \%$ ) and returned to lower values during the afternoon.

We observed the largest deviation between "bulk leaf transpiration" and "NSS transpiration" in the lower leaves, despite the simulations provided the best results in modeling isotope enrichment at the evaporation site. The reasons for this large bias could be explained by the sensitivity of the model to the relative humidity of the air normalized to the leaf surface temperature (equation 2.24) that appears in both terms of the Craig and Gordon model, and that, depending on the ratio between the temperature of the air and the temperature of the leaf, can quickly produce large uncertainties if not precisely measured.

Finally the isotopic composition of each flux was used to estimate the $T / E T$ ratio (equation 6.3) in the mature oil palm plantation. The results for the observed bulk leaf water and for the non-steady state predicted enrichment are shown in the following tables:

According to Röll et al. (2015) the T/ET ratio in a mature oil palm plantation can be up to 53\%. In their study however, Röll et al. (2015) used micrometeorological and sap flux methods to estimate the plantation water fluxes. 
TABLE 6.2: Non steady state in $\%$

\begin{tabular}{lcccccc}
\hline Hour (LT) & $\delta_{E T}$ & $\delta_{\text {Top }, N S S}$ & $\delta_{\text {Bottom }, N S S}$ & $\delta_{E}$ & $f_{\text {Top }}$ & $f_{\text {Bottom }}$ \\
\hline 09:00 & -15.23 & -22.06 & -21.15 & -18.06 & -0.707 & -0.917 \\
12:00 & -12.17 & -18.57 & -16.30 & -4.46 & $\mathbf{0 . 5 4 6}$ & $\mathbf{0 . 6 5 1}$ \\
15:00 & -3.93 & -20.53 & -16.89 & -17.62 & -4.703 & 18.743 \\
18:00 & -6.62 & -20.75 & -17.05 & -16.25 & -2.137 & -12.040 \\
\hline
\end{tabular}

TABLE 6.3: Bulk leaf water in \%o

\begin{tabular}{lcccccc}
\hline Hour $(\mathrm{LT})$ & $\delta_{E T}$ & $\delta_{T o p, L b}$ & $\delta_{\text {Bottom }, L b}$ & $\delta_{E}$ & $f_{\text {Top }}$ & $f_{\text {Bottom }}$ \\
\hline 09:00 & -15.23 & -25.66 & -24.46 & -18.06 & -0.373 & -0.443 \\
12:00 & -12.17 & -20.16 & -19.41 & -4.46 & $\mathbf{0 . 4 9 1}$ & $\mathbf{0 . 5 1 6}$ \\
15:00 & -3.93 & -22.27 & -19.85 & -17.62 & -2.948 & -6.139 \\
18:00 & -6.62 & -24.91 & -21.29 & -16.25 & -1.112 & -1.909 \\
\hline
\end{tabular}

In this study, using water stable isotopes methods, we found that for the leaf bulk isotopic composition $f$ ranged from $49 \%$ to $51 \%$ on upper and lower leaves respectively, whilst, using the predicted NSS model this ratio ranged from $54 \%$ to $65 \%$ (Table 6.2 and 6.3). Despite the application of a laser-based spectrometer for the moisture isotopic composition measurements, the determination of the $\delta_{E T}$ suffered from large uncertainties. The negative values of the $T / E T$ ratio are to be attributed to the uncertainty of the measurement of the isotopic composition of evaporation and transpiration. More precise results would have been obtained by installing chambers on the soil and on oil palm branches. However, despite the uncertainty in our measurements, we were able to obtain a ratio very close to the study mentioned above.

\subsection{Conclusion}

The continental moisture supplied to the atmosphere originates principally from the evaporation of soil water and from the evaporation of the water enclosed in the leaf lamina. Together these two fluxes constitute the evapotranspiration flux. The composition and relative contribution of these two sources to the total evapotranspiration moisture flux, expressed by the T/ET ratio, vary across ecosystems. Therefore, the contribution of humidity provided by the low atmosphere to the global water cycle changes in relation to the local climate and to each ecosystem.

In the context of a warming climate, the acceleration of large-scale land use change contributes to the alteration of the local water cycle, and therefore to changes in the $T / E T$ ratio, due to the substitution of the original vegetation cover with highly productive and performing plant species. For example, in recent years, the intensification of oil palm cultivation sparked a global debate about the consequences that this land use change introduces in 
Sumatra and in Borneo, where the largest plantations are located. In Sumatra the ongoing CRC 990 EFForTS project, partnered also by the University of Göttingen, actively investigates the ecological and socio-economic effects associated with the transition from tropical rainforest to oil palm plantation. In a mature oil palm plantation, for example, it has been shown that, on average, transpiration can represent up to the $53 \%$ of the total evapotranspiration flux, while in a young plantation this ratio can be reduced to only $8 \%$ with clear impact for the local hydrological cycle (Röll et al., 2015).

In the framework of this project we conducted a sampling campaign in the PTPN VI plantation, near Jambi, Sumatra in March 2016. We performed a comprehensive field campaign that combined direct flux observations from an eddy covariance tower with in-situ analysis of the water vapor isotopic composition together with field-sampling of soil and leaf biomass for offline water content isotopic composition analysis. For the first time we implement this integrated sampling approach in an oil palm plantation with the goal to partition the ecosystem-scale water fluxes.

Initially we calculated the isotopic composition of evapotranspiration $\left(\delta_{E T}\right)$ using the Keeling plot approach, and further, using the eddy-covariance derived evapotranspiration, estimated the ecosystems isoforcing to the lower boundary layer water vapor. While the isotopic composition of the soil evaporating moisture was calculated directly from the isotopic composition of the extracted soil water, the isotopic composition of transpiration was instead modeled using a series of leaf water enrichment models of increasing complexity. Finally, to estimate the $T / E T$ ratio of the entire plantation, we calculated the isotopic composition of the soil evaporation $\left(\delta_{E}\right)$ and leaf transpiration $\left(\delta_{T}\right)$ fluxes using the Craig and Gordon model.

Our results show that, despite the large uncertainties that were related to missing observational constraints, e.g. from compartment-scale chamber measurements, we were able to characterize the isotopic composition of ET, $\mathrm{E}$ and $\mathrm{T}$ fluxes. Further we found a good agreement between our estimated T/ET ratio and previous reports from Röll et al. (2015), with an average midday ratio of $\approx 60 \%$, using the NSS model and $\approx 50 \%$ using the observations. 


\section{Chapter 7}

\section{Conclusion}

\subsection{Conclusion}

The global water cycle consists of the transport of water within the Earths crust and in the troposphere. As for the other biogeochemical cycles, the hydrological cycle is characterized by a principal reservoir (i.e. the oceans), storing the largest amount of the substance, and by a number of fluxes responsible for the circulation of water in the environment. Since water is the only substance that can coexist in different physical states within the range of the Earths surface temperature, minor reservoirs (i.e. polar caps, glaciers) can exist when the air temperature remains below the freezing point for longer times. Above the oceans the evaporation and precipitation fluxes represent the largest moisture and liquid water exchange between the surface and the troposphere. Above continents instead, due to the combined effect of soil evaporation and plant transpiration, the evapotranspiration flux predominates the moisture input into the lower troposphere.

The magnitude and the periodicity of the global water cycle fluxes are principally determined by the intensity of the solar radiation. In other words, the hydrological cycle is responsible for the storage and transfer of heat and moisture through the Earth contributing to the regulation of its climate. Comparing to the other area of the Earth, the tropics receive the largest annual amount of solar radiation resulting in a thermal energy surplus that is dissipated towards higher latitudes via the Hadley-Ferrel-Polar cell atmospheric circulation. Furthermore, due to the energy surplus, high ocean temperatures produce large amounts of water vapor feeding the troposphere. This large release in turn, creates the conditions for the development of large-scale convective systems that are responsible for the intense precipitations normally occurring in tropical areas. These convective systems are also associated with large-scale climatic fluctuations such as e.g. monsoons, the Madden-Julian Oscillation (MJO) and the El-Niño Southern Oscillation (ENSO).

Since the climate characterizing a given area is closely linked to the moisture source area and path of the air masses, to the periodicity of atmospheric phenomena and to the topography, there is a strong link between the climatology and the hydrological cycle of a region. The continental moisture supplied to the atmosphere originates from the evaporation of soil water and 
from the evaporation of the water enclosed in the leaf lamina. Together these two fluxes constitute the evapotranspiration flux. The composition and relative contribution of these two sources to the total evapotranspiration moisture flux, expressed by the T/ET ratio, vary across ecosystems. Therefore, the contribution of humidity provided by the low atmosphere to the global water cycle changes in relation to the local climate and to each ecosystem.

Stable isotopes of water, namely deuterium and oxygen-18, form heavier water molecules due to their different number of neutrons in the atoms nuclei. These isotopically enriched water molecules have the same electric charge of the normal and abundant water molecules. Due to the different molecular weight, during phase changes, heavier and lighter water molecules fractionate, leaving the heavier water in the phase with the stronger bounding energy. By exploiting the different masses of chemically equal molecules, stable isotopes can provide unique information, i.e. on the transport of moisture from the ocean to the continent, on the interactions occurring between air masses and local topography, on the effect of large-scale weather phenomena on the local precipitation regime and, at finer scale, on the partitioning of the water fluxes within ecosystems. For this reason water stable isotopes are useful for the study of the global hydrological cycle and in climatology.

The water isotopic composition, namely the ratio between heavier and lighter isotopes measured against a reference value (usually the isotopic composition of the ocean water), is commonly calculated using the "delta-scale" and expressed in "permille" (\%). The standard of reference used in hydrological studies is the V-SMOW that represents the average isotopic composition of the ocean surface and it has a value of $0 \%$. Due to the stronger bounding energy in the liquid phase, precipitation isotopic composition is normally higher (less negative) than moisture, however both are commonly lower than the isotopic composition of seawater. After evaporation from the ocean, moisture condenses in clouds and travels from the source areas towards continents. During their travel the clouds loose their moisture content due to the rainout. At each step of this process the overall isotopic composition of the air parcel becomes less enriched (more depleted) in heavy isotopes, therefore the isotopic composition of precipitation can be considered as tracers of the microphysical processes that influence the air parcels along their trajectories.

The factors that contribute to the variation of the isotopic composition of the air masses moisture and of the precipitation that this generates are mainly latitude and altitude, due to the temperature gradient. However, while the first factor is a long-distance and less pronounced effect, the second, due to the interaction between air masses and the local topography, can be spatially more constrained (i.e. near mountain ranges) but more pronounced. Furthermore, in some cases, the amount of rain lost due to precipitation is not counterbalanced from an equal moisture uptake from the ocean. This effect, 
known as continentality, affects air masses traveling over continents. One last but important factor occurring exclusively in the tropical precipitation and called "amount effect" affects the isotopic composition of the rainfall in an inverse proportion to its intensity.

The distribution of water stable isotopes in precipitation and in moisture around the Earth is studied by a number of researchers and it now plays a central role for the climatology due to the inclusion of these proxies in global circulation models. A worldwide log-term monitoring system is established by the International Atomic Energy Agency that is also one of the two institutes providing the laboratories with the reference materials for the isotopic analysis. However, despite the global coverage of this sampling stations network, some areas of the globe are still under-represented. An area of the globe that still suffers from this sparse monitoring system is Indonesia. The maritime continent develops along the Equator covering an area (considering land and seas together) close to that of the United States. However Indonesia is an archipelago formed by roughly 17000 islands stretching in the middle of the Indo-Pacific Warm Pool. The climate of Indonesia is tropical and characterized by high temperatures and relative humidity all year around. The intense evaporation from the ocean is responsible for the high convective phenomena that bring heavy rains especially during the monsoons. Furthermore, due to the complex topography of this region, with mountains higher than $3000 \mathrm{~m}$, local weather phenomena exist.

In Indonesia, due to the scarcity of water stable isotopes measurements (especially for water vapor) and the complexity of the territory, each sampling campaign can significantly increase our understanding of the local climatology and its controlling factors. In this context and in the framework of the BaririFlux and the SFB990 project, we provide new water stable isotope results in areas where these where not monitored before. The research project presented here was carried out in Indonesia in different sampling campaigns on the islands of Sulawesi and Sumatra, during a period of almost 3 years.

In 2014-15 we conducted a precipitation isotopic characterization study in Central Sulawesi. The sampling sites were chosen in order to represent unique and distinct hydrological conditions and thus we selected a coastal site, at the tip of the bay of Palu in Tanjung Karang, a land-coastal site at the campus of Tadulako University in Palu and a montane rainforest site in Bariri, at the edge of the Lore Lindu National Park. Sampling was conducted at rain event frequency following the guidelines provided by the IAEA and the isotopic composition of the samples measured using a Cavity Ring-Down Spectrometer (Picarro $\AA$ model L2120-i). Our results show that, despite the ENSO intensification, the precipitation regime of this area was still characterized by winter months (October to January), influenced by the north-west Monsoon and marked by an intensification of the precipitation regime and summer months (July to September), influenced by the south-east Monsoon effect, with prevalently dry conditions and occasional heavy rainfall events, 
especially near the coast. Palu, the site located at the end of a narrow bay, was the driest place among our measuring sites due to the rain shadowing effect from the surrounding mountains. These dry conditions were not only evident from the amount of precipitation collected, but also manifested in the lowest deuterium excess values observed in the area. The influence of the winter Monsoon was reflected in both the amount and in the precipitation isotopic composition. During these months not only the intensification of the convective activity, associated with the winter monsoon, promoted an increase in the precipitation rate, but also the decrease of the isotopic composition confirmed the role played by the amount effect in tropical precipitation. Furthermore this effect was observed at all measuring sites, but the most significant was found at the site near the coast. The particular topography and local circulation in the Palu site and the altitude and different location of the Bariri site may explain the different incidence of this effect. Our results show that, despite the relatively small spatial extent of our research area, the 3 sites exhibit distinguishable responses in the rainfall isotopic composition due to the influence of the strong effect of 2015 ENSO, elevation and clouds type.

From March $12^{\text {th }}$ to $26^{\text {th }}$ in 2016 , we sampled water vapor and precipitation in the middle of a mature oil palm plantation in Eastern Sumatra, close to the city of Jambi. Measurements of water vapor isotopic measurements were performed using a WS-CRDS located in a temperature-controlled hut next to a flux tower that was also equipped with meteorological sensors. During the campaign, we observed a significant and rapid negative shift in both the water vapor and rainfall isotopic composition. This shift took place after the peak of the active phase of the Madden-Julian Oscillation (MJO) event. Combining the information obtained from the measured isotopic composition of water vapor and precipitation with external data sources such as outgoing longwave radiation (OLR), tropical rainfall measurement mission (TRMM), the ARL-Hysplit particle dispersion model and using an isotopic mixing model, we investigated the influence of this active phase of the MJO exerted on the atmospheric surface moisture isotopic composition at our site. Our results show that, during the formation and propagation of the convective clouds cluster in the Indian Ocean, corresponding to the onset stage of the active MJO phase, the South China Sea and the water bodies close to the Malaysian Peninsula were the principal sources of marine moisture for the Jambi area due to the predominant action of the westerlies in the lower troposphere. At the peak of the active phase, the most intense precipitation rate was observed on the western coast of Sumatra, suggesting a possible interaction between the propagation of the convective cluster and the mountain range characterizing the topography of the area. In Jambi instead we observed a rapid shift towards lighter precipitation and moisture and dryer conditions culminated with the most depleted rainfall and moisture recorded 3 days after the MJO maximal intensity. The air parcels backward trajectories simulations showed a shift of the moisture sources from the South China Sea to the Indian Ocean during the peak of the MJO active phase followed by an 
equally rapid shift to the normal conditions concurrently to the loss of intensity of the convective cluster. The longer distance, together with the higher traveling altitudes of the air parcels arriving in Jambi from the Indian Ocean showed the strong effect of convection on the isotopic composition of precipitation and moisture recorded at the measuring site. Indeed the effect of convection was also revealed in the precipitation amount, where a stronger relationship was observed in the samples associated with the Indian Ocean in comparison to those associated with the South China Sea origin. Our observations showed the evolution of the atmospheric surface layer specific humidity and moisture isotopic composition under the influence of a MJO event. However, before this study, these observations were limited to shipbased or remote sensed measurements, in that no other study analyzed these parameters on the Island of Sumatra before.

At the same time of the previous study (March $12^{\text {th }}$ to $26^{\text {th }}$ in 2016), we performed a 3 days comprehensive field campaign that combined direct flux observations from an eddy covariance tower with in-situ analysis of the water vapor isotopic composition together with field-sampling of soil and leaf biomass for offline water content isotopic composition analysis. For the first time we implement this integrated sampling approach in an oil palm plantation with the goal to partition the ecosystem-scale water fluxes. Initially we calculated the isotopic composition of evapotranspiration using the Keeling plot approach, and further, using the eddy-covariance derived evapotranspiration, estimated the ecosystems isoforcing to the lower boundary layer water vapor. While the isotopic composition of the soil evaporating moisture was calculated directly from the isotopic composition of the extracted soil water, the isotopic composition of transpiration was instead modeled using a series of leaf water enrichment models of increasing complexity. Finally, to estimate the T/ET ratio of the plantation, we calculated the isotopic composition of the soil evaporation and leaf transpiration fluxes using the Craig and Gordon model. Our results show that, despite the large uncertainties that were related to missing observational constraints, e.g. from compartmentscale chamber measurements, we were able to characterize the isotopic composition of ET, E and T fluxes. Further we found a good agreement between our estimated $T / E T$ ratio and previous reports from (Röll et al., 2015), with an average midday ratio of approx. $60 \%$, using the NSS model and approx. $50 \%$ using the observations.

In conclusion, stable water isotopes are important tools for studying the global water cycle at various scales. Acting as tracers for different physical and biogeochemical processes, they can provide unique information for a wide range of applications and in a variety of contexts ranging from climatology to plant water use efficiency and more. In this research we have used the most common methods adopted in the field of isotopic water geochemistry analysis (i.e. IRMS and Laser Spectrometry). This research has mainly focused on determining the causes of the isotopic composition variability of 
precipitation and surface layer water vapor on two islands of the Indonesian archipelago (Sulawesi and Sumatra) and on disentangling net water exchange into the transpiration and evaporation fluxes in a mature oil palm plantation. Given that this work was conducted mostly in the field and confronted with many logistical and technical issues, we can be satisfied to have contributed, albeit marginally, to a better understanding of the phenomena, like the effect of convection on the precipitation and surface moisture isotopic composition, that regulate the distribution of stable water isotopes in such a complex territory as the Indonesian archipelago. 


\section{Bibliography}

Abatzoglou, J.T. et al. (2018). "TerraClimate, a high-resolution global dataset of monthly climate and climatic water balance from 1958-2015". In: Scientific data 5, p. 170191.

Aemisegger, F. et al. (2014). "Deuterium excess as a proxy for continental moisture recycling and plant transpiration". In: Atmospheric Chemistry and Physics 14.8, pp. 4029-4054.

Aemisegger, F. et al. (2015). "Isotope meteorology of cold front passages: A case study combining observations and modeling". In: Geophysical Research Letters 42.13, pp. 5652-5660.

Aggarwal, P. K. et al. (2012). "Stable isotopes in global precipitation: A unified interpretation based on atmospheric moisture residence time: Stable isotopes in global precipitation". en. In: Geophysical Research Letters 39.11, n/a-n/a. ISSN: 00948276. DOI: $10.1029 / 2012$ GL051937.

Aggarwal, P. K. et al. (2016). "Proportions of convective and stratiform precipitation revealed in water isotope ratios". In: Nature Geoscience 9, p. 624.

Aldrian, E. and R. Dwi Susanto (2003). "Identification of three dominant rainfall regions within Indonesia and their relationship to sea surface temperature". In: International Journal of Climatology: A Journal of the Royal Meteorological Society 23.12, pp. 1435-1452. DOI: 10.1002 / joc. 950.

Amante, C. and B. W. Eakins (2009). "ETOPO1 arc-minute global relief model: procedures, data sources and analysis". In:

Ambach, W. et al. (1968). "The altitude effect on the isotopic composition of precipitation and glacier ice in the Alps". In: Tellus 20.4, pp. 595-600. DOI: 10.1111/j.2153-3490.1968.tb00402.x.

Araguás-Araguás, L., K. Froehlich, and K. Rozanski (2000). “Deuterium and oxygen-18 isotope composition of precipitation and atmospheric moisture". In: Hydrological processes 14.8, pp. 1341-1355.

Araguas-Araguas, L. J. and K. O. Froehlich (1998). "Stable isotope composition of precipitation over southeast Asia". In: Journal of Geophysical Research 103.D22, pp. 28,721-28,742.

As-syakur, Abd. Rahman et al. (2013). “Indonesian rainfall variability observation using TRMM multi-satellite data". In: International Journal of Remote Sensing 34.21, pp. 7723-7738. DOI: $10.1080 / 01431161.2013 .826837$.

Baer, D. et al. (2012). "Environmental and atmospheric monitoring using offaxis integrated cavity output spectroscopy (OA-ICOS)". In: American Laboratory 44 , pp. $20-23$.

Baer, D. S. et al. (2002). "Sensitive absorption measurements in the nearinfrared region using off-axis integrated-cavity-output spectroscopy". In: Applied Physics B 75.2-3, pp. 261-265. 
Baertschi, P. (1976). "Absolute180 content of standard mean ocean water". In: Earth and Planetary Science Letters 31.3, pp. 341-344.

Bailey, A., D. Toohey, and D. Noone (2013). "Characterizing moisture exchange between the Hawaiian convective boundary layer and free troposphere using stable isotopes in water". In: Journal of Geophysical Research: Atmospheres 118.15, pp. 8208-8221.

Baker, D. N. and D. L. Myhre (1969). "Effects of leaf shape and boundary layer thickness on photosynthesis in cotton (Gossypium hirsutum)". In: Physiologia plantarum 22.5, pp. 1043-1049.

Barbour, M. M. et al. (2000). "Variation in the oxygen isotope ratio of phloem sap sucrose from castor bean. Evidence in support of the Péclet effect". In: Plant physiology 123.2, pp. 671-680.

Barnes, A. D. et al. (2014). "Consequences of tropical land use for multitrophic biodiversity and ecosystem functioning". In: Nature communications 5.1, pp. 1-7.

Bastrikov, V. et al. (2014). "Continuous measurements of atmospheric water vapour isotopes in Western Siberia (Kourovka)". en. In: Atmospheric Measurement Techniques 7.1, pp. 475-507. ISSN: 1867-8610. DOI: $10.5194 /$ amtd-7-475-2014.

Behrangi, A., T. Kubar, and B. Lambrigtsen (2012). "Phenomenological description of tropical clouds using cloudsat cloud classification". In: Mon. Weather Rev. ISSN: 00270644. DOI: $10.1175 /$ MWR-D-11-00247.1.

Belgaman, H. et al. (2016). "Intraseasonal Variability of $\delta 180$ of Precipitation over the Indonesian Maritime Continent Related to the Madden-Julian Oscillation". In: SOLA 12, pp. 192-197. DOI: 10.2151 / sola.2016-036.

Belgaman, H. et al. (2017). "Characteristics of seasonal precipitation isotope variability in Indonesia". In: Hydrological Research Letters 11, pp. 92-98. DOI: $10.3178 / \mathrm{hrl} .11 .92$.

Benedict, J. J. and D. A. Randall (2007). "Observed characteristics of the MJO relative to maximum rainfall". In: Journal of the atmospheric sciences 64.7, pp. 2332-2354.

Benetti, M. et al. (2014). "Deuterium excess in marine water vapor: Dependency on relative humidity and surface wind speed during evaporation: d-excess variability during evaporation". en. In: Journal of Geophysical Research: Atmospheres 119.2, pp. 584-593. ISSN: 2169897X. DOI: 10.1002 / 2013 JD020535.

Benetti, M. et al. (2015). "Importance of boundary layer mixing for the isotopic composition of surface vapor over the subtropical North Atlantic Ocean". In: Journal of Geophysical Research: Atmospheres 120.6, pp. 21902209.

Benetti, M. et al. (2017). "Stable isotopes in the atmospheric marine boundary layer water vapour over the Atlantic Ocean, 2012-2015". In: Scientific data 4, p. 160128. DOI: 10.1038 / sdata.2016.128.

Berden, G., R. Peeters, and G. Meijer (2000). "Cavity ring-down spectroscopy: Experimental schemes and applications". In: International Reviews in Physical Chemistry 19.4, pp. 565-607. DOI: $10.1080 / 014423500750040627$. 
Berkelhammer, M. et al. (2012). "The moisture source sequence for the MaddenJulian Oscillation as derived from satellite retrievals of $\mathrm{HDO}$ and $\mathrm{H} 2 \mathrm{O}$ ". In: Journal of Geophysical Research: Atmospheres 117.D3. D03106, n/a-n/a. ISSN: 2156-2202. DOI: $10.1029 / 2011$ JD016803.

Berkelhammer, M. et al. (2013). "The nocturnal water cycle in an open-canopy forest". In: Journal of Geophysical Research: Atmospheres 118.17, pp. 10,22510,242. ISSN: 2169-8996. DOI: $10.1002 / \mathrm{jgrd} .50701$.

Berkelhammer, M. et al. (2016). "Convergent approaches to determine an ecosystem's transpiration fraction". In: Global Biogeochemical Cycles 30.6, pp. 933-951.

Bigeleisen, J. (1961). "Statistical Mechanics of Isotope Effects on the Thermodynamic Properties of Condensed Systems". In: The Journal of Chemical Physics 34.5, pp. 1485-1493. DOI: $10.1063 / 1.1701033$.

Bonan, G. (2015). Ecological Climatology: Concepts and Applications. 3rd ed. Cambridge University Press. DOI: 10.1017/CBO9781107339200.

Bonne, J.-L. et al. (2014). "The isotopic composition of water vapour and precipitation in Ivittuut, southern Greenland". In: Atmospheric Chemistry and Physics 14.9, pp. 4419-4439. (Visited on 01/28/2016).

Bowen, G. J. and B. Wilkinson (2002). "Spatial distribution of $\delta 180$ in meteoric precipitation". In: Geology 30.4, pp. 315-318.

Bowen, G. J. et al. (2019). "Isotopes in the Water Cycle: Regional- to GlobalScale Patterns and Applications". In: Annual Review of Earth and Planetary Sciences 47.1, pp. 453-479. DOI: 10 . 1146 / annurev-earth-053018060220.

Braden-Behrens, J., C. Markwitz, and A. Knohl (2019). “Eddy covariance measurements of the dual-isotope composition of evapotranspiration". In: Agricultural and Forest Meteorology 269, pp. 203-219.

Breitenbach, S. F. M. et al. (2010). "Strong influence of water vapor source dynamics on stable isotopes in precipitation observed in Southern Meghalaya, NE India". en. In: Earth and Planetary Science Letters 292.1-2, pp. 212220. ISSN: 0012821X. DOI: $10.1016 / j$.epsl.2010.01.038.

Brenner, A. J. and P. G. Jarvis (1995). "A heated leaf replica technique for determination of leaf boundary layer conductance in the field". In: Agricultural and Forest Meteorology 72.3-4, pp. 261-275.

Brown, D., J. Worden, and D. Noone (2008). “Comparison of atmospheric hydrology over convective continental regions using water vapor isotope measurements from space". en. In: Journal of Geophysical Research 113.D15. DOI: $10.1029 / 2007$ JD009676.

Brubaker, K. L., D. Entekhabi, and P. S. Eagleson (1993). "Estimation of continental precipitation recycling". In: Journal of Climate 6.6, pp. 1077-1089.

Brutsaert, W. (1975a). "A theory for local evaporation (or heat transfer) from rough and smooth surfaces at ground level". In: Water resources research 11.4, pp. 543-550.

- (1975b). "The roughness length for water vapor sensible heat, and other scalars". In: Journal of the Atmospheric Sciences 32.10, pp. 2028-2031. 
Buckley, T. N. (2005). "The control of stomata by water balance". In: New Phytologist 168.2, pp. 275-292. DOI: 10.1111 / j.1469-8137.2005 . $01543 . x$.

Cai, Z., L. Tian, and G. J. Bowen (2017). “ENSO variability reflected in precipitation oxygen isotopes across the Asian Summer Monsoon region". In: Earth Planet. Sci. Lett. 475, pp. 25-33. ISSN: 0012821X. DOI: $10.1016 /$ j.eps1.2017.06.035.

Cappa, C. D. (2003). "Isotopic fractionation of water during evaporation". en. In: Journal of Geophysical Research 108.D16. ISSN: 0148-0227. DOI: 10 . $1029 / 2003$ JD003597.

Carlson, K. M. et al. (2012). “Committed carbon emissions, deforestation, and community land conversion from oil palm plantation expansion in West Kalimantan, Indonesia". In: Proceedings of the National Academy of Sciences 109.19, pp. 7559-7564.

Carr, M. K. V. (2011). "The water relations and irrigation requirements of oil palm (Elaeis guineensis): A review". In: Experimental Agriculture 47 (04), pp. 629-652. DOI: 10.1017 / S0014479711000494.

Celle-Jeanton, H. et al. (2004). “Oxygen-18 variations of rainwater during precipitation: application of the Rayleigh model to selected rainfalls in Southern France". In: Journal of Hydrology 289.1-4, pp. 165-177.

Cernusak, L. A., J. S. Pate, and G. D. Farquhar (2002). "Diurnal variation in the stable isotope composition of water and dry matter in fruiting Lupinus angustifolius under field conditions". In: Plant, Cell $\mathcal{E}$ Environment 25.7, pp. 893-907.

Cernusak, L. A. et al. (2016). "Stable isotopes in leaf water of terrestrial plants". In: Plant, Cell E Environment 39.5, pp. 1087-1102.

Chadwick, R. et al. (2016). "Large rainfall changes consistently projected over substantial areas of tropical land". In: Nat. Clim. Chang. 6.2, pp. 177-181. ISSN: 17586798. DOI: $10.1038 /$ nclimate2805.

Chu, P. S. (2004). "ENSO and tropical cyclone activity". In: Hurricanes Typhoons Past, Present. Potential, pp. 297-332.

Ciais, P. and J. Jouzel (1994). "Deuterium and Oxygen 18 in precipitation: Isotopic model, including mixed cluod processe". In: Journal of Geophysical Research 99, pp. 16,793-16,804. DOI: $10.1029 / 94$ JD 00412.

Clark, I. D. and P. Fritz (1997). Environmental isotopes in hydrogeology. CRC press.

Cobb, K. M. et al. (2007). "Regional-scale climate influences on temporal variations of rainwater and cave dripwater oxygen isotopes in northern Borneo". en. In: Earth and Planetary Science Letters 263.3-4, pp. 207-220. DOI: $10.1016 / j$.epsl.2007.08.024.

Coenders-Gerrits, A. M. J. et al. (2014). "Uncertainties in transpiration estimates". In: Nature 506.7487, E1-E2.

Cole, J. et al. (1999). "Climatic controls on interannual variability of precipitation 18 Oxygen: Simulated influence of temperature, precipitation amount, and vapor source region". In: Journal of Geophysical Research 104, pp. 14,223-14,235. 
Comte, I. et al. (2012). "Agricultural practices in oil palm plantations and their impact on hydrological changes, nutrient fluxes and water quality in Indonesia: a review". In: Advances in Agronomy. Vol. 116. Elsevier, pp. 71124.

Conroy, J. L. et al. (2016). "Paired stable isotopologues in precipitation and vapor: A case study of the amount effect within western tropical Pacific storms". In: J. Geophys. Res. Atmos. 121.7, pp. 3290-3303. DOI: 10 . $1002 /$ 2015JD023844.

Contreras-Rosales, L. A. et al. (2014). "Evolution of the Indian Summer Monsoon and terrestrial vegetation in the Bengal region during the past 18 ka". In: Quaternary Science Reviews 102, pp. 133-148.

Coplen, Tyler B. (2011). "Guidelines and recommended terms for expression of stable isotope ratio and gas ratio measurement results". In: Rapid Communications in Mass Spectrometry 25.17, pp. 2538-2560. ISSN: 1097-0231. DOI: $10.1002 / \mathrm{rcm} .5129$.

Craig, H. (1961). "Isotopic variations in meteoric waters". In: Science 133.3465, pp. 1702-1703. DOI: 10.1126/science.133.3465.1702.

Craig, H. and L. I. Gordon (1965). "Deuterium and oxygen 18 variations in the ocean and the marine atmosphere". In: In proc. Stable Isotopes in Oceanographic Studies and Paleotemperatures, pp. 9-130.

Cross, M. (2015). "PySPLIT: A Package for the Generation, Analysis, and Visualizations of HYSPLIT Air Parcel Trajectories". In: Proc. 14th Ann. Scientific Computing with Python Conf.(SciPy 15).

Crosson, E.R. (2008). "A cavity ring-down analyzer for measuring atmospheric levels of methane, carbon dioxide, and water vapor". In: Applied Physics B 92.3, pp. 403-408. ISSN: 0946-2171, 1432-0649. DOI: 10.1007 / s 00340 $008-3135-y$.

Cuntz, M. et al. (2007). "Modelling advection and diffusion of water isotopologues in leaves". In: Plant, Cell E Environment 30.8, pp. 892-909. DOI: $10.1111 / j .1365-3040.2007 .01676 . x$.

Danielson, J. J. and D. B. Gesch (2011). Global multi-resolution terrain elevation data 2010 (GMTED2010). U.S.Geological Survey. Open-File Rep. 2011-1073, $26 \mathrm{pp}$.

Dansgaard, W. (1964). "Stable Isotopes in Precipitation". In: Tellus 16, pp. 436468. DOI: $10.1111 / j .2153-3490.1964$.tb00181.x.

Daudet, F. A. et al. (1998). "Leaf boundary layer conductance in a vineyard in Portugal". In: Agricultural and forest meteorology 89.3-4, pp. 255-267.

Dawson, T. E. (1993). "Water sources of plants as determined from xylemwater isotopic composition: perspectives on plant competition, distribution, and water relations". In: Stable isotopes and plant carbon-water relations. Elsevier, pp. 465-496.

Dawson, T. E. and P. D. Brooks (2001). "Fundamentals of stable isotope chemistry and measurement". In: Stable isotope techniques in the study of biological processes and functioning of ecosystems. Springer, pp. 1-18.

Dawson, T. E. and J. R. Ehleringer (1993). "Isotopic enrichment of water in the "woody" tissues of plants: implications for plant water source, water 
uptake, and other studies which use the stable isotopic composition of cellulose". In: Geochimica et Cosmochimica Acta 57.14, pp. 3487-3492.

Day, M. E. (2000). "Influence of temperature and leaf-to-air vapor pressure deficit on net photosynthesis and stomatal conductance in red spruce (Picea rubens)"'. In: Tree physiology 20.1, pp. 57-63.

Del Genio, A. D. et al. (2012). "The MJO transition from shallow to deep convection in CloudSat/CALIPSO data and GISS GCM simulations". In: Journal of Climate 25.11, pp. 3755-3770.

Delattre, H., C. Vallet-Coulomb, and C. Sonzogni (2015). “Deuterium excess in the atmospheric water vapour of a Mediterranean coastal wetland: regional vs. local signatures". en. In: Atmospheric Chemistry and Physics 15.17, pp. 10167-10181. DOI: 10.5194 / acp-15-10167-2015.

Deser, C. et al. (2010). "Sea Surface Temperature Variability: Patterns and Mechanisms". In: Ann. Rev. Mar. Sci. 2.1, pp. 115-143. DOI: $10.1146 /$ annurev-marine-120408-151453.

Dongmann, G. et al. (1974). "On the enrichment of H $218 \mathrm{O}$ in the leaves of transpiring plants". In: Radiation and environmental biophysics 11.1, pp. 4152.

Drescher, J. et al. (2016). "Ecological and socio-economic functions across tropical land use systems after rainforest conversion". In: Philosophical Transactions of the Royal Society of London B: Biological Sciences 371.1694. DOI: $10.1098 /$ rstb.2015.0275.

Dubbert, M. et al. (2013). "Partitioning evapotranspiration-Testing the Craig and Gordon model with field measurements of oxygen isotope ratios of evaporative fluxes". In: Journal of Hydrology 496, pp. 142-153.

Dubbert, M. et al. (2014). "Stable oxygen isotope and flux partitioning demonstrates understory of an oak savanna contributes up to half of ecosystem carbon and water exchange". In: Funct. Plant Ecol. 5.October, p. 530. DOI: $10.3389 / \mathrm{fpls} .2014 .00530$.

Dykoski, C. A. et al. (2005). “A high-resolution, absolute-dated Holocene and deglacial Asian monsoon record from Dongge Cave, China". In: Earth and Planetary Science Letters 233.1-2, pp. 71-86.

Dyroff, C. et al. (2015). "Airborne in situ vertical profiling of HDO/H $216 \mathrm{O}$ in the subtropical troposphere during the MUSICA remote sensing validation campaign". In: Atmospheric Measurement Techniques 8.5, pp. 20372049.

Dyurgerov, M. (2003). "Mountain and subpolar glaciers show an increase in sensitivity to climate warming and intensification of the water cycle". In: J. Hydrol. ISSN: 00221694. DOI: 10 .1016/S0022-1694 (03) 00254-3.

Edwin, M. et al. (2014). "Stable oxygen and deuterium isotope techniques to identify plant water sources". In: Journal of Water Resource and Protection 6.15 , p. 1501.

Ehleringer, J. R. and T. E. Dawson (1992). "Water uptake by plants: perspectives from stable isotope composition". In: Plant, cell E environment 15.9, pp. 1073-1082.

Ehleringer, J. R., A. E. Hall, G. D. Farquhar, et al. (1993). Stable isotopes and plant carbon-water relations. Vol. 109129. Academic Press San Diego. 
Ehleringer, J. R., J. Roden, and T. E. Dawson (2000). “Assessing ecosystemlevel water relations through stable isotope ratio analyses". In: pp. 181198.

Ellehoj, M. D. et al. (2013). “Ice-vapor equilibrium fractionation factor of hydrogen and oxygen isotopes: Experimental investigations and implications for stable water isotope studies: Ice-vapor equilibrium fractionation factor". en. In: Rapid Communications in Mass Spectrometry 27.19, pp. 21492158. DOI: $10.1002 / \mathrm{rcm} .6668$.

Epstein, S. et al. (1951). "Carbonate-water isotopic temperature scale”. In: Geological Society of America Bulletin 62.4, pp. 417-426.

Evaristo, J., S. Jasechko, and J. J. McDonnell (2015). “Global separation of plant transpiration from groundwater and streamflow". In: Nature 525.7567, pp. 91-94.

Fan, Y. et al. (2015). "A sub-canopy structure for simulating oil palm in the Community Land Model (CLM-Palm): phenology, allocation and yield". In: Geoscientific Model Development 8.11, pp. 3785-3800. DOI: 10 . 5194 / gmd-8-3785-2015.

Farquhar, G. D. and L. A. Cernusak (2005). "On the isotopic composition of leaf water in the non-steady state". en. In: Functional Plant Biology 32.4, p. 293. ISSN: 1445-4408. DOI: 10.1071 /FP 04232.

Farquhar, G. D., L. A. Cernusak, and B. Barnes (2007). “Heavy water fractionation during transpiration". In: Plant physiology 143.1, pp. 11-18.

Farquhar, G. D. et al. (1989). "Carbon isotope fractionation and plant wateruse efficiency". In: Stable isotopes in ecological research. Springer, pp. 21-40.

Farquhar, Graham D. and Jon Lloyd (1993). "Carbon and Oxygen Isotope Effects in the Exchange of Carbon Dioxide between Terrestrial Plants and the Atmosphere". In: Stable Isotopes and Plant Carbon-water Relations. Ed. by J. R. Ehleringer, A. E. Hall, and G. D. Farquhar. San Diego: Academic Press, pp. 47 -70. DOI: https : / / doi . org/10 . 1016/B978-0-08091801-3.50011-8.

Fatichi, S. and C. Pappas (2017). "Constrained variability of modeled T: ET ratio across biomes". In: Geophysical Research Letters 44.13, pp. 6795-6803.

Federer, B., N. Brichet, and J. Jouzel (1982). "Stable isotopes in hailstones. Part I: The isotopic cloud model". In: Journal of the Atmospheric Sciences 39, pp. 1323-1335.

Ferretti, D. F. et al. (2003). "Partitioning evapotranspiration fluxes from a Colorado grassland using stable isotopes: Seasonal variations and ecosystem implications of elevated atmospheric CO 2". In: Plant and Soil 254.2, pp. 291-303.

Field, R. D., D. B. A. Jones, and D. P. Brown (2010). “Effects of postcondensation exchange on the isotopic composition of water in the atmosphere". In: Journal of Geophysical Research: Atmospheres 115.D24305. DOI: $10.1029 / 2010$ JD014334.

Flanagan, L. B., J. P. Comstock, and J. R. Ehleringer (1991). “Comparison of modeled and observed environmental influences on the stable oxygen and hydrogen isotope composition of leaf water in Phaseolus vulgaris L." In: Plant Physiology 96.2, pp. 588-596. 
Förstel, H. (1978). "The enrichment of $18 \mathrm{O}$ in leaf water under natural conditions". In: Radiation and environmental biophysics 15.4, pp. 323-344.

Froehlich, K., J. J. Gibson, and P. K. Aggarwal (2002). Deuterium excess in precipitation and its climatological significance. Tech. rep.

Galewsky, J. et al. (2011). "Surface measurements of upper tropospheric water vapor isotopic composition on the Chajnantor Plateau, Chile". In: Geophysical Research Letters 38.17. DOI: $10.1029 / 2011$ GL0 48557.

Galewsky, J. et al. (2016). "Stable isotopes in atmospheric water vapor and applications to the hydrologic cycle". In: Reviews of Geophysics 54.4, pp. 809865. DOI: $10.1002 / 2015$ RG000512.

Gamache, J. F. and R. A. Houze Jr (1983). "Water budget of a mesoscale convective system in the tropics". In: Journal of the atmospheric sciences 40.7, pp. 1835-1850.

Gao, J. et al. (2011). "Precipitation Water Stable Isotopes in the South Tibetan Plateau: Observations and Modeling". In: Journal of Climate 24.13, pp. 3161-3178. DOI: $10.1175 / 2010$ JCLI3736.1.

Gat, J. R. (1983). "Precipitation, groundwater and surface waters. Control of climate parameters on their isotopic composition and their utilization as palaeoclimatological tools". In: Palaeoclimates and palaeowaters: A collection of environmental isotope studies.

- (1996). "Oxygen and hydrogen isotopes in the hydrologic cycle". In: Annual Review of Earth and Planetary Sciences 24.1, pp. 225-262. DOI: 10 . 1146 /annurev. earth.24.1.225.

Gedzelman, S. et al. (2003). "Probing hurricanes with stable isotopes of rain and water vapor". In: Monthly Weather Review 131.6, pp. 1112-1127.

Girishkumar, M. S. and M. Ravichandran (2012). "The influences of ENSO on tropical cyclone activity in the Bay of Bengal during October-December". In: J. Geophys. Res. Ocean. DOI: 10.1029/2011JC007417.

Godoy, J. M., M. L. D. P. Godoy, and A. Neto (2012). “Direct determination of $\delta(\mathrm{D})$ and $\delta(18 \mathrm{O})$ in water samples using cavity ring down spectrometry: Application to bottled mineral water". In: Journal of Geochemical Exploration 119, pp. 1-5.

Goebel, T. S., R. J. Lascano, et al. (2012). "System for high throughput water extraction from soil material for stable isotope analysis of water". In: Journal of Analytical Sciences, Methods and Instrumentation 2.04, pp. 203-207.

Gonfiantini, R., S. Gratziu, and E. Tongiorgi (1965). "Oxygen isotopic composition of water in leaves". In: Isotopes and Radiation in Soil-Plant Nutrition Studies 405, p. 410.

Gonfiantini, R. et al. (2001). "The altitude effect on the isotopic composition of tropical rains". In: Chem. Geol. 181.1-4, pp. 147-167. DOI: 10.1016 / S0009-2541(01)00279-0.

Good, S. P., D. Noone, and G. Bowen (2015). "Hydrologic connectivity constrains partitioning of global terrestrial water fluxes". In: Science 349.6244, pp. 175-177. 
Good, S. P. et al. (2012). "Uncertainties in the assessment of the isotopic composition of surface fluxes: A direct comparison of techniques using laserbased water vapor isotope analyzers". In: Journal of Geophysical Research 117.D15. DOI: $10.1029 / 2011$ JD017168.

Good, S. P. et al. (2014). " $\delta 2 \mathrm{H}$ isotopic flux partitioning of evapotranspiration over a grass field following a water pulse and subsequent dry down". In: Water Resources Research 50.2, pp. 1410-1432. DOI: 10 .10 02/2013WR014333.

Graham, N. E. and T. P. Barnett (1987). "Sea surface temperature, surface wind divergence, and convection over tropical oceans". In: Science 238.4827, pp. 657-659.

Griffis, T. J. et al. (2010). "Determining the Oxygen Isotope Composition of Evapotranspiration Using Eddy Covariance". In: Boundary-Layer Meteorology 137.2, pp. 307-326. DOI: 10.1007 / s10546-010-9529-5.

Griffis, T. J. et al. (2011). “Oxygen isotope composition of evapotranspiration and its relation to C4 photosynthetic discrimination". In: Journal of Geophysical Research: Biogeosciences 116.G1.

Gröning, M., M. van Duren, and L. Andreescu (2006). “Metrological characteristics of the conventional measurement scales for hydrogen and oxygen stable isotope amount ratios: the $\delta$-scales". In: Combining and Reporting Analytical Results, pp. 62-72.

Guan, H. et al. (2013). "Deuterium excess variations of rainfall events in a coastal area of South Australia and its relationship with synoptic weather systems and atmospheric moisture sources". In: Journal of Geophysical Research: Atmospheres 118.2, pp. 1123-1138. DOI: 10.1002 / jgrd.50137.

Guillaume, T., M. Damris, and Y. Kuzyakov (2015). “Losses of soil carbon by converting tropical forest to plantations: erosion and decomposition estimated by $\delta 13 C^{\prime \prime}$. In: Global change biology 21.9, pp. 3548-3560.

Guilpart, E. et al. (2017). "The isotopic composition of near-surface water vapor at the Maïdo observatory (Reunion Island, southwestern Indian Ocean) documents the controls of the humidity of the subtropical troposphere". In: Journal of Geophysical Research: Atmospheres 122.18, pp. 96289650.

Gupta, P. et al. (2009). "Demonstration of high-precision continuous measurements of water vapor isotopologues in laboratory and remote field deployments using wavelength-scanned cavity ring-down spectroscopy (WS-CRDS) technology". In: Rapid Communications in Mass Spectrometry 23.16, pp. 2534-2542. DOI: 10.1002 / rcm. 4100.

Hartmann, D. L. and K. Larson (2002). "An important constraint on tropical cloud - Climate feedback". In: Geophys. Res. Lett. DOI: 10 . $1029 /$ 2002 GL015835.

Harwood, K. G. et al. (1999). “Determinants of isotopic coupling of CO2 and water vapour within a Quercus petraea forest canopy". In: Oecologia 119.1, pp. 109-119. DOI: 10.1007 / s004420050766.

He, Y. et al. (2015). “Impact of atmospheric convection on south Tibet summer precipitation isotopologue composition using a combination of in situ 
measurements, satellite data, and atmospheric general circulation modeling". In: Journal of Geophysical Research: Atmospheres 120.9, pp. 3852-3871. DOI: $10.1002 / 2014$ JD022180.

Hendon, H. H. and M. L. Salby (1994). "The life cycle of the Madden-Julian oscillation". In: Journal of the Atmospheric Sciences 51.15, pp. 2225-2237.

Hendon, H. H., M. C. Wheeler, and C. Zhang (2007). "Seasonal dependence of the MJO-ENSO relationship". In: Journal of Climate 20.3, pp. 531-543.

Herman, R. L. et al. (2014). "Aircraft validation of Aura Tropospheric Emission Spectrometer retrievals of $\mathrm{HDO} / \mathrm{H}_{2} \mathrm{O}^{\prime \prime}$. In: Atmos. Meas. Tech 7.9, pp. 3127-3138.

Herreros, J. et al. (2009). "Environmental records from temperate glacier ice on Nevado Coropuna saddle, southern Peru". In: Adv. Geosci. ISSN: 16807359. DOI: $10.5194 /$ adgeo-22-27-2009.

Hetherington, A. M. and F. I. Woodward (2003). “The role of stomata in sensing and driving environmental change". In: Nature 424.6951, pp. 901-908.

Hoffmann, G., J. Jouzel, and V. Masson (2000). "Stable water isotopes in atmospheric general circulation models". In: Hydrol. Process. 14.8, pp. 13851406. DOI: 10 . 1002/1099-1085(20000615) $14: 8<1385::$ AID HYP $989>3.0 . \mathrm{CO} ; 2-1$.

Horita, J., K. Rozanski, and S. Cohen (2008). "Isotope effects in the evaporation of water: a status report of the Craig-Gordon model". In: Isotopes in environmental and health studies 44.1, pp. 23-49.

Horita, J. and D. Wesolowski (1994). "Liquid-vapor fractionation of oxygen and hydrogen isotopes of water from freezing to the critical temperature". In: Geochimica et Cosmochimica Acta 58, pp. 3425 -3437.

Hsu, C. F. and J. M. Wallace (1976). "The Global Distribution of the Annual and Semiannual Cycles in Precipitation". In: Mon. Weather Rev. 104.9, pp. 1093-1101.

$\mathrm{Hu}$, Z. et al. (2014). "Partitioning of evapotranspiration through oxygen isotopic measurements of water pools and fluxes in a temperate grassland". In: Journal of Geophysical Research: Biogeosciences 119.3, pp. 358-372.

Huffman, G. J et al. (2010). "The TRMM multi-satellite precipitation analysis (TMPA)". In: Satellite rainfall applications for surface hydrology. Springer, pp. 3-22.

Huffman, G.J. et al. (2019). “GPM IMERG Final Precipitation L3 1 day 0.1 degree x 0.1 degree V06". In: Edited by Andrey Savtchenko, Greenbelt, MD, Goddard Earth Sciences Data and Information Services Center (GES DISC). DOI: 10.5067 / GPM/IMERGDF /DAY / 06.

Huntington, T. G. (2006). "Evidence for intensification of the global water cycle: Review and synthesis". In: J. Hydrol. 319.1-4, pp. 83-95. DOI: 10 . $1016 / j$.jhydrol.2005.07.003.

- (2010). "Climate Warming-Induced Intensification of the Hydrologic Cycle". In: Adv. Agron. Pp. 1-53. DOI: 10 . $1016 /$ B978-0-12-385040$9.00001-3$.

IAEA (2014). "IAEA/GNIP precipitation sampling guide V2. 02 September 2014". In: 
Jakob, C. and C. Schumacher (2008). "Precipitation and latent heating characteristics of the major tropical western Pacific cloud regimes". In: J. Clim. 21.17, pp. 4348-4364. DOI: 10 .1175/2008 JCLI2122.1.

Jarvis, A. et al. (2008). "Hole-filled SRTM for the globe version 4. 2008". In: CGIAR-CSI SRTM 90.

Jarvis, P. G. and K. G. McNaughton (1986). "Stomatal control of transpiration: scaling up from leaf to region". In: Advances in ecological research. Vol. 15. Elsevier, pp. 1-49.

Jasechko, S. et al. (2013). "Terrestrial water fluxes dominated by transpiration". In: Nature 496.7445, pp. 347-350.

Jochum, K. P. et al. (2005). “GeoReM: A New Geochemical Database for Reference Materials and Isotopic Standards". In: Geostandards and Geoanalytical Research 29.3, pp. 333-338. DOI: 10 .1111/j.1751-908X. 2005 . tbo0904.x.

Johnsen, S. J. et al. (1972). “Oxygen isotope profiles through the Antarctic and Greenland ice sheets". In: Nature 235.5339, pp. 429-434.

Jordan, C. F. and J. Heuveldop (1981). "The water budget of an Amazonian rain forest". In: Acta Amazonica 11.1, pp. 87-92.

Jouzel, J. (1986). "Isotopes in cloud physics: Multiphase and multistage condensation processes". In: The Terrestrial Environment, B. Elsevier, pp. 61112.

Jouzel, J. and L. Merlivat (1984). "Deuterium and Oxygen 18 in precipitation: Modeling of the isotopic effects during snow formation". In: Journal of Geophysical Research 89, pp. 11,749-11,757.

Jouzel, J., L. Merlivat, and E. Roth (1975). “Isotopic study of hail”. In: Journal of Geophysical Research 80.36, pp. 5015-5030.

Jouzel, J. et al. (1987). "Simulations of the HDO and H2 $18 \mathrm{O}$ atmospheric cycles using the NASA GISS general circulation model: The seasonal cycle for present-day conditions". In: Journal of Geophysical Research: Atmospheres 92.D12, pp. 14739-14760. DOI: 10 .1029/JD092iD12p14739.

Jouzel, J. et al. (1991). "Simulations of the HDO and H2 $18 \mathrm{O}$ atmospheric cycles using the NASA GISS general circulation model: Sensitivity experiments for present-day conditions". In: Journal of Geophysical Research: Atmospheres 96.D4, pp. 7495-7507. DOI: $10.1029 / 90$ JD 02663.

Kahmen, A. et al. (2008). "Effects of environmental parameters, leaf physiological properties and leaf water relations on leaf water $\delta^{18} \mathrm{O}$ enrichment in different Eucalyptus species". In: Plant, Cell $\mathcal{E}$ Environment 31.6, pp. 738-751. DOI: 10.1111/j.1365-3040.2008.01784.x.

Kahmen, A. et al. (2009). "The influence of species and growing conditions on the 18-O enrichment of leaf water and its impact on 'effective path length'”. In: New Phytologist 184.3, pp. 619-630.

Kang, N.-Y., D. Kim, and J. B. Elsner (2019). "The contribution of super typhoons to tropical cyclone activity in response to ENSO". In: Sci. Rep. 9.1, p. 5046. DOI: $10.1038 /$ s 41598-019-41561-y.

Keeling, C. D. (1958). "The concentration and isotopic abundances of atmospheric carbon dioxide in rural areas". In: Geochimica et Cosmochimica Acta 
13.4, pp. 322 -334. DOI: http: / / dx . doi .org/10.1016/00167037 (58) $90033-4$.

Keeling, C. D. (1961). "The concentration and isotopic abundances of carbon dioxide in rural and marine air". In: Geochimica et Cosmochimica Acta 24.34, pp. 277-298.

Kendall, C. and J. J. McDonnell (2012). Isotope tracers in catchment hydrology. Elsevier.

Konecky, B. L., D. C. Noone, and K. M. Cobb (2019). “The influence of competing hydroclimate processes on stable isotope ratios in tropical rainfall". In: Geophysical Research Letters 46.3, pp. 1622-1633.

Kool, D. et al. (2014). "A review of approaches for evapotranspiration partitioning". In: Agricultural and forest meteorology 184, pp. 56-70.

Koster, R. D. et al. (2004). "Regions of strong coupling between soil moisture and precipitation". In: Science 305.5687, pp. 1138-1140.

Kotowska, M. M. et al. (2015). “Quantifying above-and belowground biomass carbon loss with forest conversion in tropical lowlands of S umatra (I ndonesia)". In: Global change biology 21.10, pp. 3620-3634.

Krishan, G. and M. S. Rao (2014). "Isotope Analysis of Air Moisture and its Applications in Hydrology". In: J. Climatol. Weather Forecast. 2.1, pp. 1-5. DOI: $10.4172 / 2332-2594.1000106$.

Kurita, N. (2013). "Water isotopic variability in response to mesoscale convective system over the tropical ocean". In: Journal of Geophysical Research: Atmospheres 118.18, pp. 10,376-10,390. DOI: 10.1002 / jgrd. 50754.

Kurita, N. et al. (2009). "The relationship between the isotopic content of precipitation and the precipitation amount in tropical regions". In: Journal of Geochemical Exploration 102.3, pp. 113-122. DOI: 10 . 1016 / j . gexplo . 2009.03 .002$.

Kurita, N. et al. (2011). "Intraseasonal isotopic variation associated with the Madden-Julian Oscillation". In: Journal of Geophysical Research: Atmospheres 116.D24. D24101, pp. 113-122. DOI: $10.1029 / 2010$ JD 015209.

Küttel, M. et al. (2012). “Seasonal climate information preserved in West Antarctic ice core water isotopes: relationships to temperature, large-scale circulation, and sea ice". In: Climate Dynamics 39.7-8, pp. 1841-1857.

LaFranchi, B. (2003). “Cavity Ring Down Spectroscopy: History, Fundamentals, and Applications". In: Chemistry 226, pp. 1-18.

Lai, C.-T. and J. R. Ehleringer (2011). "Deuterium excess reveals diurnal sources of water vapor in forest air". en. In: Oecologia 165.1, pp. 213-223. DOI: $10.1007 / \mathrm{s} 00442-010-1721-2$.

Lai, C.-T. et al. (2006). "Contributions of evaporation, isotopic non-steady state transpiration and atmospheric mixing on the $\delta 18 \mathrm{O}$ of water vapour in Pacific Northwest coniferous forests". In: Plant, Cell E Environment 29.1, pp. 77-94.

Larson, K., D. L. Hartmann, and S. A. Klein (1999). “The role of clouds, water vapor, circulation, and boundary layer structure in the sensitivity of the tropical climate". In: J. Clim. DOI: 10 . 1175/1520-0442 (1999) $012<2359$ :trocwv $>2.0 . \mathrm{co} ; 2$. 
Lauenroth, W. K. and J. B. Bradford (2012). "Ecohydrology of dry regions of the United States: water balance consequences of small precipitation events". In: Ecohydrology 5.1, pp. 46-53.

Lawrence, J. R. (2004). "Stable isotopic composition of water vapor in the tropics". en. In: Journal of Geophysical Research 109.D6. DOI: 10 . $1029 /$ 2003 JD004046.

Lee, J.-E. and I. Fung (2008). "“'Amount effect" of water isotopes and quantitative analysis of post-condensation processes". en. In: Hydrological Processes 22.1, pp. 1-8. DOI: 10.1002 / hyp. 6637.

Lee, J.-E. et al. (2007). "Analysis of the global distribution of water isotopes using the NCAR atmospheric general circulation model". In: Journal of Geophysical Research: Atmospheres 112.D16.

Lee, X. et al. (2005). "In Situ Measurement of the Water Vapor 18 O/16 O Isotope Ratio for Atmospheric and Ecological Applications." In: Journal of Atmospheric E Oceanic Technology 22.5.

Lekshmy, P. R. et al. (2014). "18O depletion in monsoon rain relates to large scale organized convection rather than the amount of rainfall". In: Scientific reports 4. DOI: 10.1038 / s rep 05661.

Lekshmy, P.R., M. Midhun, and R. Ramesh (2018). “Influence of stratiform clouds on $\delta \mathrm{D}$ and $\delta 18 \mathrm{O}$ of monsoon water vapour and rain at two tropical coastal stations". In: Journal of Hydrology 563, pp. 354 -362. DOI: https : //doi.org/10.1016/j.jhydrol.2018.06.001.

Levin, N. E. et al. (2006). "A stable isotope aridity index for terrestrial environments". In: Proc. Natl. Acad. Sci. U. S. A. 103.30, pp. 11201-11205. DOI: 10.1073 /pnas.0604719103.

Levitus, S. et al. (2012). "World ocean heat content and thermosteric sea level change (0-2000 m), 1955-2010". In: Geophys. Res. Lett. 39.10. DOI: 10 . 1029 / 2012 GL051106.

Liebmann, B. and C.A. Smith (1996). "Description of a complete (interpolated) outgoing longwave radiation dataset." In: Bull. Amer. Meteor. Soc. 77, pp. 1275-1277.

Luz, B. et al. (2009). "Fractionation of oxygen and hydrogen isotopes in evaporation water". In: Geochimica et Cosmochimica Acta 73, pp. 6697 -6703.

Madden, R. A. and P. R. Julian (1971). “Detection of a 40-50 day oscillation in the zonal wind in the tropical Pacific". In: Journal of the atmospheric sciences 28.5, pp. 702-708.

- (1972). "Description of global-scale circulation cells in the tropics with a 40-50 day period". In: Journal of the atmospheric sciences 29.6, pp. 11091123.

Maher, D. T., I. R. Santos, and D. R. Tait (2014). “Mapping methane and carbon dioxide concentrations and $\delta 13 \mathrm{C}$ values in the atmosphere of two Australian coal seam gas fields". In: Water, Air, $\mathcal{E}$ Soil Pollution 225.12, p. 2216.

Majoube, M. (1971). "Fractionnement en oxygène 18 et en deuterium entre l'eau et sa vapeur." In: Journal de Chimie Physique 58.1423 - 1436. 
Maloney, E. D. and A. H. Sobel (2004). "Surface fluxes and ocean coupling in the tropical intraseasonal oscillation". In: Journal of Climate 17.22, pp. 43684386.

Marengo, J. A. and J. C. Espinoza (2016). Extreme seasonal droughts and floods in Amazonia: Causes, trends and impacts. DOI: $10.1002 /$ joc .4420.

Margono, B. A. et al. (2014). "Primary forest cover loss in Indonesia over 2000-2012". In: Nature climate change 4.8, pp. 730-735.

Marshall, J. D., J. R. Brooks, and K. Lajtha (2007). "Sources of variation in the stable isotopic composition of plants". In: Stable isotopes in ecology and environmental science 2, pp. 22-60.

Martín-Gómez, P. et al. (2015). "Isotope-ratio infrared spectroscopy: a reliable tool for the investigation of plant-water sources?" In: New Phytologist 207.3. 2014-18805, pp. 914-927. DOI: $10.1111 / \mathrm{nph} .13376$.

Masson-Delmotte, V. et al. (2003). "Recent southern Indian Ocean climate variability inferred from a Law Dome ice core: new insights for the interpretation of coastal Antarctic isotopic records". In: Clim. Dyn. 21.2, pp. 153166. ISSN: 0930-7575. DOI: 10.1007 / s $00382-003-0321-9$.

Masson-Delmotte, V. et al. (2008). A review of antarctic surface snow isotopic composition: Observations, atmospheric circulation, and isotopic modeling. DOI: $10.1175 / 2007$ JCLI2139.1.

McKinney, C. R. et al. (1950). "Improvements in Mass Spectrometers for the Measurement of Small Differences in Isotope Abundance Ratios". In: Review of Scientific Instruments 21.8, pp. 724-730. DOI: $10.1063 / 1.1745698$.

Meijide, A. et al. (2017). "Controls of water and energy fluxes in oil palm plantations: Environmental variables and oil palm age". In: Agricultural and Forest Meteorology 239, pp. 71-85.

Meijide, A. et al. (2018). "Impact of forest conversion to oil palm and rubber plantations on microclimate and the role of the 2015 ENSO event". In: Agricultural and Forest Meteorology 252, pp. 208-219.

Merlivat, L. (1978). "Molecular diffusivities of $\mathrm{H}_{2}^{16} \mathrm{O}, \mathrm{HD}{ }^{16} \mathrm{O}$, and $\mathrm{H}_{2}^{18} \mathrm{O}$ in gases". In: The Journal of Chemical Physics 69.6, pp. 2864-2871. DOI: 10 . $1063 / 1.436884$.

Merlivat, L. and M. Coantic (1975). "Study of mass transfer at the air-water interface by an isotopic method". In: Journal of Geophysical Research (18961977) 80.24, pp. 3455-3464. DOI: 10 . 1029 / JC 080 i 024 p 03455.

Merlivat, L. and J. Jouzel (1979). "Global climatic interpretation of the DeuteriumOxygen 18 relationship for precipitation". In: Journal of Geophysical Research 84, pp. 5029-5033. DOI: 10.1029 / JC 084 iC0 8p0 5029.

Merten, J. et al. (2016). "Water scarcity and oil palm expansion: social views and environmental processes". In: Ecology and Society 21.2.

Midhun, M., P. R. Lekshmy, and R. Ramesh (2013). "Hydrogen and oxygen isotopic compositions of water vapor over the Bay of Bengal during monsoon: Vapor isotopes over the bay of Bengal". In: Geophysical Research Letters 40.23, pp. 6324-6328. DOI: 10.1002/2013GL058181.

Milly, P. C. D. et al. (2002). "Increasing risk of great floods in a changing climate". In: Nature 415.6871, pp. 514-517. DOI: 10.1038 / 415514 a. 
Moerman, J. W. et al. (2013). "Diurnal to interannual rainfall $\delta 180$ variations in northern Borneo driven by regional hydrology". In: Earth Planet. Sci. Lett. 369-370, pp. 108-119. DOI: 10.1016/j.eps .2013.03.014.

Mook, W. and K. Rozanski (2000). "Environmental isotopes in the hydrological cycle". In: IAEA Publish 39.

Moore, M., Z. Kuang, and P. N. Blossey (2014). "A moisture budget perspective of the amount effect". In: Geophys. Res. Lett. 41.4, pp. 1329-1335. DOI: $10.1002 / 2013 \mathrm{GL} 058302$.

Moore, M. et al. (2016). "Microphysical controls on the isotopic composition of wintertime orographic precipitation". In: Journal of Geophysical Research: Atmospheres 121.12, pp. 7235-7253.

Moreira, M. et al. (1997). "Contribution of transpiration to forest ambient vapour based on isotopic measurements". In: Glob. Chang. Biol. 3.5, pp. 439450. DOI: $10.1046 / j .1365-2486.1997 .00082 . x$.

Mori, S. et al. (2004). "Diurnal land-sea rainfall peak migration over Sumatera Island, Indonesian Maritime Continent, observed by TRMM satellite and intensive rawinsonde soundings". In: Monthly Weather Review 132.8, pp. 2021-2039.

Münch, T. et al. (2019). Constraints on post-depositional isotope modifications in East Antarctic firn from analysing temporal changes of isotope profiles. postprint. DOI: 10.25932 /publishup-41876.

Munksgaard, N. C et al. (2019). "Data Descriptor: Daily observations of stable isotope ratios of rainfall in the tropics". In: Scientific reports 9.1, pp. 1-7.

Nakazawa, T. (1988). "Tropical super clusters within intraseasonal variations over the western Pacific". In: Journal of the Meteorological Society of Japan. Ser. II 66.6, pp. 823-839.

Niedermeyer, E. M. et al. (2016). “The stable hydrogen isotopic composition of sedimentary plant waxes as quantitative proxy for rainfall in the West African Sahel". In: Geochimica et Cosmochimica Acta 184, pp. 55 -70. DOI: https://doi.org/10.1016/j.gca.2016.03.034.

Noone, D. (2012). "Pairing Measurements of the Water Vapor Isotope Ratio with Humidity to Deduce Atmospheric Moistening and Dehydration in the Tropical Midtroposphere". In: Journal of Climate 25.13, pp. 4476-4494. DOI: $10.1175 /$ JCLI-D-11-00582.1.

Noone, D. et al. (2011). "Properties of air mass mixing and humidity in the subtropics from measurements of the $\mathrm{D} / \mathrm{H}$ isotope ratio of water vapor at the Mauna Loa Observatory". In: Journal of Geophysical Research: Atmospheres 116.D22.

Oerlemans, J. (2005). “Atmospheric science: Extracting a climate signal from 169 glacier records". In: Science (80-. ). 308.5722, pp. 675-677. DOI: 10 . $1126 /$ science.1107046.

Ogée, J. et al. (2007). “Non-steady-state, non-uniform transpiration rate and leaf anatomy effects on the progressive stable isotope enrichment of leaf water along monocot leaves". In: Plant, Cell E Environment 30.4, pp. 367387. 
Orlowski, N. et al. (2016). "Exploring water cycle dynamics by sampling multiple stable water isotope pools in a developed landscape in Germany". In: Hydrology and Earth System Sciences 20.9, p. 3873.

Panarello, H. O. et al. (1998). The role of the global network for isotopes in precipitation (GNIP) in hydrological and hydroclimatic studies. na.

Partin, J. W. et al. (2007). "Millennial-scale trends in west Pacific warm pool hydrology since the Last Glacial Maximum". In: Nature 449.7161, pp. 452455.

Pataki, D. E. et al. (2003). “The application and interpretation of Keeling plots in terrestrial carbon cycle research". In: Global Biogeochemical Cycles 17.1. DOI: $10.1029 / 2001 \mathrm{~GB} 001850$.

Peatman, S. C., A. J. Matthews, and D. P. Stevens (2014). “Propagation of the Madden-Julian Oscillation through the Maritime Continent and scale interaction with the diurnal cycle of precipitation". In: Quarterly Journal of the Royal Meteorological Society 140.680, pp. 814-825.

Peel, M. C., B. L. Finlayson, and T. A. McMahon (2007). "Updated world map of the Köppen-Geiger climate classification". In: Hydrology and Earth System Sciences 11.5, pp. 1633-1644. DOI: 10 . 5194/ hess-11-16332007.

Penna, D. et al. (2012). "Evaluation of between-sample memory effects in the analysis of $\delta 2 \mathrm{H}$ and $\delta 18 \mathrm{O}$ of water samples measured by laser spectroscopes". In: Hydrology and Earth System Sciences 16.10, pp. 3925-3933.

Permana, D. S., L. G. Thompson, and G. Setyadi (2016). “Tropical West Pacific moisture dynamics and climate controls on rainfall isotopic ratios in southern Papua, Indonesia". In: Journal of Geophysical Research: Atmospheres 121.5, pp. 2222-2245. DOI: 10.1002 / 2015 JD 023893.

Permana, D. S. et al. (2019). "Disappearance of the last tropical glaciers in the western pacific warm pool (Papua, Indonesia) appears imminent". In: Proc. Natl. Acad. Sci. U. S. A. 116.52, pp. 26382-26388. DOI: 10.1073 / pnas. 1822037116.

Petersen, W. A. and S. A. Rutledge (2001). "Regional variability in tropical convection: Observations from TRMM". In: J. Clim. 14.17, pp. 3566-3586.

Pfahl, S. and H. Sodemann (2013). "What controls deuterium excess in global precipitation?" en. In: Climate of the Past Discussions 9.4, pp. 4745-4770. DOI: $10.5194 / \mathrm{cpd}-9-4745-2013$.

Pfahl, S. and H. Wernli (2008). "Air parcel trajectory analysis of stable isotopes in water vapor in the eastern Mediterranean". In: Journal of Geophysical Research: Atmospheres 113.D20.

Pinti, D. (2011). “Delta, Isotopic". In: Encyclopedia of Astrobiology. Ed. by Muriel Gargaud et al. Berlin, Heidelberg: Springer Berlin Heidelberg, pp. 418418. ISBN: 978-3-642-11274-4. DOI: 10 . $1007 / 978-3-642-11274-$ 4_406.

Qian, J.-H., A. W. Robertson, and V. Moron (2010). “Interactions among ENSO, the Monsoon, and Diurnal Cycle in Rainfall Variability over Java, Indonesia". en. In: Journal of the Atmospheric Sciences 67.11, pp. 3509-3524. DOI: $10.1175 / 2010$ JAS3348.1. 
Ramirez, E. et al. (2003). "A new Andean deep ice core from Nevado Illimani (6350 m), Bolivia". In: Earth Planet. Sci. Lett. DOI: $10.1016 /$ S $0012-$ $821 \times(03) 00240-1$.

Rasmusson, E. M. and P. A. Arkin (1993). "A global view of large-scale precipitation variability". In: J. Clim. ISSN: 08948755. DOI: $10.1175 / 1520-$ 0442 (1993) $006<1495$ : AGVOLS>2 . 0 . CO; 2 .

Rees, A.R. (1961). "Midday closure of stomata in the oil palm Elaeis guineensis Jacq." In: Journal of Experimental Botany 12, pp. 129-146.

Riley, E. M., B. E. Mapes, and S. N. Tulich (2011). "Clouds associated with the Madden-Julian oscillation: A new perspective from CloudSat". In: Journal of the atmospheric sciences 68.12, pp. 3032-3051.

Rintoul, S. R. et al. (2018). "Choosing the future of Antarctica". In: Nature 558.7709, pp. 233-241. DOI: 10.1038 /s 41586-018-0173-4.

Ripullone, F. et al. (2008). "Environmental effects on oxygen isotope enrichment of leaf water in cotton leaves". In: Plant Physiology 146.2, pp. 729 736.

Risi, C., S. Bony, and F. Vimeux (2008). "Influence of convective processes on the isotopic composition ( $\delta^{18} \mathrm{O}$ and $\delta \mathrm{D}$ ) of precipitation and water vapor in the tropics: 2. Physical interpretation of the amount effect". In: Journal of Geophysical Research 113.D19. DOI: $10.1029 / 2008$ JD 009943.

Risi, C. et al. (2010). "Water-stable isotopes in the LMDZ4 general circulation model: Model evaluation for present-day and past climates and applications to climatic interpretations of tropical isotopic records". In: Journal of Geophysical Research: Atmospheres 115.D12.

Risi, Camille et al. (2013). "Role of continental recycling in intraseasonal variations of continental moisture as deduced from model simulations and water vapor isotopic measurements". In: Water Resources Research 49.7, pp. 4136-4156.

Robertson, J. A. and C. A. Gazis (2006). "An oxygen isotope study of seasonal trends in soil water fluxes at two sites along a climate gradient in Washington state (USA)". In: Journal of Hydrology 328.1-2, pp. 375-387.

Roden, J. et al. (2015). "The enigma of effective path length for 180 enrichment in leaf water of conifers". In: Plant, cell E environment 38.12, pp. 25512565.

Röll, A. et al. (2015). “Transpiration in an oil palm landscape: effects of palm age". In: Biogeosciences 12.19, pp. 5619-5633.

Rothfuss, Y. et al. (2010). "Partitioning evapotranspiration fluxes into soil evaporation and plant transpiration using water stable isotopes under controlled conditions". In: Hydrological processes 24.22, pp. 3177-3194.

Roxy, M. K. et al. (2019). "Twofold expansion of the Indo-Pacific warm pool warps the MJO life cycle". In: Nature 575.7784, pp. 647-651.

Rozanski, K., L. J. Araguas-Araguas, and R. Gonfiantini (1992). “Relation between long-term trends of oxygen-18 isotope composition of precipitation and climate". In: Science 258.5084, pp. 981 -985.

- (2013). "Isotopic patterns in Modern Global Precipitation". In: Climate Change in Continental Isotopic Records, pp.1-36. DOI: 10.1029 / GM0 78p0001. 
Rumble, J. R. (2019). CRC Handbook of Chemistry and Physics, 100th Edition, 2019-2020.

Santoso, A., M. J. Mcphaden, and W. Cai (2017). "The Defining Characteristics of ENSO Extremes and the Strong 2015/2016 El Niño". In: Reviews of Geophysics 55.4, pp. 1079-1129. DOI: $10.1002 / 2017$ RG000560.

Schlesinger, W. H. and S. Jasechko (2014). "Transpiration in the global water cycle". In: Agricultural and Forest Meteorology 189, pp. 115-117.

Schmitt, R. W. (1995). "The ocean component of the global water cycle". In: Rev. Geophys. 33.S2, pp. 1395-1409. DOI: $10.1029 / 95$ RG0 0184.

Scholl, M. A. and S. F. Murphy (2014). "Precipitation isotopes link regional climate patterns to water supply in a tropical mountain forest, eastern Puerto Rico". In: Water Resources Research 50.5, pp. 4305-4322. DOI: 10 . $1002 / 2013 W R 014413$.

Seidel, D. J. et al. (2008). "Widening of the tropical belt in a changing climate". In: Nat. Methods 1.1, pp. 21-24. DOI: $10.1038 /$ ngeo.2007.38.

Sharp, Z. (2017). Principles of stable isotope geochemistry. Prentice Hall: Upper Saddle River, New Jersey.

Shi, T.-T. et al. (2008). "Comparison of methods for estimating evapotranspiration rate of dry forest canopy: Eddy covariance, Bowen ratio energy balance, and Penman-Monteith equation". In: Journal of Geophysical Research: Atmospheres 113.D19.

Shim, J. H. et al. (2013). "Hydrologic control of the oxygen isotope ratio of ecosystem respiration in a semi-arid woodland". en. In: Biogeosciences 10.7, pp. 4937-4956. DOI: $10.5194 / \mathrm{log}-10-4937-2013$.

Simonin, K. A et al. (2013). "Isotopic composition of transpiration and rates of change in leaf water isotopologue storage in response to environmental variables". In: Plant, Cell E Environment 36.12, pp. 2190-2206.

Smith, L. C. (2005). “Disappearing Arctic Lakes". In: Science (80-. ). 308.5727, pp. 1429-1429. ISSN: 0036-8075. DOI: $10.1126 /$ science.1108142.

Sokratov, S. A. and V. N. Golubev (2009). "Snow isotopic content change by sublimation". In: Journal of Glaciology 55.193, pp. 823-828.

Song, X. et al. (2013). "Transpiration rate relates to within-and across-species variations in effective path length in a leaf water model of oxygen isotope enrichment". In: Plant, Cell \& Environment 36.7, pp. 1338-1351.

Steen-Larsen, H. C. et al. (2013). "What controls the isotopic composition of Greenland surface snow?" en. In: Climate of the Past Discussions 9.5, pp. 6035-6076. DOI: $10.5194 / \mathrm{cpd}-9-6035-2013$.

Steen-Larsen, H. C. et al. (2014). "Climatic controls on water vapor deuterium excess in the marine boundary layer of the North Atlantic based on 500 days of in situ, continuous measurements". en. In: Atmospheric Chemistry and Physics Discussions 14.2, pp. 2363-2401. DOI: 10 . 5194 / acpd-142363-2014.

Steen-Larsen, H. C. et al. (2015). "Moisture sources and synoptic to seasonal variability of North Atlantic water vapor isotopic composition". In: Journal of Geophysical Research: Atmospheres 120.12, pp. 5757-5774. 
Steen-Larsen, H. C. et al. (2017). "Evaluating the skills of isotope-enabled general circulation models against in situ atmospheric water vapor isotope observations". In: Journal of Geophysical Research: Atmospheres 122.1, pp. 246-263.

Stein, A. F. et al. (2015). “NOAA's HYSPLIT Atmospheric Transport and Dispersion Modeling System". In: Bulletin of the American Meteorological Society 96.12, pp. 2059-2077. DOI: 10.1175 /BAMS-D-14-00110.1.

Stenni, B. et al. (2004). "A late-glacial high-resolution site and source temperature record derived from the EPICA Dome C isotope records (East Antarctica)". In: Earth and Planetary Science Letters 217.1-2, pp. 183-195.

Stenni, B. et al. (2016). "Three-year monitoring of stable isotopes of precipitation at Concordia Station, East Antarctica". In: The Cryosphere 10.5, pp. 24152428. DOI: $10.5194 / t c-10-2415-2016$.

Stiegler, C. et al. (2019). “El Niño-Southern Oscillation (ENSO) event reduces CO2 uptake of an Indonesian oil palm plantation". In: Biogeosciences 16.14, pp. 2873-2890.

Still, C. J. et al. (2009). "Influence of clouds and diffuse radiation on ecosystematmosphere CO2 and CO18O exchanges". In: Journal of Geophysical Research: Biogeosciences 114.G1.

Sturm, C., Q. Zhang, and D. Noone (2010). "An introduction to stable water isotopes in climate models: benefits of forward proxy modelling for paleoclimatology". In: Climate of the Past 6.1, pp. 115-129.

Sturm, P. and A. Knohl (2010). "Water vapor $\delta 2 \mathrm{H}$ and $\delta 18 \mathrm{O}$ measurements using off-axis integrated cavity output spectroscopy". In: Atmospheric Measurement Techniques 3.1, pp. 67-77. DOI: 10 . 5194 / amt-367-2010.

Sutanto, S. J. et al. (2014). "HESS Opinions: A perspective on isotope versus non-isotope approaches to determine the contribution of transpiration to total evaporation". In: Hydrology and Earth System Sciences 18.8, pp. 28152827.

Sutanto, S. J. et al. (2015). “Global-scale remote sensing of water isotopologues in the troposphere: Representation of first-order isotope effects". In: Atmos. Meas. Tech. 8.3, pp. 999-1019. ISSN: 18678548. DOI: $10.5194 /$ amt-8-999-2015.

Suwarman, R. et al. (2013). "The variability of stable isotopes and water origin of precipitation over the maritime continent". In: Sci. Online Lett. Atmos. 9.1, pp. 74-78. DOI: $10.2151 /$ sola.2013-017.

Sánchez-Murillo, R. et al. (2016). “Key drivers controlling stable isotope variations in daily precipitation of Costa Rica: Caribbean Sea versus Eastern Pacific Ocean moisture sources". en. In: Quaternary Science Reviews 131, pp. 250-261. ISSN: 02773791. DOI: 10 .1016/j . quascirev . 2015 . 08 . 028.

Terzer, S. et al. (2013). "Global isoscapes for $\delta 18 \mathrm{O}$ and $\delta 2 \mathrm{H}$ in precipitation: Improved prediction using regionalized climatic regression models". In: Hydrol. Earth Syst. Sci. 17.11, pp. 4713-4728. ISSN: 10275606. DOI: 10 . 5194/hess-17-4713-2013. 
Terzer, S. et al. (2015). "The Global Network of Isotopes in Precipitation after 55 years: assessing past, present and future developments". In: EGU General Assembly Conference Abstracts. Vol. 17.

Tharammal, T., G. Bala, and D. Noone (2017). "Impact of deep convection on the isotopic amount effect in tropical precipitation". In: Journal of Geophysical Research: Atmospheres 122.3, pp. 1505-1523.

Thompson, L. G. et al. (2002). "Kilimanjaro ice core records: Evidence of holocene climate change in tropical Africa". In: Science (80-. ). ISSN: 00368075. DOI: $10.1126 /$ science.1073198.

Thompson, L. G. et al. (2011). “Tropical glaciers, recorders and indicators of climate change, are disappearing globally". In: Ann. Glaciol. 52.59, pp. 2334. DOI: $10.3189 / 172756411799096231$.

Tian, B. et al. (2006). "Vertical moist thermodynamic structure and spatialtemporal evolution of the MJO in AIRS observations". In: Journal of the atmospheric sciences 63.10, pp. 2462-2485.

Tietjen, B. et al. (2017). "Climate change-induced vegetation shifts lead to more ecological droughts despite projected rainfall increases in many global temperate drylands". In: Glob. Chang. Biol. DOI: 10.1111 /gcb.13598.

Tindall, J. C., P. J. Valdes, and L. C. Sime (2009). "Stable water isotopes in HadCM3: Isotopic signature of El Niño-Southern Oscillation and the tropical amount effect". en. In: Journal of Geophysical Research 114.D4. DOI: 10 . $1029 / 2008$ JD010825.

Tobin, I. et al. (2013). "Does convective aggregation need to be represented in cumulus parameterizations?" In: Journal of Advances in Modeling Earth Systems 5.4, pp. 692-703.

Tokay, A. et al. (1999). “Tropical Rainfall Associated with Convective and Stratiform Clouds: Intercomparison of Disdrometer and Profiler Measurements". In: J. Appl. Meteorol. 38.3, pp. 302-320. DOI: 10 . $1175 / 1520-$ 0450 (1999) 038<0302: TRAWCA $>2$. $0 . C O ; 2$.

Torri, G., D. Ma, and Z. Kuang (2017). "Stable water isotopes and large-scale verticalmotions in the tropics". In: J. Geophys. Res. 122.7, pp. 3703-3717. DOI: $10.1002 / 2016$ JD026154.

Trenberth, K. E. (2011). "Changes in precipitation with climate change". In: Clim. Res. 47.1, pp. 123-138. DOI: 10.3354 / cr00953.

Trenberth, K. E., J. T. Fasullo, and J. Kiehl (2009). "Earth's Global Energy Budget". In: Bulletin of the American Meteorological Society 90.3, pp. 311-324. DOI: $10.1175 / 2008$ BAMS2634.1.

Trenberth, K. E. and D. P. Stepaniak (2001). "Indices of El Niño Evolution". In: Journal of Climate 14.8, pp. 1697-1701. DOI: $10.1175 / 1520-0442$ (2001) $014<1697$ : LIOENO $>2.0 . \mathrm{CO} ; 2$.

Trenberth, K. E. et al. (2007). "Estimates of the Global Water Budget and Its Annual Cycle Using Observational and Model Data". In: J. Hydrometeorol. 8.4, pp. 758-769. DOI: $10.1175 /$ JHM600.1.

Tuinenburg, O. A. et al. (2015). "Moist processes during MJO events as diagnosed from water isotopic measurements from the IASI satellite". In: Journal of Geophysical Research: Atmospheres 120.20, pp. 10-619. 
Uemura, R. et al. (2008). "Evidence of deuterium excess in water vapor as an indicator of ocean surface conditions". In: Journal of Geophysical Research 113.D19. DOI: $10.1029 / 2008$ JD010209.

Urey, H. C., F. G. Brickwedde, and G. M. Murphy (1932). “A Hydrogen Isotope of Mass 2". In: Phys. Rev. 39 (1), pp. 164-165. DOI: 10.1103 / Phy s Rev . 39.164.

Urey, H. C. et al. (1948). "Method for measurement of paleotemperatures". In: Geological Society of America Bulletin. Vol. 59. 12, pp. 1359-1360.

Urey, H. C. et al. (1951). "Measurement of paleotemperatures and temperatures of the Upper Cretaceous of England, Denmark, and the southeastern United States". In: Geological Society of America Bulletin 62.4, pp. 399-416.

Vesala, T. (1998). "On the concept of leaf boundary layer resistance for forced convection". In: Journal of theoretical biology 194.1, pp. 91-100.

Vihma, T. et al. (2016). "The atmospheric role in the Arctic water cycle: A review on processes, past and future changes, and their impacts". In: J. Geophys. Res. Biogeosciences 121.3, pp. 586-620. DOI: 10 . 1002 / 2015 JG0 03132.

Viljoen, G. J., A. G. Luckins, and I. Naletoski (2016). "Animal Migration Tracking Methods". In: Stable Isotopes to Trace Migratory Birds and to Identify Harmful Diseases : An Introductory Guide. Cham: Springer International Publishing, pp. 11-33. ISBN: 978-3-319-28298-5. DOI: 10 . $1007 / 978-3-$ 319-28298-5_2.

Vimeux, F. et al. (2005). "What are the climate controls on $\delta \mathrm{D}$ in precipitation in the Zongo Valley (Bolivia)? Implications for the Illimani ice core interpretation". In: Earth and Planetary Science Letters 240.2, pp. 205-220.

Vuille, M. et al. (2003). "Modeling $\delta 18 \mathrm{O}$ in precipitation over the tropical Americas: 1. Interannual variability and climatic controls". In: J. Geophys. Res. D Atmos. 108.6. ISSN: 01480227. DOI: $10.1029 / 2001$ jd002038.

Vuille, M. et al. (2005). "Stable isotopes in precipitation in the Asian monsoon region". en. In: Journal of Geophysical Research 110.D23. DOI: $10.1029 /$ 2005 JD006022.

Waliser, D. E, N. E Graham, and C. Gautier (1993). "Comparison of the highly reflective cloud and outgoing longwave radiation datasets for use in estimating tropical deep convection". In: Journal of Climate 6.2, pp. 331-353.

Wallace, J. M. (1992). "Effect of deep convection on the regulation of tropical sea surface temperature". In: Nature 357.6375, pp. 230-231. DOI: 10 . $1038 / 357230$ a0.

Wang, B. and T. Li (1994). "Convective interaction with boundary-layer dynamics in the development of a tropical intraseasonal system". In: Journal of the atmospheric sciences 51.11, pp. 1386-1400.

Wang, B. and H. Rui (1990). "Synoptic climatology of transient tropical intraseasonal convection anomalies: 1975-1985". In: Meteorology and Atmospheric Physics 44.1-4, pp. 43-61.

Wang, L. et al. (2010). "Partitioning evapotranspiration across gradients of woody plant cover: Assessment of a stable isotope technique". In: Geophysical Research Letters 37.9. L09401, n/a-n/a. DOI: 10 . 1029 / 2010 GL 043228.

Wang, L. et al. (2012). "Direct quantification of leaf transpiration isotopic composition". In: Agricultural and Forest Meteorology 154, pp. 127-135. 
Wang, P. et al. (2015). "Partitioning evapotranspiration in a temperate grassland ecosystem: Numerical modeling with isotopic tracers". In: Agricultural and Forest Meteorology 208, pp. 16-31.

Wassenaar, L. I. et al. (2012). "Worldwide proficiency test for routine analysis of $\delta 2 \mathrm{H}$ and $\delta 18 \mathrm{O}$ in water by isotope-ratio mass spectrometry and laser absorption spectroscopy". In: Rapid Communications in Mass Spectrometry 26.15, pp. 1641-1648. DOI: 10.1002 / rcm. 6270.

Wassenaar, L. I. et al. (2018). "Seeking excellence: An evaluation of 235 international laboratories conducting water isotope analyses by isotope-ratio and laser-absorption spectrometry". In: Rapid Communications in Mass Spectrometry 32.5, pp. 393-406.

Wei, Z. et al. (2015). "Partitioning of evapotranspiration using high-frequency water vapor isotopic measurement over a rice paddy field". In: Water Resources Research 51.5, pp. 3716-3729. DOI: $10.1002 / 2014$ WR016737.

Wei, Z. et al. (2017). "Revisiting the contribution of transpiration to global terrestrial evapotranspiration". In: Geophysical Research Letters 44.6, pp. 27922801. DOI: $10.1002 / 2016$ GL072235.

Welp, L. R. et al. (2008). " $\delta{ }^{18} \mathrm{O}$ of water vapour, evapotranspiration and the sites of leaf water evaporation in a soybean canopy". en. In: Plant, Cell $\mathcal{E}$ Environment 31.9, pp. 1214-1228. DOI: $10.1111 / j .1365-3040.2008$. $01826 . x$.

Welp, L. R. et al. (2012). "A meta-analysis of water vapor deuterium-excess in the midlatitude atmospheric surface layer". In: Global Biogeochemical Cycles 26.3, n/a-n/a. DOI: 10.1029/2011GB004246.

Wen, X. et al. (2016). "Evapotranspiration partitioning through in-situ oxygen isotope measurements in an oasis cropland". In: Agricultural and Forest Meteorology 230, pp. 89-96.

Wen, X.-F. et al. (2008). "Continuous measurement of water vapor D/H and $18 \mathrm{O} / 16 \mathrm{O}$ isotope ratios in the atmosphere". en. In: Journal of Hydrology 349.3-4, pp. 489-500. DOI: 10.1016/j.jhydrol.2007.11.021.

Werner, M. et al. (2011). "Stable water isotopes in the ECHAM5 general circulation model: Toward high-resolution isotope modeling on a global scale". In: Journal of Geophysical Research: Atmospheres 116.D15.

West, A., S. J. Patrickson, and J. Ehleringer (2006). “Water extraction times for plant and soil materials used in stable isotope analysis". In: 20, pp. 131721.

Wheeler, M. C. and H. H. Hendon (2004). "An all-season real-time multivariate MJO index: Development of an index for monitoring and prediction". In: Monthly weather review 132.8, pp. 1917-1932.

Williams, C. R., W. L. Ecklund, and K. S. Gage (1995). Classification of Precipitating Clouds in the Tropics Using 915-MHz Wind Profilers. DOI: $10.1175 /$ $1520-0426$ (1995) 012<0996:copcit>2.0.co;2.

Williams, D. G. and J. R. Ehleringer (2000). "Intra-and interspecific variation for summer precipitation use in pinyon-juniper woodlands". In: Ecological Monographs 70.4, pp. 517-537.

Windhorst, D. et al. (2013). "Impact of elevation and weather patterns on the isotopic composition of precipitation in a tropical montane rainforest". 
In: Hydrology and Earth System Sciences 17.1, pp. 409-419. DOI: $10.5194 /$ hess-17-409-2013.

Wirmvem, M. J. et al. (2017). "Variation in stable isotope ratios of monthly rainfall in the Douala and Yaounde cities, Cameroon: local meteoric lines and relationship to regional precipitation cycle". In: Appl. Water Sci. 7.5, pp. 2343-2356. ISSN: 2190-5487. DOI: 10 . 1007 / s13201-016-0413-4.

Wit, J.C. de, C.M. van der Straaten, and W.G. Mook (1980). "Determination of the Absolute Hydrogen Isotopic Ratio of V-SMOW and SLAP". In: Geostandards Newsletter 4.1, pp.33-36. DOI: $10.1111 /$ j.1751-908X.1980 . tbo0 $0270 . x$.

Wolf, B. et al. (2015). "First on-line isotopic characterization of N2O emitted from intensively managed grassland". In: Biogeosciences Discussions 12.8, pp. 1573-1611.

Wolter, K. and M. S. Timlin (1998). "Measuring the strength of ENSO events: How does 1997/98 rank?" In: Weather 53.9, pp. 315-324. DOI: $10.1002 /$ j.1477-8696.1998.tb06408.x.

Worden, J. et al. (2006). "Tropospheric Emission Spectrometer observations of the tropospheric $\mathrm{HDO} / \mathrm{H}_{2} \mathrm{O}$ ratio: Estimation approach and characterization". en. In: Journal of Geophysical Research 111.D16. ISSN: 0148-0227. DOI: $10.1029 / 2005$ JD 006606 . (Visited on 01/28/2016).

Worden, J. et al. (2007). "Importance of rain evaporation and continental convection in the tropical water cycle". In: Nature 445.7127, pp. 528-532. DOI: $10.1038 /$ nature05508.

Worden, J. et al. (2011). "Estimate of bias in Aura TES HDO/H2O profiles from comparison of TES and in situ $\mathrm{HDO} / \mathrm{H} 2 \mathrm{O}$ measurements at the Mauna Loa observatory". In: Atmospheric Chemistry and Physics 11.9, p. 4491.

$\mathrm{Wu}, \mathrm{H}$. et al. (2015). "Seasonal variations of deuterium and oxygen-18 isotopes and their response to moisture source for precipitation events in the subtropical monsoon region". In: Hydrol. Process. 29.1, pp. 90-102. ISSN: 08856087. DOI: 10.1002 / hyp. 10132.

$\mathrm{Wu}$, P. et al. (2017). "Why torrential rain occurs on the western coast of Sumatra Island at the leading edge of the MJO westerly wind bursts". In: Sola 13, pp. 36-40.

Xia, Z., N. Butorovic, and Z. Yu (2020). “The Influence of Synoptic Weather Types and Moisture Transport Pathways on Precipitation Isotopes in Southern Patagonia". In: Atmosphere 11.5, p. 514.

Yakir, D. and L. D. S. L. Sternberg (2000). "The use of stable isotopes to study ecosystem gas exchange". In: Oecologia 123.3, pp. 297-311.

Yakir, D. and X.-F. Wang (1996). "Fluxes of CO2 and water between terrestrial vegetation and the atmosphere estimated from isotope measurements". In: Nature 380.6574, pp. 515-517. DOI: $10.1038 / 380515$ a 0.

Yepez, E. A. et al. (2005). "Dynamics of transpiration and evaporation following a moisture pulse in semiarid grassland: A chamber-based isotope method for partitioning flux components". In: Agricultural and Forest Meteorology 132.3-4, pp. 359-376. 
Yoshimura, K. et al. (2008). "Historical isotope simulation using Reanalysis atmospheric data". In: J. Geophys. Res. Atmos. 113.19, pp. 1-15. ISSN: 01480227. DOI: 10 .1029/2008JD010074. arXiv: D19108.

Yurtsever, Y. and International Atomic Energy Agency. Isotope Hydrology Section (1975). Worldwide Survey of Stable Isotopes in Precipitation. IAEA.

Zencich, S. J. et al. (2002). "Influence of groundwater depth on the seasonal sources of water accessed by Banksia tree species on a shallow, sandy coastal aquifer". In: Oecologia 131.1, pp. 8-19.

Zhang, C. (2005). “Madden-Julian Oscillation". In: Reviews of Geophysics 43.2. RG2003, n/a-n/a. DOI: 10.1029/2004RG000158.

Zhang, S. et al. (2010). "The use of stable isotopes to partition evapotranspiration fluxes into evaporation and transpiration". In: Acta Ecologica Sinica 30.4, pp. 201-209.

Zhang, Y. et al. (2007). "Cluster analysis of tropical clouds using CloudSat data". In: Geophys. Res. Lett. 34.12, p. L12813. DOI: 10 . 1029/2007GL029336.

Zhao, L. et al. (2014). "The patterns and implications of diurnal variations in the d-excess of plant water, shallow soil water and air moisture". In:

Zhu, B. and B. Wang (1993). "The 30-60-day convection seesaw between the tropical Indian and western Pacific Oceans". In: Journal of the atmospheric sciences 50.2, pp. 184-199.

Zimmerman, U., D. Ehhalt, and K. O. Münnich (1967). "Soil-water and evapotranspiration: changes in the isotopic composition of the water $\mathrm{P}^{\prime \prime}$. In: Proc. IAEA Symp. Isot. Hydrol., IAEA, Vienna.-1967.

Zobitz, J. M. et al. (2006). "Sensitivity analysis and quantification of uncertainty for isotopic mixing relationships in carbon cycle research". In: Agricultural and Forest Meteorology 136.1, pp. 56-75. 